Cibele Hummel do Amaral

\title{
SENSORIAMENTO REMOTO HIPERESPECTRAL E DEFINIÇÃO DE ESPÉCIES INDICADORAS APLICADOS À GEOBOTÂNICA NO BIOMA CERRADO
}

Tese apresentada ao Instituto de Geociências da Universidade de São Paulo, como parte dos requisitos para obtenção do grau de Doutor em Ciências

Área de Concentração: Recursos Minerais e Meio Ambiente

Orientador: Prof. Dr. Teodoro Isnard Ribeiro de Almeida

\author{
SÃO PAULO \\ 2014 \\ VERSÃO CORRIGIDA
}


Autorizo a reprodução e divulgação total ou parcial deste trabalho, por qualquer meio convencional ou eletrônico, para fins de estudo e pesquisa, desde que citada a fonte.

Ficha catalográfica preparada pelo Serviço de Biblioteca e Documentação do Instituto de Geociências da Universidade de São Paulo

Amaral, Cibele Hummel do

Sensoriamento remoto hiperespectral e definição de espécies indicadoras aplicados à Geobotânica no bioma Cerrado / Cibele Hummel do Amaral. - São Paulo, 2014 .

$201 f+3$ Apêndices + 1 Anexo.

Tese (Doutorado) : IGc/USP

Orient.: Almeida, Teodoro Isnard Ribeiro de

1. Geobotânica 2. Bioma Cerrado 3. Formações sedimentares 4. Sensoriamento remoto hiperespectral 5. Análise multivariada I. Título 
Nome: Amaral, Cibele Hummel do

Título: Sensoriamento remoto hiperespectral e definição de espécies indicadoras aplicados à Geobotânica no bioma Cerrado.

Tese apresentada ao Instituto de Geociências da Universidade de São Paulo para obtenção do título de Doutor em Ciências.

Aprovado em:

Banca Examinadora

Prof. Dr. Instituição:

Julgamento:

Assinatura:

Prof. Dr. Instituição:

Julgamento: Assinatura:

Prof. Dr. Instituição: Julgamento: Assinatura:

Prof. Dr. Instituição: Julgamento: Assinatura:

Prof. Dr. Instituição: Julgamento: Assinatura: 
A minha família e a meu companheiro pelo apoio incondicional. 


\section{AGRADECIMENTOS}

Ao Prof. Dr. Teodoro Isnard Ribeiro de Almeida que sempre me contagiou com seu fascínio à geobotânica e à investigação científica. Obrigada pelas oportunidades, pela orientação, pela confiança em meu trabalho e por sua amizade. Obrigada por sua vibração a cada resultado alcançado e pelo prazer de termos constituído uma equipe apaixonada pelo que faz.

Ao Prof. Dr. Carlos Roberto de Souza Filho, do Instituto de Geociências da Universidade de Campinas, que me co-orientou e me estimulou a crescer profissionalmente. Muito obrigada pela confiança, pelas oportunidades, pelas orientações e por todo seu empenho e amizade.

Ao Dr. Marcos Nopper Alves de Almeida, do Centro Pluridisciplinar de Pesquisas Químicas, Biológicas e Agrícolas, da Universidade de Campinas, por toda ajuda e suporte dado ao desenvolvimento desta pesquisa e por sua amizade.

Ao Dr. Stephen J. Fraser, do Queensland Centre for Advanced Technologies, CSIRO/AUS, por me recepcionar tão bem em sua instituição e em seu país. Muito obrigada pela orientação e pela oportunidade de trabalharmos juntos.

Ao Prof. Dr. Dar A. Roberts, do Departamento de Geografia, da Universidade da Califórnia, Santa Barbara/EUA, por tudo que me ensinou, essencial para o desenvolvimento da pesquisa de doutorado e para minha formação profissional, por confiar em meu trabalho, pelas oportunidades e por sua amizade.

Aos Profs. Drs. Lênio Soares Galvão, da divisão de Sensoriamento Remoto, do Instituto Nacional de Pesquisas Espaciais, e Waldir Mantovani, professor titular aposentado da Universidade de São Paulo, por contribuírem substancialmente com suas observações à pesquisa, na qualificação de meu doutoramento.

Ao Prof. Dr. Agostinho Lopes de Souza, professor titular aposentado da Universidade Federal de Viçosa, que me orientou técnica e academicamente durante meu doutoramento. 
Aos funcionários da Estação Ecológica de Mogi-Guaçu, do Instituto Florestal do Estado de São Paulo, especialmente a Dirceu de Souza, Arnaldo Pereira (em memória), Omar Jorge Di Dio, Giovani Germano, José Carlos de Lima e Silvia de Souza Bonatti, que me acolheram de braços abertos e me deram muito mais do que o apoio necessário para a realização da pesquisa. Obrigada pela doação de vocês e pela amizade.

Aos colegas que me ajudaram, de alguma forma, em campo ou nos diversos processamentos necessários ao desenvolvimento desta pesquisa. Muito obrigada Moreno Botelho, Lucíola Magalhães, Giuliana Quitério, Flávia Mendes, Cleyton Carneiro, Natasha Penatti, Enos Sato, Sidney Goveia, Carlos Carrasco, Daniela Gamito, Vitor Ribeiro, Francisco Cavallaro, Susan Meerdink, Keely Roth e Seth Peterson. Muito obrigada, meus colegas, por compartilharem comigo o conhecimento e o tempo de vocês!

À equipe FOTOTERRA/SpecTIR, particularmente a Guilherme Pinho e Conrad Wright, pela cessão das imagens hiperespectrais utilizadas nessa pesquisa.

Ao Instituto Agronômico de Campinas pela realização de análises granulométricas e químicas de solos e de sedimentos para a pesquisa.

Ao Laboratório de Fisiologia Vegetal, da Universidade de Campinas, especialmente ao Prof. Dr. Paulo Mazzafera, pela realização de análises químicas foliares para a pesquisa.

Ao Instituto Florestal do Estado de São Paulo pela permissão e suporte dados à execução da pesquisa na Estação Ecológica de Mogi-Guaçu.

Ao Instituto de Geociências, da Universidade de São Paulo, ao Programa de Pósgraduação em Recursos Minerais e Hidrogeologia do Departamento de Geologia Sedimentar e Ambiental (coordenadores e chefias) e ao Laboratório de Informática Geológica por todo apoio ao desenvolvimento dessa pesquisa, bem como à minha formação profissional. Obrigada Antônio, Samuel, Denise, Rita, Tadeu, Magali, Leonardo, Katherine, Claudionor, Henrique, Edmir, José, Solange e Maria Ivone por todo apoio técnico e amizade.

Ao Instituto de Geociências, da Universidade de Campinas, por todo apoio concedido à pesquisa, principalmente ao Laboratório de Espectroscopia de Reflectância pela cessão de espectrorradiômetro de campo, bem como do espaço físico para mensurações realizadas 
em laboratório. Agradeço a essa instituição também pelos convites para participação em cursos essenciais para o desenvolvimento desta pesquisa: "Self-Organizing Maps", ministrado pelo pesquisador Dr. Stephen J. Fraser (CSIRO/AUS) e pelo Prof. Dr. Cleyton C. Carneiro (POLI-USP, na época doutorando daquele instituto); e "Workshop on spectroscopic remote sensing and the USGS PRISM software", ministrado pelo pesquisador Raymond Kokaly (USGS/EUA).

Ao Centro Pluridisciplinar de Pesquisas Químicas, Biológicas e Agrícolas, da Universidade de Campinas, por todo suporte infraestrutural dado a esta pesquisa, quanto a utilização de equipamentos e espaço para armazenamento de amostras foliares, bem como, ao empréstimo de equipamentos utilizados em campo.

Ao Queensland Centre for Advanced Technologies, CSIRO/AUS, por todo o apoio infraestrutural durante o período em que estive na instituição.

Ao Departamento de Geografia, da Universidade da Califórnia, Santa Barbara/EUA, em especial a Dylan Parenti, Bryan Karaffa, Connie Padilla e José Saleta por todo apoio técnico, durante meu estágio na instituição. Ao Visualization \& Image Processing for Environmental Research Laboratory por todo apoio infraestrutural, pela utilização de softwares e pela recepção e convivência amistosas do "VIPER team".

À Fundação de Amparo à Pesquisa do Estado de São Paulo (FAPESP) pelo financiamento desta pesquisa - auxílio pesquisa regular (2010/51758-2) e bolsa de doutorado (2010/51718-0). Ao Instituto de Geociências da USP, ao PROAP-CAPES e à Próreitoria de Pós-graduação da USP por também terem colaborado financeiramente para o desenvolvimento desta pesquisa e para minha formação acadêmica. 
A alegria de ver e compreender é a mais bela dádiva da natureza. Albert Einstein 


\section{RESUMO}

Amaral, C. H. (2014). Sensoriamento remoto hiperespectral e definição de espécies indicadoras aplicados à Geobotânica no bioma Cerrado. Tese de doutorado. Instituto de Geociências, Universidade de São Paulo, São Paulo.

A Geobotânica por sensoriamento remoto é uma técnica de obtenção de informações geológicas indiretas em ambientes cobertos por vegetação e apresenta grandes perspectivas por sua capacidade de otimizar trabalhos de campo e gerar possíveis alvos a serem examinados. O objetivo deste estudo foi realizar a discriminação espectral, em escala de folha e de copa, de espécies arbóreas neotropicais associadas localmente a diferentes formações e fácies geológicas, bem como defini-las remotamente como indicadoras geológicas na Estação Ecológica de Mogi-Guaçu, São Paulo, Brasil. Dados obtidos em 70 unidades amostrais, como texturais de solos e sedimentos, químicos de solos, de nível do freático, altitudinais (modelo digital de terreno), fitossociológicos e fisiológicos/estruturais de vegetação (índices hiperespectrais de vegetação), foram minerados e analisados através da técnica de quantização vetorial Self-Organizing Maps (SOM). Inga vera Willd. subsp. affinis (DC.) T.D. Penn (INVE) e Calophyllum brasiliense Cambess. (CABR) mostraram-se associadas à planície de inundação, incluindo meandros abandonados (Depósitos Aluvionares), com amplo domínio das frações argila e silte nos sedimentos. Qualea grandiflora Mart. (QUGR) e Tabebuia ochracea (Cham.) Standl. (TAOC) foram identificadas apenas nas colinas e platôs da Formação Aquidauana, com altas porcentagens das frações areia fina, média e grossa, e escasso silte. Cedrela fissilis Vell. (CEFI) e Zeyheria tuberculosa (Vell.) Bur. (ZETU) demonstraram estar associadas a uma fácies aflorante da Formação Aquidauana, com distinta presença das frações de areia grossa e muito grossa, além da baixa porcentagem das frações silte e areia fina. As cinco primeiras espécies tiveram dados bioquímicos e espectrais $(400-2.500$ nm, FieldSpec 3 Hi-Res) coletados, em escala de folha, tanto no período chuvoso quanto no seco. Seus espectros foram 
classificados através da técnica Multiple Endmember Spectral Mixture Analysis (MESMA). As espécies foram bem discriminadas em ambos os momentos sazonais, nessa escala de trabalho. Dentre os melhores resultados por intervalo espectral, as exatidões do produtor e do usuário não foram inferiores a $87,5 \%$. Esse sucesso mostrou estar intimamente ligado à alta variabilidade bioquímica observada em suas folhas. As variações intra e interespecíficas em compostos bioquímicos puderam ser correlacionadas às suas variações espectrais. $A$ discriminação espectral em escala de copa foi realizada com dois membros-finais (MF) via MESMA para CEFI, INVE e QUGR. Os pixels das imagens pré-processadas do sistema de sensores aeroportados ProSpecTIR-VS (530-2.532 nm, $1 \mathrm{~m}$ de resolução espacial) foram modelados por três MF: MF da classe de espécie-alvo, MF de outras classes de vegetação e sombra fotométrica. A falta de comissão espectral e a relativa baixa omissão espectral atingidas por QUGR na modelagem com dois MF, que incluiu outras classes de vegetação, refletiu em um mapeamento satisfatório de sua fração espectral. As tendências em distribuição dessa espécie indicaram claramente as colinas e platôs da Formação Aquidauana na área estudada.

Palavras-chave: Geobotânica, bioma Cerrado, formações sedimentares, sensoriamento remoto hiperespectral, análise multivariada, análise de mistura espectral. 


\begin{abstract}
Amaral, C. H. (2014). Hyperspectral remote sensing and definition of indicator species applied to Geobotany in the Cerrado biome. Doctoral dissertation. Institute of Geosciences, University of São Paulo, São Paulo.
\end{abstract}

Geobotany via remote sensing is a technique for obtaining indirect geological information in vegetated areas and presents great perspectives by its capability for field work optimization and target generation to be evaluated afterwards. The aim of this research was to perform the spectral discrimination of Neotropical tree species (at leaf and crown levels) which are locally associated to geological facies and formations in the Mogi-Guaçu Ecological Station, in southeastern Brazil. Data from 70 sampling units, such as soils and sediments texture, soils chemistry, groundwater level, elevation (digital terrain model), plant sociology and vegetation physiology/structure (hyperspectral vegetation indices), were mined and analyzed through the vetorial quantization method called Self-Organizing Maps (SOM; Kohonen, 1982). Inga vera Willd. subsp. affinis (DC.) T.D. Penn (INVE) and Calophyllum brasiliense Cambess. (CABR) demonstrated to be associated to the floodplain, including paleochannels (Alluvial Deposits sequence), with clayey-silty sediments. Qualea grandiflora Mart. (QUGR) and Tabebuia ochracea (Cham.) Standl. (TAOC) were sampled on hills and plateaus of the Aquidauna Formation, which stood out for higher fine, medium and coarse sand contents and lower silt content. Cedrela fissilis Vell. (CEFI) and Zeyheria tuberculosa (Vell.) Bur. (ZETU) showed be associated to one outcrop facies of the Aquidauna Formation, with distinctive presence of coarse and very coarse sand as well as lower silt and very fine sand contents. Biochemical and spectral $(400-2.500 \mathrm{~nm}$, FieldSpec Hi-Res 3) data were collected from the leaves of the first five species, during both rainy and dry seasons. Their spectra were classified through Multiple Endmember Spectral Mixture Analysis (MESMA). All target species were well discriminated at leaf scale. Considering the best classification results per spectral range, user's and producer's accuracies were always higher than $87,5 \%$. These 
results seem to be linked to the great biochemical variability of their leaves. The intra and interspecific variability of biochemical compounds were correlated with spectral variability. The spectral discrimination at crown scale was performed with two endmembers (EM) via MESMA for CEFI, INVE e QUGR. The 1-m pixels of the preprocessed ProSpecTIR-VS images $(530-2.532 \mathrm{~nm})$ were modeled by three EM: EM of the target species, EM of other vegetation classes, and photometric shade. The QUGR class achieved a relatively lower spectral omission and had no spectra erroneously assigned to its class in the two EM classification, which included other vegetation classes. This classification result was reproduced in the three EM image unmixing. The distribution tendency of that species clearly indicated the hills and plateaus of the Aquidauana Formation in the study area.

Keywords: Geobotany, Cerrado biome, sedimentary formations, hiperspectral remote sensing, multivariate analysis, spectral mixture analysis. 


\section{LISTA DE FIGURAS}

Figura 1.1. Figura 1.1. Localização da área de estudo. Fonte: IBGE (2004 e 2005)......

Figura 2.1. Comportamento espectral médio de folhas de Dendrocalamus sp. (bambú, em cinza escuro) e Pinus elliottii (pinheiro, em cinza claro) e indicação das regiões onde ocorrem feições de absorção por pigmentos foliares, compostos bioquímicos e água, bem como de espalhamento da energia devido à estrutura de copa e/ou folha (adaptado de Kokaly et al., 2003).

Figura 2.2. Espectros puros de vegetação verde - fotossinteticamente ativa (GV), vegetação não fotossintética (NPV), solo e sombra, extraídos de imagens hiperespectrais ProSpecTIRVS, com exclusão das regiões espectrais de baixa razão sinal-ruído.

Figura 2.3. Visualização da vetorização de dados no espaço $\mathrm{N}$-dimensional e esquema dos domínios formados pelas medidas de similaridade entre vetores.

Figura 2.4. Espectros foliares de Dendrocalamus sp. (bambú, em cinza escuro) e Pinus elliottii (pinheiro, em cinza claro) originais de reflectância $(A)$ e com contínuo removido (B)....74

Figura 3.1. Disposição das parcelas de $20 \times 60 \mathrm{~m}$, subdivididas em 3 unidades amostrais de $20 \times 20$ $\mathrm{m}$, para amostragem de parâmetros biofisicoquímicos na Estação Ecológica de MogiGuaçu.

Figura 3.2. Disposição dos transectos de $5 \times 100 \mathrm{~m}$, subdivididos em 10 unidades amostrais de $5 \times 10$ $\mathrm{m}$, para amostragem de parâmetros biofísicoquímicos, na Estação Ecológica de MogiGuaçu.

Figura 3.3. Contribuições das frações granulométricas à formação dos nós no SOM, representação em matriz U e mapa auto-organizado, colorido pelos sete domínios formados. Estes resultados resumem a estrutura dos dados nas 70 unidades amostrais. As sete componentes (variáveis) são apresentadas em cor-temperatura variando do menor (azul) ao maior valor (vermelho) observado. A Matriz U, também em cor-temperatura, representa as similaridades (azul-verde) e dissimilaridades (laranja-vermelho) entre nós adjacentes. 102

Figura 3.4. Distribuição dos scores das frações granulométricas de sedimentos nas componentes principais (PC1 e PC2), e discriminação dos principais geoambientes da Estação Ecológica de Mogi-Guaçu.

Figura 3.5. Representações gráficas esquemáticas da elevação do terreno e linhas de drenagem (A), em duas dimensões, e da geologia local (B), da cobertura da terra (C) e dos geoambientes (D), em três dimensões, na Estação Ecológica de Mogi-Guaçu... 106

Figura 3.6. Composição granulométrica dos sedimentos dos domínios formados sobre o SOM baseado nos dados de granulometria de solos e sedimentos, fertilidade de solos, nível do freático, valor de cobertura de espécies, dados altitudinais e índices hyperespectrais de vegetação das 30 subparcelas, na Estação Ecológica de Mogi-Guaçu. Arg = Argila, Sil $=$ Silte, $A M F=$ Areia muito fina,$A F=$ Areia fina, $A M=$ Areia média, $A G=$ Areia grossa, $A M G=$ Areia muito grossa, $C R D=$ Cerradão, $M G(N) I=$ Mata de galeria (não) inundável, MC(TA ou TB) = Mata ciliar (de terras altas ou de terras baixas).......

Figura 3.7. Padrões texturais dos sedimentos sob as espécies indicadoras dos geoambientes na Estação Ecológica de Mogi-Guaçu.

Figura 3.8. Fatores condicionantes à colonização de espécies em ambientes sazonalmente inundados.... 
Figura 3.9. Fertilidade dos solos sob a mata ciliar de terras altas, sem influência fluvial - P7, em preto, e sob o cerradão - P8, em cinza. Al (Alumínio), Ca (Cálcio), CTC (Capacidade de Troca Catiônica), $\mathrm{H}+\mathrm{Al}$ (Acidez potencial), K (Potássio), Mg (Magnésio) e SB (Soma de Bases) em mmolc $/ \mathrm{dm}^{3} ; \mathrm{P}$ (Fósforo) em $\mathrm{mg} / \mathrm{dm}^{3}$; MO (Matéria Orgânica) em $\mathrm{g} / \mathrm{dm}^{3} ; \mathrm{pH}$ (Acidez ativa), escala de 0 a 14; V (Saturação por bases) em porcentagem....................................................................................................

Figura 4.1. Localização da área de estudo e geoambientes de ocorrência das espécies alvo do estudo: Calophyllum brasiliense e Inga vera subsp. affinis (geoambiente I), Qualea grandiflora e Tabebuia ochracea (geoambiente III) e Cedrela fissilis (geoambiente IV)

Figura 4.2. Variações de compostos bioquímicos entre espécies-alvo, estatisticamente significantes a $0,1 \%$ : Clorofila a $(\mu \mathrm{g} / \mathrm{mg})$, período chuvoso - PC (A); Antocianina $(\Delta / \mathrm{mg})-\mathrm{PC}(\mathrm{B})$; Celulose (mg/g) - PC (C); Hemicelulose (mg/g), período seco - PS (D); Lignina insolúvel (\%) - PS (E) e Água (\%) - PS (F)..... 138

Figura 4.3. Exatidão global (\%) e coeficiente Kappa das classificações MESMA com dois membrosfinais aplicadas aos dados espectrais foliares de cinco espécies arbóreas, coletados no período chuvoso. Dados VIS, NIR, SWIR e VSWIR, em reflectância ou o com contínuo removido (CR), e métricas para seleção de membros-finais EMC ou IES(IES*). Dados apresentados de forma ranqueada do maior para o menor coeficiente Kappa. 141

Figura 4.4. Exatidão global (\%) e coeficiente Kappa das classificações MESMA com dois membrosfinais aplicadas aos dados espectrais foliares de cinco espécies arbóreas, coletados no período seco. Dados VIS, NIR, SWIR e VSWIR, em reflectância ou com o contínuo removido (CR), e métricas para seleção de membros-finais EMC ou IES(IES*). Dados apresentados de forma ranqueada do maior para o menor coeficiente Kappa.

Figura 4.5. Espectros médios por classe de espécie-alvo, desvios padrões intraclasse, considerando os espectros médios de cada indivíduo/espécie, e desvios padrões interclasse, considerando o espectro médio da espécie em relação à média da população, apresentados respectivamente sobre os dados do período chuvoso ( $\mathrm{A}, \mathrm{B}$ e C) e do período seco (D, E e F). 150

Figura 4.6. Relações entre as variáveis dependentes (exatidão do produtor (EP) da classificação MESMA para determinada região espectral) e independentes (desvios padrão intra ou interespecíficos de compostos bioquímicos): A) EPs da classificação espectral utilizando o intervalo do visível (VIS) e variações em pigmentos foliares que os expressam, no período chuvoso; B) EP do infravermelho ondas curtas (SWIR) e variações em composto estrutural e água, do período seco; C) EP da classificação espectral utilizando todo o intervalo óptico (VSWIR) e compostos que expressam aqueles resultados, no período seco. Cloro $=$ clorofila; Carot $=$ carotenoides; Antoc $=$ antocianina.......

Figura 5.1. Mosaico de imagens hiperespectrais ProSpecTIR-VS obtidas para o estudo na Estação Ecológica de Mogi-Guaçu, São Paulo, Brasil.....

Figura 5.2. Regiões espectrais excluídas dos dados (áreas hachuradas) e mantidas para o processamento (espectro/ linha) dos dados ProSpecTIR-VS.

Figura 5.3. Coeficientes Kappa e exatidões globais (\%) das classificações MESMA com dois membros-finais, obtidos sobre diferentes dados espectrais e métricas para seleção de membros-finais, ranqueados do maior ao menor coeficiente Kappa... 
Figura 5.4. Taxas de mistura espectral observadas entre as classes de espécie-alvo, Cedrela fissilis (CEFI), Inga vera subsp. affinis (INVE) e Qualea grandiflora (QUGR), nas classificações espectrais de dados VIS-NIR1, NIR2-SWIR e VSWIR. As linhas centrais horizontais indicam as medianas das populações, as bordas inferior e superior das caixas o intervalo entre 25 e $75 \%$ da distribuição dos dados da população e as linhas extremas horizontais os valores mínimo e máximo do conjunto de dados (não considerados os outliers). 176

Figura 5.5. Imagem classificada de fração espectral de Cedrela fissilis (CEFI), na Estação Ecológica de Mogi-Guaçu, São Paulo, Brasil: pixels com menos de $80 \%$ de sua fração em verde e com mais de $80 \%$ de sua fração em magenta. 179

Figura 5.6. Imagem classificada de fração espectral de Inga vera subsp. affinis (INVE), na Estação Ecológica de Mogi-Guaçu, São Paulo, Brasil: pixels com menos de $85 \%$ de sua fração em verde e com mais de $85 \%$ de sua fração em magenta. 180

Figura 5.7. Imagem classificada de fração espectral de Qualea grandiflora (QUGR), na Estação Ecológica de Mogi-Guaçu, São Paulo, Brasil: pixels com menos de $65 \%$ de sua fração em verde e com mais de $65 \%$ de sua fração em magenta. 180

Figura 5.8. Espectros médios das copas de Cedrela fissilis (CEFI, $n=22)$, Inga vera subsp. affinis (INVE, $n=31$ ) e Qualea grandiflora (QUGR, $n=28$ ) e membros-finais de vegetação verde (GV), vegetação não fotossintética (NPV) e sombra (SHADE), obtidos no mosaico de imagens ProSpecTIR-VS da Estação Ecológica de Mogi-Guaçu, São Paulo, Brasil. 182

Figura 5.9. Frações espectrais de Cedrela fissilis (CEFI - em verde, $\geq 0,80$ ), Inga vera subsp. affinis (INVE - em azul, $\geq 0,85$ ) e Qualea grandiflora (QUGR - em vermelho, $\geq 0,65$ ), na Estação Ecológica de Mogi-Guaçu, São Paulo, Brasil. Contato geológico esquemático (capítulo 3), em escala aproximada de 1:10.000..... 185

Figura 6.1. Trecho de Floresta Estacional Semidecidual às margens do rio Mogi-Guaçu, na área de estudo. A) em composição colorida em cores naturais (canais $686 \mathrm{~nm}, 553 \mathrm{~nm}, 479 \mathrm{~nm}$, em RGB); B) em cor sintética, razão simples $\rho 740 / p 677 \mathrm{~nm}$ (realce para clorofila a). Ver variação espectral da vegetação evidenciando paleoleito (à esquerda do rio), em relação aos terrenos adjacentes. 


\section{LISTA DE TABELAS}

Tabela 1.1. Especificações técnicas do espectrorradiômetro FieldSpec 3 Hi-Res (ASD, 2008)........33

Tabela 1.2. Especificações técnicas do sistema de sensores ProSpecTIR-VS (SpecTIR, 2011).....34

Tabela 3.1. Classificação granulométrica de solos e de sedimentos adotada no estudo.

Tabela 3.2. Índices espectrais de vegetação extraídos de Ustin (2008) e aplicados nas imagens hiperespectrais da área de estudo......

Tabela 3.3. Especificações da formação dos Self-organizing maps por análise específica

Tabela 3.4. Fisionomias florestais amostradas na Estação Ecológica de Mogi-Guaçu, parâmetros fitossociológicos e ambientais de ocorrência. $\mathrm{N}=$ número de indivíduos amostrados, $\mathrm{S}=$ riqueza de espécies, $\mathrm{H}^{\prime}$ = Índice de diversidade de Shannon-Wiener, CSS = Cerrado "sensu stricto" e FES = Floresta Estacional Semidecidual......

Tabela 3.5. Definição dos geoambientes sob o contínuo de Floresta Estacional Semidecidual observados na amostragem por transectos. qe = erro de quantização; te = erro de topologia.

Tabela 3.6. Domínios formados para o SOM de dados granulométricos de sedimentos das 70 unidades amostrais e definição dos geoambientes

Tabela 3.7. Domínios das 30 subparcelas, obtidos pelo menor índice Davies-Bouldin, sobre os resultados do SOM aplicados aos dados de granulometria de solos e sedimentos, fertilidade de solos, nível do lençol freático, altitude, valor de cobertura de espécies e índices hiperespectrais de vegetação.

Tabela 3.8. Coeficiente de correlação de Spearman ( $\rho$ ), onde $-0.4 \geq \rho \geq 0.4$ indica a existência de correlação, e probabilidade de t-student, entre as espécies selecionadas e as frações granulométricas dos sedimentos da Estação Ecológica de Mogi-Guaçu. 112

Tabela 4.1. Informações ecológicas das espécies alvo do estudo. $P E R=$ perenifólia; $D E C=$ decídua; $\mathrm{BDC}$ = brevidecídua; GLA = glabra; $\mathrm{PUB}=$ pubescente; IAF = índice de área foliar (Digital Plant Canopy Imager, CID Bio-science, Camas, WA, Estados Unidos) dos indivíduos amostrados no período seco (jun-jul./2012).

Tabela 4.2. Análise de variância (teste F) de compostos bioquímicos foliares entre as espécies-alvo, para os diferentes períodos estudados, sendo que $\mathrm{H}_{0}$ assume a inexistência de variação estatisticamente significante de determinado composto entre as espécies estudadas.

Tabela 4.3. Significância das variações de compostos bioquímicos entre os períodos chuvoso (C) e seco (S) nas folhas das espécies-alvo: período de maior concentração $(\mathrm{P})$ e valor de $p$ do teste $F(A N O V A)$.

Tabela 4.4. Exatidões do produtor (EP) e do usuário (EU), em porcentagem, para cada classe (espécie-alvo) do estudo, obtidas sobre os melhores resultados globais por região espectral (VSWIR, VIS, NIR, SWIR) e período sazonal (chuvoso e seco)

Tabela 4.5. Média $(\bar{X})$ (desvio padrão $(\sigma)$ ) e estimativa de contraste entre médias das taxas de mistura espectral entre pares de classes, provenientes das classificações MESMA de espectros do período seco... 
Tabela 4.6. Regressões lineares, com significância de $\mathrm{F}$ acima de $5 \%$, de melhor ajuste e menor erro padrão, por período de amostragem. Considerando as relações de causalidade das variações intra e interespecíficas de compostos bioquímicos $-X_{i}$ (desvio padrão considerado/ coeficiente de correlação de Pearson com a variável $Y$ ) nas exatidões do produtor (EP) - Y, obtidas nas classificações MESMA com dois membros-finais, utilizando-se dados do visível (VIS), infravermelho ondas curtas (SWIR) e todo espectro óptico (VSWIR)

Tabela 5.1. Classe, sigla utilizada no estudo e número de espectros extraídos de seis imagens: VSWIR (530-2.352 nm), VIS-NIR1 (530-919 nm) e NIR2-SWIR (1.141-2.352 nm), de reflectância e com contínuo removido, para realização das diferentes análises propostas.

Tabela 5.2. Avaliação das imagens de frações de Cedrela fissilis (CEFI; VSWIR(CR)/IES), Inga vera subsp. affinis (INVE; VSWIR/IES) e Qualea grandiflora (QUGR; VSWIR(CR)/EMC). Porcentagem de pixels (\%PM) e copas (\%CM) modelados e respectivos valores médios $(\bar{X})$ (desvios-padrão $(\sigma))$ da fração de espécie-alvo às classes do estudo. 178 


\section{LISTA DE SIGLAS E ABREVIATURAS}

\begin{tabular}{|c|c|}
\hline 2D & - Duas dimensões \\
\hline 3D & - Três dimensões \\
\hline Achl & - Absorption of chlorophyll Index \\
\hline AF & - Areia Fina \\
\hline AG & - Areia Grossa \\
\hline Al & - Alumínio \\
\hline AM & - Areia Média \\
\hline AMF & - Areia Muito Fina \\
\hline AMG & - Areia Muito Grossa \\
\hline ANN & - Artificial Neural Networks \\
\hline ANOVA & - Analysis of Variance \\
\hline Antoc. & - Antocianina \\
\hline APC & - Análise por Principais Componentes \\
\hline APG & - Angiosperm Phylogeny Group \\
\hline Arg & - Argila \\
\hline ARI & - Anthocyanin Reflectance Index \\
\hline ASTER & - Advanced Spaceborne Thermal Emission and Reflection Radiometer \\
\hline $\mathrm{Au}$ & - Ouro \\
\hline AUS & - Austrália \\
\hline AVIRIS & - Airborne Visible/ Infrared Imaging Spectrometer \\
\hline BA & - Bahia \\
\hline BDC & - Brevidecídua \\
\hline BMU & - Best Matching Units \\
\hline $\mathrm{BNb}$ & - Index for chlorophyll content \\
\hline BRA & - Brasil \\
\hline BRDF & - Bidirectional Reflectance Distribution Function \\
\hline BSQ & - Band Sequential Image \\
\hline $\mathrm{Ca}$ & - Cálcio \\
\hline CA & - Califórnia \\
\hline CABR & - Calophyllum brasiliense Cambess. \\
\hline CAl & - Cellulose Absorption Index \\
\hline Carot. & - Carotenoides \\
\hline CEFI & - Cedrela fissilis Vell. \\
\hline CERspp & - Espécies de cerradão \\
\hline CITspp & - Citrus spp. \\
\hline Cloro A & - Clorofila a \\
\hline Cloro B & - Clorofila b \\
\hline Co & - Colorado \\
\hline CoB & - Count-based \\
\hline CoBln & - Count-based In \\
\hline CoBIndex & - Count-based Index \\
\hline CoBOut & - Count-based Out \\
\hline CPQBA & - Centro Pluridisciplinar de Pesquisas Químicas, Biológicas e Agrícolas \\
\hline CPRM & - Serviço Geológico do Brasil \\
\hline CR & - Contínuo Removido \\
\hline CRD & - Cerradão \\
\hline
\end{tabular}




\begin{tabular}{|c|c|}
\hline CRI & - Carotenoid Reflectance Index \\
\hline css & - Cerrado "sensu stricto" \\
\hline СТС & - Capacidade de Troca Catiônica \\
\hline $\mathrm{Cu}$ & - Cobre \\
\hline DA & - Densidade Absoluta \\
\hline DAF & - Distribuição Angular das Folhas \\
\hline DEC & - Decídua \\
\hline DENDsp & - Dendrocalamus sp. \\
\hline DoA & - Dominância Absoluta \\
\hline DP & - Desvio Padrão \\
\hline DP-INTER & - Desvio Padrão Interclasse \\
\hline DP-INTRA & - Desvio Padrão Intraclasse \\
\hline EAR & - Endmember Average RMSE \\
\hline EEMG & - Estação Ecológica de Mogi-Guaçu \\
\hline EM & - Endmember \\
\hline EMC & - EAR-MASA-CoB \\
\hline EP & - Exatidão do Produtor \\
\hline EQM & - Erro Quadrático Médio \\
\hline ETM+ & - Enhanced Thematic Mapper Plus \\
\hline EU & - Exatidão do Usuário \\
\hline EUA & - Estados Unidos da América \\
\hline EUCspp & - Eucalyptus spp. \\
\hline FA & - Frequência Absoluta \\
\hline $\mathrm{Fe}$ & - Ferro \\
\hline FES & - Floresta Estacional Semidecidual \\
\hline GIFOV & - Ground Instantaneous Field Of View \\
\hline GLA & - Glabra \\
\hline GLT & - Geographic Look Table \\
\hline GNMDS & - Global Non-Metric Multidimensional Scaling \\
\hline GNSS & - Global Navigation Satellite System \\
\hline GO & - Goiás \\
\hline GPS & - Global Positioning System \\
\hline GV & - Green vegetation \\
\hline $\mathbf{H}$ & - Altura \\
\hline $\mathbf{H}^{\prime}$ & - Índice de diversidade de Shannon-Wiener \\
\hline $\mathrm{H}+\mathrm{Al}$ & - Acidez potencial \\
\hline IAF & - Índice de Área Foliar \\
\hline IBGE & - Instituto Brasileiro de Geografia e Estatística \\
\hline IDL & - Interactive Data Language \\
\hline IES & - Iterative Endmember Selection \\
\hline INPE & - Instituto Nacional de Pesquisas Espaciais \\
\hline INVE & - Inga vera Willd. subsp. affinis (DC.) T.D. Penn. \\
\hline IR & - Infrared \\
\hline ISA & - Indicator Species Analysis \\
\hline IVI & - Índice de Valor de Importância \\
\hline$J_{\text {acc }}$ & - Índice de similaridade de Jaccard \\
\hline K & - Potássio \\
\hline LIDAR & - Light Detection And Ranging \\
\hline
\end{tabular}




\begin{tabular}{|c|c|}
\hline MAClspp & - Espécies de mata ciliar \\
\hline MASA & - Minimum Average Spectral Angle \\
\hline MCTA & - Mata Ciliar de Terras Altas \\
\hline МСТВ & - Mata Ciliar de Terras Baixas \\
\hline MDT & - Modelo Digital de Terreno \\
\hline MESMA & - Multiple Endmember Spectral Mixture Analysis \\
\hline MF & - Membro-Final \\
\hline Mg & - Magnésio \\
\hline MG & - Minas Gerais \\
\hline MGI & - Mata de Galeria Inundável \\
\hline MGNI & - Mata de Galeria Não Inundável \\
\hline Mn & - Manganês \\
\hline MNF & - Minimum Noise Fraction \\
\hline MO & - Matéria Orgânica \\
\hline MODIS & - Moderate-Resolution Imaging Spectroradiometer \\
\hline MSS & - Multi Spectral Scanner \\
\hline NASA & - National Aeronautics and Space Administration \\
\hline NDVI & - Normalized Difference Vegetation Index \\
\hline NDWI & - Normalized Difference Water Index \\
\hline $\mathrm{Ni}$ & - Níquel \\
\hline NIR & - Near Infrared \\
\hline NMDS & - Non-Metric Multidimensional Scaling \\
\hline NPV & - Non-Photosynthetic Vegetation \\
\hline NV & - Nevada \\
\hline O-H & - Oxigênio-Hidrogênio \\
\hline $\mathbf{P}$ & - Fósforo \\
\hline PA & - Pará \\
\hline PC & - Principal Componente \\
\hline PC & - Período Chuvoso \\
\hline PER & - Perenifólia \\
\hline pH & - Acidez ativa \\
\hline PI & - Piauí \\
\hline PINspp & - Pinus spp. \\
\hline POAspp & - Poaceae spp. \\
\hline PPI & - Pixel Purity Index \\
\hline PRISM & - Processing Routines in IDL for Spectroscopic Measurements \\
\hline PS & - Período Seco \\
\hline PUB & - Pubescente \\
\hline PV & - Photosynthetic vegetation \\
\hline qe & - Erro de quantização médio \\
\hline QLD & - Queensland \\
\hline QUGR & - Qualea grandiflora Mart. \\
\hline RGB & - Red:Green:Blue \\
\hline RMSE & - Root Mean Square Error \\
\hline S & - Riqueza de espécies \\
\hline SACspp & - Sacharum spp. \\
\hline SAM & - Spectral Angle Mapper \\
\hline SB & - Soma de Bases \\
\hline
\end{tabular}




$\begin{array}{ll}\text { SCM } & \text { - Spectral Correlation Mapper } \\ \text { Sil } & - \text { Silte } \\ \text { SMA } & - \text { Spectral Mixture Analysis } \\ \text { SOM } & - \text { Self-Organizing Maps } \\ \text { SP } & \text { - São Paulo } \\ \text { SWIR } & - \text { Shortwave Infrared } \\ \text { TAOC } & - \text { Tabebuia ochracea (Cham.) Standl. } \\ \text { te } & - \text { Erro de topologia } \\ \text { TM } & - \text { Thematic Mapper } \\ \text { TM3 } & - \text { Thematic Mapper/banda 3 } \\ \text { TM4 } & - \text { Thematic Mapper/banda 4 } \\ \text { UA } & - \text { Unidade Amostral } \\ \text { UNICAMP } & - \text { Universidade Estadual de Campinas } \\ \text { UPGMA } & - \text { Hierarchical clustering analysis with group-average linking } \\ \text { USP } & - \text { Universidade de São Paulo } \\ \text { V\% } & - \text { Saturação por bases } \\ \text { VC } & - \text { Valor de Cobertura } \\ \text { VI } & - \text { Valor de Importância } \\ \text { VIS } & - \text { Visible } \\ \text { VNIR } & - \text { Visible-Near Infrared } \\ \text { VSWIR } & - \text { Visible-Shortwave Infrared } \\ \text { WA } & - \text { Washington } \\ \text { WBI } & - \text { Water Band Index } \\ \text { ZETU } & - \text { Zeyheria tuberculosa (Vell.) Bureau } \\ \text { Zn } & - \text { Zinco } \\ \end{array}$




\section{SUMÁRIO}

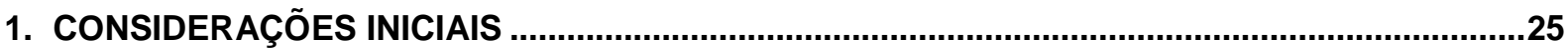

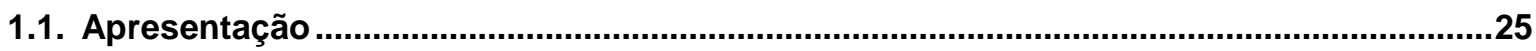

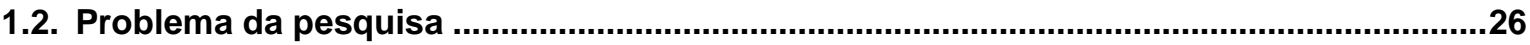

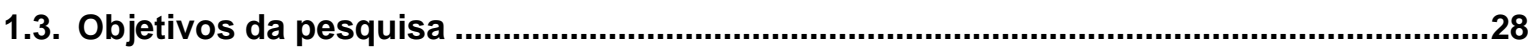

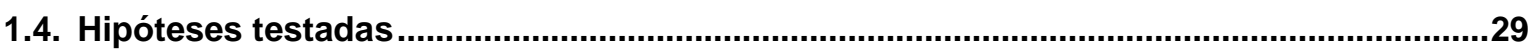

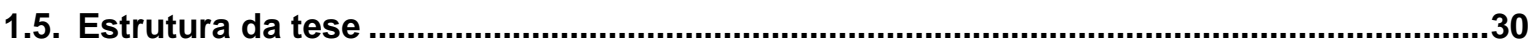

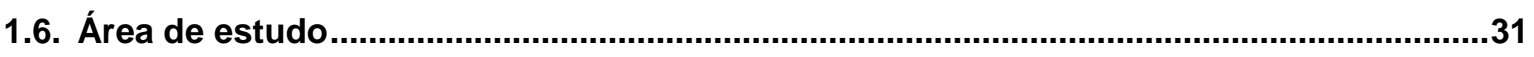

1.7. Sistemas de sensores ópticos utilizados no estudo .......................................................33

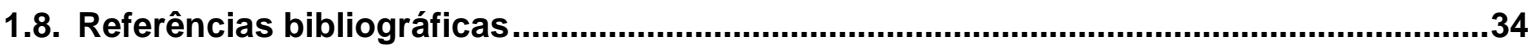

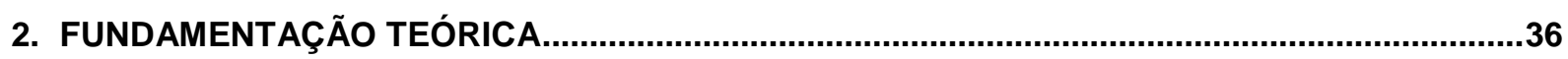

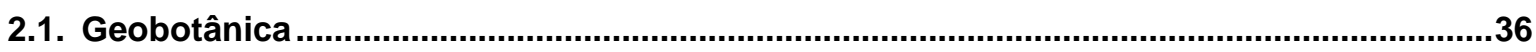

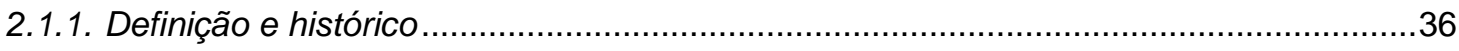

2.1.2. Geobotânica de campo em ambientes tropicais brasileiros ..........................................40

2.1.2.1.A vegetação do bioma Cerrado e sua relação com o meio físico........................46

2.1.3. Geobotânica por sensoriamento remoto em ambientes tropicais .................................50

2.1.3.1. Histórico da geobotânica por sensoriamento remoto no Brasil ...........................53

2.1.3.1.1.Geobotânica por sensoriamento remoto no bioma Cerrado .................56

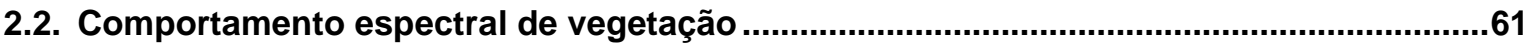

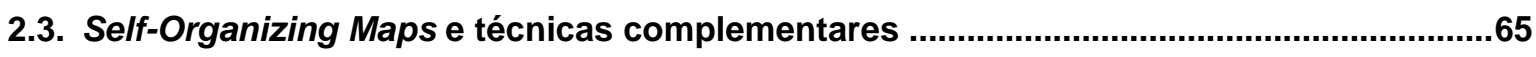

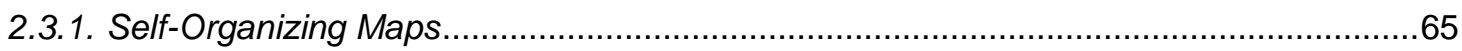

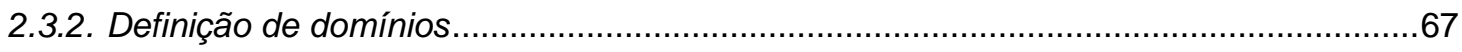

2.3.3. Análises estatísticas periféricas do software SiroSOM................................................68

2.4. Multiple Endmember Spectral Mixture Analysis e técnicas complementares...................69

2.4.1. Multiple endmember spectral mixture analysis ..........................................................69

2.4.2. Métricas para seleção de membros-finais .................................................................. 71

2.4.3. Remoção do contínuo de espectros ........................................................................73

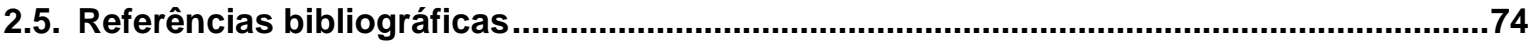

3. DEFINIÇÃO DE GEOAMBIENTES E DE ESPÉCIES ARBÓREAS INDICADORAS EM UM

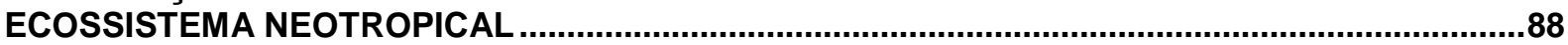

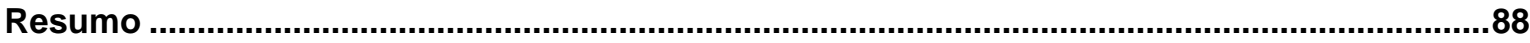

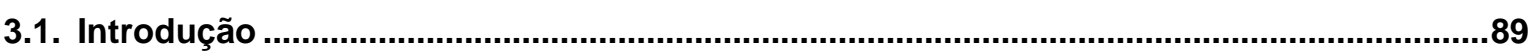

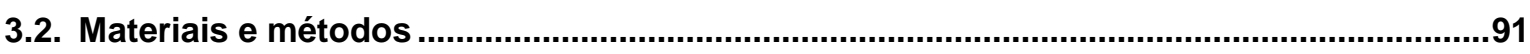

3.2.1. Caracterização florística e fitossociológica das fisionomias florestais............................91

3.2.2. Gradientes da vegetação e do meio físico na floresta estacional semidecidual .............93

3.2.3. Aquisição dos dados de elevação e dos índices hiperespectrais de vegetação.............94

3.2.4. Análise dos dados multivariados no software SiroSOM .............................................95

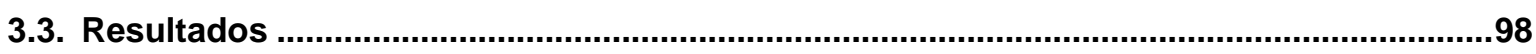

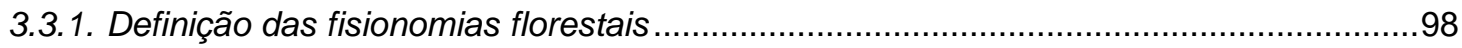


3.3.2. Variações geoedáficas sob a floresta estacional semidecidual....................................100

3.3.3. Definição dos geoambientes da área de estudo......................................................101

3.3.4. Relações entre as fisionomias florestais e a textura dos sedimentos ...........................106

3.3.5. Definição de espécies indicadoras dos geoambientes.............................................109

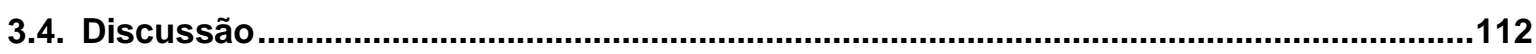

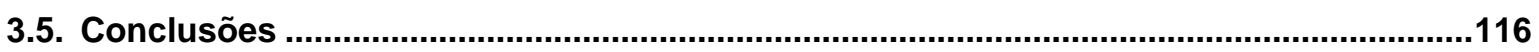

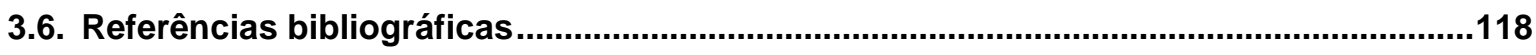

4. ANÁLISE DE MISTURA ESPECTRAL EM ESCALA DE FOLHA ENTRE ESPÉCIES INDICADORAS GEOLÓGICAS: VARIAÇÃO SAZONAL E RELAÇÃO COM COMPOSTOS

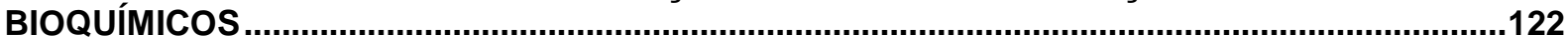

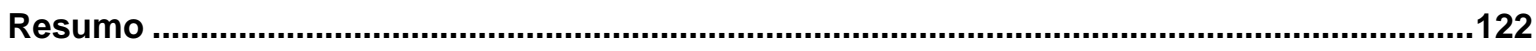

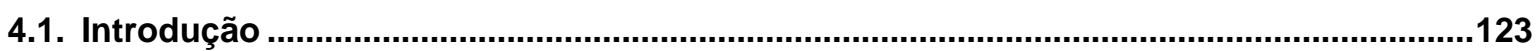

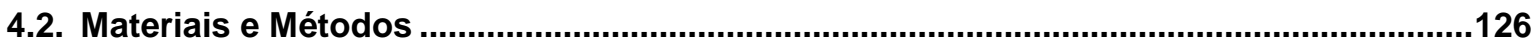

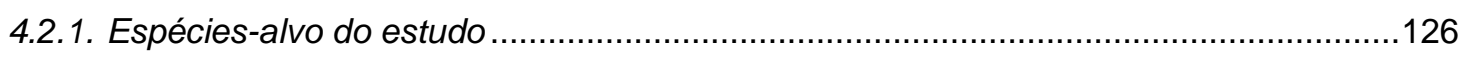

4.2.2. Coleta e armazenamento de amostras foliares ..........................................................127

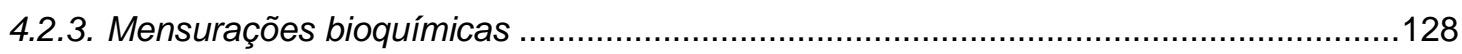

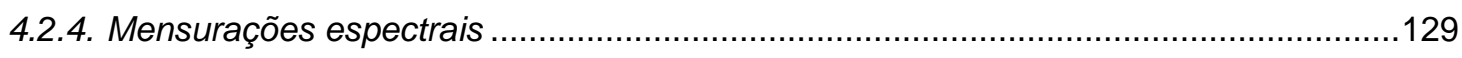

4.2.5. Análise das variações bioquímicas entre espécies-alvo e momentos sazonais ..........129

4.2.6. Análise de mistura espectral com múltiplos membros-finais .....................................130

4.2.6.1. Elaboração das bibliotecas espectrais .....................................................130

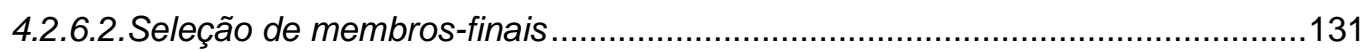

4.2.6.3. Modelagem espectral com dois membros-finais...........................................132

4.2.6.4.Análises de mistura espectral entre as classes de espécies-alvo ....................133

4.2.7. Influência das variações bioquímicas na desmistura espectral das espécies-alvo......134

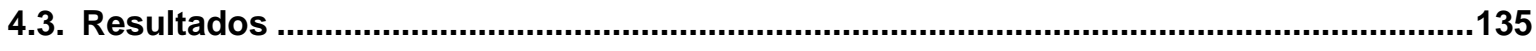

4.3.1. Variações bioquímicas entre espécies e momentos sazonais ....................................135

4.3.2. Classificações espectrais MESMA com dois membros-finais ...................................140

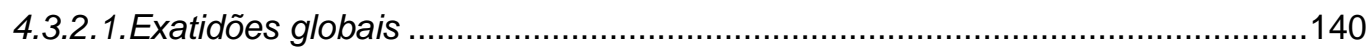

4.3.2.2. Exatidões específicas e relações de mistura espectral entre espécies-alvo....143

4.3.3. Influência das variações bioquímicas na desmistura espectral das espécies-alvo......145

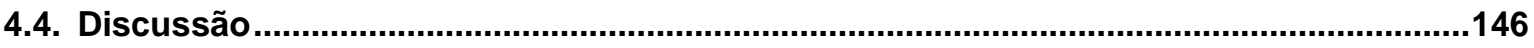

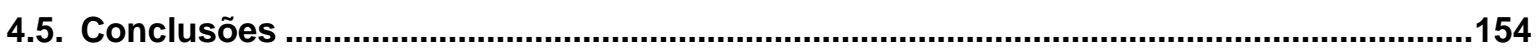

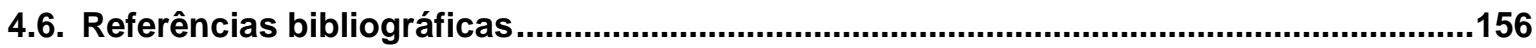

5. ANÁLISE DE MISTURA ESPECTRAL EM ESCALA DE COPA ENTRE ESPÉCIES INDICADORAS GEOLÓGICAS E MAPEAMENTO DE FRAÇÕES ESPECTRAIS ............................161

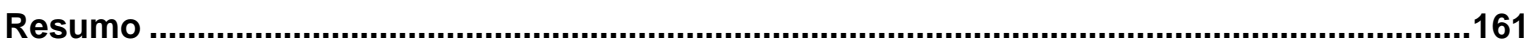

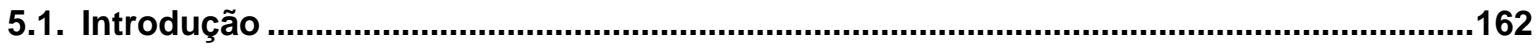

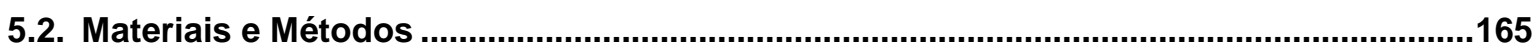

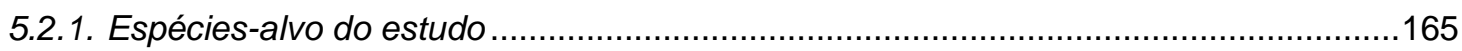

5.2.2. Aquisição e pré-processamento de dados hiperespectrais .........................................165

5.2.3. Obtenção das amostras de referência e bibliotecas espectrais ...................................168 
5.2.4. Geração e extração de informações das bibliotecas espectrais

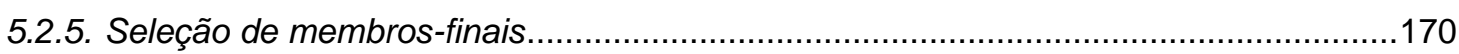

5.2.6. Análise de mistura espectral com múltiplos membros-finais .....................................171

5.2.6.1. Classificação espectral com dois membros-finais .............................................171

5.2.6.2. Obtenção de imagens de fração espectral das espécies-alvo ...........................172

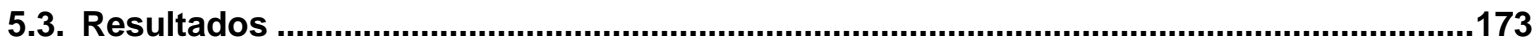

5.3.1. Análise de mistura espectral entre espécies-alvo.....................................................173

5.3.2. Análise de mistura espectral entre espécies-alvo e outras classes de vegetação.......176

5.3.3. Modelagem espectral de imagens hiperespectrais.....................................................177

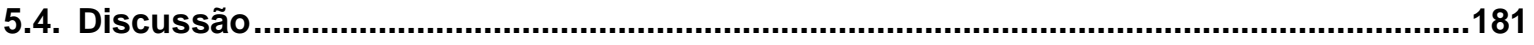

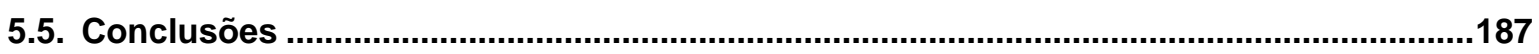

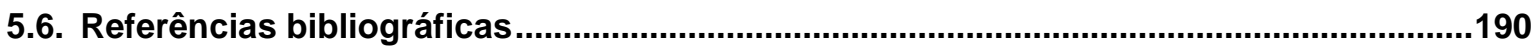

6. CONSIDERAÇÕES FINAIS

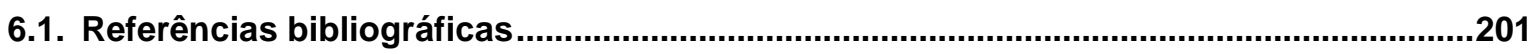

APÊNDICES

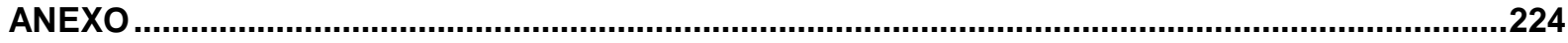




\section{CONSIDERAÇÕES INICIAIS}

\subsection{Apresentação}

A geobotânica por sensoriamento remoto em terrenos tropicais, como fonte de informação geológica em mapeamento geológico ou em geologia de exploração, é uma técnica pouco utilizada e com muito a ser desenvolvido. Ainda que resultados com imagens multiespectrais relativos à variabilidade espectral e florística venham sendo publicados na literatura, não são observados estudos voltados à identificação de espécies arbóreas indicadoras de ambientes geológicos comuns e sua posterior discriminação com sensores hiper e ultraespectrais.

Esta tese tem como área de estudo a Estação Ecológica de Mogi-Guaçu, a nordeste do Estado de São Paulo, Brasil, onde há deposição de sedimentos quaternários associados ao rio Mogi-Guaçu (sequência Depósitos Aluvionares) e afloramentos da Formação Aquidauana, do Paleozóico da Bacia Sedimentar do Paraná. O experimento foi realizado em área marginal do bioma Cerrado e apresenta fisionomias exclusivas do bioma, bem como extensa mata ciliar, que floristicamente se aproxima ao bioma Mata Atlântica. Não há, do ponto de vista geoquímico, solos particulares na região que permitam o reconhecimento imediato de espécies indicadoras, como descreve a literatura para ocorrências de minérios metálicos. A definição de um grupo de espécies, de hábito arbóreo, que se associe a pequenas variações na granulometria dos sedimentos e solos, sejam elas fisionomicamente pertencentes ao cerradão ou à mata ciliar, é um resultado de importância para a geobotânica. A discriminação espectral dessas espécies em escala de folha e de copa e seu mapeamento, em imagens hiperespectrais de resolução espacial fina, completam uma abordagem geobotânica em nível específico com grande potencial para futuras aplicações.

Atendendo à tendência dominante no Programa de Pós-Graduação em Recursos Minerais e Hidrogeologia, do Instituto de Geociências da Universidade de São Paulo, esta tese tem, como capítulos 3, 4 e 5, três trabalhos que serão transformados em artigos, além de considerações iniciais, fundamentação teórica geral e considerações finais. Como 
apêndices, são apresentadas as listas de espécies amostradas na área de estudo, os dados químicos e granulométricos dos solos e dos sedimentos amostrados e os dados bioquímicos foliares das espécies alvo do estudo. Como anexo, um trabalho recém-submetido acerca de espécies de plantas invasoras naquela estação ecológica. Não é uma abordagem geobotânica, mas devido à maior simplicidade em abordar espécies exóticas, o referido trabalho serviu como treinamento em técnicas de processamento de imagens hiperespectrais.

\subsection{Problema da pesquisa}

A geobotânica por sensoriamento remoto, que, em seu sentido restrito, é referida como uma técnica de acesso a informações geológicas através das propriedades ópticas da vegetação sobrejacente, tem como objetivo principal a prospecção de mineralizações (ou exsudações de hidrocarbonetos), bem como o mapeamento geológico de áreas cobertas por vegetação. Os resultados de um mapeamento geobotânico acurado podem ser funcionais à geologia de exploração por indicar alvos, otimizando campanhas de campo.

Diferentemente das regiões frias e temperadas do planeta, com baixa diversidade florística, onde o estresse químico constitue o maior interesse geobotânico, nas regiões tropicais, altamente biodiversas, as variações florísticas e fisionômicas representam o principal fator de prospecção (Almeida et al., 2009). Nesses ambientes, o estresse químico só deve ser observado quando a concentração de dado minério (ou gás) é elevada a ponto de causar toxicidade nos solos ou condições secundárias adversas à vegetação.

Embora não sejam observados muitos trabalhos sobre o tema, aplicações de sensoriamento remoto multiespectral têm demonstrado nos ambientes altamente biodiversos, como a Amazônia, variações florísticas associadas às litologias subjacentes (p.ex., Higgins et al., 2011, 2012 e 2014). No bioma Cerrado, conhecido também como savana tropical basileira, inúmeras pesquisas baseadas em dados de campo - desde o estudo pioneiro de Eugen Warming em 1908: "Lagoa Santa, Contribuição para geografia 
fitobiológica" - têm demostrado a importância do meio físico na distribuição das fisionomias do bioma e, até mesmo, de espécies. Contudo, não são observados na literatura trabalhos que indicam associações entre espécies e geologia. De fato, para o estabelecimento seguro dessas associações, há de se considerar a dinâmica do sistema estudado. Essa dinâmica é resultado da interação de tudo que o constitui: o clima, a biologia, a hidrologia, a geomorfologia, os solos e, também, a geologia que, não menos importante, representa a base de todo o sistema edáfico.

Como já previsto em 1999 por Floyd Sabins (Sabins, 1999), pesquisador em sensoriamento remoto geológico, novas investigações geobotânicas deveriam ser estimuladas com o advento do sensoriamento remoto hiperespectral. Imagens de bandas estreitas (hiperespectrais) de qualidade satisfatória (do sensor Airborne Visible/Infrared Imaging Spectrometer - AVIRIS, NASA) começaram a ser disponibilizadas ainda naquela década. Contudo, apesar do entusiasmo nas previsões desse pesquisador, ainda são raras as pesquisas em geobotânica por sensoriamento remoto hiperespectral entre os trópicos, tanto em geologia de exploração e de petróleo (exsudações de hidrocarbonetos), quanto no mapeamento geológico básico.

O sensoriamento remoto hiperespectral (ou espectroscopia de imageamento) da vegetação encontra-se em amplo e rápido desenvolvimento desde a década de 1990 . No entanto, as técnicas de processamento e os resultados que vêm sendo apresentados na literatura vão além do exposto, até o momento, em geobotânica. Já é possível o mapeamento específico da vegetação, ao menos de espécies dominantes, em escala de copas individuais (Ustin e Gamon, 2010). O primeiro registro de sucesso em discriminação espectral de espécies nativas, em ambientes tropicais, possível apenas com sensores de alta resolução espectral e espacial, ocorreu no ano de 2005 (Clark et al., 2005). No entanto, o mapeamento de espécies nativas em escala de copas individuais entre os trópicos ainda constitui uma difícil tarefa, devido à elevada diversidade florística, bioquímica, fisiológica e estrutural presente no dossel de suas florestas. Essa diversidade ainda é pouco compreendida pela comunidade científica (Asner, 2008; Asner e Martin, 2008). 
Possivelmente por esse fato, as técnicas de discriminação espectral em escala de copas individuais e de mapeamento de espécies de plantas em imagens hiperespectrais são utilizadas mais comumente para espécies exóticas invasoras. Como essas plantas apresentam características fisiológicas, morfológicas e fenológicas distintas das outras espécies, que estão em seus ambientes naturais, o seu mapeamento é mais facilmente atingido (Ustin e Gamon, 2010). Essas observações foram essenciais ao "senso comum" que vem se estabelecendo entre os principais pesquisadores da área: o sensoriamento remoto hiperespectral da vegetação pode identificar e mapear espécies de plantas; contudo, para que isso aconteça, essas espécies devem apresentar espectros singulares (Asner e Martin, 2009). Ou seja, o sucesso de mapeamento de uma determinada espécie se dá quando essa se distingue estrutural, bioquímica, fisiológica e fenologicamente das outras espécies presentes na paisagem (Gamon, 2008; Ustin e Gamon, 2010).

\subsection{Objetivos da pesquisa}

O objetivo geral desta pesquisa é realizar a discriminação espectral em escala de folha e de copa de espécies neotropicais de ocorrência associada a diferentes formações e fácies geológicas, bem como verificar se o mapeamento baseado em pixel dessas espécies pode defini-las como indicadoras geológicas na Estação Ecológica de Mogi-Guaçu, São Paulo, Brasil.

A fim de atender esse objetivo maior, os objetivos específicos da pesquisa são:

- Definir ambientes geológicos, através de análise multivariada de dados do meio físico, bem como verificar a possibilidade de definição "in loco" de espécies arbóreas com ocorrências associadas aos diferentes geoambientes (formações e fácies geológicas) da área de estudo.

- Discriminar espectralmente, em escala de folha, espécies consideradas indicadoras de formações e fácies geológicas da área de estudo, bem como verificar a existência de um período sazonal mais adequado à discriminação. 
- Realizar a discriminação espectral, em escala de copa, entre espécies consideradas indicadoras de diferentes formações e fácies geológicas, e também entre elas e outras classes de vegetação pertencentes à paisagem estudada.

- Analisar as taxas de mistura espectral, em escala de folha e de copa, entre espécies arbóreas neotropicais e verificar se aquelas consideradas indicadoras de mesma formação e fácies geológicas apresentam composição bioquímica e comportamento espectral semelhantes entre si e distintos em relação às outras espécies.

- Gerar imagens de frações espectrais de espécies consideradas indicadoras geológicas da área estudada e verificar se esse mapeamento, baseado em pixels de $1 \mathrm{~m}$, pode prover informações quanto à ocorrência de determinada formação e fácies geológicas.

\subsection{Hipóteses testadas}

Abaixo estão descritas as seis hipóteses testadas nesta pesquisa:

1. Considerando a variabilidade geológica, de microambientes e de comunidades vegetais, presentes na Estação Ecológica de Mogi-Guaçu, São Paulo, Brasil, existem espécies no dossel das diferentes fisionomias florestais que podem ser consideradas indicadoras de formações e fácies geológicas.

2. Considerando a elevada sazonalidade bioquímica-espectral dos dosséis de formações neotropicais, existe um melhor período do ano (seco ou chuvoso) no qual espécies consideradas indicadoras de fácies e formações geológicas são mais bem discriminadas espectralmente, em escala de folha.

3. Tendo em vista os variados regimes de deciduidade observados entre espécies consideradas indicadoras de diferentes formações geológicas da área de estudo, então essas espécies podem ser discriminadas espectralmente, em escala de copa, utilizando imagens do sistema de sensores aeroportados ProSpecTIR-VS obtidas no final do outono.

4. Considerando uma possível existência de padrões ecofisiológicos (e estruturais) nas copas de espécies associadas ao mesmo ambiente geológico na Estação Ecológica de 
Mogi-Guaçu, então essas espécies apresentam maior mistura espectral, tanto em escala de folha quanto de copa.

5. Tendo em conta que é possível o mapeamento de espécies, ao menos das mais abundantes, em imagens hiperespectrais de resolução espacial fina, então o mapeamento de frações espectrais de espécies consideradas localmente indicadoras de ambientes geológicos, em mosaico de imagens ProSpecTIR-VS, permite inferir sobre a ocorrência de diferentes formações e fácies geológicas da área de estudo.

\subsection{Estrutura da tese}

Esta tese é composta por seis capítulos, três apêndices e um anexo, sendo o primeiro e o último capítulos as considerações iniciais e finais.

O segundo capítulo é constituído por uma fundamentação teórica geral dos principais temas abordados e métodos utilizados para a concretização da tese: i) Geobotânica de campo e por sensoriamento remoto, incluindo subtópicos com enfoque no bioma Cerrado; ii) Comportamento espectral de vegetação; iii) Self-Organizing Maps (SOM) e técnicas complementares; iv) Multiple Endmember Spectral Mixture Analysis (MESMA) e técnicas complementares.

O terceiro capítulo é composto pela definição de geoambientes (formações e fácies geológicas) de ocorrência na Estação Ecológica de Mogi-Guaçu (EEMG) e de espécies de hábito arbóreo presentes no dossel florestal e associadas a esses ambientes. A definição de ambos (geoambientes e espécies) é resultado de análises multivariadas, baseadas em quantização vetorial (SOM) de dados amostrados em campo, dados vetoriais e índices hiperespectrais de vegetação. Esse capítulo tem como apêndices a lista de espécies amostradas na EEMG (Apêndice A) e os dados granulométricos e químicos dos sedimentos e dos solos amostrados (Apêndice B).

O quarto capítulo é constituído pela discriminação espectral, em escala de folha, de espécies consideradas indicadoras de formações e fácies geológicas da EEMG, utilizando 
dados dos períodos chuvoso e seco do ano. Nesse capítulo também são apresentadas análises intra e interespecíficas das variações em compostos bioquímicos e comportamentos espectrais foliares e suas implicações à geobotânica por sensoriamento remoto. As análises de mistura e discriminação espectral foram realizadas sobre dados ultraespectrais foliares utilizando a técnica MESMA. Os dados bioquímicos totais das espécies-alvo desse estudo são apresentados no Apêndice C.

No quinto capítulo são apresentadas as análises de mistura espectral, em escala de copa, entre classes de espécies indicadoras de diferentes formações e fácies geológicas da EEMG, bem como entre elas e outras classes de vegetação representativas da paisagem. Nesse capítulo também são expostas as modelagens das imagens hiperespectrais, baseadas em pixel, via MESMA. São ainda discutidas a importância e as implicações desse estudo para a geobotânica por sensoriamento remoto.

Nas considerações finais (capítulo 6) são discutidos os resultados das hipóteses testadas, os desafios encontrados durante a execução desta pesquisa e a influência da escala de trabalho no estabelecimento de relações geobotânicas.

Como anexo é apresentado um trabalho recém-submetido à publicação em periódico, a respeito de espécies de plantas invasoras na EEMG. Esse estudo é resultante do aprendizado e treinamento em técnicas de pré-processamento e processamento de dados hiperespectrais, realizados durante estágio no exterior.

\section{6. Área de estudo}

A área de estudo compreende a Estação Ecológica de Mogi-Guaçu - EEMG, no município de Mogi-Guaçu, Estado de São Paulo, sudeste do Brasil (Figura 1.1). Apresenta área de aproximadamente $1.200,30$ ha e está localizada entre as coordenadas $22^{\circ} 16^{\prime}$ e $22^{\circ} 18^{\prime} \mathrm{S}$ e $47^{\circ} 08^{\prime} 30^{\prime \prime}$ e $47^{\circ} 12^{\prime} 30^{\prime \prime}$ W. Sua topografia é caracterizada por colinas amplas e planície aluvial, com altitudes entre 560 e 700 m. Os solos, em sua maioria, são hidromórficos de planície de inundação. A EEMG abriga cerca de 17 km do rio Mogi-Guaçu. 
A geologia local é representada pela Formação Aquidauana e pela sequência Depósitos Aluvionares, associada ao rio (CPRM, 2006). A Formação Aquidauana (Carbonífero da Bacia do Paraná) é caracterizada por depósitos continentais e constituída por arenitos e siltitos de cores avermelhadas, além de conglomerados, diamictitos, ritmitos e folhelhos. Os diamictitos presentes, também vermelhos, apresentam clastos dispersos, alguns com estrias de origem glacial, constituindo tilitos, e de deposição subaquosa. Apesar desta diversidade litológica, Fúlfaro e Bjomberg (1993) observam que os solos desenvolvidos sobre esta formação são comumente arenosos. A sequência Depósitos Aluvionares, que tem naquela formação sua área-fonte, é formada por areias, cascalheiras, siltes, argilas e, localmente, turfas (CPRM, 2006).

A EEMG está localizada em área marginal do bioma Cerrado e apresenta mosaicos de formações características tanto do Cerrado quanto da Mata Atlântica (Joly e Bicudo,1999). As formações de floresta estacional semidecidual, de origem atlântica, estão inseridas no bioma como formações extra-Cerrado por suas associações, mesmo que remota, com os cursos d'água (Ribeiro e Walter, 2008). Eiten (1963), no primeiro estudo florístico realizado na área, notou que as ocorrências dos cerradões (formações florestais xeromórficas do bioma) e das matas ciliares estão associadas, respectivamente, a porções de relevo mais alto e mais baixo, que, por sua vez, são dominados por substrato composto por rochas da Formação Aquidauna e por sedimentos quaternários. 


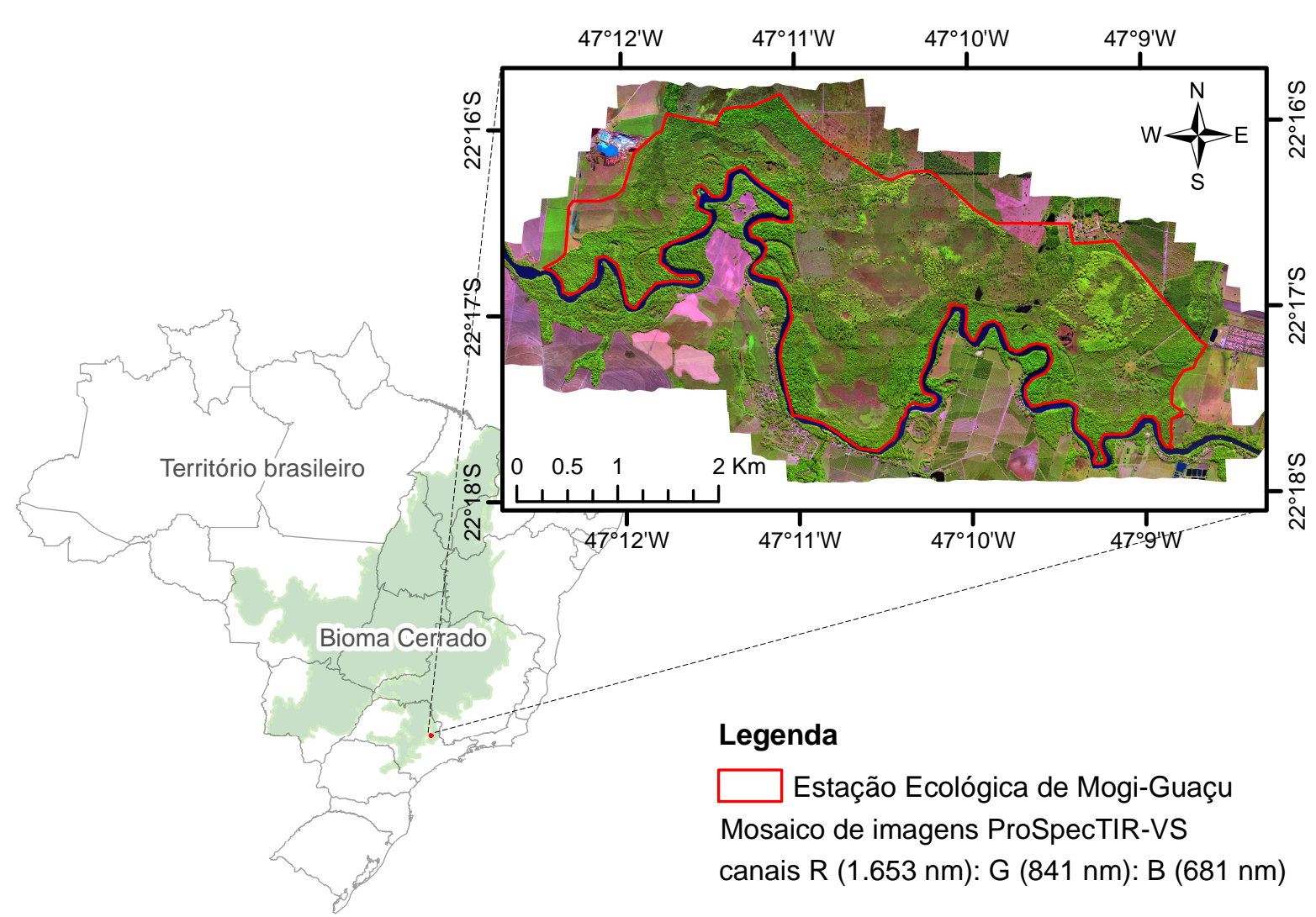

Figura 1.1. Localização da área de estudo. Fonte: IBGE (2004 e 2005).

\subsection{Sistemas de sensores ópticos utilizados no estudo}

Foram utilizados dados de diferentes sensores ópticos para o desenvolvimento desta pesquisa. Para as análises espectrais em escala de folha (capítulo 4) e realce espectral das faixas de imageamento (capítulo 5), foram utilizados dados ultraespectrais coletados com espectrorradiômetro portátil FieldSpec 3 Hi-Res da Analytical Spectral Devices (ASD Inc. Boulder, CO, EUA). As especificações técnicas do equipamento utilizado estão descritas na Tabela 1.1.

Tabela 1.1. Especificações técnicas do espectrorradiômetro FieldSpec 3 Hi-Res (ASD, 2008).

\begin{tabular}{c|c}
\hline \multicolumn{2}{c}{ Espectrorradiômetro portátil FieldSpec 3 Hi-Res (ASD) } \\
\hline Cobertura espectral & de 350 a $2.500 \mathrm{~nm}$ \\
\hline & $3,0 \mathrm{~nm}(\sim 700 \mathrm{~nm})$ \\
Resolução espectral & $8,5 \mathrm{~nm}(\sim 1.400 \mathrm{~nm})$ \\
& $6,5 \mathrm{~nm}(\sim 2.100 \mathrm{~nm})$ \\
\hline Intervalo espectral & 1,4 e $2,0 \mathrm{~nm}$ \\
\hline Número de bandas & 2.151 \\
\hline
\end{tabular}


Para obtenção de índices espectrais de vegetação (capítulo 3), análises de mistura espectral em escala copa e mapeamento de frações espectrais em escala de pixel (capítulo 5), foram utilizadas imagens hiperespectrais obtidas com o sistema de sensores aeroportados ProSpecTIR-VS (SpecTIR - Reno, NV, EUA/ FotoTerra - São Paulo, SP, BRA). As especificações desse sistema são apresentadas na Tabela 1.2.

Tabela 1.2. Especificações técnicas do sistema de sensores ProSpecTIR-VS (SpecTIR, 2011).

\begin{tabular}{c|c}
\hline \multicolumn{2}{c}{ Sistema de sensores aeroportados ProSpecTIR-VS (SpecTIR/FotoTerra) } \\
\hline Cobertura espectral & de 400 a $2.450 \mathrm{~nm}$ \\
\hline Resolução espectral & $2,9 \mathrm{~nm}($ de 400 a $970 \mathrm{~nm})$ \\
& $8,5 \mathrm{~nm}($ de 970 a $2.450 \mathrm{~nm})$ \\
\hline Número de bandas & 357 \\
\hline Largura do imageamento & $\sim 320 \mathrm{~m}$ \\
\hline GIFOV (pixel) & $1 \mathrm{~m}$ \\
\hline
\end{tabular}

\subsection{Referências bibliográficas}

Almeida, T. I. R., Souza Filho, C. R., Juliani, C., \& Branco, F. C. (2009). Application of Remote Sensing to Geobotany to Detect Hydrothermal Alteration Facies in Epithermal High Sulfidation Gold Deposits in the Amazon Region. In R. Bedell, S. Simmons, E. Grunsky, \& A. Crósta. (Orgs.), SEG Reviews in Economic Geology - Remote Sensing and Spectral Geology, $1^{\text {st }}$ ed. (pp. 135-142). Society of Economic Geologists.

Analytical Spectral Devices Inc. - ASD (2008). FieldSpec 3 Hi-Res. Recuperado em 13 de abril de 2015, de http://www.diessechem.com/download.php?file=1295619738ASD\%20FieldSpec3\%20Hi-Res\%202008.pdf/

Asner, G. P. (2008). Hyperspectral remote sensing of canopy chemistry, physiology, and biodiversity in tropical rainforests. In M. Kalacska, \& G. A. Sanchez-Azofeifa (Eds.), Hyperspectral remote sensing of tropical and subtropical forests (pp. 261-296). Boca Raton: CRC Press Taylor \& Francis Group.

Asner, G. P., \& Martin, R. E. (2008). Spectral and chemical analysis of tropical forests: scaling from leaf to canopy levels. Remote Sensing of Environment, 112, 3958-3970.

Asner, G. P., \& Martin, R. E. (2009). Airborne spectranomics: mapping canopy chemical and taxonomic diversity in tropical forests. Frontiers in Ecology and the Environment, 7(5), 269-276.

Gamon, J.A. (2008). Tropical Remote Sensing - Opportunities and Challenges. In: M. Kalacska, \& G. A. Sanchez-Azofeifa (Orgs.) Hyperspectral remote sensing of tropical and subtropical forests (pp. 297-304), New York: Taylor \& Francis Group.

Higgins, M. A., Asner, G. P., Perez, E., Elespuru, N., \& Alonso, A. (2014). Variation in photosynthetic and nonphotosynthetic vegetation along edaphic and compositional gradients in northwestern Amazonia. Biogeosciences, 11(3), 3505-3513.

Higgins, M. A., Asner, G. P., Perez, E., Elespuru, N., Tuomisto, H., Ruokolainen, K., et al. (2012). Use of Landsat and SRTM data to detect broad-scale biodiversity patterns in Northwestern Amazonia. Remote Sensing, 4(8), 2401-2418. 
Higgins, M. A., Ruokolainen, K., Tuomisto, H., Llerena, N., Cardenas, G., Phillips, O. L., et al. (2011). Geological control of floristic composition in Amazonian forests. Journal of Biogeography, 38(11): 2136-2149.

Instituto Brasileiro de Geografia e Estatística - IBGE (2004). Mapa de biomas do Brasil. Escala 1:5.000.000. Recuperado em 11 de agosto de 2014, de http://www.ibge.gov.br/home/geociencias/default_prod.shtm\#TERRIT

Instituto Brasileiro de Geografia e Estatística - IBGE (2005). Malha muncipal digital 2005. Escala 1:2.500.000. Recuperado em 11 de agosto de 2014, de http://www.ibge.gov.br/home/geociencias/default_prod.shtm\#TERRIT

Sabins, F. F. (1999). Remote sensing for mineral exploration. Ore Geology Reviews, 14(3), 157-183.

SpecTIR $^{T M}$ (2011). ProSpecTIR ${ }^{T M}$ VS: VNIR - SWIR Hyperspectral Instrument. Recuperado em 13 de abril de 2015, de http://www.spectir.com/wpcontent/uploads/2012/02/ProSpecTIR_VS_specs_2011.pdf

Ustin, S. L., \& Gamon, J. A. (2010). Remote sensing of plant functional types. New Phytologist, 186(4), 795-816. 


\section{FUNDAMENTAÇÃO TEÓRICA}

\subsection{Geobotânica}

\subsubsection{Definição e histórico}

A observação da relação entre a vegetação e a geologia decerto vem das origens de nossa espécie, na busca de rochas úteis à sua sobrevivência ou na procura de vegetais em ambientes caracterizados por determinada rocha (Almeida, 2005). O primeiro registro dessa relação na literatura ocidental provavelmente ocorreu no século IV a.C., quando Teofrasto, discípulo de Aristóteles, citou em seus compêndios sobre botânica a associação de uma espécie vegetal a solos sobre rochas calcárias (Kruckeberg, 2002). Outro registro é o de Vitruvius, no ano 10 a.C., que descreveu a presença de espécies de plantas associadas a terrenos pantanosos (Brooks, 1972). Em 1556, Georgius Agrícola, em seu livro "De Re Metallica", citou haver senescência precoce, rebrota tardia e nanismo de plantas crescidas sobre corpos de minério, expondo a observação de sintomas fisiológicos e morfológicos de plantas sobre solos anômalos (Ustin et al., 1999). Segundo Ruisong e Yueliang (2004), a técnica é utilizada na China há mais de 2000 anos, sendo reconhecidas, desde então, plantas indicadoras de depósitos minerais. Contudo, o termo geobotânica foi sugerido apenas em 1866 (Fuller, 1920). Em meados da década de 1920, Eduard Rübel (Rübel, 1927) iniciou sua publicação com a pergunta: Ecologia, fitogeografia e geobotânica constituem três diferentes ciências ou diferentes pontos de vista de uma mesma ciência? Uma é parte de outra, ou todas são sinônimas?

Embora na literatura moderna a geobotânica tenha sido comumente entendida como uma técnica de prospecção mineral em áreas vegetadas (p.ex., Brooks, 1972 e 1983), em seu sentido amplo pode ser considerada como o estudo da integração de processos físicos e biológicos de interesse às Ciências da Terra (Ustin et al., 1999). Heshmatti e Squires (1997), por exemplo, descrevem-na como um ramo de estudos ecológicos em fitogeografia, enquanto Amaral (1992) a caracteriza como um ramo da geoquímica que se ocupa das relações entre a composição química de solos e a cobertura vegetal. Soares (2012) define-a 
de modo mais amplo, como a ciência que estuda a expressão fisionômica, morfológica, taxonômica, fenológica e fisiológica da vegetação em função do meio físico onde ela se estabelece. Independentemente de termos ou de ramos de origem, a geobotânica tem o potencial de oferecer um melhor entendimento da fenologia, abundância e distribuição de plantas através de modelos ecofisiológicos holísticos, conectando o comportamento das plantas com as condições edáficas e a geologia (Ustin et al., 1999). Nesta pesquisa, a geobotânica em seu sentido amplo é tratada como a ciência que estuda a expressão da vegetação em relação ao meio físico, levando também em consideração aspectos geológicos.

Além das variações morfofisiológicas observadas na vegetação em ambientes geoquimicamente extremos, como sobre mineralizações (p.ex., Brooks, 1983) e exsudações de hidrocarbonetos (p.ex., Smith et al., 2004; Sanches et al., 2013a e b), pode haver a presença de espécies indicadoras que se estabelecem e sobrevivem em ambientes adversos a outras espécies (p.ex., Cannon, 1971; Prasad, 1987). Muitos pesquisadores discorreram sobre a geobotânica em seu sentido restrito, como Cannon (1960 e 1971), Raney (1966), Brooks (1972, 1980 e 1983), Major (1975), Prasad (1987), nas décadas em que a técnica, realizada em campo, esteve mais presente na literatura.

Brooks (1982) cita, a título de curiosidade, haver no século XIX frequentes relatos da presença de espécies indicadoras de depósitos auríferos, inclusive na Amazônia, como o dos naturalistas austríacos Spix e Martius em 1824. Brooks citou, como talvez o mais interessante mito no tema, um trabalho publicado em 1936 que apontava Equisetum como um gênero botânico indicador de depósitos de ouro. No entanto, Brooks et al. (1981) mostram que Equisetum spp. tem excepcional tolerância a arsênico, elemento muitas vezes associado a mineralizações auríferas primárias, como constataram na Nova Escócia. Ou seja, esses autores comprovaram que Equisetum é um indicador indireto de depósitos auríferos, mas de utilidade geobotânica restrita devido à sua ampla distribuição. Há diversos casos comprovados de espécies indicadoras de anomalias geoquímicas, mas a 
aplicabilidade em geologia de exploração foi pequena, tratando-se mais de curiosidade científica. Essas pesquisas nunca passaram à fase seguinte, de reconhecimento remoto

Ao exigir uma formação complexa do pesquisador ou equipes multidisciplinares, a geobotânica de campo em seu sentido restrito nunca se consolidou operacionalmente como técnica de prospecção mineral (Brooks, 1972 e 1983). Esse fato é potencializado nas regiões tropicais, considerando-se a dificuldade de acesso em áreas altamente vegetadas (Baker e Brooks, 1988). De acordo com Brooks (1972), entre 1857 e 1968, foram publicados 199 trabalhos sobre o tema, dos quais 89 foram realizados por pesquisadores da extinta União das Repúblicas Socialistas Soviéticas e 61 por pesquisadores dos Estados Unidos da América.

Com a disponibilidade de imagens orbitais multiespectrais no domínio óptico a partir da década de 1970 (sensor Multi Spectral Scanner - MSS, do satélite Landsat 1), a geobotânica recebeu um enorme impulso. Os geólogos, antigos usuários das fotografias aéreas pancromáticas, rapidamente procuraram desenvolver a técnica com dados multiespectrais. Através da variabilidade florística e eventuais estresses químicos, a geobotânica por sensoriamento remoto é uma técnica ainda mais promissora na obtenção de informações geológicas indiretas. Ela permite a otimização dos trabalhos de campo, por gerar possíveis alvos a serem examinados (Almeida, 2005).

Arden e Westra (1977), além de exporem uma excelente revisão de geobotânica, apresentaram resultados de quatro diferentes investigações na Geórgia (EUA), discutindo a aplicação da geobotânica por sensoriamento remoto e as potencialidades de diferentes sistemas fotográficos e imagens do sensor MSS/Landsat. Segundo esses autores, cada caso tem suas particularidades e não existe, portanto, um produto ou técnica mais adequados a investigações geobotânicas em geral. Os autores ressaltaram também a particularidade das relações geobotânicas a cada área e ocorrência mineral. Segundo eles, o controle geológico na distribuição de plantas é mais efetivo quando rochas contrastantes ocorrem em ambientes uniformes, semiáridos, subalpinos ou em platôs. 
De acordo com Almeida (2005), a frequente falta de padrões em resposta espectral da vegetação, citada por Arden e Westra em 1977 e experimentada por pesquisadores nos anos seguintes, fez com que a técnica passasse por um período de quase ostracismo. Segundo Sabins (1999), os pesquisadores geobotânicos estavam se aposentando e, junto com eles, a técnica estava se ausentando da literatura. Apesar dessas constatações, com frequência relativamente baixa, trabalhos de geobotânica "sensu stricto" por sensoriamento remoto foram e ainda são desenvolvidos. Esses têm, em sua maioria, atingido com sucesso seus objetivos, como será apresentado mais à frente, e demonstram a evolução da técnica com a disponibilização subsequente de dados multiespectrais Thematic Mapper (TM)/Landsat, Enhanced Thematic Mapper Plus (ETM+/Landsat), Advanced Spaceborne Thermal Emission and Reflection Radiometer (ASTER/Terra) e imagens hiperespectrais, como do sensor Airborne Visible/ Infrared Imaging Spectrometer (AVIRIS).

O sensoriamento remoto hiperespectral (e ultraespectral) é relativamente novo, tendo as primeiras imagens hiperespectrais, do sensor AVIRIS, sido disponibilizadas na década de 1990. Como previsto por Sabins (1999), novas pesquisas geobotânicas estão sendo desenvolvidas com essa tecnologia, mas ainda há muito a ser desenvolvido. Cabem ressaltar os trabalhos geobotânicos, no estado da arte, sobre vazamentos experimentais de hidrocarbonetos e realizados por equipes multidisciplinares, sob coordenação do pesquisador Carlos R. Souza Filho, da UNICAMP.

É inegável o caráter multidisciplinar da geobotânica, bem como o caráter cartesiano das disciplinas acadêmicas, que se estende até os dias de hoje. Assim, é possível fazer uma análise paralela entre a mudança de paradigma experimentada pela humanidade e a que vem ocorrendo na geobotânica. Atualmente, ela aparece na literatura de forma mais frequente em seu sentido amplo, em trabalhos de cunho ecológico ou fitogeográfico. Esses trabalhos têm sido realizados geralmente por ecólogos e/ou equipes multidisciplinares, não mais por geólogos de exploração. É provável que esse seja um renascimento da técnica oriundo da mudança de paradigma, sentida mais fortemente no final do século $X X$, na qual a concepção mecanicista de Descartes e Newton abre espaço para uma visão holística e 
ecológica (Capra, 1982). De acordo com Capra (1996), a "ecologia profunda" está rapidamente atingindo proeminência e, segundo Arne Naess (filósofo norueguês), ela consiste em formular questões mais profundas. Essa mudança de percepção, faz com que a ciência, reduzida para o entendimento das partes menores, seja agora reintegrada e enxergada de forma sistêmica.

Deve-se ressaltar a importância das geotecnologias, que vêm evoluindo juntamente a essa mudança de percepção, para a geobotânica em sentido amplo. Higgins et al. (2011, 2012 e 2014a), no estado da arte, salientam que a geologia controla diversas variações florísticas e estruturais nas florestas tropicais, em especial na Amazônia. Esse fato foi muito discutido e, algumas vezes, negado pela comunidade científica nas décadas anteriores (p.ex., Hubell, 1997; Condit et al., 2002). Aqueles autores ressaltam que o sensoriamento remoto representa uma oportunidade única de explorar as variações florísticas e estruturais da vegetação tropical e, mais do que isso, correlacioná-las com as propriedades dos solos e litologias subjacentes.

Normalmente, as variações geológicas sem a presença de solos anômalos, como sobre mineralizações metálicas, são difíceis de serem quantificadas em campo, extrapoladas e espacializadas - principalmente quando sob florestas densas. Assim, as análises ficam, em sua maioria, no nível edáfico e altitudinal. Já em escala de paisagem, com apoio de modelos digitais de elevação (ou de terreno) e de mapas geológicos, as observações de campo, sejam elas edáficas, altitudinais e/ou vegetais, podem ser associadas de forma mais segura à geologia local.

\subsubsection{Geobotânica de campo em ambientes tropicais brasileiros}

Investigações botânicas sobre mineralizações ou sobre diferentes litologias, visando correlacionar essas variações à florística dos biomas brasileiros, não são comuns. Enquanto as relações da vegetação com a topografia, as características químicas e físicas dos solos, o nível do freático, a iluminação solar e o clima, por exemplo, são exaustivamente 
estudadas, a geologia é praticamente ausente desses estudos. Assim, são inúmeros os trabalhos que tratam dessas relações sem discutir a influência geológica na distribuição de espécies e fisionomias, na estrutura do dossel, ou mesmo na fenologia de espécies e/ou comunidades.

É evidente o maior número de pesquisas geobotânicas em seu sentido amplo nos biomas essencialmente florestais do Brasil, como a Mata Atlântica e a Amazônia. Novas variáveis, que não as usualmente estudadas, parecem estar sendo incorporadas nas análises e/ou discussões que visam estabelecer relações seguras entre variação florística (fisionômica ou estrutural) e o meio. A geologia parece ser uma dessas variáveis, devido à sua presença em trabalhos ecológicos recentes. Contudo, ela ainda é tratada secundariamente, pois seus dados não são acessados de forma direta. Estudam-se as características físicas e químicas dos solos, com suporte das geotecnologias, acessam-se as características topográficas e, com apoio de mapas geológicos, associam-se aquelas variáveis às litologias subjacentes. Obviamente o acesso à rocha-mãe, em terrenos não litólicos, não é uma tarefa fácil. Além disso, parece que essas associações, mais frequentes na Amazônia e com necessidade de aparato remoto, estão descritas em ambientes que apresentam maior dificuldade acesso e, portanto, o uso de produtos de sensoriamento remoto e mapas é essencial.

Scudeller et al. (2001), para analisar as variações florísticas e estruturais na floresta atlântica ombrófila densa, aplicaram diversas técnicas estatísticas multivariadas sobre 17 estudos florísticos realizados nesse domínio, no leste paulista. Duas das análises distinguiram dois grandes grupos florístico-estruturais, um sobre a Província Costeira e outro sobre o Platô Atlântico. A análise de correlação canônica confirmou a existência desses dois grupos e mostrou que esse gradiente poderia estar associado à altitude, por um lado, e à temperatura e precipitação, por outro. Contudo, a predominância de espécies arbóreas com distribuição restrita, a alta variação espacial em abundância dessas espécies - indicando a existência de nichos ecológicos -, a disposição das amostras no espaço de ordenação e a relativa baixa variância explicada pelo primeiro eixo, comprovaram a existência de 
gradientes longos, complexos e não lineares, que podem estar relacionados a diversos outros fatores abióticos.

Godoy (2001) e Adair et al. (2001) observaram elevada variação florística entre comunidades atlânticas sobre cálcarios e filitos, no Vale do Ribeira (SP). No primeiro trabalho o autor observou que, das espécies amostradas, 68 delas ocorriam apenas sobre calcários e 38 apenas sobre filitos. No segundo, os autores ressaltam que Piptadenia gonoacantha ocorre apenas sobre solos calcáreos e que Tibouchina pulchra é menos importante sobre esses solos quando comparados aos solos sobre filitos.

Sztutman e Rodrigues (2002) estudaram o mosaico vegetacional numa área de floresta contínua da planície litorânea, preservada no Parque Estadual da Campina do Encantado, sul do Estado de São Paulo. A alta diversidade florística, estrutural e fisionômica das três florestas estudadas, considerando que estão sujeitas ao mesmo clima e com pequenas variações de altitude, deixam a causa de sua dissimilaridade à variabilidade edafogeológica. Na floresta sobre morrote foram encontradas 112 espécies (ordenadas por riqueza encontrou-se Myrtaceae, Lauraceae, Leguminosae e Rubiaceae). Na floresta turfosa rasa, com um total de 46 espécies, as duas famílias mais ricas também foram Myrtaceae e Lauraceae. Por fim, na floresta turfosa profunda foram descritas apenas cinco espécies, com dominância absoluta das espécies Ternstroemia brasiliensis e llex pseudobuxus (97,3\% dos indivíduos). O índice de similaridade de Jaccard $\left(\mathrm{J}_{\mathrm{acc}}\right)$ entre a floresta sobre morrote e a turfosa rasa foi de 0,109, com apenas 16 espécies em comum. Considera-se que comunidades similares apresentam $J_{\text {acc }} \geq 0,250$. Os autores observaram completa ausência na floresta sobre morrote das espécies dominantes na floresta turfosa profunda. Regionalmente, a floresta sobre morrote tem alta similaridade com as florestas sobre 0 embasamento cristalino em Pariquera-Açu $\left(\mathrm{J}_{\mathrm{acc}}=0,460\right)$ e baixa com floresta sobre planície litorânea em Cananéia $\left(\mathrm{J}_{\mathrm{acc}}=0,103\right)$. Já a floresta turfosa rasa, ao contrário, apresentou alta similaridade com floresta sobre planície litorânea em Cananéia $\left(J_{a c c}=0,328\right)$ e baixa com florestas sobre embasamento cristalino em Pariquera-Açu $\left(J_{a c c}=0,088\right)$. As florestas 
estudadas por Sztutman e Rodrigues (2002) mostraram que a proximidade geográfica é parâmetro que não prepondera sobre a variabilidade ambiental.

Almeida et al. (2007a) estudaram a similaridade de comunidades vegetais em floresta atlântica ombrófila densa montana. Os autores encontraram, em dois perfis alocados em contínuo florestal, com iguais condições de topografia e orientação de vertente, importante dissimilaridade para o conjunto de plantas amostradas sobre terrenos com substrato de rochas metaintermediárias com e sem alteração hidrotermal. Em termos de similaridade florística entre aqueles dois ambientes, o $\mathrm{J}_{\mathrm{acc}}$ calculado ao estrato arbóreo foi de 0,15 e, para o total das espécies (incluindo arbustos e lianas) de 0,08. Na floresta sobre rochas com alteração hidrotermal foi encontrada menor diversidade vegetal, tanto em espécies arbóreas (0,78 vezes menos espécies, do que no outro ambiente) como em arbustos e lianas (0,48 vezes menos). Além disso, uma maior proporção de espécies pioneiras foi observada sobre as rochas alteradas. Essas representavam $18,2 \%$ do total de espécies amostradas sobre as rochas com alteração, contra 5,9\% fora da zona de alteração. Das 49 espécies amostradas nos dois perfis, 27 espécies ocorriam exclusivamente fora da zona de alteração e 15 no perfil com alteração hidrotermal. Sete espécies foram comuns a ambos os perfis.

Cabe ressaltar que trabalhos ecológicos no domínio atlântico têm, em sua maioria, correlacionado as variações florísticas do bioma a gradientes altitudinais (p.ex., Rodrigues and Shepherd, 1992; Oliveira-Filho e Fontes, 2000; Moreno et al., 2003; Sanchez et al., 2013; Eisenlohr et al., 2013). Sanchez et al. (2013) analisaram a variação florística de floresta ombrófila densa, em um gradiente altitudinal de 1.000 m, na Serra do Mar, Estado de São Paulo. Esses autores observaram que diferentes situações edáficas estão associadas ao gradiente altitudinal e às variações fisionômicas e em abundância de espécies. Eles discutiram o processo de formação dos solos amostrados naquele gradiente e associaram-no à geologia. Os neossolos quartzarênicos da planície costeira, a $2 \mathrm{~m}$ de altitude, foram formados sobre sedimentos marinhos quaternários e, portanto, são relativamente jovens e arenosos. Já as situação de média (entre 100 e 600 m) e de altas 
altitudes $(1.000 \mathrm{~m})$ apresentam solos mais antigos e estruturados, dadas as características das rochas aflorantes do Mesozóico. Sobre o cristalino, os autores associaram os solos menos argilosos, a $1.000 \mathrm{~m}$, aos processos de erosão do terreno fortemente inclinado. Nas médias altitudes, considerando a inclinação mais suave do terreno, os autores descrevem solos mais estáveis e deposição de frações finas carreadas das áreas mais elevadas. A maior riqueza de espécies observada a 300 m (105 espécies) e 600 m (104) foi associada à maior soma de bases e mais elevadas concentrações de potássio, cálcio e magnésio de seus argissolos vermelho-amarelos. A 2 m foram observadas 55 espécies, a $100 \mathrm{~m} 68$ espécies e a 1.000 m 90 espécies. A altitude, os teores de argila e silte, a fertilidade e o pH dos solos demonstraram alta correlação com a abundância de espécies no gradiente altitudinal. Diferentes fatores condicionantes foram descritos e associados à riqueza e abundância de espécies nesses ambientes.

Na Amazônia, por sua vez, diversos fatores que condicionam a distribuição da flora já foram defendidos, como o modelo ecológico neutro (p.ex., Hubell, 1997), a distância geográfica (p.ex., Condit et al., 2002) e as condições ambientais (p.ex., Phillips et al., 2003; Tuomisto et al., 2003a-c; Síren et al., 2013). Trabalhos recentes como os de Quesada et al. (2010), Higgins et al. (2011, 2012 e 2014a), Figueiredo et al. (2014) e Moser et al. (2014), mesmo que de cunho ecológico, defendem a importância da geologia na distribuição de diferentes assembleias de plantas no bioma.

Mesmo que curto e estritamente botânico, Silva e Rosa (1989) observaram que as fisionomias e a estrutura da vegetação não se alteravam sobre jazidas de cobre, na Serra do Carajás, Pará. Os autores concluíram que, embora espécies arbóreas exclusivas às jazidas não tenham sido observadas, as variações em composição florística, em nível de família botânica e espécie, foram evidentes entre os terrenos com e sem mineralizações.

Figueiredo et al. (2014) analisaram de forma integrada dados florísticos e edáficos de campo com dados de modelo digital de elevação e mapa geológico na Amazônia Central. Esses autores comprovaram que as características edáficas e a distribuição de espécies nessa região estão diretamente ligadas às formas de relevo e unidades litológicas 
subjacentes. Para tanto, inventariaram espécies monocotiledôneas da ordem Zingiberales em 123 transectos de 250x2 m. Em cada transecto, de 50 em 50 m, dados de textura de solos e soma de bases trocáveis ( $\mathrm{K}, \mathrm{Ca}$ e $\mathrm{Mg}$ ) foram obtidos. Informações de elevação ao longo da rede de canais e de declividade foram extraídas de modelo digital de elevação de $30 \mathrm{~m}$. As análises foram realizadas em quatro passos: i) model-based clustering (MC), considerando presença e ausência de espécies; ii) comparação com a técnica convencional de agrupamento hierárquico; iii) ANOVA para testar as diferenças edáficas e topográficas nos grupos de espécies formados; iv) ANOVA para testar se as classes geológicas refletem as variações edáficas e florísticas observadas. Variações em conteúdo de areia e de cátions entre diferentes vales analisados, rejeitaram a hipótese, antes defendida na Amazônia central, que a florística apresenta relação com a topografia, tais como vegetações de terras baixas e de terras altas. Aquelas variações edáficas puderam ser relacionadas às variações litológicas, considerando as características das rochas subjacentes. A soma de cátions foi estatisticamente diferente entre as litologias (rochas sedimentares do Cretáceo, do Paleozóico e ígneas do Pré-Cambriano), mesmo em situações de fundo de vale. A quantidade de areia nos solos também demonstrou ser um fator significante de diferenciação entre vegetações de terra alta e de terra baixa. A litologia e as formas de relevo mostraram ser os principais fatores controladores da florística na Amazônia central. Os autores concluem que esses dados, extraídos de mapas geológicos e modelos digitais de elevação, podem servir ao mapeamento de padrões florísticos da vegetação amazônica em áreas mais amplas e menos acessíveis.

Também na Amazônia central, Assis et al. (2014) analisaram 41 inventários arbóreos realizados em paleovárzeas, várzeas e igapós de sete bacias hidrográficas. A observação de padrões florísticos, em nível de gênero botânico, foi realizada através de global nonmetric multidimensional scaling (GNMDS) e análise de agrupamento hierárquica UPGMA. Dentre outras técnicas utilizadas no estudo, foi realizada uma análise de espécies indicadoras (ISA). Os autores observaram que a riqueza de espécies nas florestas de várzea e paleovárzeas são similares e maiores que nas florestas de igapós. Mesmo que 
floristicamente similares, observaram que Euterpe spp., Dipteryx spp. e Goupia spp. podem ser consideradas indicadoras de paleovárzeas amazônicas.

O Pantanal, caracterizado como uma planície de depósitos aluvionares do Quaternário, é um complexo de comunidades vegetais. Embora essas comunidades apresentem relações geográficas com as formações amazônica, atlântica, chaquenha e com o Cerrado, suas disposições mostram-se associadas a diferentes litologias, a formas de relevo e a transições climáticas (Calheiro e Fonseca Jr., 1996). Considerando os pulsos de inundação ocorrentes na planície, são observados diferentes habitats, de aquáticos a terrestres (Junk et al., 2006). Assim, de acordo com Rizzini (1997), comunidades de plantas hidrófilas, submersas e natantes, helófilas, higrófilas, mesófilas e até xerófilas estão presentes na paisagem pantaneira. Formações monodominantes também são observadas, como os paratudais (Tabebuia aurea (Silva Manso) Benth. \& Hook.f ex. S. Moore), carandazais (Copernicia alba Morong) e buritizais (Mauritia flexuosa L. F.). Talvez pela dificuldade de acesso, estudos quantitativos de campo de relação florística com o meio físico são raros, mas alguns trabalhos demonstram associações fisionômicas com os pulsos de inundação, topografia e granulometria de sedimentos, mesmo que de forma descritiva (Pott, 1982; Allem e Valls, 1987; Silva e Abdon, 1998; Silva et al., 2000; Abdon et al., 1998; Pott et al., 2009). Uma associação geobotânica de campo, rara ao Pantanal, datada de 1988 (Conceição e Paula, $1986^{1}$ apud Almeida, 2005), foi realizada na região da Nhecolândia. Esses autores associaram a ocorrência da palmeira $C$. alba (carandá) ao entorno de lagos salinos da região, o que foi confirmado mais recentemente por Almeida et al. (2003).

\subsubsection{A vegetação do bioma Cerrado e sua relação com o meio físico}

O bioma Cerrado, também conhecido como savana tropical brasileira, é o segundo maior do país - seguindo a Amazônia - e apresenta cobertura de aproximadamente $21 \%$ do

\footnotetext{
${ }^{1}$ Conceição, C. D. A., \& Paula, J. D. (1986). Contribuição para o conhecimento da flora do Pantanal Mato-grossense e sua relação com a fauna eo homem. Anais do $1^{\circ}$ Simpósio Sobre Recursos Naturais e Sócio-econômicos do Pantanal, 107-130.
} 
território nacional (Klink e Machado, 2005). Sendo um bioma ecologicamente muito estudado, existe um consenso da influência climática, edáfica e da ação do fogo sobre sua vegetação. Contudo, são raras as associações estudadas entre a vegetação e seus padrões e a geologia local. Apenas trabalhos descritivos e antigos relatam essas associações.

De acordo com Lopes (1984), a geologia do Planalto Central do Brasil ("core" do bioma), que consiste basicamente de formações pré-cambrianas de rochas ígneas e metamórficas, parcialmente cobertas por rochas sedimentares do Paleozóico e Mesozóico e sedimentos cenozóicos, tem sofrido dissecação e nivelamento por ciclos sucessivos de erosão. As principais unidades de solos sob o bioma Cerrado são de latossolos, ocupando cerca de $56 \%$ do total, seguindo-se cerca de $20 \%$ de areias quartzosas, $10 \%$ de lateritas hidromórficas, 9\% de litossolos e menores porcentagens de podzólicos (Lopes, 1984).

A vegetação do bioma apresenta fisionomias que englobam formações florestais, savânicas e campestres (Ribeiro e Walter, 2008). De acordo com esses autores, as formações florestais são representadas pelas fisionomias mata ciliar, mata de galeria (e subdivisões), mata seca (e subdivisões) e cerradão; as formações savânicas, pelas fisionomias cerrado "sensu stricto" (e subdivisões), vereda, parque de cerrado e palmeiral; e as formações campestres, pelas fisionomias designadas campo rupestre, campo limpo e campo sujo. As fisionomias de cerrado "sensu stricto", o cerradão e as fisionomias campo sujo e campo limpo podem ser consideradas conjuntamente como cerrado "sensu lato" (Ribeiro e Walter, 2008). Há cerca de 800 espécies de árvores e arbustos e um número muito maior de espécies de ervas e subarbustos descritas no cerrado "sensu lato" (Ratter et al., 1997). Incluindo a flora das matas de galeria, matas mesófilas e outros habitats que ocorrem no bioma, são estimadas cerca de 12.300 espécies de plantas vasculares (Mendonça et al., 2008).

Eiten $(1963,1972)$ e Cole (1982) observaram que as distribuições de diferentes fitofisionomias no bioma estão associadas à geologia, à geomorfologia e aos diferentes tipos de solos. Os solos sob a vegetação xeromórfica são tipicamente senis, profundos, com deficiência pronunciada em macro e micronutrientes e alta disponibilidade de alumínio 
(Eiten, 1972). Essa baixa fertilidade dos solos é considerada por Arens (1963) como a causa do escleromorfismo oligotrófico observado nos vegetais superiores das formações de cerrado "sensu lato". Nas formações savânicas, conforme foi sugerido por Waibel (1948) e Beard (1953), as variações estruturais gradativas entre campestre e florestal podem estar diretamente ligadas às condições edáficas. Haridasan e Araújo (1988), a título de curiosidade, observaram que muitas das espécies de cerrado acumuladoras de alumínio geralmente ocorrem apenas em solos distróficos e ácidos e se apresentam nestas áreas em maior densidade e valor de importância (VI).

Segundo Ribeiro e Walter (2008), as formações florestais do bioma também apresentam relações com o meio físico, ocorrendo somente em solos bem drenados. As matas ciliar e de galeria estão associadas à hidrografia (perene ou intermitente), enquanto a mata seca e o cerradão encontram-se sobre os interflúvios. Ruggiero et al. (2002) observaram variações em fertilidade e textura de solos entre as fisionomias "sensu lato" do bioma no Brasil central, com as florestas estacional semidecidual e ripária associando-se aos solos mais argilosos e férteis.

Como já foi descrito em Eiten (1972), a vegetação de cerrado, em seu sentido restrito, também se mostra associada a solos bem drenados. Assis et al. (2011) observaram que a disponibidade hídrica é o principal fator na diferenciação edáfica entre o cerrado "sensu stricto" e o cerradão. Oliveira-Filho et al. (1989) correlacionaram as variações da vegetação com a flutuação do freático, em um cerrado interfluvial na região de Salgadeira, Estado do Mato Grosso. Esses autores alocaram um transecto de 20x500 m da borda ao topo da área de interflúvio e reconheceram 5 subtipos de cerrado: cerrado de borda arenosa, cerrado de interflúvio elevado, cerrado de borda rochosa, cerrado de talude e cerradão. Os solos desse gradiente são essencialmente arenosos, embora com intensa variação em coloração. Com coletas de 0-20 cm, 40-60 cm e $80-100 \mathrm{~cm}$, os autores observaram uma composição média de $86,9 \%$ de areia, 1,4 de silte e 11,7 de argila. Dez perfurações, de até $2 \mathrm{~m}$, foram realizadas no pico da estação chuvosa. Como o freático atinge a superfície até a borda da primeira fisionomia (em contato com campos alagados) a 
sua altura foi estimada para o resto do transecto, pelo cálculo da distância vertical. A coloração dos solos no gradiente também indicaram essa variação. No cerrado de borda arenosa, com o freático a $1 \mathrm{~m}$, os solos são acinzentados e no cerrado interfluvial, a $8 \mathrm{~m}$, são amarelo-avermelhados. Além da variação fisionômica abrupta, algumas espécies apresentaram padrão de distribuição ao longo do gradiente.

Em se tratando das formações florestais extracerrado (associadas aos cursos d'água), Eiten (1972) observou que é variável a extensão do terreno em que as florestas de terras baixas do bioma sobem pelas laterais dos vales. Variações florísticas associadas ao tipo de solo, à topografia e às condições de drenagem, observadas nessas florestas, também são descritas na literatura, como em Oliveira-Filho et al. (1990, 1994a e b e 1997). Outros estudos que analisaram essas relações são curtos e descritivos, apenas com dados florísticos e fitossociológicos e pouca ou nenhuma informação ecológica (Oliveira-Filho et al.,1994a e b). Oliveira-Filho et al. (1997) estudaram as variações florísticas e sua relação com o meio edáfico em uma floresta estacional semidecidual no município de Conquista, Estado de Minas Gerais. Dois transectos foram alocados da margem do rio às terras altas: um com 30x195 m e outro de 45×120 m, e ambos constituídos por unidades amostrais de 15x15 m. Nessas unidades amostrais a vegetação arbórea foi inventariada e amostras de solos foram coletadas, para análise química e granulométrica. Os solos foram classificados quanto ao tipo e à drenagem. Diversas análises estatísticas foram realizadas, incluindo uma correlação ranqueada de Spearman entre abundância de espécies e drenagem de solos e análise de correspondência canônica. Os autores observaram que a variação em nível do freático é o principal fator controlador da distribuição de espécies no gradiente estudado. As variações de solos nas terras altas, segundo os autores, podem estar relacionadas às diferentes litologias e processos pedogênicos. Nas terras baixas, a variação florística foi associadas a pequenas variações no relevo. Sobre os solos aluviais, os autores associaram, dentre outras espécies, Inga affinis aos solos pobremente drenados e Calophyllum brasiliense aos solos imperfeitamente drenados. 
Eiten (1963), na antiga Fazenda Campininha - da qual a Estação Ecológica de MogiGuaçu (SP), área do presente estudo, é pertencente -, observou clara relação entre as grandes fisionomias da paisagem e a geologia. O autor associou a ocorrência das florestas e pântanos às terras baixas, próximos aos cursos dá água e, nas elevações suaves dos terrenos da Formação Itararé do Carbonífero, a composição de espécies entre as florestas secas e os cerradões variando abruptamente. A diferenciação entre as florestas úmidas e secas, segundo o autor, ocorria gradualmente. A presença de diversas fisionomias de cerrado, de savanas a cerradões, estava relacionada às terras altas, acima de $600 \mathrm{~m}$ (área da atual Reserva Biológica de Mogi-Guaçu) e sobre rochas do Permiano, de acordo com a fonte utilizada. Contudo, essas associações foram realizadas de forma apenas descritiva.

Em se tratando de Geobotânica "sensu stricto" no Cerrado, apenas dois trabalhos estritamente de campo foram observados na literatura. Amaral (1968) descreveu a associação de espécies vegetais a depósitos de zinco de Vazante (MG). O autor observou a preferência de Heteropogon spp. sobre minério e de Panicum spp. sobre material estéril. Sobre as rochas mineralizadas constatou a presença de Paspalum spp., Axonopus spp. e de Gomphera spp., sendo que espécies desse último gênero botânico foram encontradas inclusive sobre pilhas de minério. O segundo trabalho, de cunho mais biogeoquímico do que geobotânico, foi realizado por Brooks et al. (1988). Os autores analisaram a acumulação de níquel em plantas presentes sobre serpentinas do Complexo Niquelândia (GO). Além de observarem diversas espécies hiperacumuladoras de $\mathrm{Ni}$, principalmente Jatropha spp, registraram a primeira ocorrência de samambaia com aquele comportamento.

\subsubsection{Geobotânica por sensoriamento remoto em ambientes tropicais}

O mapeamento geológico e a prospecção mineral em diversas regiões do planeta, utilizando técnicas de sensoriamento remoto óptico, constituem uma tarefa difícil. As características espectrais dos depósitos minerais e tipos de rochas muitas vezes não podem ser acessadas diretamente, considerando que a maior parte da superfície terrestre é coberta 
por vegetação (Ustin et al., 1999). Nas regiões subtropicais a equatoriais, altamente biodiversas, as variações florísticas e fisionômicas constituem a principal fonte de informação geobotânica (Almeida et al., 2009). Nesses ambientes o estresse químico é observado apenas quando as condições geoquímicas são fortemente anômalas, causando toxicidade nos solos ou condições secundárias adversas à vegetação.

Segundo Almeida (2005), a interação rocha-solo-vegetação mais intensa, a presença de vegetações com ciclo fenológico bem definido (excetuando-se as florestas de coníferas) e a baixa diversidade no dossel - que implica em maior homogeneidade em resposta espectral e facilita a interpretação de imagens - explicam a tendência à priorização da aplicação da técnica "sensu stricto" em mais altas latitudes. Como exemplo, Almeida et al. (1995 e 1997) acreditam que a maior interação rocha-solo-vegetação presente nos campos sobre solos rasos de topografia plana, do Estado do Rio Grande do Sul, foi fundamental à interpretação geológica de imagens TM/Landsat 5 na região de Camaquã. Saldanha e Cunha (2005) identificaram remotamente a sequência Cerro Mantiqueira, também no sul do país. Sobre suas rochas ocorrem comunidades graminoides esparsas com menor NDVI (Normalized Difference Vegetation Index) que a vegetação adjacente. Contudo, diversas investigações geobotânicas de sucesso em ambientes tropicais também podem ser observadas. Algumas delas são apresentadas mais a frente.

Paradella \& Bruce $\left(1989^{2}\right.$, apud Almeida, 2005) sugeriram dividir os estudos geobotânicos por sensoriamento remoto em função de sua escala: a geobotânica de reconhecimento, quando as anomalias são caracterizadas por mudanças fisionômicas e taxonômicas passíveis de detecção por sensores de baixa a média resolução espacial e espectral; e a geobotânica de alvo, que busca variações morfológicas, fisiológicas ou fenológicas nas plantas, requerendo sensores de alta resolução espectral e espacial.

\footnotetext{
${ }^{2}$ Paradella W. R., \& Bruce, W. D. (1989). Geobotânica por Sensores Remotos: Uma Revisão. Revista Brasileira de Geociências, 19(4), 425-435.
} 
Seguindo essa classificação, em geobotânica de reconhecimento, destacam-se estudos em identificação de comunidades vegetais associadas à geologia na Amazônia peruana (Tuomisto et al., 2003a-c; Higgins et al., 2011, 2012 e 2014a) e no Panamá (Higgins et al., 2014b); no mapeamento geológico em Rondônia (Brasil) (Almeida et al., 2007b); na prospecção de alterações hidrotermais em Baghio (Filipinas) (Carranza e Hale, 2002) e no Amazonas (Brasil) (Almeida et al.; 2009); e na prospecção de estoques subterrâneos de carbono também sob vegetação amazônica na Colômbia (Asner et al., 2012). Já a geobotânica de alvo, entre os trópicos, pode ser observada em trabalhos como de Vitousek et al. (2009) sobre substratos de 300 anos a 4,1 milhões de anos no Havaí (Estados Unidos); de Amaral et al. (2012) sobre solos e sedimentos de granulometrias variadas, no Estado de São Paulo (Brasil); e de Sanches et al. (2013a e b e 2014) sobre contaminações por hidrocarbonetos induzidas, também em São Paulo (Brasil).

Como exemplo dessas aplicações de sucesso, Higgins et al. (2014a) realizaram análise de mistura espectral (SMA) em imagens multitemporais TM/Landsat 5 e ETM+/Landsat 7 sobre vegetação amazônica de terra firme, no Peru. Como base, os autores utilizaram dados de campo obtidos por Higgins et al. (2011), em 117 transectos de 5x500 m, interceptando quatro diferentes formações geológicas, onde foram anotadas as presenças e ausências de pteridófitas e onde, a 50 m, $250 \mathrm{~m}$ e $450 \mathrm{~m}$, quatro coletas de solos superficiais foram realizadas para análises químicas e granulométricas. Variações catiônicas abruptas foram observadas entre as formações geológicas. Um buffer de 250 m foi aplicado a esses transectos para análise das frações espectrais de vegetação fotossinteticamente ativa (PV) e não fotossiteticamente ativa (NPV). Eles utilizaram o método de ordenação NMDS (non-metric multidimensional scaling) para reduzir os dados florísticos de campo e comparar com os dados de solos e porcentagens de PV e NPV (técnica publicada em Higgins et al., 2012). Análises de regressão simples foram realizadas para calcular as porcentagens de PV e NPV que podem ser explicadas pelas variações florísticas e edáficas. Como essas frações espectrais variaram entre imagens de diferentes datas, a diferença PV-NPV foi aplicada como forma de normalização dos dados. Então 
utilizaram regressões lineares e não lineares, a fim de verificar o quanto as variações em dados de campo poderiam explicar as diferenças em PV-NPV. As variações catiônicas, observadas entre formações geológicas, foram traduzidas em cobertura de PV e NPV. Áreas mais férteis apresentaram aumento de PV. 60\% e 67\% das variações em PV e NPV, respectivamente, foram explicadas pela variação de cátions entre formações geológicas na região de Pastaza-Tigre, e 42\% (PV) e 65\% (NPV) na região de Curaray. Essas variações foram igualmente explicadas pela composição florística. Os valores de ordenação NMDS explicaram $68 \%$ e $59 \%$ das variações em PV e NPV, respectivamente, na primeira região e $41 \%$ e $61 \%$ na segunda. As variações em PV-NPV puderam ser 72\% (Pastaza-Tigre) e 67\% (Curaray) explicadas pelos dados de solos e de vegetação, conjuntamente. Esses resultados sugeriram aos autores que as variações em PV e NPV, causadas pela fertilidade dos solos associados a diferentes formações geológicas, são mediadas pelas variações em composição de espécies.

\subsubsection{Histórico da geobotânica por sensoriamento remoto no Brasil}

A geobotânica por sensoriamento remoto no Brasil começou a ser frequente na literatura em meados de 1980, com trabalhos realizados por pesquisadores como Gilberto Amaral (Instituto de Geociências, USP), Raimundo Almeida-Filho e Waldir Renato Paradella (Instituto Nacional de Pesquisas Espaciais - INPE) e equipes. Por volta dos anos 2000, G. Amaral faleceu e os outros pesquisadores citados passaram a estudar mais raramente a geobotânica propriamente dita. Uma nova geração de pesquisadores, como Teodoro Isnard Ribeiro de Almeida (Universidade de São Paulo), Carlos Roberto Souza Filho (Universidade de Campinas) e equipes, tem dado prosseguimento às investigações geobotânicas no país. T.I.R. Almeida, nos últimos anos, tem se dedicado principalmente à geobotânica de reconhecimento, com enfoque em mapeamento geológico e uso de diversos produtos de sensoriamento remoto óptico para tal fim. C.R. Souza Filho tem como principal destaque, 
em geobotânica, pesquisas de alvo aplicadas a exsudações ou contaminações induzidas de hidrocarbonetos.

Historicamente, na Amazônia, Amaral (1982) utilizou imagens MSS/Landsat para discriminação via geobotânica de granitos estaníferos e de depósitos de $\mathrm{Fe}, \mathrm{Mn}, \mathrm{Cu}, \mathrm{Ni}, \mathrm{Al}$ e Au (Serra do Carajás) no Pará; Almeida-Filho et al. (1984) estudaram a discriminação de corpos granitóides através de imagens TM/Landsat em Rondônia; Paradella et al. (1989), utilizando dados TM/Landsat e modelo digital de terreno, analisaram os depósitos Pojuca de Zn-Cu, na Província de Carajás (PA); Paradella et al. (1994), com uso de imagens TM/Landsat e modelo digital de terreno, também de Carajás, examinaram a discriminação de unidades litológicas; Almeida et al. (2007b) aplicaram o método sistêmico de Almeida (2005) como técnica auxiliar para o mapeamento geológico no Vale do Guaporé (RO), por meio de imagens ASTER/Terra; Almeida et al. (2009) estudaram a detecção de alterações hidrotermais na Província Aurífera de Tapajós fazendo uso de dados TM/Landsat e método sistêmico supracitado. A integração de dados geofísicos aéreos e de radar a produtos de sensoriamento remoto óptico também é observada frequentemente em estudos geológicos na Amazônia (p.ex., Paradella et al., 1997; Souza Filho e Paradella, 2002; Teruiya et al., 2008; Perrota et al., 2008).

No domínio da Caatinga são observadas aplicações geobotânicas como de Paradella e Vitorello (1995) que estudaram a diferenciação litotógica de um complexo metamórfico pré-cambriano na Bahia, por meio de imagens MSS/Landsat, TM/Landsat e SPOT. Almeida-Filho et al. (1999) e Almeida-Filho (2002) descreveram variações tonais anômalas da vegetação, associando-as a microexsudações de hidrocarbonetos na Bacia do Tucano (BA) utilizando imagens TM/Landsat. No primeiro trabalho as variações tonais foram observadas em composição RGB de equações espectrais e, no segundo, via Análise por Principais Componentes (APC). Lammoglia et al. (2007), ainda nessa localidade, realizaram APC em imagens ETM+/Landsat, métodos de classificação e redes neurais em imagens ASTER/Terra, a fim de caracterizar anomalias gasosas associadas a exsudações de hidrocarbonetos, indicadas por gasometria. Lammoglia e Souza Filho (2013) apresentaram 
uma metodologia que utiliza as 14 bandas ASTER/Terra (do visível ao termal) para identificação de anomalias causadas por exsudações gasosas. Essas vão desde a descoloração dos solos às maiores presenças de minerais argilosos e carbonatos e às anomalias geobotânicas - ausência de vegetação fotossinteticamente ativa, variação florística e na estrutura de dossel.

No domínio florestal atlântico, destacam-se estudos no Vale do Ribeira (SP), como o de Amaral (1992) que citou a relação geobotânica de oito agrupamentos, obtidos com classificação K-means de imagens MSS/Landsat, com o mapa geológico regional. No Parque Estadual Campina do Encantado, também nessa região, Pacheco (2009) discriminou três unidades geobotânicas associadas à presença/ausência de tipos de turfeiras, através do método sistêmico de Almeida (2005), aplicado em imagem ASTER/Terra. Utilizando mesma técnica e produto, Soares (2012) identificou unidades geobotânicas sobre sedimentos holocênicos (cordões arenosos) da planície do Una, em Iguape (SP). A autora observou que as unidades geobotânicas definidas no produto final correlacionam-se principalmente à granulometria e à fertilidade dos solos.

No Pantanal, como foi dito anteriormente, o meio físico parece ser determinante na distribuição de fisionomias e espécies de plantas. Ao longo da história, subdivisões da planície pantaneira foram realizadas com a utlização de produtos de sensoriamento remoto óptico, através da análise de critérios como os fitogeográficos, geomorfológicos e hidrológicos (p.ex., Adámoli, 1982; Alvarenga et al., 1984; Silva e Abdon, 1998). Nesse último, por meio de imagens TM/Landsat, os autores delimitaram o Pantanal brasileiro em 11 subregiões e concluíram que os fatores mais importantes da delimitação realizada são o regime de inundação e o relevo. Essa é a subdivisão mais aceita até os dias de hoje. Baseados nesse histórico, Penatti e Almeida (2012) testaram a hipótese de que a granulometria de sedimentos é um elemento condicionante das variações fenológicas da vegetação pantaneira, associadas ao período de seca. Para tanto, os autores analisaram uma série temporal de NDVI (composição de 16 dias) do sensor Moderate-Resolution 
Imaging Spectroradiometer - MODIS/Terra-Aqua, métricas fenológicas e dados de campo, e comprovaram a relevância da textura de sedimentos na fenologia do Pantanal.

\subsection{Geobotânica por sensoriamento remoto no bioma Cerrado}

As aplicações geobotânicas "sensu stricto" no bioma Cerrado são mais frequentes através de sensoriamento remoto óptico, do que através de dados de campo. Apenas dois trabalhos de campo foram observados, sendo um deles com caráter biogeoquímico. Dos trabalhos de geobotânica por sensoriamento remoto, destacam-se aqueles realizados nas décadas de 1980 e 1990 pelo pesquisador Raimundo Almeida-Filho e equipe, sobre diferentes ocorrências minerais. Contudo, em seu sentido amplo a geobotânica foi pouco desenvolvida no bioma. A geologia, como controladora da distribuição de espécies, foi estudada apenas em trabalhos descritivos e antigos, quando as geotecnologias eram recentes e dominadas por poucos profissionais. Atualmente a geobotânica em seu sentido amplo é visivelmente apoiada pelas geotecnologias e está sendo feita em áreas de acesso dificultado, aspecto que foi anteriormente discutido de forma hipotética. Esse não é o caso do Cerrado, considerando a predominância de formações savânicas, bem como de áreas mais restritas em vegetação florestal. Talvez, por essa maior facilidade de acesso, a realização de estudos ecológicos vegetação-sistema edáfico no bioma, baseados exclusivamente em dados de campo, tenha sido favorecida.

Utilizando produtos de sensoriamento remoto óptico, são observados estudos de caracterização e dinâmica do uso da terra (p.ex., Brannstrom et al., 2008; Sano et al., 2010, Trabaquini et al., 2013), de detecção de áreas e vegetação atingida por incêndios (p.ex., França e Setzer, 2001; Ferreira et al., 2013; Daldegan et al., 2014), de distinção e/ou fenologia de fisionomias vegetais (p.ex., Ferreira et al., 2003; Ferreira et al., 2004; Ferreira e Huete, 2004; Ratana et al., 2005; Ferreira et al., 2007; Souza et al., 2010; Ferreira et al., 2011), bem como das implicações dos ângulos de iluminação e visada (p.ex., Liesemberg et al., 2007) e do efeito da largura e posição de bandas (p.ex., Galvão et al., 1999) em tais 
caracterizações. Espera-se que, assim como na Amazônia, a utilização das geotecnologias, cada vez mais presentes em trabalhos ecológicos, estimule a geobotânica por sensoriamento remoto em seu sentido amplo no Cerrado. O histórico de aplicação da técnica no bioma é apresentado a frente.

Carraro $\left(1972^{3}\right.$, apud Nascimento e Chen, 1976) analisou levantamentos aerofotográficos de diferentes escalas, sobre mineralizações de zinco da região de Vazante (MG). Dentre os produtos analisados, as imagens obtidas com Filme Aerochrome Infravermelho com filtro laranja mostraram-se adequadas para fotointerpretação de zonas mineralizadas, tanto em escala 1:15.000 como 1:30.000. Em campo, o autor ressaltou que, embora o arbusto Gophrena sp. estivesse associado ao minério, ele não ocorria extensivamente pela área e, portanto, não poderia ser observado nessas escalas de trabalho. Já a gramínea Heteropogon villosus Ness. pareceu ser a espécie de maior representatividade por se desenvolver extensivamente sobre as zonas mineralizadas. Nascimento e Chen (1976), também na região de Vazante, analisaram diversos levantamentos aerofotográficos, de 1:15.000 a 1:90.000, além de amostras geoquímicas e bioquímicas coletadas em campo. Os autores concluíram que a geobotânica apresenta maior aplicabilidade à prospecção mineral na área do que a geoquímica. Apenas cinco espécies mostraram-se capazes de sobreviver em solos anômalos, tóxicos em Zn. Os autores ressaltaram que as imagens pancromáticas com filtro vermelho e as transparências multiespectrais I2S foram essenciais para a interpretação geológica e seleção de áreas à prospecção mineral.

Almeida-Filho (1984) realizou análise sazonal de imagens MSS/Landsat na Serra da Pedra Branca (GO), caracterizada por granito maciço e pela presença de mineralizações de cassiterita. O autor concluiu que as associações geobotânicas foram essenciais para observação das rochas alteradas e que o contraste entre a vegetação com anomalia geobotânica e sem (vegetação normal) foi mais evidente na imagem do período chuvoso, do

\footnotetext{
${ }^{3}$ Carraro, C. C. (1971). Reconhecimento de rocha mineralizada de vazante nas transparências falsa cor. São José dos Campos: Instituto Nacional de Pesquisas Espaciais. (Relatório INPE-2882$\mathrm{RI} / 71)$.
} 
que naquela coletada no período seco. Almeida-Filho e Castelo Branco (1992) analisaram imagens TM/Landsat e fotografias aéreas sobre a diatrema de Redondão (PI), com o intuito de localizar materiais derivados de kimberlitos via geobotânica. Através de razão de bandas foi possível realçar a vegetação graminoide-arbustiva, que caracteriza espacialmente os solos derivados de kimberlitos e se difere da vegetação adjacente (savana-parque). Contudo, a baixa resolução espacial do produto e a remoção de efeitos de sombreamento associados à topografia, pela razão de bandas, deixaram de evidenciar diversas feições da paisagem. Os autores fundiram as imagens TM a uma imagem pancromática com $5 \mathrm{~m}$ de resolução espacial, oriunda de uma fotografia aérea digitalizada, e a um modelo digital de terreno. Como produto final, e em perspectiva 3D, a vegetação associada ao material kimberlítico foi realçada com maior detalhe, expressando a ocorrência dos corpos de kimberlitos, além da morfologia da diatrema. Os autores ressaltaram a adequação da resolução espacial aos alvos estudados.

Baseado no trabalho de Almeida-Filho (1984), Almeida-Filho et al. (1996) selecionaram imagem TM/Landsat da estação chuvosa para identificar rochas metassomáticas sob a vegetação de cerrado na Província Estanífera de Goiás (GO). Uma razão de bandas TM4/TM3 mostrou-se suficiente à análise geobotânica, considerando a importância da informação de cobertura vegetal a essa ocorrência mineral. Em campo, os autores observaram que a distribuição de uma vegetação estritamente graminoide e esparsa estava associada à presença de metassomatismo gerador das mineralizações de cassiterita. A vegetação sobre as áreas não mineralizadas foi caracterizada como savana típica com espécies de hábito graminoide, arbustivo e arbóreo. Almeida-Filho e Vitorello (1997) realizaram análise geobotânica em granito da Serra do Mendes (GO), a fim de prospectar alterações hidrotermais. Utilizando imagem TM/Landsat e medidas espectrais de materiais alterados, os autores observaram que a composição em cores naturais dos canais do visível (azul, verde e vermelho) já eram capazes de informar sobre as ocorrências de alteração hidrotermal, mesmo quando cobertas por gramíneas. Essa imagem foi fundida à fotografia aérea para melhora da resolução espacial, através de transformação por intensidade, matiz 
e saturação (IHS). Nesse produto as áreas com alteração hidrotermal foram realçadas pela presença de solos claros e gramíneas esparsas. Adicionalmente, a imagem foi segmentada e classificada de forma não supervisionada (distância de Mahalanobis). Cinco grupos "fitogeológicos" foram definidos indicando, também, as zonas alteradas.

Carvalho Júnior et al. (2003) utilizaram imagens hiperespectrais do sensor AVIRIS e técnica Spectral Correlation Mapper (SCM), a fim de associar os padrões da vegetação às estruturas geológicas presentes na cena, obtida em Goiás. Os dados foram espectralmente minerados pela transformação Minimum Noise Fraction (MNF) e espacialmente reduzidos pelo Pixel Purity Index (PPI), para seleção manual de pixels considerados puros (membrosfinais). Esses compuseram três grupos principais de membros-finais: vegetação fotossintética, vegetação não fotossintética e vegetação queimada. A composição colorida das imagens classificadas via SCM, utilizando os membros-finais médios daquelas classes, pôde indicar diferenças na distribuição da vegetação. Essas variações foram correlacionadas aos aspectos estruturais e geomorfológicos da área. Carvalho Júnior et al. (2004) realizaram análise geobotânica, a fim de discriminar rochas máficas e ultramáficas do Complexo de Niquelândia (GO) sob vegetação de cerrado. Os autores utilizaram imagens ASTER/Terra, do visível (VIS) ao infravermelho ondas curtas (SWIR), sendo essas últimas reamostradas para $15 \mathrm{~m}$. O processo de seleção de membros-finais foi semelhante ao realizado por Carvalho Júnior et al. (2003). Uma análise de mistura espectral foi aplicada sobre a imagem utilizando membros-finais de vegetação fotossitética (PV), vegetação não fotossintética (NPV) e solo exposto. As razões entre PV e NPV da vegetação sobre as diferentes unidades litológicas puderam indicar sobre suas ocorrências. Os autores concluíram que a utilização de imagem obtida no período seco foi essencial para tornar as diferenças mais nítidas. A vegetação sobre rocha ultramáfica apresenta grande quantidade de NPV nesse período.

Embora não se caracterize com uma investigação geobotânica, Galvão et al. (2005) visaram ao mapeamento de caulinita e muscovita, associadas aos processos de alteração hidrotermal no granitoide Serra do Mendes (GO), e discorreram sobre a discriminação 
espectral desses minerais em ambiente de cerrado. Os autores utilizaram imagens ASTER/Terra do período seco, considerando que a vegetação graminoide estaria seca e, portanto, a discriminação espectral solo-rocha seria favorecida. A fim de preservar as características espectrais do SWIR, as imagens do visível ao infravermelho próximo (VNIR) foram reamostradas às características espaciais do primeiro $(30 \mathrm{~m})$. Primeiramente, a técnica Spectral Angle Mapper (SAM) foi aplicada para testar a similaridade entre os espectros coletados na imagem e espectros de referência de caulinita e muscovita (oriundos do Jet Propulsion Laboratory, NASA). Utilizando as bandas em torno de $2.200 \mathrm{~nm}$, diagnósticas àqueles minerais, a similaridade espectral foi calculada com baixos ângulos espectrais. Uma análise de mistura espectral com três membros-finais (vegetação fotossintética, solo e sombra) foi realizada, a fim de verificar o impacto da cobertura vegetal na identificação daqueles minerais. Os membros-finais foram definidos após aplicação de MNF e PPI, como foi descrito anteriormente. Embora nas áreas de solo exposto aqueles minerais tenham sido bem mapeados via SAM, com baixo ângulo espectral, as áreas cobertas por gramíneas afetaram seu mapeamento. Isso aconteceu pela sobreposição de feições de absorção pelos minerais-alvo e por materiais lignocelulósicos da vegetação, em torno de $2.200 \mathrm{~nm}$. Assim, a utilização de dados ASTER da região do SWIR pareceu indicar mais sobre as associações rocha-solo-vegetação do que sobre a presença de minerais de alteração hidrotermal.

Souza Filho et al. (2008) realizaram análise geobotânica sobre microexsudações de hidrocarbonetos em Remanso do Fogo, Buritizeiro (MG). Para isso, os autores utilizaram imagens VNIR-SWIR do sensor ASTER/Terra, tanto do período chuvoso quanto do seco. As imagens do SWIR foram reamostradas para $15 \mathrm{~m}$. Dados geoquímicos prévios foram analisados e a área delimitada categoricamente (em três níveis) por suas concentrações de exsudações superficiais. As vegetações sadia e estressada foram caracterizadas espectralmente e três diferentes processamentos foram realizados: geração de NDVl; desmistura espectral parcial, multi-criterial, via Matched Filtering e Mixture Tuning (MF-MT); e classificação espectral supervisionada SAM. Os resultados foram validados em campo e 
com sobrevoo de helicóptero. Os produtos de classificação SAM foram combinados com aqueles de NDVI em um diagrama de dispersão (escatergrama) e representaram a melhor metodologia na identificação das anomalias geobotânicas. Contudo, a excelência dos resultados obtidos sobre o povoamento homogêneo de eucalipto não se estendeu às áreas de vegetação nativa de cerrado. No período seco a vegetação do bioma, sobre áreas sem ocorrência de microexsudações, demonstrou semelhança espectral a eucaliptos estressados. Assim, os autores ressaltaram que características espectrais da vegetação de cerrado, semelhantes às descritas para as anomalias geobotânicas, nem sempre irão indicar a ocorrência de microexsudações de hidrocarbonetos.

\subsection{Comportamento espectral de vegetação}

O comportamento espectral da vegetação é dependente da escala de trabalho utilizada, quer seja parte de uma planta, uma planta ou um conjunto de plantas (Roberts et al., 2004). No entanto, devido à fotossíntese - processo fundamental e inerente à vida de uma planta e que ocorre nos cloroplastos das folhas - as características espectrais de folhas são essenciais para o estudo de uma vegetação fotossinteticamente ativa em qualquer escala de trabalho (Ponzoni \& Shimabukuro, 2007).

Em uma folha, a absorção da energia eletromagnética incidente por clorofilas e outros pigmentos foliares no intervalo espectral do visível (VIS, entre $0,4-0,7 \mu \mathrm{m}$ ) e a grande reflectância na região do infravermelho próximo (NIR, 0,7-1,3 $\mu \mathrm{m})$ - função principalmente da estrutura interna e espalhamento da radiação - constituem uma configuração espectral que as diferem de qualquer outro alvo na superfície terrestre. Nos intervalos espectrais do NIR e do infravermelho ondas curtas (SWIR, 1,4-2,5 $\mu \mathrm{m}$ ), as ligações O-H - da água e de compostos bioquímicos, como lignina e celulose - geram diversas feições de absorção (Figura 2.1). De forma mais detalhada, a reflectância de folhas no NIR é descrita como resultado do menor ou maior espalhamento de fótons produzido pelas interfaces parede celular-espaços gasosos - função da espessura das paredes e do teor de água - no 
mesófilo esponjoso (Wooley, 1971; Gausman, 1985; Grant, 1987) e, externamente, pela espessura da cutícula e presença de tricomas (Billings e Morris, 1951; Gausman et al., 1972; Grant, 1987).

Curran (1989) fez uma revisão sobre espectroscopia foliar, citando detalhadas medidas espectrais realizadas por pesquisadores do Departamento de Agricultura dos Estados Unidos, nas décadas de 60 e 70. Foram identificadas cinco grandes feições de absorção associadas à transição de elétrons em pigmentos no VIS e à flexão e alongamento das ligações $\mathrm{O}-\mathrm{H}$ em água e outros compostos químicos no infravermelho, como citado anteriormente. Essas feições dominantes encobrem 42 outras, de menor expressão, associadas a compostos orgânicos como celulose, lignina, proteínas, ácidos graxos, açúcares e amido (Curran, 1989). Nas últimas décadas, diversas relações bioquímicoespectrais têm sido realizadas através de análises de regressão, índices espectrais ou análises de profundidade de feições de absorção (p.ex., Chappelle et al., 1992; Blackburn, 1998a, 1998b e 2007; Asner, 1998; Kokaly e Clark, 1999; Curran et al., 2001; Sims e Gamon, 2002; Gitelson e Merzlyak, 2003; Gitelson et al., 2006; Gitelson, 2012).

Em folhas verdes, feições de absorção máxima por clorofila a são observadas em 0,58, 0,63 e 0,68 $\mu \mathrm{m}$ e clorofila b em 0,46, 0,635 e 0,65 $\mu \mathrm{m}$ (Chappelle et al., 1992; Blackburn, 1998a), por carotenoides em 0,47 e 0,50 $\mu \mathrm{m}$ (Chappelle et al., 1992; Blackburn, 1998a) e entre 0,50 e 0,52 $\mu \mathrm{m}$ (Gitelson et al., 2006; Gitelson, 2012) e por antocianina em 0,53 e entre 0,54 e 0,56 $\mu \mathrm{m}$ (Gitelson et al., 2006; Gitelson et al., 2009, Gitelson, 2012). Os componentes estruturais carboidratados, como celulose, hemicelulose e lignina, são usualmente estudados em folhas desidratadas, quando o obscurecimento de suas feições de absorção pela água é atenuado (p.ex., Kokaly e Clark, 1999; Jacquemoud et al., 2006). Contudo, essas feições são geralmente sobrepostas às observadas a outros compostos não fotossintéticos como nitrogênio, proteínas e açúcares (Curran, 1989; Kokaly e Clark, 1999; Kokaly, 2009). Feições isoladas de absorção por celulose foram descritas por Curran (1989) a 1,82 e 2,34 $\mu \mathrm{m}$, e por lignina a 1,12 e 1,42 $\mu \mathrm{m}$. 


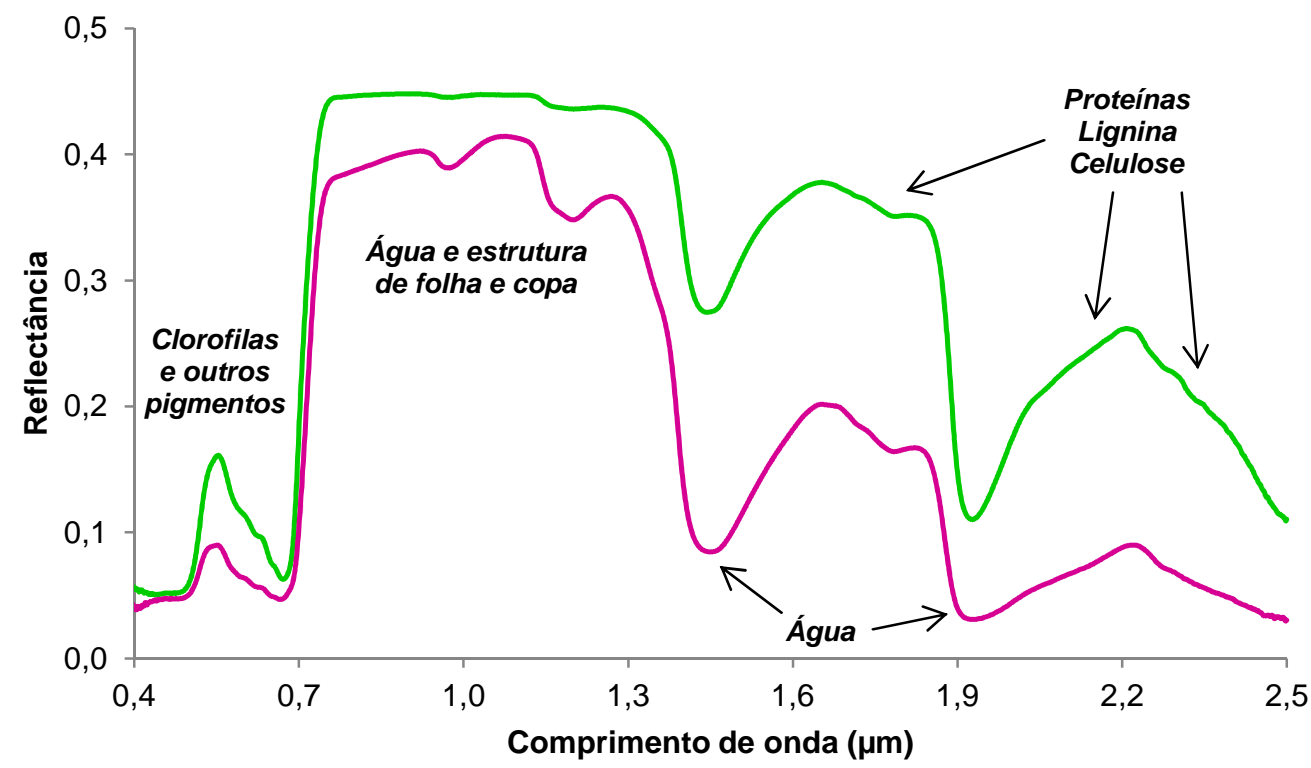

Figura 2.1. Comportamento espectral médio de folhas de Dendrocalamus sp. (bambú, em verde) e Pinus elliottii (pinheiro, em magenta) e indicação das regiões onde ocorrem feições de absorção por pigmentos foliares, compostos bioquímicos e água, bem como de espalhamento da energia devido à estrutura de copa e/ou folha (adaptado de Kokaly et al., 2003).

Diferentemente do comportamento espectral de folhas isoladas, que apresentam Fator de Reflectância Direcional-Hemisférico, ao se analisar o dossel florestal ou a copa de uma árvore - alvos anisotrópicos -, a reflectância da energia incidida não se apresentará como sobre uma superfície de fato Lambertiana, que reflete em todas as direções igualmente. As diferenças de iluminação (ângulos azimutal e zenital solar) e de visada (posição do sensor, no nadir ou off-nadir) implicam uma Reflectância Bidirecional (Ponzoni \& Shimabukuro, 2007; Jensen, 2009). Além disso, a energia incidente será dividida entre aquela que refletirá, após sua interação com a superfície imediata, e aquela que será transmitida e retransmitida entre camadas sucessivas de folhas antes de seu retorno à atmosfera. De acordo com Ponzoni \& Shimabukuro (2007), esse processo de espalhamento múltiplo, que ocorre no interior do dossel/copa, promove o fenômeno de caráter assintótico de diminuição da reflectância no VIS e de aumento no NIR, conforme o aumento das camadas de folhas. Dessa forma, dois parâmetros biofísicos são considerados essenciais no estudo da vegetação por sensoriamento remoto em escala de dossel (Ponzoni \& Shimabukuro, 2007; Jensen, 2009): 
- Índice de Área Foliar (IAF), que se refere à quantidade de área foliar, por área de terreno sob a copa/dossel do alvo estudado;

- Distribuição Angular das folhas (DAF), que se refere à disposição angular das folhas de uma copa, ou à angulação média de um dossel. Essa medida pode variar durante o dia conforme a iluminação solar.

Assim, as variações em reflectância de um pixel pertencente a dado dossel/copa podem ser descritas como uma mistura de até quatro frações espectrais, em análise de mistura espectral (Adams et al., 1993): GV (green vegetation) refere-se aos materiais fotossintetizantes (com cloroplastos ativos), como as folhas verdes; NPV (nonphotosynthetic vegetation) representa o material vegetal não fotossintético presente em um dossel/copa, como ramos, troncos e folhas secas; solo é a fração de solo presente no pixel, como resultado da estrutura do dossel/copa estudado; e sombra, função da estrutura e anisotropia da superfície, bem como dos ângulos de iluminação solar e visada do sensor (Figura 2.2).

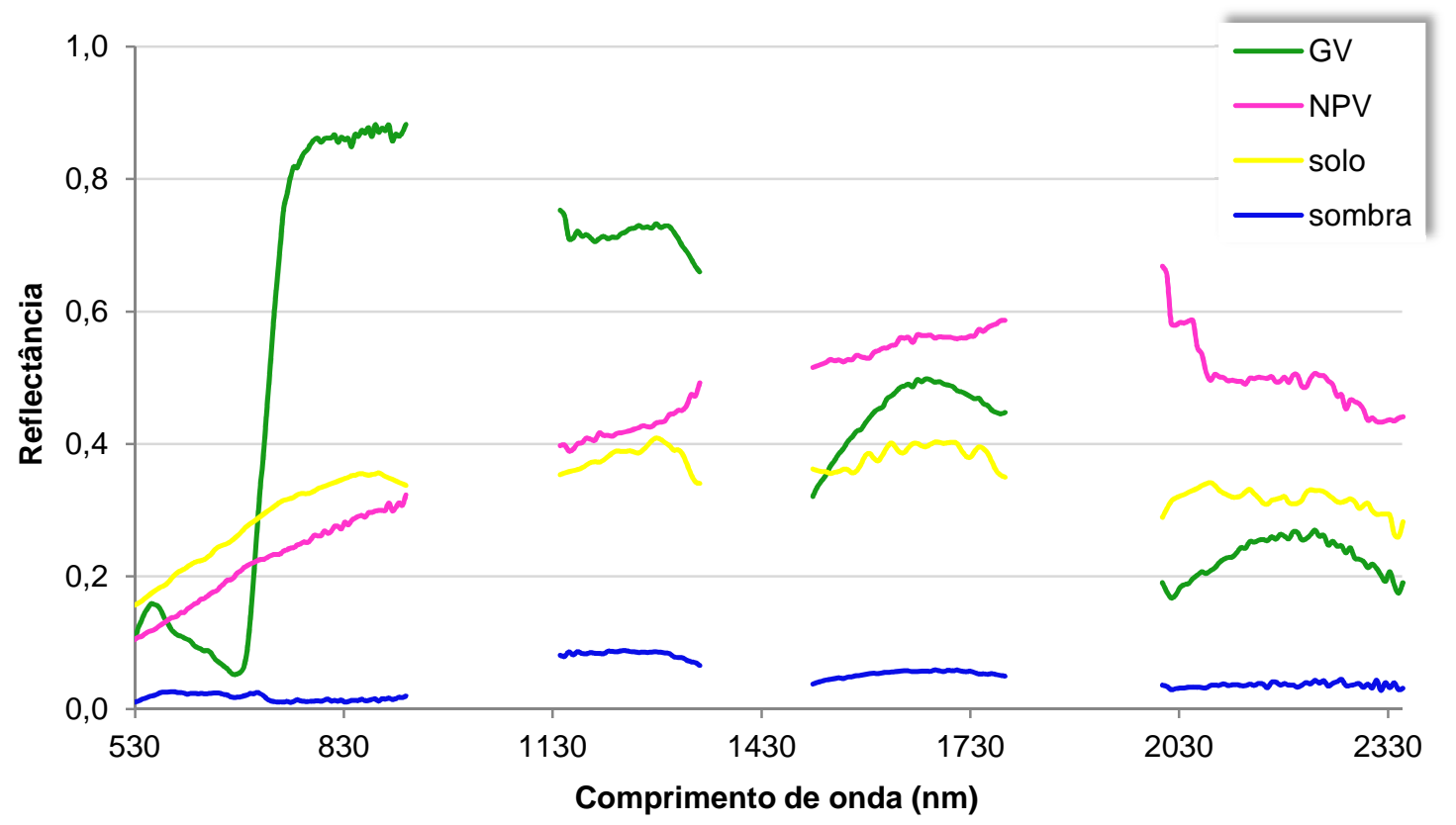

Figura 2.2. Espectros puros de vegetação verde - fotossinteticamente ativa (GV), vegetação não fotossintética (NPV), solo e sombra, extraídos de imagens hiperespectrais ProSpecTIR-VS, com exclusão das regiões espectrais de baixa razão sinal-ruído. 


\subsection{Self-Organizing Maps e técnicas complementares}

\subsubsection{Self-Organizing Maps}

Os Self-Organizing Maps ou mapas auto-organizáveis (SOM) constituem uma técnica de análise multivariada em redes neurais (Artificial Neural Networks, ANN) não supervisionada (Kohonen, 1982). Essa técnica, no entanto, se difere dos outros métodos em ANN por agrupar e reduzir a dimensionalidade dos dados mutuamente (Agarwal e Skupin, 2008). De acordo com Kohonen (1998 e 2013), autor e desenvolvedor da técnica, os SOM são baseados na quantificação vetorial e são capazes de converter relações estatísticas complexas e não lineares, entre dados de alta dimensionalidade, em simples relações geométricas com visualização de baixa dimensão. Na análise, as "células" de informação, dispostas em rede neural, competem entre si por meio de interações laterais múltiplas. Assim, promovem agrupamentos (domínios) não supervisionados com representações altamente visualizáveis das relações, mesmo que sutis, entre diferentes tipos de dados (Kohonen, 2001; Fraser \& Dickson, 2007).

Desta forma, vetores-nós (node-vectors) são treinados para representar a estrutura e os padrões das amostras de entrada em um espaço n-dimensional de dados (Figura 2.3). O dado de saída de uma análise SOM é tipicamente um mapa auto-organizado linear, de duas dimensões, composto por "células" (denominadas nós). Cada nó representa um vetor-nó no espaço de dados, definido por suas variáveis. O número de vetores a serem lançados no espaço n-dimensional de dados (seed-vectors), e subsequentemente treinados pelo processo, é definido pelo tamanho do mapa auto-organizado de saída, estabelecido previamente pelo usuário, em consonância com o número de unidades amostrais (Fraser e Dickson, 2007).

A análise é realizada por processo interativo de dois passos: o competitivo e o cooperativo. O primeiro passo compara cada amostra a todos os seed-vectors dentro de um determinado raio da amostra (no espaço n-dimensional) e, então, um seed-vector é determinado como vencedor por sua maior similaridade (cosseno ou distância Euclidiana). 
Uma vez definido o vetor vencedor do passo competitivo, suas propriedades são alteradas por um percentual, de forma a se assemelhar às propriedades do dado de entrada mais próximo. No segundo passo, o cooperativo, todos os seed-vectors dentro de um determinado raio do seed-vector vencedor têm suas propriedades também alteradas, de forma a se assemelharem ao dado de entrada em questão. Esse processo é, então, realizado para as próximas unidades amostrais. Assim, reduzindo o raio de influência e mudando o percentual de modificação aplicados aos seed-vectors durante cada interação, esses vetores tornam-se treinados (vencedores, vetores-nós ou node-vectors) para representar a estrutura dos dados originais. Centenas a milhares de interações desses dois passos (rough e fine training) podem ser realizadas sobre cada unidade amostral (Fraser e Dickson, 2007; Hodgkinson et al., 2012).

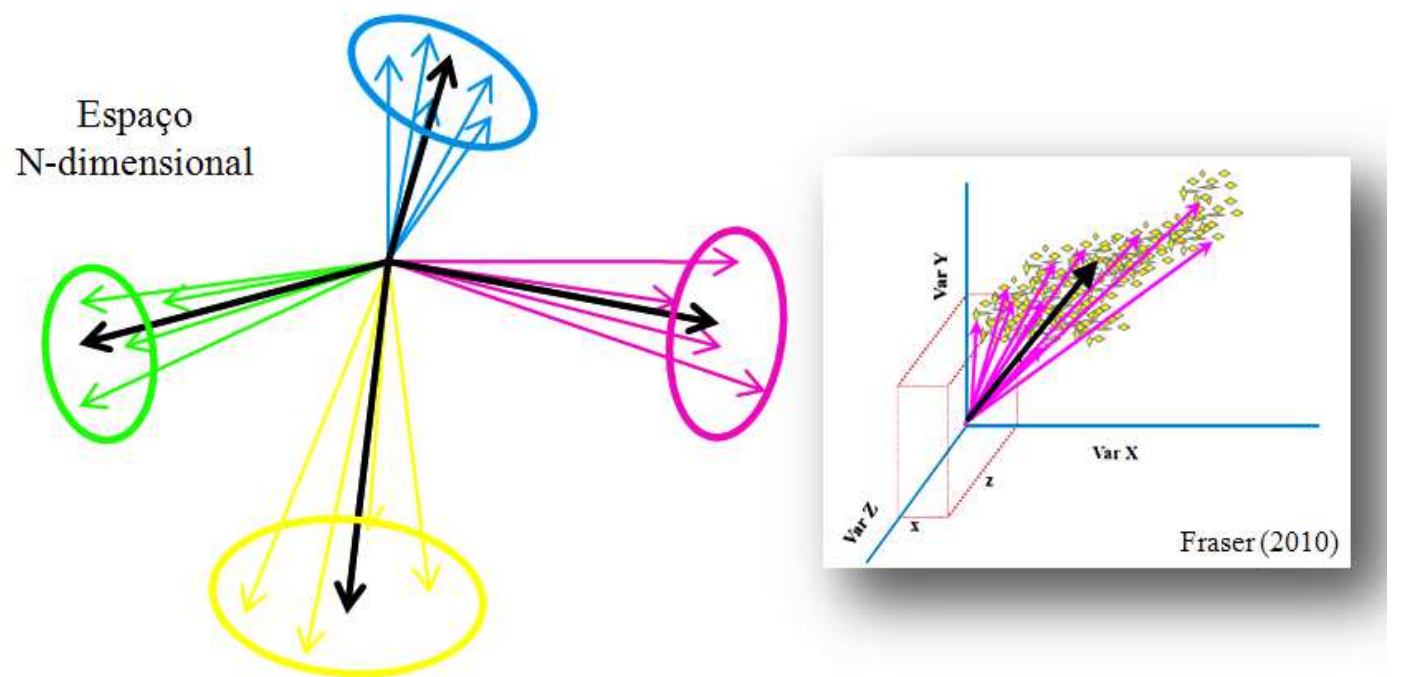

Figura 2.3. Visualização da vetorização de dados no espaço N-dimensional e esquema dos domínios formados pelas medidas de similaridade entre vetores.

Uma vez definidos todos os vetores-nós para representar a estrutura dos dados, todos os dados originais mais próximos a determinado vetor-nó são representados por ele, como um nó, no mapa 2D. O mapeamento dos dados n-dimensionais na representação 2D é realizado através de regressão. Esse mapeamento apresenta caraterística-chave de preservação das relações relativas topológicas entre os vetores-nós. No entanto, se um nó está perto de outros no mapa 2D, esses podem representar subconjuntos de um grupo 
maior formado pela similaridade das unidades amostrais (Fraser e Dickson, 2007). Os nós, que representam as amostras similares no mapa 2D, são agora denominados best matching units (BMU) e são utilizados nos processamentos subsequentes de agrupamento K-means e validação via Índice de Davies-Bouldin (Hodgkinson et al., 2009) no software SiroSOM (CSIRO Mineral Resources Flagship - Pullenvale, QLD, AUS). Existem duas métricas de validação de um SOM: a primeira, denominada erro de quantização médio (qe), refere-se à média das distâncias entre cada vetor de dados e seu BMU, e é uma medida de resolução do mapa 2D; a segundo, o erro de topologia (te), refere-se à proporção de todos os vetores de dados, de forma que o primeiro e o segundo BMU não sejam unidades adjacentes, e essa representa uma medida de preservação da topologia.

Os SOM têm apresentado resultados significativos na mineração de dados de alta dimensionalidade e análise multivariada em diversas áreas do conhecimento, como nas geociências (p.ex., Penn, 2005; Bação et al., 2005; Klose, 2006; Iwashita et al, 2011 e 2012; Carneiro et al., 2012) e na ecologia vegetal (p.ex., Foody, 1999; Zhang e Yang, 2008; Suriguga et al., 2011 e Adamczyk et al., 2013). Adamczyk et al. (2013), realizando análise temporal de dados fitossociológicos em reserva natural da Polônia central, puderam correlacionar amostragens temporais quantitativas de espécies com as condições abióticas locais. Os autores concluíram que a aplicação dos SOM fornece informações quanto à preferência de habitats pelas espécies e ajuda a indicar os fatores abióticos cruciais na formação de comunidades de plantas. Além disso, os autores acreditam que os SOM podem ser úteis e eficientes nos estudos de vegetação, mesmo em áreas edaficamente complexas.

\subsubsection{Definição de domínios}

Com sua primeira publicação em 1955, a técnica de agrupamento K-means continua sendo amplamente utilizada pela popularidade, simplicidade e eficiência de seu algoritmo (Jain, 2010; Benna et al., 2013). O algoritmo consiste em duas fases: primeira delas define centroides iniciais $\mathrm{K}$, um para cada agrupamento (domínio); a segunda fase associa cada 
ponto do dado conjunto de dados ao centroide mais próximo. Normalmente, a distância Euclidiana é utilizada para medir a distância entre a amostra e o centroide mais próximo. Quando todos os pontos são incluídos em um grupo, a primeira fase é completada e domínios preliminares são formados. Os centroides são recalculados e novos domínios são formados com os novos centroides até que esses não mudem mais (Benna et al., 2013). O índice de Davies-Bouldin (Davies e Bouldin, 1979) indica a similaridade entre os domínios, inferindo sobre a adequação das diferentes partições de dados independentemente da técnica de agrupamento utilizada e do número de domínios formados, que precisam ser ao menos dois. Esse método incorpora as características fundamentais de medidas de similaridade, bem como satisfaz certos critérios heurísticos (Davies e Bouldin, 1979). Quanto menor o índice de Davies-Bouldin mais naturais são considerados os domínios.

\subsubsection{Análises estatísticas periféricas do software SiroSOM}

O software SiroSOM, além de realizar os SOM e definir domínios, permite a análise do SOM através de outros métodos estatísticos, dentre eles, análises por principais componentes (APC) (Pearson, 1901) e análise de correlação entre variáveis através do coeficiente de correlação ranqueada de Spearman (Spearman, 1904 e 1906).

A APC é um sistema de representação de dados em duas até n-dimensões, por linhas (ou planos) às quais os dados apresentam melhor ajuste (Pearson, 1901). A ideia central da APC é reduzir a dimensionalidade dos dados que consistem em um grande número de variáveis inter-relacionadas, retendo ao máximo a variação presente no conjunto de dados. Isso é possível pela formação de um novo conjunto de variáveis (PCs) não correlacionadas (Jolliffe, 1986). Essas composições lineares são ordenadas de acordo com suas variações, de modo que as primeiras PCs explicam a maior parte das variações presentes nas variáveis originais (Jolliffe, 1986; Dunteman, 1989). Geometricamente, a primeira PC é a linha que apresenta maior ajuste às $n$ observações, no espaço n- 
dimensional de variáveis. Equivalentemente, a segunda PC é a linha que mais se ajusta aos resíduos da primeira componente (Dunteman, 1989).

O coeficiente de correlação ranqueada de Spearman ( $\rho)$ é uma estatística não paramétrica e representa uma extensão ranqueada do coeficiente de correlação produtomomento de Pearson (Borkowf, 2000). De acordo com Hollander et al. (2013), dentre muitas vantagens as estatísticas não paramétricas permitem ao usuário obter os exatos $P$-values para testes estatísticos, bem como exatas probabilidades para intervalos de confiança sem a dependência da hipótese de que a distribuição da população é normal. O coeficiente de correlação ranqueada de Spearman $(\rho)$ é considerado significativo quando $\rho \geq|0,04|$. Os valores significativos positivos indicam a ocorrência de relação diretamente proporcional entre as variáveis analisadas e os negativos indicam a ocorrência de relação inversamente proporcional entre elas. Acompanhando os valores de $\rho$ são gerados os valores de probabilidade de t-student (desenvolvido por Sealy Gosset em 1908), como forma de validação do índice. Quando mais próximo de zero forem esses últimos, mais simétricas são consideradas as distribuições das populações analisadas.

\subsection{Multiple Endmember Spectral Mixture Analysis e técnicas complementares}

\subsubsection{Multiple endmember spectral mixture analysis}

Multiple Endmember Spectral Mixture Analysis (MESMA; Roberts et al., 1998) é a técnica de Spectral Mixture Analysis - SMA mais amplamente utilizada e com sucesso na literatura (Somers et al., 2011). A técnica SMA modela os espectros de uma imagem como uma combinação linear de espectros puros (endmembers, em português membros-finais), determinando sua relativa proporção dentro de um espectro misto (Adams et al., 1993). Um espectro dentro de um Ground Instantaneous Field Of View (GIFOV, pixel) é modelado de acordo com o melhor ajuste entre as frações de membros-finais na composição do espectro misto. Isso é feito pela soma das reflectâncias de um conjunto fixo de membros-finais multiplicados por suas frações de cobertura, ou seja: 
$\rho^{\prime} \lambda=\sum_{i=1}^{N} f_{\mathrm{i}} * \rho_{\mathrm{i} \lambda}+\varepsilon_{\lambda}$

onde $\rho_{\lambda}^{\prime}$ é a reflectância em um determinado comprimento de onda $\lambda, \rho_{\mathrm{i} \lambda}$ é a reflectância do membro-final i no comprimento de onda $(\lambda)$ e $f_{j}$ é a fração de cobertura do membro-final i. $N$ é o número total de membros-finais no modelo e $\varepsilon_{\lambda}$ é o erro residual do modelo. As frações de membros-finais são tipicamente restringidas ao somatório igual a 1,0, assumindo que determinado espectro é $100 \%$ modelado pelos membros-finais analisados:

$\sum_{i=1}^{N} f_{i}=1$

A avaliação do modelo com melhor ajuste é realizada através do erro quadrático médio EQM (RMSE, em inglês) e utilizando o erro residual do modelo $\left(\varepsilon_{\lambda}\right)$ :

$E Q M=\sqrt{\frac{\sum_{\lambda=1}^{M}\left(\varepsilon_{\lambda}\right)^{2}}{M}}$

onde M é o número total de bandas.

Objetivando sanar as limitações observadas em vários métodos de SMA, que comportam apenas um membro-final por classe, MESMA permite que o tipo e o número de membros-finais variem (dentro de uma única classe) em uma per pixel basis (Roberts et al., 1998). A técnica gera modelos lineares utilizando diferentes conjuntos de membros-finais a partir de bibliotecas espectrais de até centenas de membros-finais e, então, seleciona para cada pixel o modelo de mistura espectral com o menor EQM. Além de permitir repetições e membros-finais que podem ser replicados entre imagens, MESMA gera imagens de frações correspondentes aos espectros dos materiais reais (Roberts et al., 1998). Com dois membros-finais, MESMA gera modelos entre um dos membros-finais de determinada classe 
e o membro-final de sombra fotométrica. Essa modelagem tem sido utilizada com sucesso como um algoritmo de classificação e mapeamento de espécies de plantas e tipos funcionais, como em vegetações arbustivas (chaparral) do sudeste da Califórnia, EUA (Roberts et al., 1998; Dennison and Roberts, 2003a e 2003b; Roth et al., 2012); em floresta boreal no Canadá (Roberts et al., 1999); em vegetações aquáticas e de pântano no nordeste da Califórnia, EUA (Li et al., 2005; Rosso et al., 2005; Underwood et al., 2006); em floresta temperada em New Hampshire, EUA (Plourde et al., 2007); nas serras ao norte de Utah, EUA (Schaaf et al., 2011); em florestas de eucaliptos em New South Wales, Austrália (Youngentob et al., 2011); e em floresta tropical montana no Havaí, EUA (Tits et al., 2012; Somers e Asner, 2013 e 2014). Embora os modelos com dois membros-finais apresentem melhor separação entre as classes do que aqueles com três membros-finais (Roberts et al., 1998), a aplicação de MESMA com três membros-finais também pode gerar o mapeamento preciso de frações de membros-finais através da desmistura espectral de imagens (Roberts et al., 1998; Dennison and Roberts, 2003a e 2003b).

De acordo com Roberts et al. (1998), a chave para a abordagem com múltiplos membros-finais é iniciar com séries de modelos candidatos com dois membros-finais, avaliar cada modelo de acordo com os critérios de seleção e, então, se requerido, construir modelos candidatos que incorporem mais membros-finais.

\subsubsection{Métricas para seleção de membros-finais}

A seleção de membros-finais envolve a identificação dos tipos e números de membros-finais, bem como de suas assinaturas espectrais (Somers et al., 2011). Diversas métricas de seleção de membros-finais têm sido desenvolvidas para aplicação em MESMA, visando capturar o menor número de membros-finais que representem e modelem a variabilidade espectral de uma determinada classe (Roth et al., 2012).

Roberts et al. (2003) criaram a métrica Count-based (CoB), a fim de selecionar os membros-finais que modelem o maior número de espectros dentro de sua classe. O Índice 
Count-based, por sua vez, foi criado por Clark (2005) para ranquear os membros-finais de acordo com a razão obtida entre espectros modelados dentro de sua classe $(C o B I n)$ e os espectros modelados fora de sua classe (CoBOut). Dennison e Roberts (2003a) desenvolveram a métrica Endmember Average RMSE (EAR), que utiliza cada espectro dentro de uma classe para modelar todos os outros espectros daquela classe através de uma SMA linear. O EAR é equivalente à média dos EQM de todos os modelos de um único membro-final dentro da mesma classe. Os membros-finais são selecionados por seu menor EAR:

$E_{A R}=\frac{\sum_{j=1}^{n} E Q M_{A i} A j}{n-1}$

onde $A$ é uma única classe, $A_{i}$ é o espectro sendo testado como um membro-final e $A_{j}$ é um espectro modelado, n é o número total de espectros da classe A e o termo "n-1" refere-se ao espectro automodelado. A métrica Minimum Average Spectral Angle (MASA), criado por Dennison et al. (2004), é similar ao EAR, mas utiliza o ângulo espectral (Kruse et al., 1993) como métrica para seleção de membros-finais, no lugar do EQM. Os membros-finais são selecionados através de seu menor valor MASA.

Embora essas métricas sejam comumente aplicadas na seleção de membros-finais para aplicações de MESMA, EAR, MASA e CoB (conjuntamente designados EMC) falham por considerarem apenas as variações espectrais intraclasse, não observando as interações resultantes entre os membros-finais selecionados para as diferentes classes (Roth et al., 2012). Schaaf et al. (2011) propôs, assim, o algoritmo Iterative Endmember Selection (IES), que considera, na seleção de membros-finais, as interações entre todos aqueles selecionados para múltiplas classes, ou seja, as variações interclasse. IES é um algoritmo stepwise que, primeiramente, testa todas as possibilidades par a par a fim de encontrar os dois membros-finais que geram o maior coeficiente Kappa em uma classificação MESMA dentro da biblioteca global de treinamento; sequencialmente, todos os potenciais membros- 
finais são adicionados (e subtraídos) e comparados para verificar a possibilidade de incremento na classificação. Assim, adicionando e subtraindo espectros, o conjunto de membros-finais é selecionado quando o maior coeficiente Kappa é atingido para a biblioteca global de treinamento (Schaaf et al., 2011).

Roth et al. (2012) desenvolveram o método híbrido que combina as métricas EMC e IES, a fim de otimizar o processo de seleção de membros-finais via IES. Essa técnica é proposta para os casos em que membros-finais não são selecionados para algumas das classes através do método IES. Assim, o conjunto inicial de membros-finais selecionados via IES, pela otimização do coeficiente Kappa, é adaptado com a inserção dos membros-finais das classes faltantes selecionados através das métricas CoB e EAR, do método EMC.

\subsubsection{Remoção do contínuo de espectros}

Um contínuo aparente, em um espectro de reflectância, é modelado como uma função matemática e pode ser removido de segmentos ou de espectros inteiros, normalizando as diferenças de brilho dos dados e enfatizando as feições de absorção presentes no intervalo (Clark e Roush, 1984). O contínuo é um convex hull composto por segmentos de linhas retas que conectam as extremidades do espectro e/ou os picos de reflectância presentes naquele intervalo. Com a remoção do contínuo esses pontos de interseção são normalizados a um $(1,0)$ e os valores de reflectância das feições de absorção passam a variar entre um e zero (Figura 2.4). O contínuo é removido (CR) através da divisão do valor da reflectância $(\rho)$ em um determinado comprimento de onda $(\lambda)$ pelo valor da reflectância do contínuo $\left(\rho_{C} \lambda\right)$ no mesmo comprimento de onda:

$$
C R=\frac{\rho \lambda}{\rho_{C} \lambda}
$$



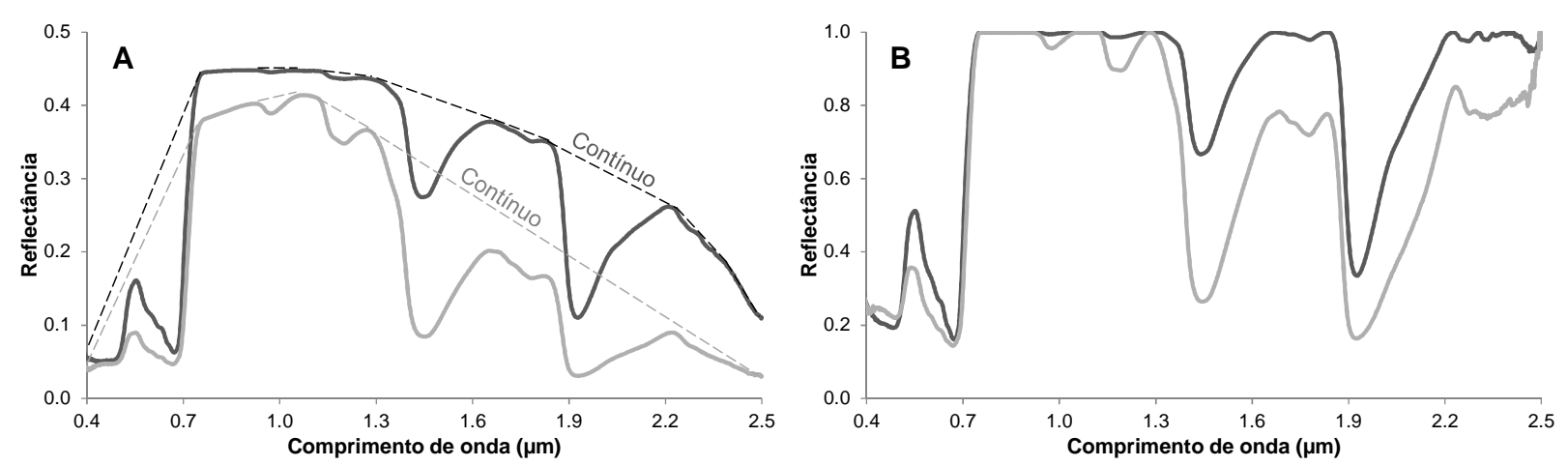

Figura 2.4. Espectros foliares de Dendrocalamus sp. (bambú, em cinza escuro) e Pinus elliottii (pinheiro, em cinza claro) originais de reflectância (A) e com contínuo removido (B).

Em espectroscopia de vegetação, a remoção do contínuo tem sido utilizada, principalmente, para análises de feições de absorção localizadas nas regiões do infravermelho próximo (NIR) e infravermelho ondas curtas (SWIR) na estimação de compostos bioquímicos (não pigmentos) da vegetação, como nitrogênio, lignina e celulose (p.ex., Kokaly e Clark, 1999; Curran et al., 2001; Kokaly, 2001; Huang et al., 2004; Kokaly et al., 2009). A técnica também tem sido aplicada no pré-processamento de dados hiperespectrais ao mapeamento de espécies como, por exemplo, de invasoras na Califórnia, EUA (Underwood et al., 2003; Hestir et al., 2008). Nesses trabalhos, os autores utilizaram a técnica para realce das feições espectrais de absorção por água foliar na região do NIR. Youngentob et al. (2011) utilizaram dados com CR no mapeamento via MESMA de dois subgêneros de eucalipto em New South Wales, AUS. Os autores compararam a precisão da modelagem MESMA utilizando dados VSWIR (do visível ao infravermelho ondas curtas) com CR e sem CR (originais de reflectância). Eles concluíram que, mesmo com maior número de espectros não modelados, as classificações MESMA foram mais precisas utilizando-se os dados com CR.

\subsection{Referências bibliográficas}

Abdon, M. M., Silva, J. D. S. V., Pott, V. J., Pott, A., \& Silva, M. P. (1998). Utilização de dados analógicos do Landsat-TM na discriminação da vegetação de parte da sub-região da Nhecolândia no Pantanal. Pesquisa Agropecuária Brasileira, 33(13), 1799-1813. 
Adamczyk, J.J., Kurzac, M., Park, Y. S., \& Kruk, A. (2013). Application of a Kohonen's self-organizing map for evaluation of long-term changes in forest vegetation. Journal of Vegetation Science, 24(2), 405-414.

Adámoli, J. (1982). O Pantanal e suas relações fitogeográficas com os cerrados: discussão sobre o conceito "Complexo do Pantanal". In Congresso Nacional de Botânica, 32 (pp.109-119). Teresina, PI.

Adams, J. B., Smith, M. O., \& Gillespie, A. R. (1993). Imaging spectroscopy: Interpretation based on spectral mixture analysis. In C. M. Pieters, \& P. A. J. Englert (Eds.), Remote geochemical analyses: Elemental and mineralogical composition (pp. 145-166). Cambridge: Cambridge University Press.

Agarwal, P., \& Skupin, A. (2008). Self-Organising Maps: Applications in Geographic Information Science. Chichester (WS): John Wiley \& Sons Ltd. 214p.

Aidar, M. P., Godoy, J. R. L. D., Bergmann, J., \& Joly, C. A. (2001). Atlantic Forest succession over calcareous soil, Parque Estadual Turístico do Alto Ribeira-PETAR, SP. Brazilian Journal of Botany, 24(4), 455-469.

Allem, A. C., \& Valls, J. F. M. (1987). Recursos forrageiros nativos do Pantanal Matogrossense. Brasília: Departamento de Difusao de Tecnologia, Empresa Brasileira de Pesquisa Agropecuaria.

Almeida, T. I. R. (2005). Geobotânica por sensoriamento remoto em florestas tropicais e a abordagem sistêmica: uma ferramenta auxiliar no mapeamento geológico regional e na prospecção mineral. Tese de Livre Docência, Instituto de Geociências, Universidade de São Paulo, São Paulo.

Almeida, T. I. R., Fambrini, G. L., Sayeg, H., Mcreath, I., Machado, R., \& Cesar, A. R. S. F. (1995). Procesamiento digital y interpretación geológica de imágenes TM-Landsat del área al Este de la Mina de Camaquã (Límite Proterozóico-Fanerozóico), Estado do Rio Grande do Sul, Brazil. In Simpósio Latinoamericano de Percepción Remota, 7. (pp.457469). Puerto Vallarta, JAL.

Almeida, T. I. R., Juliani, C., Mantovani, W., \& Pérez-Aguilar, A. (2007a). Comunidades florestais como indicadores geobotânicos: o caso da mineralização aurífera do Grupo Serra do Itaberaba, Guarulhos, São Paulo. Brazilian Journal of Geology, 37(1), 37-49.

Almeida, T. I. R., Perrotta, M. M., Souza Filho, C. R., \& Santos, M. (2007b). Geobotânica por sensoriamento remoto no mapeamento geológico de região recoberta por floresta amazônica de terra firme: uma avaliação metodológica na região do Vale do Guaporé (RO). In Simpósio Brasileiro de Sensoriamento Remoto, 13 (pp.1951-1958). Florianópolis, SC.

Almeida, T. I. R., Sígolo, J. B., Fernandes, E., Queiroz Neto, J. P., Barbiero, L., \& Sakamoto, A. Y. (2003). Proposta de classificação e gênese das lagoas da baixa nhecolândia-ms com base em sensoriamento remoto e dados de campo. Brazilian Journal of Geology, 33(2), 83-90.

Almeida, T. I. R., Silva Filho, W. F., Fambrini, G. L., Sayeg, H., Mcreath, I., Machado, R. et al. (1997). Digital processing and geological interpretation of TM-Labdsat images of the area east of the Camaquã mine in Rio Grande do Sul State, southern Brazil. Boletim IGUSP. Série Científica, 28, 101-118.

Almeida, T. I. R., Souza Filho, C. R., Juliani, C., \& Branco, F. C. (2009). Application of Remote Sensing to Geobotany to Detect Hydrothermal Alteration Facies in Epithermal High Sulfidation Gold Deposits in the Amazon Region. In R. Bedell, S. Simmons, E. Grunsky, \& A. Crósta. (Orgs.), SEG Reviews in Economic Geology - Remote Sensing and Spectral Geology, $1^{\text {st }}$ ed. (pp. 135-142). Society of Economic Geologists. 
Almeida-Filho, R, \& Castelo Branco, R. M. G. (1992). Location of kimberlites using Landsat Thematic Mapper images and aerial photographs: the Redondão diatreme, Brazil. International Journal of Remote Sensing, 13, 1449-1457.

Almeida-Filho, R. (1984). Multiseazonal and geobotanical approach in remote detection of albitized-greizenized areas in the Serra da Pedra Branca granitic massif, Goiás State, Brazil. Economic Geology and the Bulletin of the Society of Economic Geologists, 78(8), 1914-1920.

Almeida-Filho, R. (2002). Remote detection of hydrocarbon microseepage areas in the Serra do Tonã region, Tucano basin, Brazil. Canadian journal of remote sensing, 28(6), 750757.

Almeida-Filho, R., \& Vitorello, I. (1997). Remote sensing data integration in the definition of hydrotermally altered areas in vegetated terrain, central Brazil. International Journal of Remote Sensing, 18(8), 1835-1842.

Almeida-Filho, R., Miranda, F. P., \& Yamakawa, T. (1999). Remote detection of a tonal anomaly in an area of hydrocarbon microseepage, Tucano basin, north-eastern Brazil. International Journal of Remote Sensing, 20(13), 2683-2688.

Almeida-Filho, R., Payolla, B. L., Pinto, O. G., \& Bettencourt, J. S. (1984). Utilização de imagens digitais Landsat no estudo de corpos granitóides em Rondônia: caso-exemplo do maciço de Pedra Branca. In Symposium Amazônico, 2 (pp.409-416). Manaus, AM.

Almeida-Filho, R., Vitorello, I., \& Correia, V. R. (1996). Use of Landsat Thematic Mapper imagery as mineral prospecting tool in the tin province of Goias, Brazil. Geocarto International, 11(1), 61-69.

Alvarenga, S. M., Brasil, A. E., Pinheiro, R., \& Kux, H. J. H. (1984). Estudo geomorfológico aplicado à Bacia do Alto Paraguai e Pantanais Mato-grossenses. Boletim Técnico, Série Geomorfológica (pp.89-183). Salvador: Projeto RADAMBRASIL.

Amaral, G. (1968). Geologia e depósitos de minério da região de Vazante, Estado de Minas Gerais. Tese de doutorado, Escola Politécnica, Universidade de São Paulo, São Paulo.

Amaral, G. (1982). Aplicabilidade da análise automática de imagens Landsat na pesquisa mineral no interflúvio Araguaia Xingu. In Simpósio Brasileiro de Sensoriamento Remoto, 2 (pp. 197-206). Brasília, DF.

Amaral, G. (1992). Estudos geobotânicos no Vale do Ribeira com base em sensoriamento remoto. Boletim IG-USP. Publicação Especial, 12, 11-12.

Arden Jr, D. D., \& Westra, R. N. (1977). Remote sensing of geobotanical relations in Georgia. Technical Report (NASA-CR-150709) 103p.

Arens, K. (1963). As plantas lenhosas dos campos cerrados como vegetação adaptada às deficiências minerais do solo. Anais do III Simpósio Sobre o Cerrado (pp. 13-115). São Paulo: EdgardBlucher/ EDUSP.

Asner, G. P. (1998). Biophysical and biochemical sources of variability in canopy reflectance. Remote Sensing of Environment, 64(3), 234-253.

Asner, G. P., Clark, J. K., Mascaro, J., Galindo García, G. A., Chadwick, K. D., Navarrete Encinales, D. A. et al. (2012). High-resolution mapping of forest carbon stocks in the Colombian Amazon. Biogeosciences, 9(3), 2683-2696.

Assis, A. C. C., Coelho, R. M., Silva Pinheiro, E., \& Durigan, G. (2011). Water availability determines physiognomic gradient in an area of low-fertility soils under Cerrado vegetation. Plant Ecology, 212(7), 1135-1147. 
Assis, R. L., Haugaasen, T., Schöngart, J., Montero, J. C., Piedade, M. T., \& Wittmann, F. (2014). Patterns of tree diversity and composition in Amazonian floodplain paleo-várzea forest. Journal of Vegetation Science. DOI: 10.1111/jvs.12229.

Bação, F., Lobo, V., \& Painho, M. (2005). The self-organizing map, the Geo-SOM, and relevant variants for geosciences. Computers \& Geosciences, 31(2), 155-163.

Baker, A. M. J., \& Brooks, R. R. (1988). Botanical exploration for minerals in the humid tropics. Journal of Biogeography, 15, 221-229.

Beard, J. S. (1953). Savanna vegetation of Northern Tropical America. Ecology Monography, 23, $149-215$.

Beena P., Sunil Kumar, P. V., \& Balachandran, K. P. (2013). K-Means Clustering - Review of Various Methods for Initial Selection of Centroids. International Journal of Scientific \& Engineering Research, 4(8), 1844-1847.

Billings, W. D., \& Morris, R. J. (1951). Reflection of visible and infrared radiation from leaves of differing ecological groups. American Journal of Botany, 38, 327-331.

Blackburn, G. A. (1998a). Spectral indices for estimating photosynthetic pigment concentrations: a test using senescent tree leaves. International Journal of Remote Sensing, 19(4), 657-675.

Blackburn, G. A. (1998b). Quantifying chlorophylls and carotenoids at leaf and canopy scales: An evaluation of some hyperspectral approaches. Remote sensing of environment, 66(3), 273-285.

Blackburn, G.A. (2007). Hyperspectral remote sensing of plant pigments. Journal of Experimental Botany, 58(4), 855-867.

Borkowf, C. B. (2000). A new nonparametric method for variance estimation and confidence interval construction for Spearman's rank correlation. Computational statistics \& data analysis, 34(2), 219-241.

Brannstrom, C., Jepson, W., Filippi, A. M., Redo, D., Xu, Z., \& Ganesh, S. (2008). Land change in the Brazilian Savanna (Cerrado), 1986-2002: comparative analysis and implications for land-use policy. Land Use Policy, 25(4), 579-595.

Brooks, R. R. (1972). Geobotany and biogeochemistry in mineral exploration. New York: Harper \& Row. 290 p.

Brooks, R. R. (1980). Indicator plants for mineral prospecting - A critique. Journal of Geochemical Exploration, 12, 67-78.

Brooks, R. R. (1982). Biological methods of prospecting for gold. Journal of Geochemical Exploration, 17(2), 109-122.

Brooks, R. R. (1983). Biological Methods of prospecting for minerals, $2^{\text {nd }}$ ed. New York: John Wiley \& Sons. 322 p.

Brooks, R. R., Holzbecher, J., \& Ryan, D. E. (1981). Horsetails (Equisetum) as indirect indicators of gold mineralization. Journal of Geochemical Exploration, 16(1), 21-26.

Brooks, R. R., Reeves, R. D., Baker, A. J. M., Rizzo, J. A., \& Diaz Ferreira, H. (1990). The Brazilian Serpentine Plant Expedition (BRASPEX), 1988. National Geographic Research, 6(2), 205-219.

Calheiros, D. F., \& Fonseca Junior, W. D. (1996). Pespectivas de estudos ecológicos sobre o Pantanal. Corumbá: EMBRAPA-CPAP.

Cannon, H. L. (1960). Botanical prospecting for ore deposits. Science, 132(3427), 591-598.

Cannon, H. L. (1971). The use of plant indicators in ground water surveys, geologic mapping, and mineral prospecting. Taxon, 227-256. 
Capra, F. (1982). O ponto de mutação. Tradução: A. Cabral. São Paulo: Editora Cultrix, 2006. 444p.

Capra, F. (1996). A teia da vida: uma nova compreensão científica dos sistemas vivos. Tradução: N. R. Eichemberg. São Paulo: Editora Cultrix, 2006. 249p.

Carneiro, C. D. C., Fraser, S. J., Crósta, A. P., Silva, A. M., \& Barros, C. E. D. M. (2012). Semiautomated geologic mapping using self-organizing maps and airborne geophysics in the Brazilian Amazon. Geophysics, 77(4), K17-K24.

Carranza, E. J. M., \& Hale, M. (2002). Mineral imaging with Landsat Thematic Mapper data for hydrothermal alteration mapping in heavily vegetated terrane. International Journal of Remote Sensing, 23(22), 4827-4852.

Carvalho Júnior, O. A., Carvalho, A. P. F., Guimarães, R. F., Lopes, R. A. S., Guimarães, P. A., Souza Martins, E. et al. (2003). Classification of hyperspectral image using SCM methods for geobotanical analysis in the Brazilian savanna region. In IEEE Geoscience and Remote Sensing Symposium, 2003 (pp.3754-3756). Toulouse, FRA.

Carvalho Júnior, O. A., Guimarães, R. F., Carvalho, A. P. F., \& Souza Martins, E. (2004). Spectral mixture analysis of ASTER image to geobotanical investigation between ultramafic and mafic rocks from Niquelandia, Brazil. In IEEE Geoscience and Remote Sensing Symposium, 2004 (pp.250-253). Anchorage, AK.

Chappelle, E. W., Kim, M. S., \& McMurtrey III, J. E. (1992). Ratio analysis of reflectance spectra (RARS): an algorithm for the remote estimation of the concentrations of chlorophyll a, chlorophyll b, and carotenoids in soybean leaves. Remote Sensing of Environment, 39(3), 239-247.

Clark, M. L. (2005). An assessment of Hyperspectral and Lidar Remote Sensing for the Monitoring of Tropical Rain Forest Trees. PhD. Thesis, Department of Geography, University of California, Santa Barbara. (UMI No. 3186829).

Clark, R. N., \& Roush, T. L. (1984). Reflectance spectroscopy: Quantitative analysis techniques for remote sensing applications. Journal of Geophysical Research, 89, 63296340.

Cole, M. M. (1982). The influence of soils, geomorphology and geology on the distribution of plant communities in savanna ecosystems. In B. J. Huntley, \& B. H. Walker (Eds.), Ecology of tropical savannas (pp. 145-174). Berlin: Springer Berlin Heidelberg.

Condit, R., Pitman, N., Leigh, E. G., Chave, J., Terborgh, J., Foster, R. B., et al. (2002). Beta-diversity in tropical forest trees. Science, 295(5555), 666-669.

Curran, P. J. (1989). Remote sensing of foliar chemistry. Remote sensing of Environment, 30(3), 271-278.

Curran, P. J., Dungan, J. L., \& Peterson, D. L. (2001). Estimating the foliar biochemical concentration of leaves with reflectance spectrometry: testing the Kokaly and Clark methodologies. Remote Sensing of Environment, 76(3), 349-359.

Daldegan, G. A., de Carvalho, O. A., Guimarães, R. F., Gomes, R. A. T., Ribeiro, F. D. F., \& McManus, C. (2014). Spatial Patterns of Fire Recurrence Using Remote Sensing and GIS in the Brazilian Savanna: Serra do Tombador Nature Reserve, Brazil. Remote Sensing, 6(10), 9873-9894.

Davies, D. L., \& Bouldin, D. W. (1979). A cluster separation measure. IEEE Transactions on Pattern Analysis and Machine Intelligence, 2, 224-227.

Dennison, P. E., \& Roberts, D. A. (2003a). Endmember selection for multiple endmember spectral mixture analysis using endmember average RMSE. Remote Sensing of Environment, 87, 123-135. 
Dennison, P. E., \& Roberts, D. A. (2003b). The effects of vegetation phenology on endmember selection and species mapping in southern California chaparral. Remote Sensing of Environment, 87, 295-309.

Dennison, P. E., Halligan, K. Q. \& Roberts, D. A. (2004). A comparison of error metrics and constraints for multiple endmember spectral mixture analysis and spectral angle mapper. Remote Sensing of Environment, 93, 359-367.

Dunteman, G. H. (1989). Principal components analysis (No. 69). Newbury Park: Sage Publications.

Eisenlohr, P. V., Alves, L. F., Bernacci, L. C., Padgurschi, M. C., Torres, R. B., Prata, E. M., et al. (2013). Disturbances, elevation, topography and spatial proximity drive vegetation patterns along an altitudinal gradient of a top biodiversity hotspot. Biodiversity and conservation, 22(12), 2767-2783.

Eiten, G. (1963). Habitat flora of Fazenda Campininha. Anais do $1^{\circ}$ Simpósio sobre Cerrado (pp. 157-202). São Paulo: Universidade de São Paulo.

Eiten, G. (1972). The cerrado vegetation of Brazil. Botanical Review, 38, 201-341.

Ferreira, L. G., \& Huete, A. R. (2004). Assessing the seasonal dynamics of the Brazilian Cerrado vegetation through the use of spectral vegetation indices. International Journal of Remote Sensing, 25(10), 1837-1860.

Ferreira, L. G., Asner, G. P., Knapp, D. E., Davidson, E. A., Coe, M., Bustamante, M. M., \& de Oliveira, E. L. (2011). Equivalent water thickness in savanna ecosystems: MODIS estimates based on ground and EO-1 Hyperion data. International Journal of Remote Sensing, 32(22), 7423-7440.

Ferreira, L. G., Sano, E. E., Fernandez, L. E., \& Araújo, F. M. (2013). Biophysical characteristics and fire occurrence of cultivated pastures in the Brazilian savanna observed by moderate resolution satellite data.International Journal of Remote Sensing, 34(1), 154-167.

Ferreira, L. G., Yoshioka, H., Huete, A., \& Sano, E. E. (2003). Seasonal landscape and spectral vegetation index dynamics in the Brazilian Cerrado: An analysis within the Large-Scale Biosphere-Atmosphere Experiment in Amazônia (LBA). Remote Sensing of Environment, 87(4), 534-550.

Ferreira, L. G., Yoshioka, H., Huete, A., \& Sano, E. E. (2004). Optical characterization of the Brazilian savanna physiognomies for improved land cover monitoring of the cerrado biome: preliminary assessments from an airborne campaign over an LBA core site. Journal of Arid Environments, 56(3), 425-447.

Ferreira, M. E., Ferreira, L. G., Sano, E. E., \& Shimabukuro, Y. E. (2007). Spectral linear mixture modelling approaches for land cover mapping of tropical savanna areas in Brazil. International Journal of Remote Sensing, 28(2), 413-429.

Figueiredo, F. O., Costa, F. R., Nelson, B. W., \& Pimentel, T. P. (2014). Validating forest types based on geological and land-form features in central Amazonia. Journal of Vegetation Science, 25(1), 198-212.

Foody, G. (1999). Applications of the self-organising feature map neural network in community data analysis. Ecological Modelling, 210, 97-107.

França, H., \& Setzer, A. W. (2001). AVHRR analysis of a savanna site through a fire season in Brazil. International Journal of Remote Sensing, 22(13), 2449-2461.

Fraser, S. J. 2010. SiroSOM Workshop - UNICAMP, May 31- June 2, 2010. CSIRO Earth Science and Resource Engineering. Report Number P 2010/723. 182p. 
Fraser, S., \& Dickson, B. L. (2007). A new method for data integration and integrated data interpretation: self-organizing maps. In Proceedings of exploration (Vol. 7, pp. 907-910).

Fuller, D. (1920). Ecological Terms and Concepts. Botanical Gazette, 69(2), 183-185.

Galvão, L. S., Almeida-Filho, R., \& Vitorello, Í. (2005). Spectral discrimination of hydrothermally altered materials using ASTER short-wave infrared bands: Evaluation in a tropical savannah environment. International journal of applied earth observation and geoinformation, 7(2), 107-114.

Galvão, L. S., Vitorello, I., \& Filho, R. A. (1999). Effects of band positioning and bandwidth on NDVI measurements of tropical savannas. Remote Sensing of Environment, 67(2), 181193.

Gausman, H. W. (1985). Plant leaf properties in visible and near infrared light. Lubbock: Texas Tech Press.

Gausman, H. W., Allen, W. A., \& Wiegand, C. L. (1972). Plant factors affecting electromagnetic radiation. Soil and Water Conservation Research Division, Agricultural Research Service, US Department of Agriculture.

Gitelson, A. A. (2012). Nondestructive Estimation of Foliar Pigment (Chlorophylls, Carotenoids, and Anthocyanins) Contents: Evaluating a Semianalytical Three-Band Model. In P.S. Thenkabail, J.G. Lyon, \& A. Huete (Orgs.), Hyperspectral Remote Sensing of Vegetation (pp. 141-165). New York: CRC Press.

Gitelson, A. A., \& Merzlyak, M. N. (2003). Relationships between leaf chlorophyll content and spectral reflectance and algorithms for non-destructive chlorophyll assessment in higher plant leaves. Journal of plant physiology, 160(3), 271-282.

Gitelson, A. A., Chivkunova, O. B., \& Merzlyak, M. N. (2009). Nondestructive estimation of anthocyanins and chlorophylls in anthocyanic leaves. American journal of botany, 96(10), 1861-1868.

Gitelson, A. A., Keydan, G. P., \& Merzlyak, M. N. (2006). Three-band model for noninvasive estimation of chlorophyll, carotenoids, and anthocyanin contents in higher plant leaves. Geophysical Research Letters, 33. L11402.

Godoy, J. R. L. (2001). Estrutura e composição específica da Mata Atlântica secundária de encosta sobre calcário e filito, no Parque Estadual Turístico do Alto Ribeira, Iporanga, $S P$. Dissertação de Mestrado, Instituto de Biociências, Universidade de São Paulo, São Paulo.

Grant, L. (1987). Diffuse and specular characteristics of leaf reflectance. Remote Sensing of Environment, 22(2), 309-322.

Haridasan, M. \& Araújo, G. M. (1988). Aluminium-Accumulating species in two forest communities in the cerrado region of Central Brazil. Forest Ecology and Management, 24, 15-26.

Heshmatti, G. A., \& Squires, V. R. (1997). Geobotany and range ecology: a convergence of thought? Journal of Arid Environments, 35, 395-405.

Hestir, E. L., Khanna, S., Andrew, M. E., Santos, M. J., Viers, J. H., Greenberg, J. A., Rajapakse, S. S., \& Ustin, S.L. (2008). Identification of invasive vegetation using hyperspectral remote sensing in the California Delta ecosystem. Remote Sensing of Environment, 112, 4034-4047.

Higgins, M. A., Asner, G. P., Martin, R. E., Knapp, D. E., Anderson, C., Kennedy-Bowdoin, T. et al. (2014b). Linking imaging spectroscopy and LiDAR with floristic composition and forest structure in Panama. Remote Sensing of Environment, 154, 358-367. 
Higgins, M. A., Asner, G. P., Perez, E., Elespuru, N., \& Alonso, A. (2014a). Variation in photosynthetic and nonphotosynthetic vegetation along edaphic and compositional gradients in northwestern Amazonia. Biogeosciences, 11(3), 3505-3513.

Higgins, M. A., Asner, G. P., Perez, E., Elespuru, N., Tuomisto, H., Ruokolainen, K., et al. (2012). Use of Landsat and SRTM data to detect broad-scale biodiversity patterns in Northwestern Amazonia. Remote Sensing, 4(8), 2401-2418.

Higgins, M. A., Ruokolainen, K., Tuomisto, H., Llerena, N., Cardenas, G., Phillips, O. L., et al. (2011). Geological control of floristic composition in Amazonian forests. Journal of Biogeography, 38(11): 2136-2149.

Hodgkinson, J. H., Fraser, S. J., \& Donchak, P. Using self-organising maps to derive lithological boundaries from geophysically-derived data in the Mt. Isa region, Queensland. ASEG Extended Abstracts, 2012(1), 1-4.

Hollander, M., Wolfe, D. A., \& Chicken, E. (2013). Nonparametric statistical methods . $3^{\text {rd }}$ ed. New Jersey: John Wiley \& Sons.

Huang, Z., Turner, B. J., Dury, S. J., Wallis, I. R., \& Foley, W. J. (2004). Estimating foliage nitrogen concentration from HYMAP data using continuum removal analysis. Remote Sensing of Environment, 93(1), 18-29.

Hubbell, S. P. (1997). A unified theory of biogeography and relative species abundance and its application to tropical rain forests and coral reefs. Coral reefs, 16(1), S9-S21.

Iwashita, F., Friedel, M. J., \& Fraser, S. J. (2011). Hillslope chemical weathering across Paraná, Brazil: a data mining-GIS hybrid approach.Geomorphology, 132(3), 167-175.

Iwashita, F., Friedel, M. J., Ribeiro, G. F., \& Fraser, S. J. (2012). Intelligent estimation of spatially distributed soil physical properties. Geoderma, 170, 1-10.

Jacquemoud, S., Ustin, S. L., Verdebout, J., Schmuck, G., Andreoli, G., \& Hosgood, B. (1996). Estimating leaf biochemistry using the PROSPECT leaf optical properties model. Remote sensing of environment, 56(3), 194-202.

Jain, A. K. (2010). Data clustering: 50 years beyond K-means. Pattern Recognition Letters, 31(8), 651-666.

Jensen, J. R. (2009). Sensoriamento remoto do ambiente: uma perspectiva em recursos terrestres. $2^{\mathrm{a}}$ ed. Tradução: J. C. N. Epiphanio, A. R. Formaggio, A. R. Santos, B. F. T. Rudorff, C. M. Almeida, \& L. S. Galvão. São José dos Campos: Parêntese. 672p.

Jolliffe, I. T. (1986). Principal component analysis. New York: Springer.

Klink, C. A., \& Machado, R. B. (2005). Conservation of the Brazilian Cerrado. Conservation Biology, 19(3), 707-713.

Kohonen, T. (1982). Self-organized formation of topologically correct feature maps. Biological Cybernetics, 43, 59-69.

Kohonen, T. (1998). The self-organizing map. Neurocomputing, 21, 01-06.

Kohonen, T. (2001). Self-Organizing Maps. $3^{\text {rd }}$ ed. New York: Springer-Verlag. 528p.

Kohonen, T. (2013). Essentials of the self-organizing map. Neural Networks, 37, 52-65.

Kokaly, R. F. (2001). Investigating a physical basis for spectroscopic estimates of leaf nitrogen concentration. Remote Sensing of Environment, 75, 153-161.

Kokaly, R. F. Despain, D. G., Clark, R. N., \& Livo, K. E. (2003). Mapping vegetation in Yellowstone National Park using spectral feature analysis of AVIRIS data. Remote Sensing of Environment, 84, 437-456. 
Kokaly, R. F., \& Clark, R. N. (1999). Spectroscopic determination of leaf biochemistry using band-depth analysis of absorption features and stepwise multiple linear regression. Remote Sensing of Environment, 67(3), 267-287.

Kokaly, R. F., Asner, G. P., Ollinger, S. V., Martin, M. E., \& Wessman, C. A. (2009). Characterizing canopy biochemistry from imaging spectroscopy and its application to ecosystem studies. Remote Sensing of Environment, 113, S78-S91.

Kruckeberg, A. R. (2002). Geology and plant life: the effects of landforms and rock types on plants. Seatle: University of Washington Press. 360p.

Kruse, F. A., Lefkoff, A. B., Boardman, J. W., Heidebrecht, K. B., Shapiro, A. T., Barloon, P. J., \& Goetz, A. F. H. (1993). The spectral image processing system (SIPS)-interactive visualization and analysis of imaging spectrometer data. Remote Sensing of Environment, 44(2-3), 145-163.

Lammoglia, T., \& de Souza Filho, C. R. (2013). Unraveling Hydrocarbon Microseepages in Onshore Basins Using Spectral-Spatial Processing of Advanced Spaceborne Thermal Emission and Reflection Radiometer (ASTER) Data. Surveys in Geophysics, 34(3), 349373.

Lammoglia, T., de Souza Filho, C. R., \& Almeida Filho, R. (2007). Caracterização de microexsudações de hidrocarbonetos na Bacia do Tucano Norte (BA) por geoestatística, classificação hiperespectral e redes neurais. Brazilian Journal of Geology, 37(4), 798811.

Li, L., Ustin, S. L., \& Lay, M. (2005). Application of multiple endmember spectral mixture analysis (MESMA) to AVIRIS imagery for coastal salt marsh mapping: A case study in China Camp, CA, USA. International Journal of Remote Sensing, 26, 5193-5207.

Liesenberg, V., Galvão, L. S., \& Ponzoni, F. J. (2007). Variations in reflectance with seasonality and viewing geometry: implications for classification of Brazilian savanna physiognomies with MISR/Terra data. Remote Sensing of Environment, 107(1), 276-286.

Lopes, A. S. (1984). Solos sob "Cerrado": características, propriedades e manejo. Piracicaba: Associação Brasileira para Pesquisa da Potassa e do Fosfato. 162p.

Major, J. (1975). Geobotany. Ecology, 56, 1465-1465.

Mendonça, R. C., Felfili, J. M., Walter, B. M. T., Silva Júnior, M. C., Rezende, A. V., Filgueiras, T. S., et al. (2008). Flora Vascular do Bioma Cerrado: checklist com 12.356 espécies. In S.M. Sano, S. P. Almeida, \& J. F. Ribeiro (Eds.). Cerrado: ecologia e flora (pp. 421-1279). Planaltina: EMBRAPA-CPAC.

Moreno, M. R., Nascimento, M. T., \& Kurtz, B. C. (2003). Estrutura e composição florística do estrato arbóreo em duas zonas altitudinais na Mata Atlântica de encosta da região do Imbé, RJ. Acta Botanica Brasilica, 17(3), 371-386.

Moser, P., Oliveira, W. L., Medeiros, M. B., Pinto, J. R., Eisenlohr, P. V., Lima, I. L., et al. (2014). Tree Species Distribution along Environmental Gradients in an Area Affected by a Hydroelectric Dam in Southern Amazonia. Biotropica, 46(3), 367-376.

Nascimento, F. S., \& Chen, S. C. (1976). Sensoriamento Remoto Aplicado à Prospecção de Minerais de Zinco no Grupo Bambuí, Baseado em Estudos Geobotânicos. In Congresso Brasileiro de Geologia, 29 (pp.195-205). Ouro Preto, MG.

Oliveira-Filho, A. T., \& Fontes, M. A. L. (2000). Patterns of Floristic Differentiation among Atlantic Forests in Southeastern Brazil and the Influence of Climate. Biotropica, 32(4b), 793-810.

Oliveira-Filho, A. T., Curi, N., Vilela, E. A., \& Carvalho, D. A. (1997). Tree species distribution along soil catenas in a riverside semideciduous forest in southeastern Brazil. Flora, 192(1), 47-64. 
Oliveira-Filho, A. T., Ratter, J. A., \& Shepherd, G. J. (1990). Floristic composition and community structure of a central Brazilian gallery forest. Flora, 184(2), 103-117.

Oliveira-Filho, A. T., Shepherd, G. J., Martins, F. R., \& Stubblebine, W. H. (1989). Environmental factors affecting physiognomic and floristic variation in an area of cerrado in central Brazil. Journal of Tropical Ecology, 5(4), 413-431.

Oliveira-Filho, A. T., Vilela, E. A., Carvalho, D. A., \& Gavilanes, M. L. (1994a). Differentiation of streamside and upland vegetation in an area of montane semideciduous forest in southeastern Brazil. Flora, 189, 287-305.

Oliveira-Filho, A.T., Vilela, E. A, Carvalho, D. A., \& Gavilanes, M. L. (1994b). Effects of soils and topography on the distribution of tree species in a tropical riverine forest in southeastern Brazil. Journal of Tropical Ecology, 10(4), 483-508.

Pacheco, R. C. (2009). Processamento de dados de imagem multiespectral aplicado à geobotânica por sensoriamento remoto: uma abordagem para áreas cobertas por Floresta Atlântica da planície costeira. Dissertação de Mestrado, Faculdade de Filosofia, Letras e Ciências Humanas, Universidade de São Paulo, São Paulo.

Paradella, W. R., \& Vitorello, I. (1995). Geobotanical and soil spectral investigation for rock discrimination in the "Caatinga" environment (Brazil) based on multitemporal remote sensing data. Canadian journal of remote sensing, 21(1), 52-59.

Paradella, W. R., Bignelli, P. A., Veneziani, P., Pietsch, R. W., \& Toutin, T. (1997). Airborne and spaceborne Synthetic Aperture Radar (SAR) integration with Landsat TM and gamma ray spectrometry for geological mapping in a tropical rainforest environment, the Carajás Mineral Province, Brazil. International Journal of Remote Sensing, 18(7), 14831501.

Paradella, W. R., Bruce, W. D., Hornsb, J. K., \& Kushigbor, C. (1989). A Background Geobotany model applied to geologic exploration in tropical forest environments: first results from Landsat-TM and DTM for the Pojuca Cu-Zn deposits, Carajas province, Brazil. In IEEE Geoscience and Remote Sensing Symposium, 1989 (v.4, pp.2511-2513). Vancouver, BC.

Paradella, W. R., Da Silva, M. F. F., \& Rosa, N. D. A. (1994). A geobotanical approach to the tropical rain forest environment of the Carajás Mineral Province (Amazon Region, Brazil), based on digital TM-Landsat and DEM data. International Journal of Remote Sensing, 15(8), 1633-1648.

Pearson K. (1901). LIII. On lines and planes of closest fit to systems of points in space. The London, Edinburgh, and Dublin Philosophical Magazine and Journal of Science, 2(11), 559-572.

Penatti, N. C., \& Almeida, T. I. R. (2012). Subdivision of Pantanal quaternary wetlands: Modis NDVI time-series in the indirect detection of sediments granulometry. ISPRSInternational Archives of the Photogrammetry, Remote Sensing and Spatial Information Sciences, 1, 311-316.

Penn, B. S. (2005). Using self-organizing maps to visualize high-dimensional data. Computers \& Geosciences, 31(5), 531-544.

Perrotta, M. M., Almeida, T. I. R., Andrade, J. B. F., Souza Filho, C. R., Rizzotto, G. J., \& Santos, M. G. M. (2008). Geobotânica por sensoriamento remoto e aerogamaespectrometria aplicados ao mapeamento geológico da Amazônia: um estudo comparativo no vale do Guaporé (MT). Brazilian Journal of Geology, 38(1), 153-166.

Phillips, O. L., Vargas, P. N., Monteagudo, A. L., Cruz, A. P., Zans, M. E. C., Sánchez, W. G., et al. (2003). Habitat association among Amazonian tree species: a landscape-scale approach. Journal of Ecology, 91(5), 757-775. 
Plourde, L. C., Ollinger, S. V., Smith, M. L., \& Martin, M. E. (2007). Estimating species abundance in a northern temperate forest using spectral mixture analysis. Photogrammetric Engineering and Remote Sensing, 73, 829-840.

Ponzoni, F.J., \& Shimabukuro, Y.E. (2007). Sensoriamento remoto no estudo da vegetação, $1^{\mathrm{a}}$ ed. São José dos Campos: Parêntese. 127p.

Pott, A. (1982). Pastagens das sub-regiões dos Paiaguás e da Nhecolândia do Pantanal Mato-Grossense. Corumbá: Embrapa-UEPAE. 49p.

Pott, A., Pott, V. J., \& Damasceno Júnior, G. A. (2009). Fitogeografia do Pantanal. In III Congresso Latino Americano de Ecologia-CLAE, IX Congresso de Ecologia do BrasilCEB. São Lourenço (pp. 1-4).

Prasad, E. A. V. (1987). Geobotany and Biogeochemistry in Mineral Exploration in the Tropics. Journal of Geochemical Exploration, 29, 427-428.

Quesada, C. A., Lloyd, J., Schwarz, M., Patiño, S., Baker, T. R., Czimczik, C., et al. (2010). Variations in chemical and physical properties of Amazon forest soils in relation to their genesis. Biogeosciences, 7(5), 1515-1541.

Raney, F.C. (1966). Geobotany. Ecology, 47, 173-174.

Ratana, P., Ferreira, L., \& Huete, A. (2005). Analysis of Cerrado physiognomies and conversion in the MODIS seasonal-temporal domain. Earth Interactions, 9(3), 1-22.

Ratter, J. A., Ribeiro, J. F., \& Bridgewater, S. (1997). The Brazilian cerrado vegetation and threats to its biodiversity. Annals of Botany, 80(3), 223-230.

Ribeiro, J. F., \& Walter, B. M. T. (2008). As principais fitofisionomias do Bioma Cerrado. In S.M. Sano, S. P. Almeida, \& J. F. Ribeiro (Eds.), Cerrado: ecologia e flora (pp. 153-212). Planaltina: EMBRAPA-CPAC.

Rizzini, C. T. (1997). Tratado de fitogeografia do Brasil: aspectos ecológicos, sociológicos e florísticos, $2^{\underline{a}}$ ed. Rio de Janeiro: Âmbito Cultural. 747p.

Roberts, D. A., Dennison, P. E., Gardner, M., Hetzel, Y. L., Ustin, S. L., \& Lee, C. (2003). Evaluation of the potential of Hyperion for fire danger assessment by comparison to the Airborne Visible Infrared Imaging Spectrometer. IEEE Transactions on Geoscience and Remote Sensing, 41, 1297-1310.

Roberts, D. A., Gamon, J., Keightley, K., Prentiss, D., Reith, E., \& Green, R. O. (1999). AVIRIS land-surface mapping in support of the BOReal Ecosystem-Atmosphere Study (BOREAS). In $8^{\text {th }}$ AVIRIS Earth Science Workshop (pp. 355-364). Pasadena: Jet Propulsion Laboratory.

Roberts, D. A., Gardner, M., Church, R., Ustin, S., Scheer, G., \& Green, R. O. (1998). Mapping Chaparral in the Santa Monica Mountains using multiple endmember spectral mixture models. Remote Sensing of Environment, 65, 267-279.

Roberts, D. A., Ustin, S. L., Ogunjemiyo, S., Greenberg, J., Dobrowski, S. Z., Chen, J. et al. (2004). Spectral and structural measures of northwest forest vegetation at leaf to landscape scales. Ecosystems, 7(5), 545-562.

Rodrigues, R. R., Shepherd, G. J., \& Morellato, L. P. C. (1992). Análise da variação estrutural e fisionômica da vegetação e características edáficas, num gradiente altitudinal na Serra do Japi. In L. P. C. Morelatto (Ed.), História natural da Serra do Japi (pp. 64-96). Campinas: Editora da UNICAMP.

Rosso, P. H., Ustin, S. L., \& Hastings, A. (2005). Mapping marshland vegetation of San Francisco Bay, California, using hyperspectral data. International Journal of Remote Sensing, 26, 5169-5191. 
Roth, K. L., Dennison, P. E. \& Roberts, D. A. (2012). Comparing endmember selection techniques for accurate mapping of plant species and land cover using imaging spectrometer data. Remote Sensing of Environment, 127, 139-152.

Ruggiero, P. G. C., Batalha, M. A, Pivello, V. R., \& Meirelles, S. T. (2002). Soil-vegetation relationships in cerrado (Brazilian savanna) and semideciduous forest, Southeastern Brazil. Plant Ecology, 160, 1-16.

Ruisong, X., \& Yueliang, M. (2004). Remote sensing research in biogeochemistry of the Hetai gold deposit, Guangdong Province, China. International Journal of Remote Sensing, 25(2), 437-453.

Sabins, F. F. (1999). Remote sensing for mineral exploration. Ore Geology Reviews, 14(3), 157-183.

Saldanha, D. L., \& Cunha, M. C. L. (2005). Anomalia geobotânica de reconhecimento e de alvo em área de ocorrência de rochas ultramáficas no Rio Grande do Sul. In Simpósio Brasileiro de Sensoriamento Remoto, 12 (pp.1883-1890). Goiânia, GO.

Sanches, I. D., Souza Filho, C. R., \& Kokaly, R. F. (2014). Spectroscopic remote sensing of plant stress at leaf and canopy levels using the chlorophyll $680 \mathrm{~nm}$ absorption feature with continuum removal. ISPRS Journal of Photogrammetry and Remote Sensing, 97, 111122.

Sanches, I. D., Souza Filho, C. R., Magalhães, L. A., Quiterio, G. C. M., Alves, M. N., \& Oliveira, W. J. (2013a). Unravelling remote sensing signatures of plants contaminated with gasoline and diesel: an approach using the red edge spectral feature. Environmental Pollution, 174, 16-27.

Sanches, I. D., Souza Filho, C. R., Magalhães, L. A., Quitério, G. C. M., Alves, M. N., \& Oliveira, W. J. (2013b). Assessing the impact of hydrocarbon leakages on vegetation using reflectance spectroscopy. ISPRS Journal of Photogrammetry and Remote Sensing, 78, 85-101.

Sanchez, M., Pedroni, F., Eisenlohr, P. V., \& Oliveira-Filho, A. T. (2013). Changes in tree community composition and structure of Atlantic rain forest on a slope of the Serra do Mar range, southeastern Brazil, from near sea level to $1000 \mathrm{~m}$ of altitude. FloraMorphology, Distribution, Functional Ecology of Plants, 208(3), 184-196.

Sano, E. E., Rosa, R., Brito, J. L., \& Ferreira, L. G. (2010). Land cover mapping of the tropical savanna region in Brazil. Environmental monitoring and assessment, 166(1-4), 113-124.

Schaaf, A. N., Dennison, P. E., Fryer, G. K., Roth, K. L., \& Roberts, D. A. (2011). Mapping plant functional types at three spatial resolutions using multiple endmember spectral mixture analysis. GIScience and Remote Sensing, 48, 324-344.

Scudeller, V. V., Martins, F. R., \& Shepherd, G. J. (2001). Distribution and abundance of arboreal species in the atlantic ombrophilous dense forest in Southeastern Brazil. Plant ecology, 152(2), 185-199.

Silva, J. D. S. V., \& Abdon, M. M. (1998). Delimitação do Pantanal brasileiro e suas subregiões. Pesquisa agropecuária brasileira, 33(13), 1703-1711.

Silva, M. F. F., \& Rosa, N. A. (1989). Análise do estrato arbóreo da vegetação sobre jazidas de cobre na Serra dos Carajás. Boletim do Instituto Paraense Emílio Goeldi (Série Botânica), 5, 176-206.

Silva, M. P., Mauro, R., Mourão, G., \& Coutinho, M. (2000). Distribuição e quantificação de classes de vegetação do Pantanal através de levantamento aéreo. Revista Brasileira de Botânica, 23(2), 143-152. 
Sims, D. A., \& Gamon, J. A. (2002). Relationships between leaf pigment content and spectral reflectance across a wide range of species, leaf structures and developmental stages. Remote sensing of environment, 81(2), 337-354.

Sirén, A., Tuomisto, H., \& Navarrete, H. (2013). Mapping environmental variation in lowland Amazonian rainforests using remote sensing and floristic data. International Journal of Remote Sensing, 34(5), 1561-1575.

Smith, K. L., Steven, M. D., \& Colls, J. J. (2004). Use of hyperspectral derivative ratios in the red-edge region to identify plant stress responses to gas leaks. Remote sensing of environment, 92(2), 207-217.

Soares, C. T. (2012). Geobotânica por sensoriamento remoto em florestas de Restinga sobre sedimentos holocênicos, Iguape-SP. Dissertação de Mestrado, Instituto de Geociências, Universidade de São Paulo, São Paulo.

Somers, B., \& Asner, G. P. (2013). Multi-temporal hyperspectral mixture analysis and feature selection for invasive species mapping in rainforests. Remote Sensing of Environment, 136, 14-27.

Somers, B., \& Asner, G. P. (2014). Tree species mapping in tropical forests using multitemporal imaging spectroscopy: Wavelength adaptive spectral mixture analysis. International Journal of Applied Earth Observation and Geoinformation, 31, 57-66.

Somers, B., Asner, G. P., Tits, L., \& Coppin, P. (2011). Endmember variability in spectral mixture analysis: A review. Remote Sensing of Environment, 115(7), 1603-1616.

Souza Filho, C. R., Augusto, V., Oliveira, W. J., \& Lammoglia, T. (2008). Detecção de exsudações de hidrocarbonetos por geobotânica e sensoriamento remoto multi-temporal: estudo de caso no Remanso do Fogo (MG). Revista Brasileira de Geociências, 38(2), 228-243.

Souza Filho, P. W. M., \& Paradella, W. R. (2002). Recognition of the main geobotanical features along the Bragança mangrove coast (Brazilian Amazon Region) from Landsat TM and RADARSAT-1 data. Wetlands Ecology and Management, 10(2), 121-130.

Spearman, C. (1904). General Intelligence, Objectively Determined and Measured. The American Journal of Psychology, 15(2), 201-292.

Spearman, C. (1906). 'Footrule' for measuring correlation. British Journal of Psychology, 1904-1920, 2(1), 89-108.

Suriguga Zhang, J. T., Zhang, B., Chen, J. J., Zhang, Q. D., Tian, S. G., \& Liu, S. J. (2011). Forest community analysis in the Songshan National Nature Reserve of China using selforganizing map. Russian Journal of Ecology, 42, 216-222.

Sztutman, M., \& Rodrigues, R. R. (2002). O mosaico vegetacional numa área de floresta contínua da planície litorânea, Parque Estadual da Campina do Encantado, PariqueraAçu, SP. Revista Brasileira de Botânica, 25(2), 161-176.

Teruiya, R. K., Paradella, W. R., Santos, A. R., Dall'Agnol, R., \& Veneziani, P. (2008). Integrating airborne SAR, Landsat TM and airborne geophysics data for improving geological mapping in the Amazon Region: the Cigano Granite, Carajás Province, Brazil. International Journal of Remote Sensing, 29(13), 3957-3974.

Tits, L., De Keersmaecker, W., Somers, B., Asner, G. P., Farifteh, J., \& Coppin, P. (2012). Hyperspectral shape-based unmixing to improve intra-and interclass variability for forest and agro-ecosystem monitoring. ISPRS Journal of Photogrammetry and Remote Sensing, 74, 163-174.

Trabaquini, K., Formaggio, A. R., \& Galvão, L. S. (2013). Changes in physical properties of soils with land use time in the Brazilian savanna environment. Land Degradation \& Development, 24. DOI: 10.1002/ldr.2222. 
Tuomisto, H., Poulsen, A. D., Ruokolainen, K., Moran, R. C., Quintana, C., Celi, J., \& Cañas, G. (2003b). Linking floristic patterns with soil heterogeneity and satellite imagery in Ecuadorian Amazonia. Ecological Applications, 13(2), 352-371.

Tuomisto, H., Ruokolainen, K., \& Yli-Halla, M. (2003c). Dispersal, environment, and floristic variation of western Amazonian forests. Science, 299(5604), 241-244.

Tuomisto, H., Ruokolainen, K., Aguilar, M., \& Sarmiento, A. (2003a). Floristic patterns along a 43-km long transect in an Amazonian rain forest. Journal of Ecology, 91(5), 743-756.

Underwood, E. C., Mulitsch, M. J., Greenberg, J. A., Whiting, M. L., Ustin, S. L., \& Kefauver, S. C. (2006). Mapping invasive aquatic vegetation in the Sacramento-San Joaquin Delta using hyperspectral imagery. Environmental Monitoring and Assessment, 121, 47-64.

Underwood, E. C., Ustin, S. L., \& Di Pietro, D. (2003). Mapping nonnative plants using hyperspectral imagery, Remote Sensing of Environment, 86, 150-161.

Ustin, S. L., Smith, M. O., Jacquemoud, S., Verstraete, M. M., \& Govaerts, Y. (1999). Geobotany: vegetation mapping for Earth Sciences. In: A. N. Rencz (Org.). Remote sensing for the Earth Sciences, ${ }^{\text {rd }}$ ed. (pp. 189-233). New York: John Wiley and sons.

Vitousek, P., Asner, G. P., Chadwick, O. A., \& Hotchkiss, S. (2009). Landscape-level variation in forest structure and biogeochemistry across a substrate age gradient in Hawaii. Ecology, 90(11), 3074-3086.

Waibel, L. (1948). A vegetação e o uso da terra no Planalto Central. Revista Brasileira de Geografia, 38, 529-554.

Woolley, J. T. (1971). Reflectance and transmittance of light by leaves. Plant Physiology, 47, 656-662.

Youngentob, K. N., Roberts, D. A., Held, A. A., Dennison, P. E., Jia, X., \& Lindenmayer, D. B. (2011). Mapping two Eucalyptus subgenera using multiple endmember spectral mixture analysis and continuum-removed imaging spectrometry data. Remote Sensing of Environment, 115(5), 1115-1128.

Zhang, J., \& Yang, H. (2008). Application of self-organizing neural networks to classification of plant communities in Pangquangou Nature Reserve, North China. Frontiers of Biology in China, 3(4), 512-517. 


\section{DEFINIÇÃO DE GEOAMBIENTES E DE ESPÉCIES ARBÓREAS INDICADORAS EM UM ECOSSISTEMA NEOTROPICAL}

\section{Resumo}

Como suporte à geobotânica em ambientes tropicais, o objetivo desta pesquisa foi definir ambientes geológicos (geoambientes) na Estação Ecológica de Mogi-Guaçu, no sudeste do Brasil, e suas relações com a distribuição de fisionomias lenhosas e espécies arbóreas. A técnica Self-Organizing Maps (SOM) foi aplicada a dados fisicoquímicos do sistema geopedológico, obtidos em campo, a dados de elevação, de base cartográfica, bem como a dados fitossociológicos de campo e fitofisiológicos, obtidos em imagens hiperespectrais. Primeiramente, um inventário da vegetação arbustivo-arbórea foi realizado para definição das fisionomias florestais presentes na área. No interior das 70 unidades amostrais (30 subparcelas de $20 \times 20 \mathrm{~m}$ e 40 subtransectos de $5 \times 10 \mathrm{~m}$ ), além do levantamento da vegetação, foram coletados dados do nível do freático (quando $\leq 2 \mathrm{~m}$ ), amostras de solos e de sedimentos para análise química e textural. O modelo digital de terreno foi desenvolvido a partir de mapa topográfico e pontos de controle. Os dados fitofisiológicos e estruturais do dossel foram obtidos através de Indices espectrais de vegetação gerados em imagens hiperespectrais, do sistema de sensores aeroportados ProSpecTIR-VS. Foram definidos quatro geoambientes na área estudada. Dois sobre rocha sedimentar (Formação Aquidauana) e dois sobre sedimentos quaternários (Depósitos Aluvionares). A vegetação não apresentou variação fisionômica sobre os geoambientes internos ao pacote quaternário e apenas um desses ambientes apresentou espécies associadas. Embora diversos fatores controlem a presença de uma espécie em um determinado ambiente, a granulometria dos sedimentos mostrou-se relevante na formação de microambientes, onde são observadas fisionomias e espécies florestais únicas. 


\subsection{Introdução}

O termo Geobotânica, sugerido pela escola Suíça em 1866 (Fuller, 1920), foi bem definido por Georgius Agrícola em 1556 ao citar haver senescência precoce e nanismo de plantas crescidas sobre corpos de minério (Ustin et al., 1999). A relação das coberturas vegetais com a geologia, a qual influencia tanto os solos como o relevo, é intuitiva. Já no século IV a.C., Teofrasto, discípulo de Aristóteles, citou em seus compêndios sobre botânica a associação de uma espécie a solos sobre rochas calcárias (Kruckeberg, 2002). À luz da literatura moderna, a geobotânica estuda a associação da geologia à variações abruptas ou graduais na estrutura, na florística, na fisiologia ou fenologia das comunidades vegetais. A geobotânica experimentou um renascimento com o advento dos sensoriamento remoto multiespectral. Com a aplicação dessa tecnologia, foi possível inferir características edafogeológicas através do estudo das comunidades vegetais sobrejacentes, como as observadas na Amazônia para predizer propriedades pedológicas (p.ex., Sirén et al., 2013) e geológicas (p.ex., Higgins et al., 2011, 2012 e 2014). Essas aplicações constituem um campo importante para a geologia regional e de exploração e para o planejamento da conservação e do uso do solo. Estudos como esses ainda são incomuns na literatura sobre o bioma Cerrado (savana tropical brasileira), que ocupa cerca de $21 \%$ do território brasileiro e é o maior bioma do país, após a Amazônia (Klink e Machado, 2005).

Eiten (1972) observou que a ocorrência de diferentes fitofisionomias no Cerrado está associada a ambientes geológicos específicos e que os solos do bioma são normalmente senis, profundos, com baixa fertilidade e alta disponidade de alumínio. No entanto, os primeiros estudos que sustentam a presença de correlações significativas entre os parâmetros edáficos e a vegetação de cerrado foram embasados nas propriedades químicas e físicas das primeiras camadas de solos (p.ex., Lopes e Cox, 1977; Goodland e Pollard, 1973). Outros autores, entretanto, ao analisarem solos em maiores profundidades demonstram que as variações da vegetação dos cerrados em áreas de interflúvio podem apresentar ligação com a flutuação sazonal do lençol freático (Oliveira-Filho et al. 1989). O 
mesmo foi observado por Assis et al. (2011) na diferenciação entre formações savânicas e florestais do bioma. Ruggiero et al. (2002), embora não tenham observado relações significantemente diferentes entre as formações de cerrado "sensu lato", descrevem associação de solos mais argilosos e férteis às florestas estacionais semideciduais presentes na paisagem.

A extensão em que as florestas de terras baixas do bioma (matas ciliares ou de galerias) sobem pelas laterais dos vales é variável. Assim, a diferença entre elas e aquelas de terras altas é associada à topografia, ao tipo de rocha e às condições de drenagem (Eiten, 1972). As matas ciliares e matas de galerias também têm sido analisadas em função da miscelânea de fatores edáficos e topográficos que promovem sua heterogeneidade e especialização de habitats pelas comunidades de plantas. Os fundos de vales, onde essas fisionomias geralmente ocorrem, são mosaicos de superfícies geomorfológicas/fácies de ambiente deposicional que incluem canais ativos, planícies de inundação, terraços, leques aluviais, bem como antigos canais de drenagem (cut-off meanders, oxbow lakes, ou "billabongs") e paleodiques marginais (Gregory et al., 1991; Bren, 1993). Dessa forma, aí estão presentes diferentes microambientes, que podem favorecer o estabelecimento de determinadas espécies ou comunidade de plantas. Os limites das áreas ripárias podem se estender além da planície de inundação. Nesse caso, as dimensões da zona de influência de um processo ecológico específico são determinadas por seu padrão espacial e dinâmica temporal únicos (Gregory et al., 1991). Numerosos estudos visaram à análise da relação entre a distribuição de espécies e fatores ambientais nessas florestas, tanto nas de galeria no Brasil central como no domínio das florestas estacionais semideciduais, no sudeste do Brasil. Entretanto, tratam-se de estudos curtos e descritivos que fornecem dados apenas florísticos e fitossociológicos, com pouca ou nenhuma informação ecológica (Oliveira-Filho et al., 1994a e 1994b).

Nos estudos geobotânicos, deve-se considerar que todo sistema é dinâmico e resultado da interação das partes que o constituem: não somente a geologia, que representa a base do sistema edáfico, mas também a pedologia, a geomorfologia, a 
hidrologia, o clima e a biologia. Assim, técnicas de análise multivariada e de mineração de dados são necessárias para analisar esse complexo sistema e identificar a existência de fatores geológicos condicionantes à ocorrência de comunidades vegetais e espécies. Os Self-Organizing Maps (SOM) (Kohonen, 1982 e 2001) representam uma técnica simultânea de mineração de dados e de análise multivariada (Agarwal e Skupin, 2008), bem adaptada à abordagens geobotânicas, mesmo em ambientes complexos (Adamczyk et al., 2013).

Nesse contexto, o objetivo desta pesquisa é analisar e definir geoambientes, bem como suas possíveis relações com a distribuição de fisionomias florestais e espécies arbóreas na Estação Ecológica de Mogi-Guaçu, no Estado de São Paulo, Brasil. Para tanto, pretende-se analisar, de forma integrada, dados fitossociológicos, fitofisiológicos e físicoquímicos do sistema geopedológico, obtidos em campo e a partir de dados cartográficos e de sensoriamento remoto hiperespectral. A possível definição de espécies indicadoras de geoambientes na área de estudo permitirá, no futuro, a análise da distribuição dessas espécies via sensoriamento remoto e seu uso para a predição de variáveis do meio físico no domínio do bioma Cerrado.

\subsection{Materiais e métodos}

\subsubsection{Caracterização florística e fitossociológica das fisionomias florestais}

Inicialmente, foi realizado em campo um extenso reconhecimento dos estratos (fisionomias) da vegetação, considerando a classificação fisionômica do Cerrado de Ribeiro e Walter (2008). Esse trabalho foi auxiliado por análise e fotointerpretação de imagens hiperespectrais ProSpecTIR-VS, com $1 \mathrm{~m}$ de resolução espacial. A amostragem das fisionomias florestais realizada neste estudo é classificada como estratificada seletiva, considerando a estratificação prévia das tipologias florestais e a seleção de subambientes para amostragem. Foram alocadas 10 parcelas de 20x60 m (Figura 3.1). A densidade amostral foi estimada dentro de cada estrato por sua representatividade, por unidade de área. Essas parcelas foram alocadas seletivamente, objetivando a amostragem da 
vegetação sobre variações edafogeológicas ocorrentes dentro de cada estrato. As parcelas foram subdivididas em três subparcelas contíguas de 20x20 m (Figura 3.1). Isso permitiu a amostragem de variações sutis do meio físico, que podem influenciar a densidade e dominância de espécies, aspecto que é fundamental à análise geobotânica. No centro de cada subparcela foram coletados solos com trado $(10 \mathrm{~cm}$ superiores, após a camada de serapilheira -2 coletas) e sedimentos ( $2 \mathrm{~m}$ de profundidade -1 coleta). Também foi medida a profundidade do nível d'água, quando inferior a $2 \mathrm{~m}$. Essas mensurações e coletas foram realizadas na estação seca.

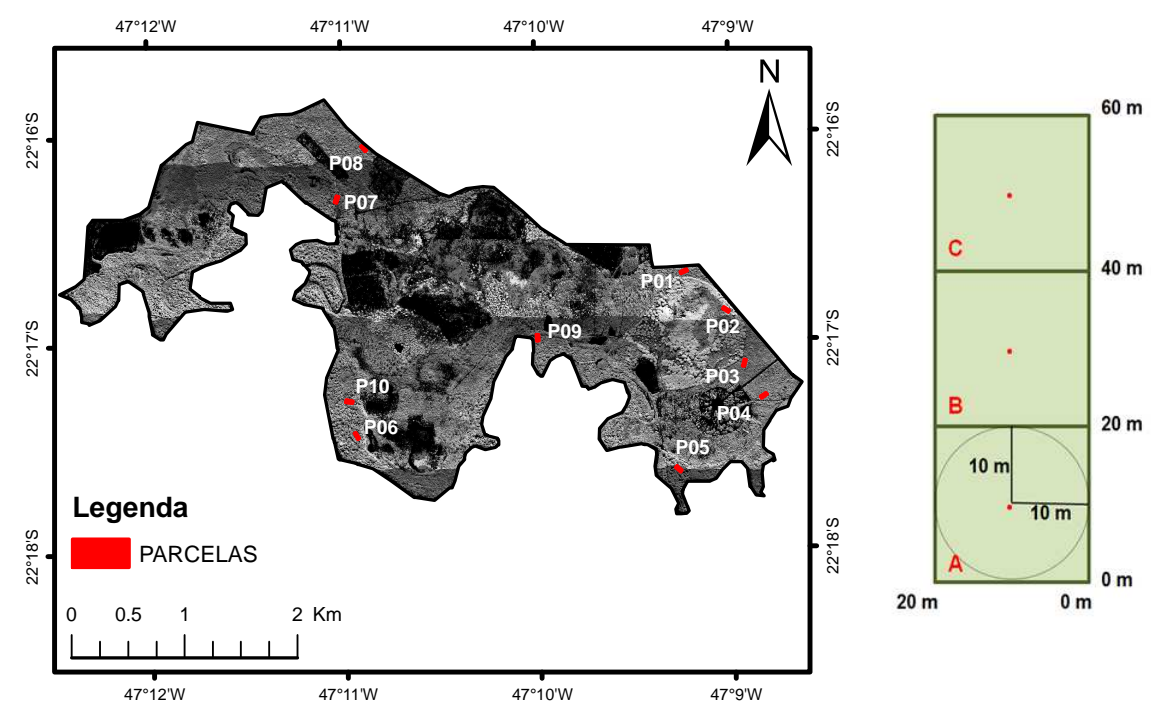

Figura 3.1. Disposição das parcelas de 20x60 m, subdivididas em 3 unidades amostrais de 20x20 m, para amostragem de parâmetros biofisicoquímicos na Estação Ecológica de Mogi-Guaçu.

$\mathrm{Na}$ amostragem do estrato arbustivo-arbóreo da vegetação, o nível de inclusão utilizado foi de diâmetro do tronco (a 1,30 $\mathrm{m}$ de altura) $\geq 5 \mathrm{~cm}$. Foram anotados o diâmetro a 1,30 m de altura, a altura estimada $(H)$, as coordenadas geográficas e a identificação taxonômica de espécies (sistema Angiosperm Phylogeny Group - APG II) para todos os indivíduos arbustivo-arbóreos amostrados. Esses dados serviram para obtenção de parâmetros fitossociológicos de densidade, dominância, freqüência, valor de cobertura (VC) e valor de importância (VI) das espécies amostradas utilizando-se o software FITOPAC 2.1 (Shepherd, 2009). As fitofisionomias foram definidas por suas características estruturais, composição florística e fitossociológica, bem como pelas características ambientais 
associadas às suas ocorrências (Ribeiro e Walter, 2008). Para classificação das fisionomias internas ao contínuo da Floresta Estacional Semidecidual foram consideradas também as classificações utilizadas por Oliveira Filho et al. (1994a e 1994b) e Rodrigues (2000).

Amostras de solos $(10 \mathrm{~cm})$ e de sedimentos $(2 \mathrm{~m})$ foram coletadas no interior das subunidades amostrais e analisadas, de acordo com Camargo et al. (2009), para determinação de teor de matéria orgânica, acidez ativa $(\mathrm{pH})$, fósforo, potássio, cálcio, magnésio, alumínio, acidez potencial $(\mathrm{H}+\mathrm{Al})$, soma de bases, saturação por bases $(\mathrm{V} \%)$ e capacidade de troca catiônica (CTC), bem como da granulometria, conforme classificação apresentada na Tabela 3.1.

Tabela 3.1. Classificação granulométrica de solos e de sedimentos adotada no estudo.

\begin{tabular}{c|c}
\hline Classificação granulométrica & Tamanho do grão (mm) \\
\hline Argila & $<0,002$ \\
\hline Silte & $0,002-0,053$ \\
\hline Areia muito fina & $0,053-0,105$ \\
\hline Areia fina & $0,105-0,210$ \\
\hline Areia média & $0,210-0,50$ \\
\hline Areia grossa & $0,50-1,0$ \\
\hline Areia muito grossa & $1,0-2,0$ \\
\hline
\end{tabular}

\subsubsection{Gradientes da vegetação e do meio físico na floresta estacional semidecidual}

Para analisar as relações entre as variações do meio físico e da vegetação, associadas à dinâmica horizontal do rio Mogi-Guaçu, foi realizada uma amostragem por transectos, também considerada como estratificada seletiva pela seleção prévia de subambientes (e nichos ecológicos) internos ao estrato em questão. Essa abordagem objetivou caracterizar gradientes granulométricos (de sedimentos e de solos) e químicos (de solos), bem como a existência de espécies dominantes ou exclusivas aos diferentes ambientes sedimentares presentes sob o contínuo de floresta estacional semidecidual (FES).

Foram alocados quatro transectos de $5 \times 100 \mathrm{~m}$ (Figura 3.2) perpendiculares ao eixo de meandros abandonados do rio Mogi-Guaçu, permitindo interceptar diferentes fácies sedimentares. O Transecto 1 interceptou paleodique (em área de interflúvio) e paleoleito, o 
Transecto 2, barras de meandro no interior da planície de inundação, o Transecto 3, paleodique marginal e depósitos de rompimento de dique marginal e o Transecto 4, paleodique marginal (na área de interflúvio), ainda sob o contínuo de FES. Esses transectos foram subdivididos em 10 unidades amostrais contíguas, de $5 \times 10 \mathrm{~m}$, para amostragem dos dados do meio físico, no centro, e coleta de dados dendrométricos e identificação taxonômica de espécies, no interior da unidade amostral (Figura 3.2).

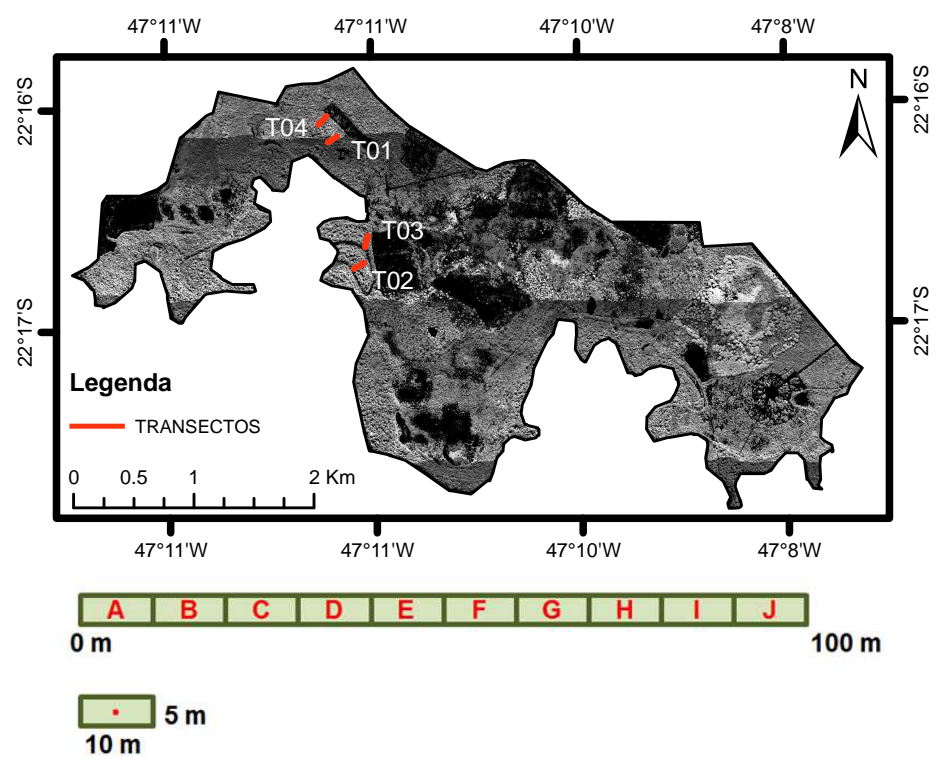

Figura 3.2. Disposição dos transectos de $5 \times 100$ m, subdivididos em 10 unidades amostrais de $5 \times 10$ m, para amostragem de parâmetros biofísicoquímicos, na Estação Ecológica de Mogi-Guaçu.

Os métodos de amostragem da vegetação e dos parâmetros do meio físico foram semelhantes ao da amostragem por parcelas. As análises químicas dos solos coletados nos transectos incluíram os micronutrientes boro, cobre, ferro, manganês e zinco, além dos parâmetros descritos na amostragem por parcelas.

\subsubsection{Aquisição dos dados de elevação e dos índices hiperespectrais de vegetação}

O modelo digital de terreno (MDT) da área de estudo foi gerado a partir da digitalização de curvas de nível, pontos cotados e hidrografia de cartas topográficas na escala 1:10.000. O MDT foi produzido com resolução espacial de $16 \mathrm{~m}$, utilizando-se a ferramenta Topo to Raster no programa ArcGIS 10.2.1 (ESRI - Redlands, CA, EUA). 
Índices hiperespectrais de vegetação, capazes de revelar informações fisiológicas e estruturais da vegetação (Ustin 2008), foram obtidos a partir de imagens ProSpecTIR-VS (SpecTIR - Reno, NV, EUA/ FotoTerra - São Paulo, SP, BRA), no software ENVI 4.8 (Exelis Visual Information Solutions Inc. - Boulder, CO, EUA) (Tabela 3.2). Essas imagens têm 121 bandas entre 400 e $970 \mathrm{~nm}$, com intervalo de amostragem de 2,9 nm, e 236 bandas entre 970 e $2.450 \mathrm{~nm}$, com intervalo de amostragem de 8,5 nm. Dezessete faixas de vôo (lesteoeste) foram adquiridas em 8 de junho de 2010, com resolução espacial de $1 \mathrm{~m}$. Os dados foram transformados para reflectância em superfície pela empresa FotoTerra/SpecTIR, que realizou o levantamento, utilizando código de transferência radiativa MODTRAN4.

Tabela 3.2. Índices espectrais de vegetação extraídos de Ustin (2008) e aplicados nas imagens hiperespectrais da área de estudo.

\begin{tabular}{|c|c|c|}
\hline Índice/equação & Descrição & Referência \\
\hline NDVI $750=(\rho 750-\rho 705) /(\rho 750+\rho 705)$ & Área foliar/ cobertura vegetal & $\begin{array}{c}\text { (Gitelson \& Merzlyak, 1994; Sims \& } \\
\text { Gamon, 2002) }\end{array}$ \\
\hline NDVI $2=(\rho 800-\rho 680) /(\rho 800+\rho 680)$ & $\begin{array}{l}\text { Eficiência de uso da radiação } \\
\text { fotossintética }\end{array}$ & $\begin{array}{c}\text { (Gamon et al., 1997; Pontius et al., } \\
\text { 2008) }\end{array}$ \\
\hline NDWI $=(\rho 857-\rho 1241) /(\rho 857+\rho 1241)$ & \multirow{2}{*}{ Conteúdo de água foliar } & $(\mathrm{Gao}, 1996)$ \\
\hline WBI $=\rho 900 / \rho 970$ & & (Peñuelas et al., 1995) \\
\hline Achl $=\rho 550 / \rho 500$ & \multirow{2}{*}{ Conteúdo de clorofila } & $\begin{array}{c}\text { (Aoki et al.,1981; Pontius et al., } \\
\text { 2008) }\end{array}$ \\
\hline $\mathbf{B N b}=\rho 800 / \rho 550$ & & $\begin{array}{c}\text { (Buschman \& Nagel, 1993; Pontius } \\
\text { et al., 2008) }\end{array}$ \\
\hline CRI 1 = (1/p510) $-(1 / \rho 550)$ & \multirow{2}{*}{$\begin{array}{l}\text { Diferença entre conteúdo de } \\
\text { carotenoides e clorofilas }\end{array}$} & (Gitelson et al., 2002) \\
\hline CRI 2 = (1/p510) $-(1 / \rho 700)$ & & (Gitelson et al., 2002) \\
\hline ARI 1 = (1/p550) $-(1 / \rho 700)$ & \multirow{2}{*}{$\begin{array}{l}\text { Diferença entre conteúdo de } \\
\text { antocianina e clorofilas }\end{array}$} & (Gitelson et al., 2002) \\
\hline ARI $2=\rho 800^{*}((1 / \rho 550)-(1 / \rho 700))$ & & (Gitelson et al., 2002) \\
\hline $\mathbf{C A I}=0.5(\rho 2000+\rho 2200)-\rho 2100$ & $\begin{array}{l}\text { Conteúdo de celulose - } \\
\text { material não fotossintético }\end{array}$ & $\begin{array}{c}\text { (Daughtry, 2001; Daughtry et al., } \\
2004)\end{array}$ \\
\hline
\end{tabular}

\subsubsection{Análise dos dados multivariados no software SiroSOM}

Os Self-Organizing Maps (SOM) (Kohonen, 1982, 2001 e 2013) é um tipo de Artificial Neural Network (ANN) não supervisionado e baseado em quantização vetorial, onde relações estatísticas complexas e não lineares entre dados multivariados de alta dimensionalidade são convertidas em relações geométricas simples, de mais baixa dimensão. A técnica tem apresentado resultados interessantes na mineração de dados de 
alta dimensionalidade e na análise multivariada em estudos de ecologia vegetal (e.g., Foody, 1999; Zhang e Yang, 2008; Suriguga et al., 2011 e Adamczyk et al., 2013). Adamczyk et al. (2013), por exemplo, correlacionaram amostragens temporais quantitativas de espécies com as condições abióticas locais, utilizando SOM. A técnica permitiu explicitar a preferência de espécies por habitats específicos, indicando os fatores abióticos essenciais na formação de comunidades de plantas.

O SOM foi aplicado sobre os dados da presente pesquisa, utilizando-se o software SiroSOM (CSIRO Mineral Resources Flagship - Pullenvale, QLD, AUS). Inicialmente, foram normalizadas as distribuições dos conjuntos de dados inseridos no programa por função logarítima. Vetores (seed-vectors) foram lançados no espaço n-dimensional, definido pelos dados de entrada, e treinados através de quantização vetorial e medidas de similaridade vetorial (distância Euclidiana), para representar a estrutura e os padrões das unidades amostrais. Esse treinamento foi realizado por processo interativo de dois passos, o competitivo (rough training) e o cooperativo (fine training). Esses passos foram aplicados diversas vezes para cada unidade amostral até que o seed-vector vencedor representasse os dados de entrada da melhor forma possível. O mapa 2D de saída apresenta caraterística chave de preservação das relações topológicas relativas entre os vetores-nós. Esses vetores são representados nesse mapa como nós ou best matching units (BMUs). Existem duas métricas de validação do SOM gerado. A primeira é o erro de quantização médio (qe) que, além de ser uma medida de resolução do mapa, indica quão distante dos nós que as representam, estão as unidades amostrais. A segunda medida refere-se ao erro de topologia (te), que traduz a preservação topológica dos dados no mapa 2D.

Subsequentemente, os BMUs foram utilizados na análise de agrupamento K-means e validação via Índice de Davies-Bouldin (Davies e Bouldin, 1979). Esse índice é utilizado pelo SiroSOM para inferir sobre a adequação das diferentes partições de dados, independentemente da técnica de agrupamento utilizada e do número de domínios formados. Quanto menor o Índice de Davies-Bouldin mais natural é considerado o agrupamento. 
Sobre os resultados do SOM foram aplicadas análises por principais componentes APC (Pearson, 1901) e análises de correlação entre as variáveis pelo coeficiente de correlação ranqueada de Spearman (Spearman, 1904 e 1906). Com essas análises, pretende-se analisar as relações entre as variáveis do sistema estudado. As correlações do coeficiente de Spearman $(\rho)$ são consideradas significativas quando $\rho \geq|0.04|$. Valores significativos positivos e negativos indicam, respectivamente, a ocorrência de relações diretamente e inversamente proporcionais entre as variáveis. Acompanhando os valores de $\rho$, são gerados os valores de probabilidade de t-student, como forma de validação do índice. Quanto mais próxima de zero for a probabilidade de t-student, mais simétrica é considerada a distribuição da população analisada.

Os dados de entrada e processamentos realizados no software SiroSOM, para cada objetivo específico, estão listados abaixo e as especificações da geração dos SOM estão apresentados na Tabela 3.3:

Análises 01 a 04 - Definição das subunidades edafogeológicas no contínuo de FES: treinamento do SOM e análise de agrupamento K-means, com validação através do Índice de Davies-Boldin, utilizando dados de granulometria de solos e de sedimentos, de química de solos e de nível do freático, para as 10 subunidades amostrais de cada um dos quatro transectos;

Análise 05 - Definição dos geoambientes por suas composições texturais discriminantes: treinamento do SOM, análise de agrupamento K-means, validação através do Índice de Davies-Boldin e análise por principais componentes (APC), utilizando dados de granulometria de sedimentos das 70 subunidades amostrais (parcelas e transectos);

Análise 06 - Análise de associação entre as fisionomias florestais e os padrões texturais dos sedimentos: treinamento do SOM e análise de agrupamento K-means, com validação pelo Índice de Davies-Boldin, utilizando dados de granulometria de solos e sedimentos, química de solos, nível do freático, altitude (MDT/ $16 \mathrm{~m}$ ), Valor de Cobertura (VC) das espécies ( $f$ dos valores relativos de densidade e dominância de cada espécie) e índices hiperespectrais de vegetação das 30 subparcelas; 
Análise 07 - Seleção de espécies amostradas exclusivamente nos geoambientes definidos e suas relações com as frações texturais de sedimentos: treinamento do SOM, análise de correlação através do coeficiente de correlação ranqueada de Spearman e de distribuição dos dados via t-student, utilizando dados de granulometria de sedimentos e presença/ausência de espécies nas 70 subunidades amostrais (parcelas e transectos).

Tabela 3.3. Especificações da formação dos Self-organizing maps por análise específica.

\begin{tabular}{|c|c|c|c|c|c|c|}
\hline \multirow{2}{*}{ Análise } & \multirow{2}{*}{$\begin{array}{c}\mathrm{N}^{\circ} \text {. de } \\
\text { variáveis }\end{array}$} & \multirow{2}{*}{$\begin{array}{l}\mathbf{N}^{\circ} \text {. de unidades } \\
\text { amostrais }\end{array}$} & \multirow{2}{*}{$\begin{array}{c}\text { Tamanho do } \\
\text { mapa }\end{array}$} & \multirow{2}{*}{$\begin{array}{l}\text { Formato } \\
\text { do mapa }\end{array}$} & \multicolumn{2}{|c|}{$\mathbf{N}^{\circ}$. de interações } \\
\hline & & & & & Rough training & Fine training \\
\hline 01 & 32 & 10 & $4 \times 4$ & sheet & 45 & 900 \\
\hline 02 & 32 & 10 & $4 \times 4$ & sheet & 45 & 900 \\
\hline 03 & 32 & 10 & $4 \times 4$ & sheet & 45 & 900 \\
\hline 04 & 32 & 10 & $4 \times 4$ & sheet & 45 & 900 \\
\hline 05 & 07 & 70 & $7 \times 6$ & sheet & 20 & 400 \\
\hline 06 & 153 & 30 & $7 \times 4$ & sheet & 30 & 600 \\
\hline 07 & 128 & 70 & $7 \times 6$ & sheet & 20 & 400 \\
\hline
\end{tabular}

\subsection{Resultados}

\subsubsection{Definição das fisionomias florestais}

No conjunto das 10 parcelas de $60 \times 20 \mathrm{~m}$ foram amostrados 1.348 indivíduos arbustivo-arbóreos distribuídos em 114 espécies e 38 famílias. As famílias com maior riqueza de espécies foram Myrtaceae (13 espécies) e Fabaceae-Faboideae (8). As espécies com maior Valor de Importância (função da densidade, dominância e frequência relativas das espécies) foram: Gallesia integrifolia (Spreng.) Harms, Alchornea sidifolia Mull. Arg. e Rapanea guianensis Aubl. O índice de diversidade de Shannon-Wiener ( $\left.H^{\prime}\right)$ variou de 1,238 a 2,851 entre as 30 unidades amostrais. As fisionomias florestais definidas a partir da amostragem por parcelas estão descritas na Tabela 3.4. 
Tabela 3.4. Fisionomias florestais amostradas na Estação Ecológica de Mogi-Guaçu, parâmetros fitossociológicos e ambientais de ocorrência. $\mathrm{N}=$ número de indivíduos amostrados, S = riqueza de espécies, H' = Índice de diversidade de Shannon-Wiener, CSS = Cerrado "sensu stricto" e FES = Floresta Estacional Semidecidual.

\begin{tabular}{|c|c|c|c|c|c|c|c|c|c|}
\hline Parcela & $\mathbf{N}$ & $\mathbf{s}$ & $\mathbf{H}^{\prime}$ & $\begin{array}{c}\text { Origem das } \\
\text { espécies }\end{array}$ & $\begin{array}{c}\text { Altura média } \\
\text { do dossel }(\mathrm{m})\end{array}$ & $\begin{array}{c}\begin{array}{c}\text { Forma de } \\
\text { relevo }\end{array} \\
\end{array}$ & $\begin{array}{c}\text { Nível do } \\
\text { freático }(\mathrm{m})\end{array}$ & Fisionomia florestal & $\begin{array}{c}\text { Tipo de mata ciliar } \\
\text { (subdivisão) }\end{array}$ \\
\hline 01 & 137 & 24 & 2,72 & CSS e FES & 8,27 & Colina & $>2,0$ & Cerradão & - \\
\hline 02 & 122 & 17 & 2,10 & $\begin{array}{l}\text { FES, incluindo } \\
\text { espécies aluviais }\end{array}$ & 10,83 & Platô & $\begin{array}{c}1,06(A), 0,83 \\
(B), 0,48(C)\end{array}$ & Mata de galeria inundável & - \\
\hline 03 & 179 & 22 & 2,41 & CSS e FES & 7,82 & Platô & $>2,0$ & Cerradão & - \\
\hline 04 & 171 & 31 & 2,76 & $\begin{array}{l}\text { CSS e FES, rico } \\
\text { em Fabaceae }\end{array}$ & 10,43 & Platô & $>2,0$ & $\begin{array}{l}\text { Transição cerradão/mata } \\
\text { de galeria não inundável }\end{array}$ & - \\
\hline 05 & 105 & 17 & 2,05 & $\begin{array}{l}\text { FES, incluindo } \\
\text { espécies aluviais }\end{array}$ & 13,19 & Planície & $>2,0$ & Mata ciliar & $\begin{array}{l}\text { Terras baixas/com } \\
\text { influência fluvial }\end{array}$ \\
\hline 06 & 139 & 34 & 2,94 & $\begin{array}{l}\text { FES, incluindo } \\
\text { espécies aluviais }\end{array}$ & 11,10 & Planície & $>2,0$ & Mata ciliar & $\begin{array}{l}\text { Terras baixas/com } \\
\text { influência fluvial }\end{array}$ \\
\hline 07 & 120 & 32 & 3,05 & $\begin{array}{c}\text { FES, apenas } \\
\text { espécies } \\
\text { submontanas }\end{array}$ & 12,06 & Colina & $>2,0$ & Mata ciliar & $\begin{array}{l}\text { Terras altas/sem } \\
\text { influência fluvial }\end{array}$ \\
\hline 08 & 119 & 31 & 2,70 & CSS e FES & 9,98 & Colina & $>2,0$ & Cerradão & - \\
\hline 09 & 134 & 14 & 1,54 & $\begin{array}{l}\text { FES, incluindo } \\
\text { espécies aluviais }\end{array}$ & 11,13 & Planície & $\begin{array}{l}1,90(A), 1,30 \\
(B), 1,20(C)\end{array}$ & Mata ciliar & $\begin{array}{l}\text { Terras baixas/com } \\
\text { influência fluvial }\end{array}$ \\
\hline 10 & 122 & 25 & 2,57 & $\begin{array}{l}\text { FES, incluindo } \\
\text { espécies aluviais }\end{array}$ & 11,76 & Planície & $>2,0$ & Mata ciliar & $\begin{array}{l}\text { Terras baixas/com } \\
\text { influência fluvial }\end{array}$ \\
\hline
\end{tabular}


Observa-se que a textura dos sedimentos e solos variou de muito argilosa a francaarenosa. O nível do fretático na estação seca variou de 0,48 a $>2,0 \mathrm{~m}$. O pH dos solos variou de 3,2 a 5,5, a acidez potencial $(\mathrm{H}+\mathrm{Al})$ de 25,0 a $429,0 \mathrm{mmolc} / \mathrm{dm}^{3}$, a soma de bases (SB) de 3,6 a 132,2 mmolc/ $\mathrm{dm}^{3}$, a capacidade de troca catiônica (CTC) de 21,7 a 440,4 mmolc/dm ${ }^{3}$ e a percentagem de saturação por bases da CTC a pH 7,0 (V\%) de 3,0 a 79,0\%. A lista de espécies amostradas e seus dados fitossociológicos estão apresentados no Apêndice A e os dados integrais de fertilidade de solos e de granulometria de solos e de sedimentos, no Apêndice B.

\subsubsection{Variações geoedáficas sob a floresta estacional semidecidual}

Após a análise dos resultados obtidos nas parcelas, quatro transectos foram alocados em áreas classificadas como mata ciliar no interior da FES, considerando a variabilidade de microambientes e nichos ecológicos observados nesse contínuo florestal. Foram gerados de dois a quatro domínios de unidades amostrais por transecto, associados a diferentes ambientes com granulometrias dominantes (Tabela 3.5).

No total dos quatro transectos de $5 \times 100 \mathrm{~m}$ foram amostrados 193 indivíduos, pertencentes a 52 espécies e 24 famílias botânicas. O Índice de Shannon-Winer foi de 3,594, indicando a alta diversidade do conjunto de dados. As espécies com maior Valor de Importância (VI) foram Gallesia integrifolia (Spreng.) Harms, Cyclolobium vecchii A. Samp. Ex Hoehne, Copaifera langsdorffii Desf., Trichilia catigua A. Juss. e Alchornea sidifolia Mull. Arg. As três primeiras apresentaram alto VI pela maior significância de suas dominâncias relativas (DoRel). Trichilia catigua A. Juss. e Alchornea sidifolia Mull. Arg. foram elencadas, respectivamente, em função de sua maior densidade relativa (DeRel) e dos três parâmetros equilibradamente (DeRel, DoRel e frequência relativa - FrRel). Os sedimentos sobre o contínuo de FES variaram de franco-arenoso a muito-argiloso. Os dados integrais da vegetação e do meio físico, obtidos nos transectos, estão apresentados nos Apêndices A e $\mathrm{B}$, respectivamente. 
Tabela 3.5. Definição dos geoambientes sob o contínuo de Floresta Estacional Semidecidual observados na amostragem por transectos. qe = erro de quantização; te = erro de topologia.

\begin{tabular}{|c|c|c|c|c|c|}
\hline Transecto & Domínio & Geologia & Relevo & $\begin{array}{c}\text { Principais frações } \\
\text { granulométricas }\end{array}$ & Geoambiente \\
\hline \multirow{3}{*}{$\begin{array}{c}01 \\
(q e=2,01 \\
\text { te }=0,0)\end{array}$} & $\mathrm{A} / \mathrm{B} / \mathrm{C} / \mathrm{D}$ & $\begin{array}{c}\text { Formação } \\
\text { Aquidauana }\end{array}$ & Colina & $\begin{array}{l}\text { Argila, Areia media e } \\
\text { Areia grossa }\end{array}$ & Paleodique erodido \\
\hline & E & $\begin{array}{c}\text { Depósitos } \\
\text { aluvionares }\end{array}$ & Encosta & $\begin{array}{c}\text { Argila, Silte e Areia } \\
\text { grossa }\end{array}$ & Terço inferior da encosta \\
\hline & $\mathrm{F} / \mathrm{G} / \mathrm{H} / \mathrm{I} / \mathrm{J}$ & $\begin{array}{l}\text { Depósitos } \\
\text { aluvionares }\end{array}$ & Planície & Argila e Silte & Meandro abandonado \\
\hline \multirow{4}{*}{$\begin{array}{c}02 \\
(q e=2,73 \\
\text { te }=0,0)\end{array}$} & $\mathrm{A} / \mathrm{D} / \mathrm{G}$ & $\begin{array}{l}\text { Depósitos } \\
\text { aluvionares }\end{array}$ & Planície & $\begin{array}{c}\text { Silte, Areia muito fina } \\
\text { e Areia fina }\end{array}$ & $\begin{array}{l}\text { Depósito de barra de } \\
\text { meandro }\end{array}$ \\
\hline & $\mathrm{B} / \mathrm{H} / \mathrm{I} / \mathrm{J}$ & $\begin{array}{l}\text { Depósitos } \\
\text { aluvionares }\end{array}$ & Planície & $\begin{array}{l}\text { Argila, Silte, Areia } \\
\text { muito fina e Areia } \\
\text { fina }\end{array}$ & $\begin{array}{l}\text { Depósito de barra de } \\
\text { meandro }\end{array}$ \\
\hline & C & $\begin{array}{l}\text { Depósitos } \\
\text { aluvionares }\end{array}$ & Planície & $\begin{array}{l}\text { Argila, Silte e Areia } \\
\text { muito fina }\end{array}$ & $\begin{array}{l}\text { Depósito de barra de } \\
\text { meandro }\end{array}$ \\
\hline & $E / F$ & $\begin{array}{c}\text { Depósitos } \\
\text { aluvionares }\end{array}$ & Planície & $\begin{array}{c}\text { Areia muito fina, } \\
\text { Areia fina e Areia } \\
\text { média }\end{array}$ & $\begin{array}{l}\text { Depósito de barra de } \\
\text { meandro }\end{array}$ \\
\hline \multirow{2}{*}{$\begin{array}{c}03 \\
(q e=2,58 \\
\text { te }=0,0)\end{array}$} & $\mathrm{A} / \mathrm{B} / \mathrm{C} / \mathrm{D} / \mathrm{E}$ & $\begin{array}{c}\text { Depósitos } \\
\text { aluvionares }\end{array}$ & Planície & $\begin{array}{c}\text { Silte, Areia muito } \\
\text { fina, Areia fina e } \\
\text { Areia média }\end{array}$ & $\begin{array}{l}\text { Depósito de dique } \\
\text { marginal }\end{array}$ \\
\hline & $\mathrm{F} / \mathrm{G} / \mathrm{H} / \mathrm{/} / \mathrm{J}$ & $\begin{array}{l}\text { Depósitos } \\
\text { aluvionares }\end{array}$ & Planície & $\begin{array}{l}\text { Silte, Areia muito fina } \\
\text { e Areia fina }\end{array}$ & $\begin{array}{c}\text { Depósito de rompimento } \\
\text { de dique marginal }\end{array}$ \\
\hline \multirow{3}{*}{$\begin{array}{c}04 \\
(q e=3,18 \\
\text { te }=0,0)\end{array}$} & $A / D$ & $\begin{array}{l}\text { Formação } \\
\text { Aquidauana }\end{array}$ & Colina & $\begin{array}{l}\text { Argila, Areia média e } \\
\text { Areia grossa }\end{array}$ & Paleomargem erodida \\
\hline & $\mathrm{B} / \mathrm{G} / \mathrm{H} / \mathrm{l} / \mathrm{J}$ & $\begin{array}{l}\text { Formação } \\
\text { Aquidauana }\end{array}$ & Colina & $\begin{array}{l}\text { Argila, Areia média e } \\
\text { Areia grossa }\end{array}$ & Paleomargem erodida \\
\hline & $\mathrm{C} / \mathrm{E} / \mathrm{F}$ & $\begin{array}{l}\text { Formação } \\
\text { Aquidauana }\end{array}$ & Colina & $\begin{array}{l}\text { Argila, Areia média e } \\
\text { Areia grossa }\end{array}$ & Paleomargem erodida \\
\hline
\end{tabular}

\subsubsection{Definição dos geoambientes da área de estudo}

Uma vez estudadas as variações internas ao contínuo de FES, principalmente aquelas relacionadas ao sistema fluvial meandrante dentro do pacote de sedimentos quaternários, todas as subunidades amostrais foram agrupadas para definição dos geoambientes (fácies) presentes na EEMG. O primeiro treinamento vetorial (rough training) do SOM foi realizado com 20 interações e o segundo (fine training) com 400 interações. Um erro de quantização médio de 0,644 e um erro topográfico de 0,00 foram atingidos na formação do SOM. As components plots, que indicam as contribuições de cada variável à formação dos nós no espaço 2D, revelaram as associações entre as classes texturais nas 70 unidades amostrais (subparcelas e subtransectos) (Figura 3.3). Essas indicaram dissimilaridades entre as frações silte e areia média e entre as frações areia muito fina e areia grossa e muito grossa, principalmente. A matriz $U$ demonstrou similaridades entre os nós formados com as unidades amostrais dos terrenos do Carbonífero e do Quaternário. 
Esses terrenos foram claramente diferenciados por nós dissimilares. A análise de agrupamento do SOM revelou a presença de sete domínios (Figura 3.3 e Tabela 3.6), os quais refletem as principais fácies geológicas observadas na área de estudo.

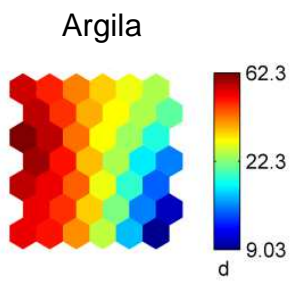

Areia fina

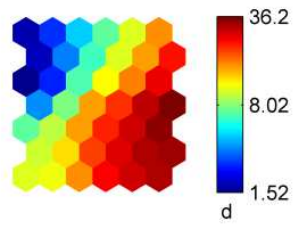

Areia muito grossa

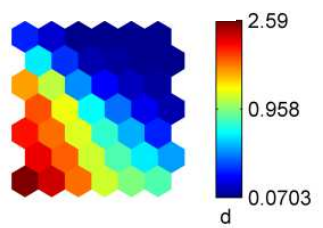

Silte

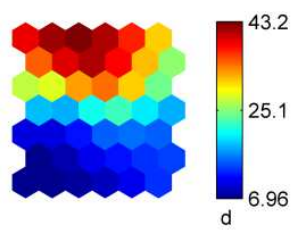

Areia média

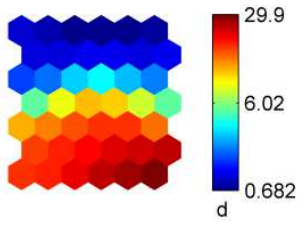

Matriz U

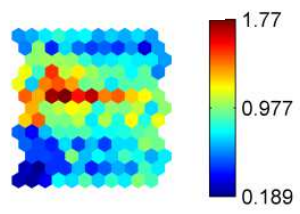

Areia muito fina

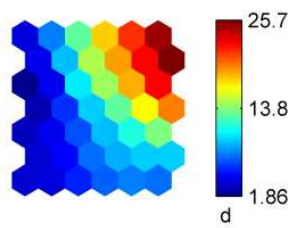

Areia grossa

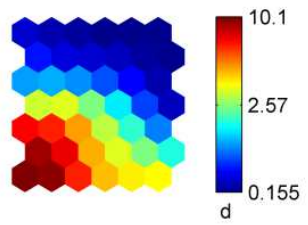

Mapa auto-organizado em domínios

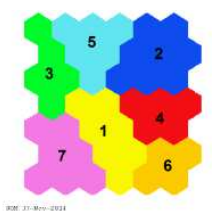

Figura 3.3. Contribuições das frações granulométricas à formação dos nós no SOM, representação em matriz U e mapa auto-organizado, colorido pelos sete domínios formados. Estes resultados resumem a estrutura dos dados nas 70 unidades amostrais. As sete componentes (variáveis) são apresentadas em cor-temperatura variando do menor (azul) ao maior valor (vermelho) observado. A Matriz U, também em cor-temperatura, representa as similaridades (azul-verde) e dissimilaridades (laranja-vermelho) entre nós adjacentes. 
Tabela 3.6. Domínios formados para o SOM de dados granulométricos de sedimentos das 70 unidades amostrais e definição dos geoambientes.

\begin{tabular}{|c|c|c|c|c|}
\hline Domínio & Unidades amostrais & $\begin{array}{l}\text { Principais frações } \\
\text { granulométricas }\end{array}$ & Geologia & Geoambiente/fácies \\
\hline 01 & $\begin{array}{c}\mathrm{P} 1(\mathrm{~A} / \mathrm{B} / \mathrm{C}), \mathrm{P} 3(\mathrm{~A} / \mathrm{B} / \mathrm{C}), \mathrm{P} 4 \\
(\mathrm{~A} / \mathrm{B}), \mathrm{P} 8(\mathrm{~A} / \mathrm{B} / \mathrm{C})\end{array}$ & $\begin{array}{c}\text { Areia fina, Areia } \\
\text { média e Areia grossa }\end{array}$ & $\begin{array}{c}\text { Formação } \\
\text { Aquidauana }\end{array}$ & Platô e Colina \\
\hline 02 & $\begin{array}{c}\mathrm{P} 5(\mathrm{~A} / \mathrm{B}), \mathrm{P} 9(\mathrm{~B}), \mathrm{P} 10(\mathrm{C}) \\
\mathrm{T} 2(\mathrm{~A} / \mathrm{C} / \mathrm{G}), \mathrm{T3} \\
(\mathrm{A} / \mathrm{B} / \mathrm{E} / \mathrm{F} / \mathrm{G} / \mathrm{H} / \mathrm{J})\end{array}$ & $\begin{array}{c}\text { Silte, Areia muito fina } \\
\text { e Areia fina }\end{array}$ & $\begin{array}{l}\text { Depósitos } \\
\text { Aluvionares }\end{array}$ & $\begin{array}{l}\text { Planície - depósitos de barra } \\
\text { de meandro, de planície de } \\
\text { inundação e de rompimento } \\
\text { de dique marginal }\end{array}$ \\
\hline 03 & $\begin{array}{c}\mathrm{P} 6 \text { (B/C), P9 (B/C), T1 } \\
(\mathrm{E} / \mathrm{F} / \mathrm{G} / \mathrm{H} / / / \mathrm{J})\end{array}$ & Argila e Silte & $\begin{array}{r}\text { Dep } \\
\text { Aluvi }\end{array}$ & $\begin{array}{l}\text { Planície - depósitos de } \\
\text { planície de inundação }\end{array}$ \\
\hline 04 & P4 (C), P5 (C), T2 (B/D/E) & $\begin{array}{c}\text { Areia muito fina, } \\
\text { Areia fina e Areia } \\
\text { média }\end{array}$ & $\begin{array}{l}\text { Depósitos } \\
\text { Aluvionares }\end{array}$ & $\begin{array}{l}\text { Planície - depósitos de barra } \\
\text { de meandro e de dique } \\
\text { marginal, principalmente }\end{array}$ \\
\hline 05 & $\begin{array}{c}\text { P6 (A), P10 (A/B), T2 } \\
\text { (H///J), T3 (C/D/ll) }\end{array}$ & Argila e Silte & $\begin{array}{l}\text { Depósitos } \\
\text { Aluvionares }\end{array}$ & $\begin{array}{l}\text { Planície - depósitos de barra } \\
\text { de meandro e de planície de } \\
\text { inundação, principalmente }\end{array}$ \\
\hline 06 & $\mathrm{P} 2(\mathrm{~A} / \mathrm{B} / \mathrm{C}), \mathrm{T} 2(\mathrm{~F})$ & $\begin{array}{l}\text { Areia fina e Areia } \\
\text { média }\end{array}$ & $\begin{array}{c}\text { Formação } \\
\text { Aquidauana }\end{array}$ & Platô, principalmente \\
\hline 07 & $\begin{array}{l}\text { P7 (A/B/C), T1 (A/B/C/D), } \\
\text { T4 (A/B/C/D/E/F/G/H/l/J) }\end{array}$ & $\begin{array}{l}\text { Argila, Areia média, } \\
\text { Areia grossa e Areia } \\
\text { muito grossa }\end{array}$ & $\begin{array}{l}\text { Formação } \\
\text { Aquidauana }\end{array}$ & $\begin{array}{l}\text { Colina (borda) - paleodique } \\
\text { erodido }\end{array}$ \\
\hline
\end{tabular}

Aplicada a análise por principais componentes sobre o SOM, a distribuição dos scores no espaço 2D (PC1 e PC2) demostra que, dentre os domínios formados, existem quatro ambientes bem definidos (Figura 3.4). Dois desses ambientes estão associados aos sedimentos quaternários (I e II) e os outros dois à Formação Aquidauana (III e IV): Depósitos de planície de inundação, principalmente, que incluem aqueles em meandros abandonados, com scores negativo na PC1 e positivo na PC2 (I); depósitos de diques marginais e de barras de meandro, com scores negativos na PC1 e na PC2 (II); colinas e platôs, com scores positivo na PC1 e negativo na PC2 (III); e bordas convexas de colina, caracterizadas como paleodiques erodidos pelo rio Mogi-Guaçu, com scores positivos na PC1 e na PC2 (IV). Os scores da PC1, assim, associam sinal negativo aos depósitos sedimentares do Quaternário e sinal positivo aos solos formados sobre a Formação Aquidauana. Fato que é significante, considerando que a PC1 concentra, por definição, a informação mais dominante ou redundante. 


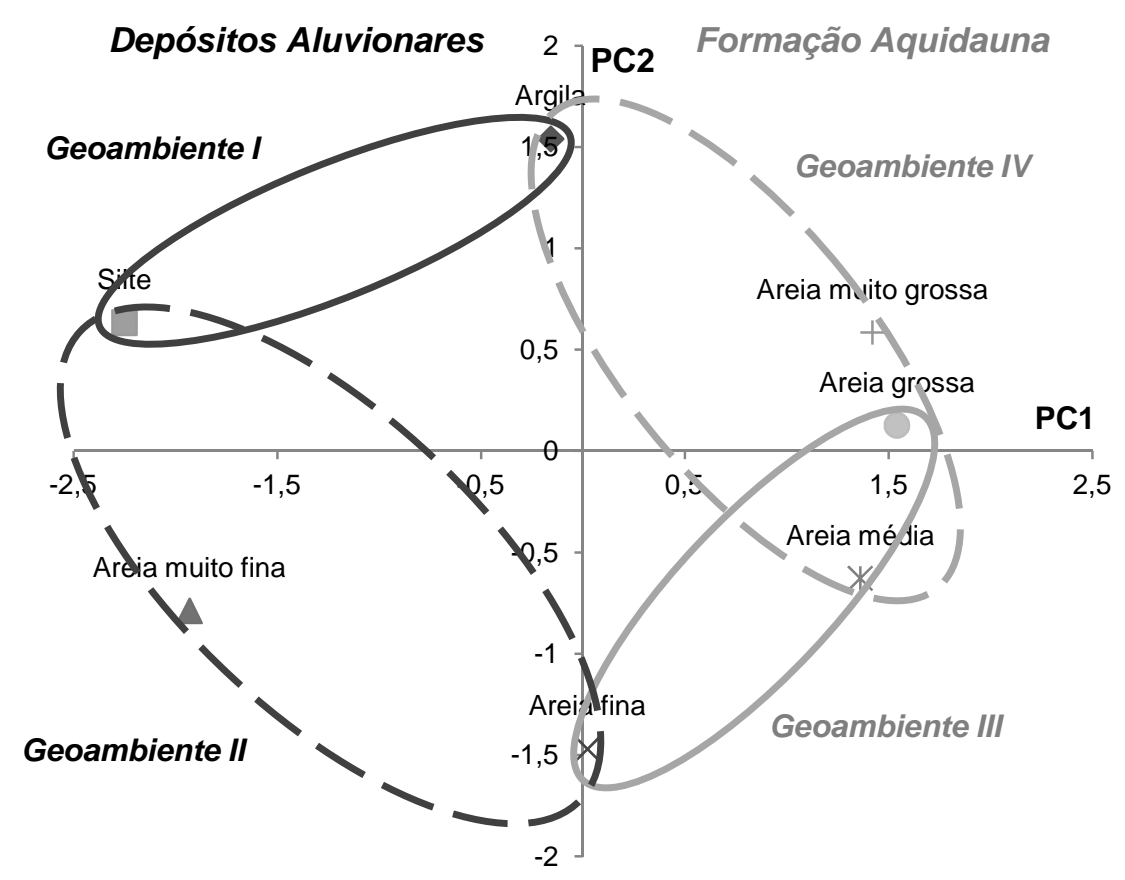

Figura 3.4. Distribuição dos scores das frações granulométricas de sedimentos nas componentes principais (PC1 e PC2) e discriminação dos principais geoambientes da Estação Ecológica de MogiGuaçu.

A Figura 3.5 sintetiza a cartografia esquemática das fitofisionomias, da estratigrafia, do relevo e drenagens e dos quatro principais geoambientes descritos abaixo, de acordo com seus dados edafogeológicos:

Geoambiente I. Solos hidromórficos, mal drenados e com saturação por base variável, em consonância com os diferentes níveis de inundação. Os sedimentos são essencialmente pelíticos (argila e silte) e apresentam presença insignificante a nula da fração areia. É a planície ordinária de inundação do rio meandrante, incluindo fácies de barras de meandros e meandros abandonados, que formam sistemas fluviolacustres durante as cheias. Ocorre até a cota $570 \mathrm{~m}$.

Geoambiente II. Representa os depósitos de diques marginais, fácies de barras de meandros e bordas da planície ordinária de inundação, onde os solos são mais bem drenados e os sedimentos são formados essencialmente pelas frações silte, areia muito fina e areia fina. Seus limites caracterizam o limite do pacote quaternário. Ocorre até a cota 573 m (a leste) e $570 \mathrm{~m}$ (a oeste). 
Geoambiente III. Solos profundos, bem drenados e em sua maioria distróficos, com textura dominada pelas frações areia fina, areia média e areia grossa. Destaca-se dos outros geoambientes pela presença discriminante nos sedimentos das frações areia fina e areia média e baixa presença (a nula) das frações silte, areia muito fina e areia muito grossa. Ocorre nas colinas e platôs sobre a Formação Aquidauana, nas regiões de interflúvio. De acordo com o nível do leito normal do rio (que corre de leste para oeste na área), pode ocorrer a partir de 573 m (à leste) e a partir de 570 m (à oeste).

Geoambiente IV. Solos mais rasos que os demais, bem drenados que, além da fração argila, apresentam frações discriminantes de areia média, areia grossa e areia muito grossa. Destaca-se dos demais geoambientes pela presença significativa das frações areia grossa e areia muito grossa e presença insignificante a nula das frações areia muito fina e silte. Ocorre nas bordas da Formação Aquidauna, nas regiões de declividade mais acentuada, aproximadamente entre as cotas 575 e $585 \mathrm{~m}$, e inclui diques (e paleodiques) convexos, erodidos por solapamento pelo rio Mogi-Guaçu.

No mapa da Figura 3.5-D, a área denominada "Geoambiente I e II" compreende aspectos mistos desses ambientes. O Geoambiente I é formado onde a velocidade do fluxo d'água é menor, dando origem localmente a ambientes lacustres, com deposição de sedimentos ricos em argila e silte. O Geoambiente II é caracterizado por fácies de barras de meandros e depósitos de diques e paleodiques marginais, onde a velocidade do fluxo d'água é maior e promove a deposição das frações silte, areia muito fina e fina (frações mais grossas que aquelas observadas no Geoambiente I). 

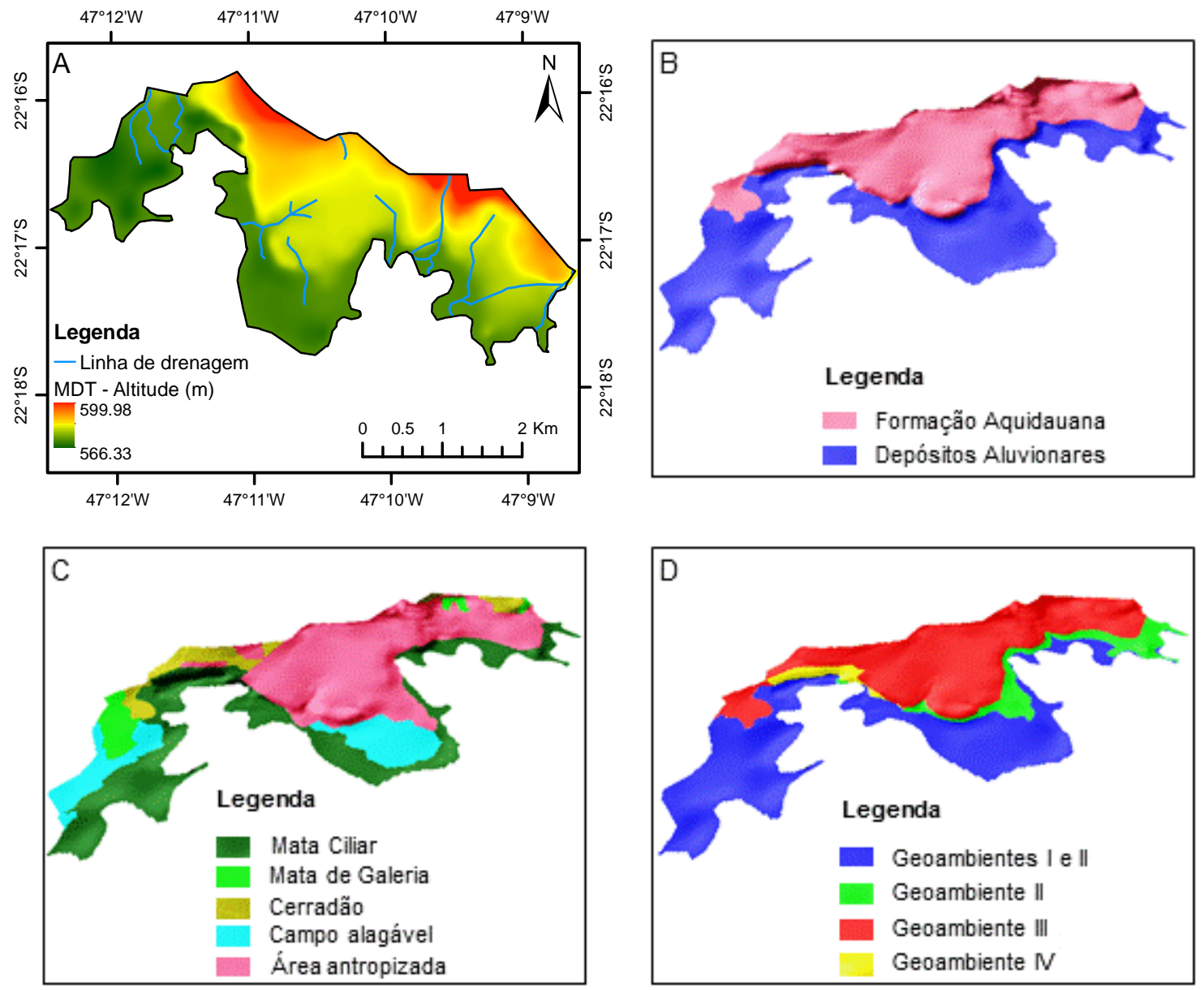

Figura 3.5. Representações gráficas esquemáticas da elevação do terreno e linhas de drenagem (A), em duas dimensões, e da geologia local (B), da cobertura da terra (C) e dos geoambientes (D), em três dimensões, na Estação Ecológica de Mogi-Guaçu.

\subsubsection{Relações entre as fisionomias florestais e a textura dos sedimentos}

O conjunto de variáveis (granulometria de solos e sedimentos, fertilidade de solos, nível do freático, valor de cobertura de espécies, altitude e índices espectrais de vegetação), que indica os subsistemas ecológicos presentes na área de estudo, permite verificar se a ocorrência das fisionomias florestais é relacionável aos geoambientes e aos padrões texturais diagnósticos de seus sedimentos; ou se outros parâmetros do meio físico estão mais fortemente ligados à ocorrência das fisionomias estudadas, descaracterizando a relação testada. Com base nas múltiplas variáveis que devem compor os subsistemas da área, cinco domínios foram definidos (Tabela 3.7). Um erro de quantização médio de 8,69 e um erro topográfico de 0,00 foram atingidos na geração do SOM. A alta variabilidade interna dos domínios, considerando as variáveis utilizadas, especialmente os 114 valores de 
cobetura de espécies, podem explicar o alto erro de quantização. Diversas espécies generalistas de FES Submontana podem ocorrer em todas as fisionomias florestais estudadas. A composição granulométrica dos sedimentos dos domínios formados (Figura 3.6) indicou que diferentes fitofisionomias se associam a diferentes padrões texturais, passíveis de diferenciação e classificação por esse parâmetro isoladamente. Ou seja, independentemente da inclusão de dados referentes à fertilidade e textura dos solos, nível do freático, altitude, cobertura de espécies e índices hiperespectrais, as fisionomias florestais demostraram relação direta com os geoambientes definidos.

Tabela 3.7. Domínios das 30 subparcelas, obtidos pelo menor índice Davies-Bouldin, sobre os resultados do SOM aplicados aos dados de granulometria de solos e sedimentos, fertilidade de solos, nível do lençol freático, altitude, valor de cobertura de espécies e índices hiperespectrais de vegetação.

\begin{tabular}{|c|c|c|c|c|c|}
\hline Domínio & $\begin{array}{l}\text { Unidades } \\
\text { amostrais }\end{array}$ & Fisionomia florestal & Geologia & Geoambientes & $\begin{array}{c}\text { Frações } \\
\text { granulométricas } \\
\text { diagnósticas }\end{array}$ \\
\hline 01 & $\begin{array}{l}\mathrm{P} 1(\mathrm{~A} / \mathrm{B} / \mathrm{C}) \\
\mathrm{P} 4(\mathrm{~A})\end{array}$ & $\begin{array}{c}\text { Cerradão (CRD), } \\
\text { Transição Cerradão - } \\
\text { Mata de galeria não } \\
\text { inundável (CRD-MGNI) }\end{array}$ & $\begin{array}{l}\text { Formação } \\
\text { Aquidauna }\end{array}$ & $\begin{array}{l}\text { Colinas e platôs } \\
\text { (iii) }\end{array}$ & $\begin{array}{l}\text { Argila, Areia fina } \\
\text { e Areia média }\end{array}$ \\
\hline 02 & $\begin{array}{c}\mathrm{P} 2(\mathrm{~A} / \mathrm{B} / \mathrm{C}) \\
\mathrm{P} 8(\mathrm{~B})\end{array}$ & $\begin{array}{c}\text { Mata de galeria } \\
\text { inundável (MGI), } \\
\text { Cerradão }\end{array}$ & $\begin{array}{l}\text { Formação } \\
\text { Aquidauna }\end{array}$ & $\begin{array}{l}\text { Colinas e platôs } \\
\text { (iii) }\end{array}$ & $\begin{array}{l}\text { Argila, Areia fina } \\
\text { e Areia média }\end{array}$ \\
\hline 03 & $\begin{array}{l}\mathrm{P} 3(\mathrm{~A} / \mathrm{B} / \mathrm{C}) \\
\mathrm{P} 4(\mathrm{~B} / \mathrm{C})\end{array}$ & $\begin{array}{l}\text { Cerradão, Transição } \\
\text { Cerradão - Mata de } \\
\text { galeria não inundável }\end{array}$ & $\begin{array}{l}\text { Formação } \\
\text { Aquidauna }\end{array}$ & $\begin{array}{c}\text { Colinas e platôs } \\
\text { (iii) }\end{array}$ & $\begin{array}{l}\text { Argila, Areia fina } \\
\text { e Areia média }\end{array}$ \\
\hline 04 & $\mathrm{P} 8(\mathrm{~A} / \mathrm{C})$ & Cerradão & $\begin{array}{l}\text { Formação } \\
\text { Aquidauna }\end{array}$ & $\begin{array}{l}\text { Colinas e platôs } \\
\text { (iii) }\end{array}$ & $\begin{array}{l}\text { Argila, Areia fina } \\
\text { e Areia média }\end{array}$ \\
\hline 05 & $\mathrm{P} 7(\mathrm{~A} / \mathrm{B} / \mathrm{C})$ & $\begin{array}{l}\text { Mata ciliar de terras } \\
\text { altas, sem influência } \\
\text { fluvial (MCTA) }\end{array}$ & $\begin{array}{l}\text { Formação } \\
\text { Aquidauna }\end{array}$ & $\begin{array}{l}\text { Bordas de colina } \\
\text { - paleodique } \\
\text { erodido (iv) }\end{array}$ & $\begin{array}{c}\text { Argila, Areia } \\
\text { média, Areia } \\
\text { grossa e Areia } \\
\text { muito grossa } \\
\end{array}$ \\
\hline 06 & $\mathrm{P} 5(\mathrm{~A} / \mathrm{B} / \mathrm{C})$ & $\begin{array}{l}\text { Mata ciliar de terras } \\
\text { baixas, com influência } \\
\text { fluvial (MCTB) }\end{array}$ & $\begin{array}{l}\text { Depósitos } \\
\text { Aluvionares }\end{array}$ & $\begin{array}{l}\text { Depósitos de } \\
\text { dique marginal (ii) }\end{array}$ & $\begin{array}{l}\text { Areia muito fina e } \\
\text { Areia fina }\end{array}$ \\
\hline 07 & $\begin{array}{l}\mathrm{P} 6(\mathrm{~A} / \mathrm{B} / \mathrm{C}) \\
\mathrm{P} 10(\mathrm{~A} / \mathrm{B} / \mathrm{C})\end{array}$ & $\begin{array}{c}\text { Mata ciliar de terras } \\
\text { baixas, com influência } \\
\text { fluvial }\end{array}$ & $\begin{array}{l}\text { Depósitos } \\
\text { Aluvionares }\end{array}$ & $\begin{array}{l}\text { Depósitos de } \\
\text { planície de } \\
\text { inundação (i) }\end{array}$ & Argila e Silte \\
\hline 08 & $\mathrm{P} 9(\mathrm{~A} / \mathrm{B} / \mathrm{C})$ & $\begin{array}{l}\text { Mata ciliar de terras } \\
\text { baixas, com influência } \\
\text { fluvial (MCTB) }\end{array}$ & $\begin{array}{l}\text { Depósitos } \\
\text { Aluvionares }\end{array}$ & $\begin{array}{l}\text { Depósitos de } \\
\text { planície de } \\
\text { inundação (i) }\end{array}$ & Argila e Silte \\
\hline
\end{tabular}




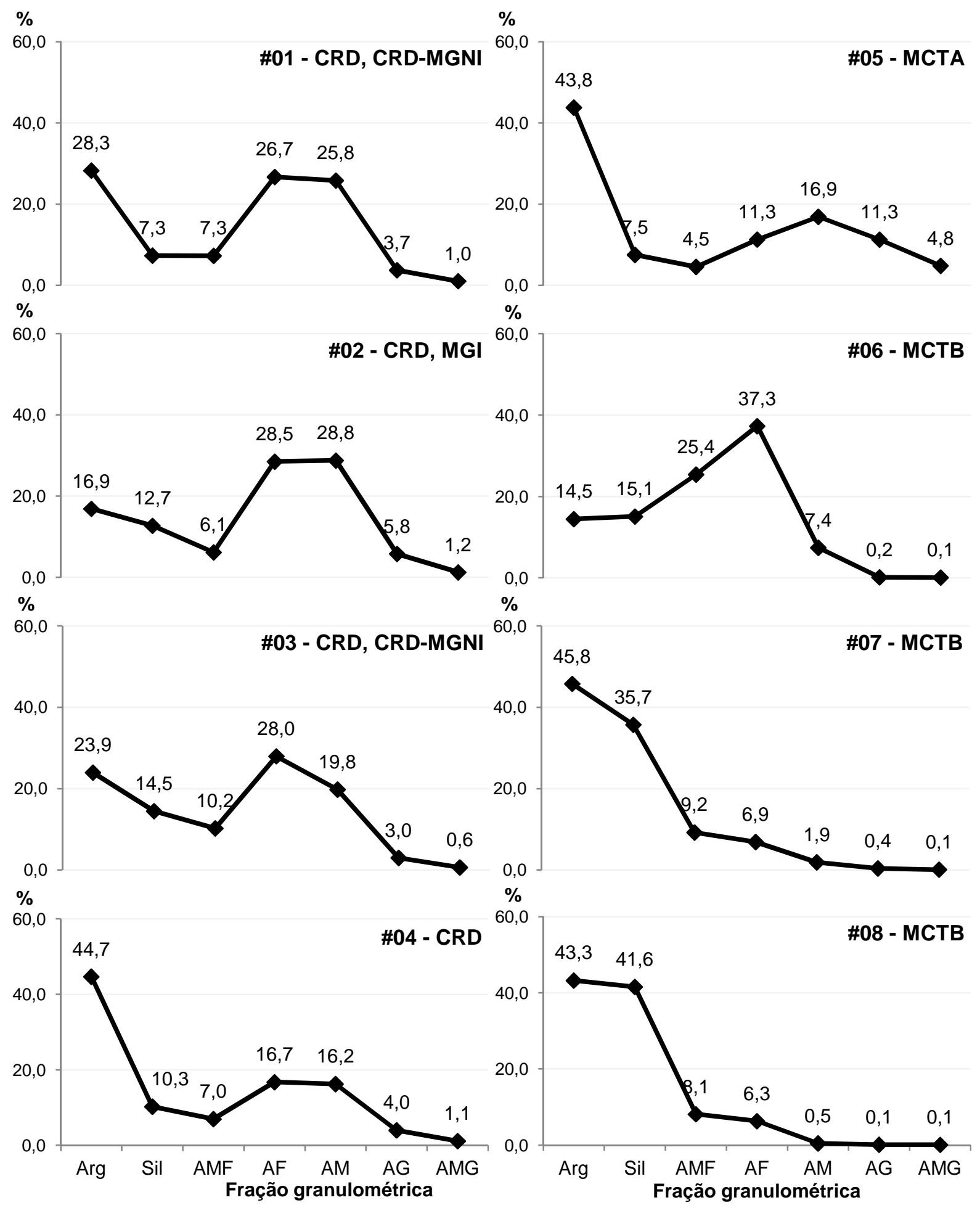

Figura 3.6. Composição granulométrica dos sedimentos dos domínios formados sobre o SOM baseado nos dados de granulometria de solos e sedimentos, fertilidade de solos, nível do freático, valor de cobertura de espécies, dados altitudinais e índices hyperespectrais de vegetação das 30 subparcelas, na Estação Ecológica de Mogi-Guaçu. Arg = Argila, Sil = Silte, AMF = Areia muito fina, $A F=$ Areia fina,$A M=$ Areia média, $A G=$ Areia grossa, $A M G=$ Areia muito grossa, $C R D=$ Cerradão, $M G(N) I=$ Mata de galeria (não) inundável, $M C(T A$ ou $T B)=$ Mata ciliar (de terras altas ou de terras baixas). 
Considerando a granulometria dos sedimentos contidos nos geoambientes é possível sugerir que os cerradões e as matas de galeria (domínios 1 a 4, geoambiente III) e a mata ciliar sem influência fluvial (de terras altas) (domínio 5, geoambiente IV) estão associados à Formação Aquidauana, que apresenta teores discriminantes das frações areia média, areia grossa e areia muito grossa. Já a mata ciliar com influência fluvial (de terras baixas) associa-se aos sedimentos quaternários, indicados pelos altos teores de silte, depositado nas planícies de inundação e paleoleitos (domínios 7 e 8, geoambiente I), e areia muito fina e fina, depositadas nos diques marginais e barras de meandro (domínio 6, geoambiente II). Os geoambientes internos às formações geológicas somente apresentam fisionomias discriminantes quando relacionados à Formação Aquidauana. Cerradões e matas de galeria, sobre as colinas e platôs, indicam alto teor de areia fina e areia média (geoambiente III). Mata ciliar sem influência fluvial (terras altas), nas áreas em que aflora, próximo ao contato com o Quaternário, indicam uma fácies com alto teor da fração areia grossa e muito grossa (geoambiente IV). Esses dois geoambientes estão associados aos baixos teores de silte e areia muito fina.

\subsubsection{Definição de espécies indicadoras dos geoambientes}

Embora quatro geoambientes tenham sido bem definidos, apenas três apresentam espécies associadas na amostragem realizada:

Geoambiente I) Sedimentos quaternários, associados à planície de inundação, incluindo meandros abandonados, com sedimentos argilossiltosos. Nesse ambiente ocorrem espécies de FES Submontana e Aluvial, sendo as seguintes associadas a esse geoambiente:

I-a) Calophyllum brasiliense Cambess.: espécie observada apenas nos paleoleitos inundáveis nos meses de cheia, no interior da mata ciliar. Amostrada com alta densidade nas subunidades amostrais $\mathrm{P} 10-\mathrm{B}, \mathrm{P} 10-\mathrm{C}$ e $\mathrm{T} 1-\mathrm{H}$. Apresenta correlação positiva com a fração silte dos sedimentos e correlação negativa com as frações areia fina, areia média, areia grossa e areia muito grossa (Figura 3.7 e Tabela 3.8). 
I-b) Inga vera Willd. subsp. affinis (DC.) T.D. Penn.: espécie amostrada nas subunidades amostrais P6-A, P6-B, P10-B, P10-C, T1-E, T1-F, T1-I e T2-G. Ocorre na mata ciliar em ambientes sazonalmente brejosos e densamente presente em alguns paleoleitos. Apresenta correlação positiva nos sedimentos com a fração silte e negativa com as frações areia fina, areia média, areia grossa e areia muito grossa (Figura 3.7 e Tabela 3.8).

Geoambiente III) Áreas de interflúvios, colinas e platôs na Formação Aquidauana, que apresentam sedimentos com predominância das frações areia fina, média e grossa e baixa concentração da fração silte. Nesse ambiente restringem-se as espécies arbustivo-arbóreas de Cerrado "sensu stricto", entre as quais:

III-a) Qualea grandiflora Mart.: espécie comum no Cerrado, observada nas subunidades amostrais $\mathrm{P} 1-\mathrm{A} / \mathrm{B}, \mathrm{P} 3-\mathrm{A} / \mathrm{B} / \mathrm{C}$ e $\mathrm{P} 8-\mathrm{A} / \mathrm{B} / \mathrm{C}$ (Cerradões). Apresenta, na área de estudo, correlação positiva com as frações areia fina e areia média dos sedimentos e correlação negativa com a fração silte (Figura 3.7 e Tabela 3.8).

III-b) Tabebuia ochracea (Cham.) Standl.: espécie presente apenas em áreas de Cerrado, observada nas subunidades amostrais P3-A e P8-A (Cerradões), bem como em diversas áreas de regeneração de Cerrado. Apresenta correlação positiva com as frações areia fina e areia média e correlações negativas com a fração silte (Figura 3.7 e Tabela 3.8).

Geoambiente IV Bordas locais da Formação Aquidauana, onde afloram rochas dessa unidade geológica em diques e paleodiques erodidos pelo rio Mogi-Guaçu, sem deposição de sedimentos (NW da área de estudo). Destacam-se pela presença das frações de areia grossa e muito grossa - praticamente nulas nos sedimentos dos outros geoambientes bem como baixa quantidade das frações silte e areia fina. A maior parte das espécies observadas nesse ambiente é de FES Submontana. Raramente são observadas espécies arbóreas de Cerrado e não há presença de espécies de FES Aluvial. As espécies definidas como indicadoras desse ambiente, por apresentarem ocorrência exclusiva na amostragem, são:

IV-a) Cedrela fissilis Vell.: espécie presente nas subunidades amostrais P7-C, T1-C, T1-D, T4-A, T4-B, T4-E, T4-J, bem como observada em outras áreas no contínuo de FES, fora da 
planície de inundação. Apresenta correlação positiva com as frações areia muito grossa, grossa e média e negativa com as frações silte e areia fina presentes nos sedimentos (Figura 3.7 e Tabela 3.8).

IV-b) Zeyheria tuberculosa (Vell.) Bureau: espécie presente apenas na mata ciliar sem influência fluvial (de terras altas), nas subunidades amostrais P7-A, P7-B, P7-C, T1-A e T4C, bem como observada em outras áreas não amostradas, mas ainda no contínuo dessa fisionomia. Apresenta correlação positiva com as frações areia muito grossa, areia grossa e argila; e negativa com as frações de sedimentos silte e areia fina (Figura 3.7 e Tabela 3.8).

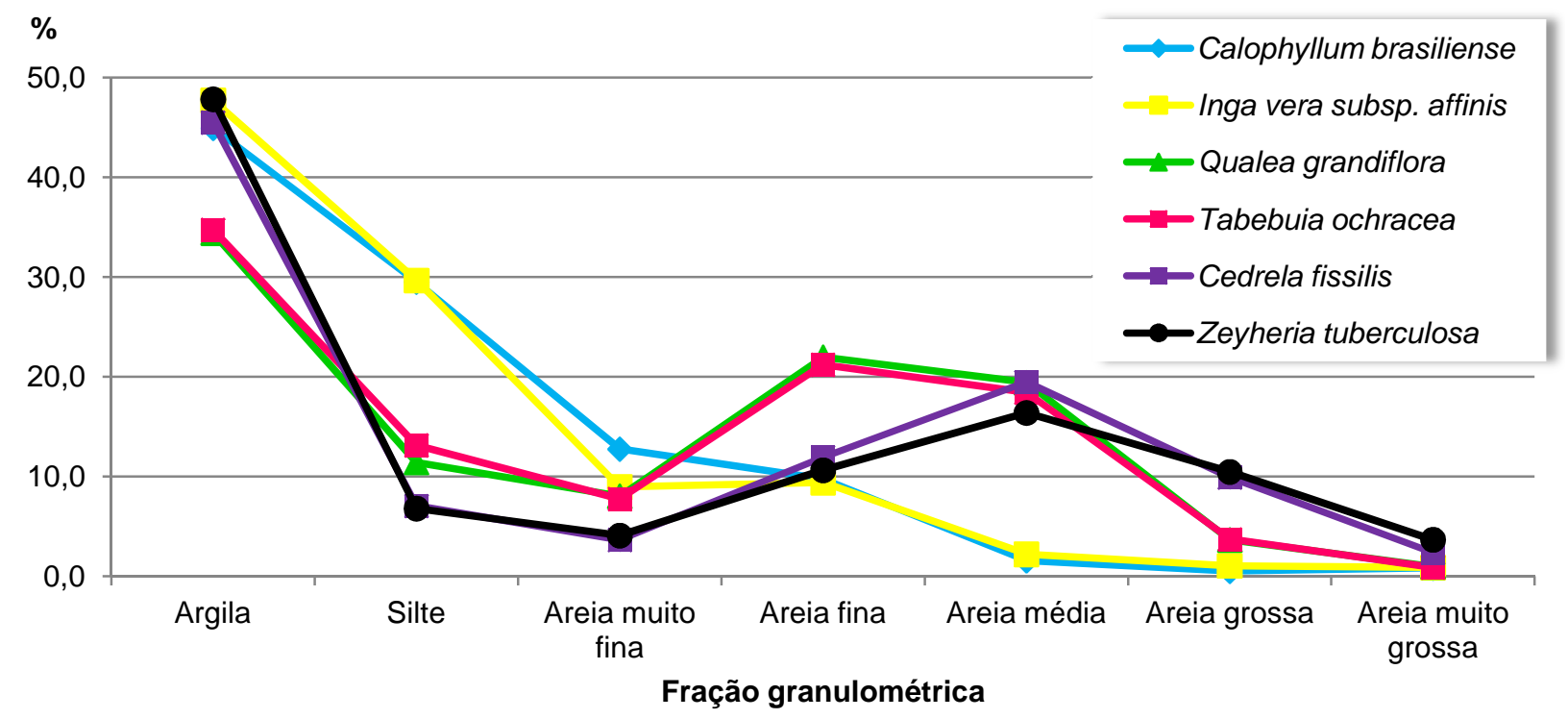

Figura 3.7. Padrões texturais dos sedimentos sob as espécies indicadoras dos geoambientes na Estação Ecológica de Mogi-Guaçu.

A Tabela 3.8 indica que as espécies associadas ao Geoambiente I (C. brasiliense e I. vera subsp. affinis) apresentam correlação negativa com as frações granulométricas discriminantes dos Geoambientes III e IV (Areias fina a muito grossa, Formação Aquidauana). Já as espécies associadas aos Geoambientes III (Q. grandiflora e $T$. ochracea) e IV (C. fissilis e Z. tuberculosa) apresentam correlação negativa com as frações discriminantes dos Geoambientes I e II (silte para o Geoambiente I e II e areia muito fina para o Geoambiente II). O valor de t-student próximo a zero indica que a população amostrada apresenta distribuição normal. 
Tabela 3.8. Coeficiente de correlação de Spearman $(\rho)$, onde $-0.4 \geq \rho \geq 0.4$ indica a existência de correlação, e probabilidade de t-student, entre as espécies selecionadas e as frações granulométricas dos sedimentos da Estação Ecológica de Mogi-Guaçu.

\begin{tabular}{|c|c|c|c|c|c|}
\hline \multicolumn{6}{|c|}{ Calophyllum brasiliense } \\
\hline \multicolumn{3}{|c|}{ Correlação positiva } & \multicolumn{3}{|c|}{ Correlação negativa } \\
\hline Fração granulométrica & $\rho$ & t-student & Fração granulométrica & $\rho$ & t-student \\
\hline \multirow[t]{4}{*}{ Silte } & 0,709 & 0,000 & Areia fina & $-0,727$ & 0,000 \\
\hline & & & Areia média & $-0,624$ & 0,000 \\
\hline & & & Areia grossa & $-0,583$ & 0,000 \\
\hline & & & Areia muito grossa & $-0,416$ & 0,006 \\
\hline \multicolumn{6}{|c|}{ Inga vera subsp. affinis } \\
\hline \multicolumn{3}{|c|}{ Correlação positiva } & \multicolumn{3}{|c|}{ Correlação negativa } \\
\hline Fração granulométrica & $\rho$ & t-student & Fração granulométrica & $\rho$ & t-student \\
\hline \multirow[t]{4}{*}{ Silte } & 0,688 & 0,000 & Areia fina & $-0,656$ & 0,000 \\
\hline & & & Areia média & $-0,626$ & 0,000 \\
\hline & & & Areia grossa & $-0,614$ & 0,000 \\
\hline & & & Areia muito grossa & $-0,491$ & 0,001 \\
\hline \multicolumn{6}{|c|}{ Qualea grandiflora } \\
\hline \multicolumn{3}{|c|}{ Correlação positiva } & \multicolumn{3}{|c|}{ Correlação negativa } \\
\hline Fração granulométrica & $\rho$ & t-student & Fração granulométrica & $\rho$ & t-student \\
\hline Areia fina & 0,660 & 0,000 & Silte & $-0,485$ & 0,001 \\
\hline Areia média & 0,583 & 0,000 & & & \\
\hline \multicolumn{6}{|c|}{ Tabebuia ochracea } \\
\hline \multicolumn{3}{|c|}{ Correlação positiva } & \multicolumn{3}{|c|}{ Correlação negativa } \\
\hline Fração granulométrica & $\rho$ & t-student & Fração granulométrica & $\rho$ & t-student \\
\hline Areia fina & 0,634 & 0,000 & Silte & $-0,483$ & 0,001 \\
\hline Areia média & 0,568 & 0,000 & & & \\
\hline \multicolumn{6}{|c|}{ Cedrela fissilis } \\
\hline \multicolumn{3}{|c|}{ Correlação positiva } & \multicolumn{3}{|c|}{ Correlação negativa } \\
\hline Fração granulométrica & $\underline{p}$ & t-student & Fração granulométrica $r$ & $\rho$ & t-student \\
\hline Areia muito grossa & 0,796 & 0,000 & Silte & $-0,632$ & 0,000 \\
\hline Areia grossa & 0,737 & 0,000 & Areia muito fina & $-0,558$ & 0,000 \\
\hline Areia média & 0,503 & 0,001 & & & \\
\hline \multicolumn{6}{|c|}{ Zeyheria tuberculosa } \\
\hline \multicolumn{3}{|c|}{ Correlação positiva } & \multicolumn{3}{|c|}{ Correlação negativa } \\
\hline Fração granulométrica & $\rho$ & t-student & Fração granulométrica & $\rho$ & t-student \\
\hline Areia muito grossa & 0,917 & 0,000 & Areia muito fina & $-0,619$ & 0,000 \\
\hline Areia grossa & 0,720 & 0,000 & Silte & $-0,547$ & 0,000 \\
\hline Argila & 0,576 & 0,000 & & & \\
\hline
\end{tabular}

\subsection{Discussão}

Foram observadas relações similares entre as unidades amostrais, quando realizados os SOM e os agrupamentos, utilizando apenas os dados granulométricos de sedimentos, e também utilizando diferentes variáveis do sistema estudado. Por um lado, essa observação pode ser diretamente relacionado ao que fez Kruckeberg (2002), que descobriu que a geologia tem um profundo efeito sobre a distribuição das espécies. Por outro lado, a constatação pode estar relacionada com a observação de que a geologia é parte de um conjunto de parâmetros que definem, com maior ou menor intensidade, diferentes ambientes. Obviamente, cada um deles é composto de um sistema. Assim, não é 
apenas a granulometria de sedimentos que leva à ocorrência de uma dada espécie, mas um sistema no qual essa variável é um fator determinante para formação de microambientes, onde são observadas fisionomias e espécies associadas. Cabe ressaltar a importância da textura dos substratos. O tamanho dos grãos influencia diretamente sua agregação, sua saturação por água e por solutos, bem como sua fertilidade (adsorção catiônica).

$\mathrm{Na}$ área de estudo as matas ciliares com influência fluvial (de terras baixas) estão associadas ao pacote sedimentar do Quaternário. Na planície ordinária de inundação, onde os sedimentos são essencialmente pelíticos, foram encontradas espécies não amostradas em nenhum outro geoambiente da área de estudo. Essas espécies, de FES Aluvial, são Inga vera subsp. affinis e Calophyllum brasiliense, que toleram sazonalmente as condições adversas de ambientes fluviolacustres, desencadeadas também pela composição argilossiltosa dos sedimentos (Figura 3.8). Ambas as espécies são descritas na literatura como sendo tolerantes a ambientes inundados e brejosos (p.ex., Oliveira Filho et al.,1990; Oliveira Filho et al.,1994a), sendo assim higrófitas seletivas. No entanto, outras características ecológicas, não vinculadas ao meio edáfico, devem ser levadas em consideração na análise de distribuição dessas espécies. $C$. brasiliense é espécie tolerante à sombra (Oliveira Filho et al.,1994a), considerada de sucessão secundária/ intermediária tardia (Durigan e Nogueira, 1990) e secundária tardia (Oliveira Filho et al.,1994a). Assim, na área de estudo, essa espécie tem distribuição restrita aos paleoleitos mais antigos no interior da mata ciliar. Já I. vera subsp. affinis é heliófita, considerada sucessionalmente como pioneira (Oliveira Filho et al.,1994a). Assim, deve ocupar, além dos paleoleitos de formação mais recente, clareiras no interior da mata, bordas e campos alagados. Essa espécie pode também ser encontrada pontualmente fora do pacote Quaternário, onde há inundação sazonal e deposição de materiais finos (sedimentos pelíticos), como na beira de lagoas e em linhas de drenagem secundárias. 


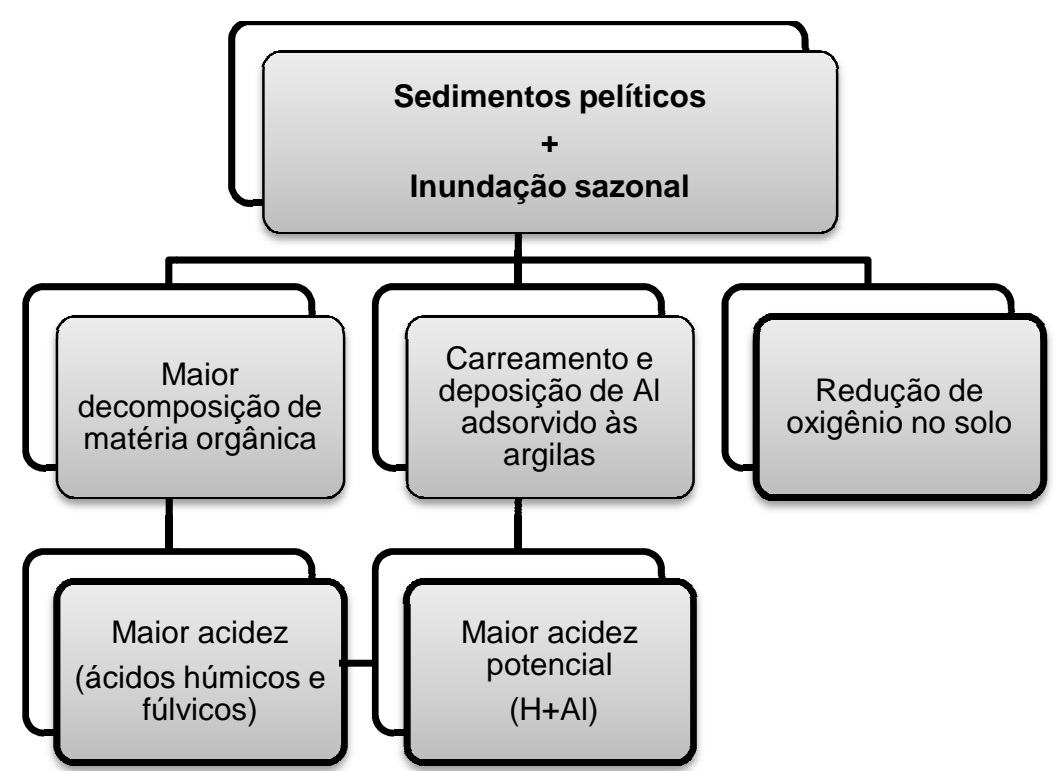

Figura 3.8. Fatores condicionantes à colonização de espécies em ambientes sazonalmente inundados.

Embora observada em altas concentrações nos sedimentos analisados, a fração argila não foi considerada discriminante, por não apresentar valores discrepantes entre os ambientes geológicos e as fitofisionomias estudadas. De acordo com Milani et al. (2007) a Formação Aquidauana se caracteriza por pacotes arenosos que gradam para seções argilosas, sendo aí comuns intercalações de lamitos seixosos. Esse fato explica os altos valores de argila encontrados também nos solos sob cerradões e sob a mata ciliar sem influência fluvial.

A Formação Aquidauana apresentou dois geoambientes associados a duas fisionomias discriminantes. Os cerradões ocorrem onde os solos são mais profundos e intemperizados, compostos pelas frações argila e areias fina, média e grossa. Essas frações estão associadas às áreas de interflúvio, colinas e platôs da EEMG. As espécies Qualea grandiflora e Tabebuia ochracea foram amostradas apenas nos cerradões e podem indicar o geoambiente em questão. A composição granulométrica média dos solos sobre cerrados é pouco variável. Lopes (1984) encontrou uma composição global de 49,2\% da fração argila, $8,5 \%$ de silte e $42,3 \%$ de areias para diferentes tipos de solos - composição semelhante à observada na área de estudo, principalmente para as frações silte e areia. Medina e Grohmann (1966) também observaram valores semelhantes, correlacionando a textura dos 
solos à disponibilidade hidrica observada nos cerrados. Q. grandiflora é observada em diversas fisionomias de cerrado "sensu lato", de savânicas à florestal (Cerradão) (Medonça et al., 2008) e não apresenta diferenças em abundância e padrão espacial entre fisionomias (Costa e Santos, 2011). T. ochracea também é observada em diversas fisionomias de cerrado (Carvalho, 2003). Assim, na EEMG, além de suas ocorrências nos cerradões, essas espécies também são observadas em áreas antropizadas em regeneração, mas sempre nos interflúvios (colinas e platôs), sobre a Formação Aquidauana.

A mata ciliar sem influência fluvial (de terras altas) ocupa faixa mais estreita da borda da Formação Aquidauna, que inclui dique e paleodique convexos do rio Mogi-Guaçu que sofreram erosão por solapamento, com afloramento das rochas sedimentares em barrancas altas. Os solos sobre essa fisionomia são mais rasos que os demais e, além da fração argila, são basicamente compostos por areia média, grossa e muito grossa, que podem estar indicando uma fácies da Formação Aquidauana. Nesta fisionomia florestal não são observadas espécies de FES Aluvial, apenas espécies de FES Submontana e baixa inserção (nas bordas) de espécies de cerrado. Cedrela fissilis e Zeyheria tuberculosa foram amostradas e observadas apenas sobre esse geoambiente e também não foram amostradas em trabalhos florísticos e fitossociológicos prévios realizados na mata ciliar sobre a planície de inundação da EEMG (Eiten, 1963; Gibbs e Leitão Filho, 1978; Gibbs et al., 1980 e Mantovani et al., 1989). C. fissilis é considerada espécie rara, comum às bordas de matas e que não se adapta a áreas com freático superficial (Carvalho, 2003). É classificada na literatura como espécie secundária inicial de sucessão florestal (Gandolfi et al., 1995) e é observada frequentemente nas matas secas do bioma Cerrado (Ribeiro e Walter, 2008). De acordo com Luz e Ferreira (1985), Z. tuberculosa também é mais frequente nas matas secas e bordas de matas galeria, preferindo topos de morro e encostas íngremes, incluindo áreas de afloramento rochoso, e evitando fundos de vales e baixadas úmidas. Essa espécie costuma aparecer nas fases iniciais de regeneração florestal, podendo inclusive apresentar comportamento invasor em áreas abertas (Carvalho, 2003). Embora sejam espécies comuns aos estágios iniciais de sucessão florestal, $C$. fissilis e $Z$. 
tuberculosa não foram observadas em clareiras e bordas de mata sobre os sedimentos quaternários.

Observa-se ainda que para diferenciação dos geoambientes e fisionomias lenhosas ocorrentes sobre a Formação Aquidauana, a fertilidade dos solos também é fator contrastante. Isso indica que os solos sobre os cerradões, essencialmente arenosos, são altamente intemperizados, com baixos teores de nutrientes e altos teores de alumínio (aspectos amplamente discutidos na literatura, p.ex., Ruggiero et al., 2002). Essa distrofia e toxicidade não são observadas nos solos sob as florestas semidecíduas, mesmo quando sobre a Formação Aquidauna (Figura 3.9).

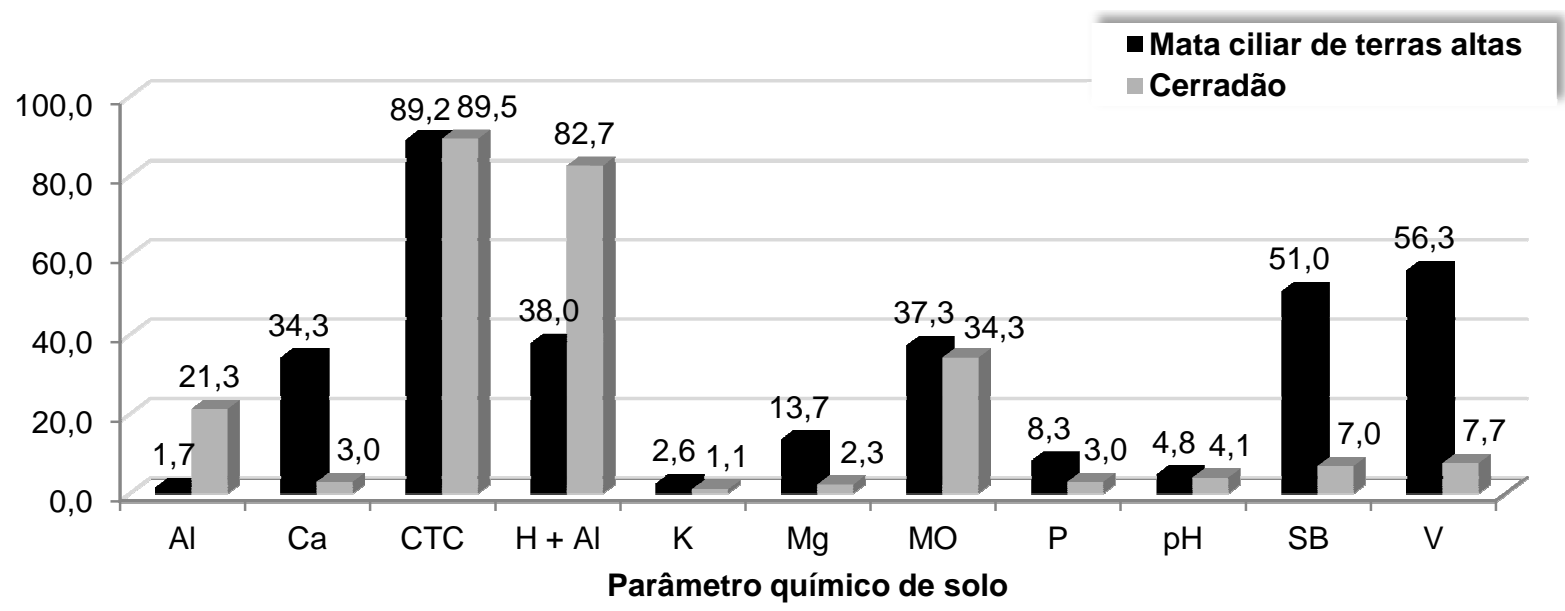

Figura 3.9. Fertilidade dos solos sob a mata ciliar de terras altas, sem influência fluvial $-P 7$, em preto, e sob o cerradão - P8, em cinza. Al (Alumínio), Ca (Cálcio), CTC (Capacidade de Troca Catiônica), $\mathrm{H}+\mathrm{Al}$ (Acidez potencial), K (Potássio), Mg (Magnésio) e SB (Soma de Bases) em $\mathrm{mmolc} / \mathrm{dm}^{3} ; \mathrm{P}$ (Fósforo) em mg/dm $\mathrm{dm}^{3}$; $\mathrm{MO}$ (Matéria Orgânica) em $\mathrm{g} / \mathrm{dm}^{3} ; \mathrm{pH}$ (Acidez ativa), escala de 0 a 14; V (Saturação por bases) em porcentagem.

\subsection{Conclusões}

Foram definidos quatro geoambientes na Estação Ecológica de Mogi-Guaçu, São Paulo, Brasil. Dois deles ocorrem no domínio de rochas sedimentares da Bacia do Paraná (Formação Aquidauana) e dois no domínio de sedimentos quaternários (Depósitos Aluvionares), sendo que apenas três deles apresentaram espécies associadas. O estudo demonstrou também a capacidade do Self-Organizing Maps (SOM) em organizar dados multivariados do sistema, bem como na mineração de informações relevantes ao estudo. 
Observou-se que a granulometria dos sedimentos é um parâmetro fundamental na formação e diferenciação dos geoambientes, onde são observadas fisionomias e espécies florestais de ocorrências exclusivas. Contudo, outros aspectos ecológicos, como tolerância à inundação e à sombra, também foram e devem ser considerados. As espécies Inga vera subsp. affinis e Calophylum brasiliense mostraram-se associadas à mata ciliar com influência fluvial (de terras baixas) na planície ordinária de inundação, com amplo domínio das frações argila e silte. As espécies Qualea grandiflora e Tabebuia ochracea foram identificadas apenas na fisionomia Cerradão. São aqui consideradas indicadoras das áreas de interflúvio (colinas e platôs) da Formação Aquidauana com altas porcentagens das frações areia fina, média e grossa, e escasso silte. As espécies Cedrela fissilis e Zeyheria tuberculosa ocorrem apenas na mata ciliar sem influência sazonal (terras altas), indicando as bordas do afloramento local da Formação Aquidauana, notadamente dique e paleodique erodidos por solapamento pelo rio Mogi-Guaçu. Essa porção da Formação Aquidauana tem granulometria mais grossa, com distinta presença das frações de areia grossa e muito grossa, praticamente ausentes nos sedimentos dos outros geoambientes, além da baixa porcentagem das frações silte e areia muito fina.

Do ponto de vista da geobotânica, a definição de espécies indicadoras geológicas é um avanço significativo, pois abre a possibilidade de, após tal definição para um dado ambiente, mapeá-las remotamente em imagens ópticas, notadamente as hiperespectrais de alta resolução espacial. A aplicação potencial do método vai desde estudos ecológicos ao planejamento de preservação do ambiente e à exploração geológica (prospecção mineral e de hidrocarbonetos). O SOM mostrou-se adaptado à integração dos dados multivariados utilizados, auxiliando a compreensão do sistema estudado e a análise geobotânica. Os resultados são encorajadores para replicação da metodologia em estudos geobotânicos em ambientes heterogêneos, com comunidades de plantas altamente biodiversas, como os observados em regiões tropicais do planeta. 


\subsection{Referências bibliográficas}

Adamczyk, J.J., Kurzac, M., Park, Y. S., \& Kruk, A. (2013). Application of a Kohonen's self-organizing map for evaluation of long-term changes in forest vegetation. Journal of Vegetation Science, 24(2), 405-414.

Agarwal, P., \& Skupin, A. (2008). Self-Organising Maps: Applications in Geographic Information Science. Chichester (WS): John Wiley \& Sons Ltd. 214p.

Aoki, M., Yabuki, K., \& Totsuka, T. (1981). An evaluation of chlorophyll content of leaves based on the spectral reflectivity in several plants. Research Reports of the National Institute of Environmental Studies of Japan, 66, 125-130.

Assis, A. C. C., Coelho, R. M., Silva Pinheiro, E., \& Durigan, G. (2011). Water availability determines physiognomic gradient in an area of low-fertility soils under Cerrado vegetation. Plant Ecology, 212(7), 1135-1147.

Bren, L. J. (1993). Riparian zone, stream, and floodplain issues: a review. Journal of Hydrology, 150(2): 277-299.

Buschmann, C., \& Nagel, E. (1993). In vivo spectroscopy and internal optics of leaves as basis for remote sensing of vegetation. International Journal of Remote Sensing, 14(4), 711-722.

Camargo, O. A., Moniz, A. C., Jorge, J. A., \& Valadares, J. M. A. S. (2009). Métodos de Análise Química, Mineralógica e Física de Solos do Instituto Agronômico de Campinas. Campinas: Instituto Agronômico. 77 p. (Boletim técnico, 106).

Carvalho, P. E. R. (2003). Espécies arbóreas brasileiras, v.1. Brasília (DF): Embrapa. 1039p.

Costa, R. C., \& Santos, F. A. M. (2011). Padrões espaciais de Qualea grandiflora Mart. em fragmentos de cerrado no estado de São Paulo. Acta Botanica Brasilica, 25(1), 215-222.

Daughtry, C.S.T. (2001). Discriminating crop residues from soil by shortwave infrared reflectance. Agronomy Journal, 93(1), 125-131.

Daughtry, C.S.T., Hunt, E.R., \& McMurtrey, J.E. (2004). Assessing crop residue cover using shortwave infrared reflectance. Remote Sensing of Environment, 90(1), 126-134.

Davies, D. L., \& Bouldin, D. W. (1979). A cluster separation measure. IEEE Transactions on Pattern Analysis and Machine Intelligence, 2, 224-227.

Durigan, G., \& Nogueira, J. C. B. (1990). Recomposição de matas ciliares. IF Série Registros, 4,1-14.

Eiten, G. (1963). Habitat flora of Fazenda Campininha. Anais do $1^{\circ}$ Simpósio sobre Cerrado (pp. 157-202). São Paulo: Universidade de São Paulo.

Eiten, G. (1972). The cerrado vegetation of Brazil. Botanical Review, 38, 201-341.

Foody, G. (1999). Applications of the self-organising feature map neural network in community data analysis. Ecological Modelling, 210, 97-107.

Fúlfaro, J. V., \& Bjomberg, A. J. S. (1993). Geologia. In: J. C. A. Cintra, \& J. H. Albiero (Eds.). Solos do interior de São Paulo (pp. 01-42). São Carlos: Associação Brasileira de Mecânica dos Solos e Engenharia Geotécnica/Universidade de São Paulo.

Fuller, D. (1920). Ecological Terms and Concepts. Botanical Gazette, 69(2), 183-185.

Gamon, J.A., Serrano, L., \& Surfus, J.S. (1997). The photochemical reflectance index: an optical indicator of photosynthetic radiation use efficiency across species, functional types, and nutrient levels. Oecologia, 112(4), 492-501. 
Gandolfi, S., Leitão Filho, H. F., \& Bezerra, C. L. F. (1995). Levantamento florístico e caráter sucessional das espécies arbustivo-arbóreas de uma Floresta Mesófila Semidecídua no município de Guarulhos, SP. Brazilian Journal of Biology, 55(4), 753-767.

Gao, B.C. (1996). NDWI-a normalized difference water index for remote sensing of vegetation liquid water from space. Remote sensing of environment, 58(3), 257-266.

Gibbs, P. E., \& Leitão Filho, H. F. (1978). Floristic composition of an area of gallery forest near Moji-Guaçu, State of São Paulo, SE Brazil. Brazilian Journal of Botany, 1, 151-156.

Gibbs, P.E., Leitão Filho, H. F., \& Abbott, R. J. (1980). Application of the pointcentred quarter method in floristic survey of an area of gallery forest at Mogi-Guaçu, SP, Brasil. Brazilian Journal of Botany, 3, 17-22.

Gitelson, A., \& Merzlyak, M.N. (1994). Spectral reflectance changes associated with autumn senescence of Aesculus hippocastanum L. and Acer platanoides L. leaves. Spectral features and relation to chlorophyll estimation. Journal of Plant Physiology, 143(3), 286292.

Gitelson, A.A., Zur, Y., Chivkunova, O.B., \& Merzlyak, M.N. (2002). Assessing Carotenoid Content in Plant Leaves with Reflectance Spectroscopy. Photochemistry and Photobiology, 75(3), 272-281.

Goodland, R., \& Pollard, R. (1973). The Brazilian cerrado vegetation: a fertility gradient. Journal of Ecology, 61(1), 219-224.

Gregory, S. V, Swanson, F. J, McKee, W. A., \& Cummins, K. W. (1991). An ecosystem perspective of riparian zones. BioScience, 41, 540-551.

Higgins, M. A., Asner, G. P., Perez, E., Elespuru, N., \& Alonso, A. (2014). Variation in photosynthetic and nonphotosynthetic vegetation along edaphic and compositional gradients in northwestern Amazonia. Biogeosciences, 11(3), 3505-3513.

Higgins, M. A., Asner, G. P., Perez, E., Elespuru, N., Tuomisto, H., Ruokolainen, K., et al. (2012). Use of Landsat and SRTM data to detect broad-scale biodiversity patterns in Northwestern Amazonia. Remote Sensing, 4(8), 2401-2418.

Higgins, M. A., Ruokolainen, K., Tuomisto, H., Llerena, N., Cardenas, G., Phillips, O. L. et al. (2011). Geological control of floristic composition in Amazonian forests. Journal of Biogeography, 38(11), 2136-2149.

Kohonen, T. (1982). Self-organized formation of topologically correct feature maps. Biological Cybernetics, 43, 59-69.

Kohonen, T. (2001). Self-Organizing Maps. $3^{\text {rd }}$ ed. New York: Springer-Verlag. 528p.

Kohonen, T. (2013). Essentials of the self-organizing map. Neural Networks, 37, 52-65.

Kruckeberg, A. R. (2002). Geology and plant life: the effects of landforms and rock types on plants. Seatle: University of Washington Press. 360p.

Lopes, A. S. (1984). Solos sob "Cerrado": características, propriedades e manejo. Piracicaba: Associação Brasileira para Pesquisa da Potassa e do Fosfato. 162p.

Lopes, A. S., \& Cox, F. R. (1977). A survey of the fertility status of surface soils under "Cerrado" vegetation in Brazil. Soil Science Society of America Journal, 41(4), 742-747.

Luz, H. D. F., \& Ferreira, M. (1985). Ipê Felpudo (Zeyhera tuberculosa (Vell) Bur.): essência nativa pioneira com grande potencial silvicultural. Revista do Instituto de Pesquisas e Estudos Florestais, 31, 13-32. 
Mantovani, W., Rossi, L., Romaniuc Neto, S., Assad-Ludewigs, I. Y., Wanderley, M. G. L., Melo, M. M. R. F., \& Toledo, C. B. (1989). Estudo fitossociológico de áreas de mata ciliar em Moji Guaçu, SP - Brasil. Anais do Simpósio sobre mata ciliar (pp. 235-267). Campinas: Fundação Cargill.

Medina, H. P., \& Grohmann, F. (1966). Disponibilidade de água em alguns solos sob cerrado. Bragantia, 25(1), 65-75.

Mendonça, R. C., Felfili, J. M., Walter, B. M. T., Silva Júnior, M. C., Rezende, A. V., Filgueiras, T. S., Nogueira, P. E., \& Fagg, C. W. (2008). Flora Vascular do Bioma Cerrado: checklist com 12.356 espécies. In S.M. Sano, S. P. Almeida, \& J. F. Ribeiro (Eds.). Cerrado: ecologia e flora (pp. 421-1279). Planaltina: EMBRAPA-CPAC.

Milani, E. J., Melo, J. H. G, Souza, P. A., Fernandes, L. A., \& França, A. B. (2007). Bacia do Paraná. Boletim Geociências Petrobrás, 15(2), 265-287.

Oliveira-Filho, A. T., Ratter, J. A., \& Shepherd, G. J. (1990). Floristic composition and community structure of a central Brazilian gallery forest. Flora, 184(2), 103-117.

Oliveira-Filho, A. T., Shepherd, G. J., Martins, F. R., \& Stubblebine, W. H. (1989). Environmental factors affecting physiognomic and floristic variation in an area of cerrado in central Brazil. Journal of Tropical Ecology, 5(4), 413-431.

Oliveira-Filho, A. T., Vilela, E. A., Carvalho, D. A., \& Gavilanes, M. L. (1994a). Differentiation of streamside and upland vegetation in an area of montane semideciduous forest in southeastern Brazil. Flora, 189, 287-305.

Oliveira-Filho, A.T., Vilela, E. A, Carvalho, D. A., \& Gavilanes, M. L. (1994b). Effects of soils and topography on the distribution of tree species in a tropical riverine forest in southeastern Brazil. Journal of Tropical Ecology, 10(4), 483-508.

Pearson K. (1901). LIII. On lines and planes of closest fit to systems of points in space. The London, Edinburgh, and Dublin Philosophical Magazine and Journal of Science, 2(11), 559-572.

Peñuelas, J., Fillela, I., Biel, C., Serrano, L., \& Save, R. (1995). The reflectance at the 950970 region as an indicator of plant water status. International Journal of Remote Sensing, 14, 1887-1905.

Pontius, J., Martin, M., Plourde, L., \& Hallett, R. (2008). Ash decline assessment in emerald ash borer-infested regions: A test of tree-level, hyperspectral technologies. Remote Sensing of Environment, 112(5), 2665-2676.

Ribeiro, J.F., \& Walter, B.M.T. (2008). As principais fitofisionomias do Bioma Cerrado. In S.M. Sano, S. P. Almeida, \& J. F. Ribeiro (Eds.). Cerrado: ecologia e flora (pp. 153-212). Planaltina: EMBRAPA-CPAC.

Rodrigues, R. R. (2000). Uma discussão nomenclatural das formações ciliares. In: R. R. Rodrigues, \& H. F. Leitão-Filho (Eds.). Matas ciliares: conservação e recuperação (pp. 91-99). São Paulo: EDUSP/FAPESP.

Ruggiero, P. G. C., Batalha, M. A, Pivello, V. R., \& Meirelles, S. T. (2002). Soil-vegetation relationships in cerrado (Brazilian savanna) and semideciduous forest, Southeastern Brazil. Plant Ecology, 160, 1-16.

Serviço Geológico do Brasil - CPRM. (2006). Geologia e recursos minerais do estado de São Paulo: sistema de informações geográficas (SIG). Mapas Geológicos Estaduais. Escala 1:750.000. Programa Geologia do Brasil. São Paulo: CPRM, 1 CD-ROM.

Shepherd, G. J. 2009. FITOPAC 2.1 (versão preliminar). Campinas: Universidade Estadual de Campinas, Departamento de Biologia Vegetal. 
Sims, D.A., \& Gamon, J.A. (2002). Relationships between leaf pigment content and spectral reflectance across a wide range of species, leaf structures and developmental stages. Remote sensing of environment, 81(2), 337-354.

Sirén, A., Hanna, A. B., Tuomisto, C., \& Navarrete, H. (2013). Mapping environmental variation in lowland Amazonian rainforests using remote sensing and floristic data. International Journal of Remote Sensing, 34(5), 1561-1575.

Spearman, C. (1904). General Intelligence, Objectively Determined and Measured. The American Journal of Psychology, 15(2), 201-292.

Spearman, C. (1906). 'Footrule' for measuring correlation. British Journal of Psychology, 1904-1920, 2(1), 89-108.

Suriguga Zhang, J. T., Zhang, B., Chen, J. J., Zhang, Q. D., Tian, S. G., \& Liu, S. J. (2011). Forest community analysis in the Songshan National Nature Reserve of China using selforganizing map. Russian Journal of Ecology, 42, 216-222.

Ustin, S. L. (2008). Analysis of hyperspectral remote sensing to detect and map tree decline at Ft. Benning, Georgia. . Fort Benning: United States Army Corps of Engineers. 33p.

Ustin, S. L., Smith, M. O., Jacquemoud, S., Verstraete, M. M., \& Govaerts, Y. (1999). Geobotany: vegetation mapping for Earth Sciences. In: A. N. Rencz (Org.). Remote sensing for the Earth Sciences, $3^{\text {rd }}$ ed (pp. 189-233). New York: John Wiley and sons.

Zhang, J., \& Yang, H. (2008). Application of self-organizing neural networks to classification of plant communities in Pangquangou Nature Reserve, North China. Frontiers of Biology in China, 3(4), 512-517. 


\section{ANÁLISE DE MISTURA ESPECTRAL EM ESCALA DE FOLHA ENTRE ESPÉCIES INDICADORAS GEOLÓGICAS: VARIAÇÃO SAZONAL E RELAÇÃO COM COMPOSTOS BIOQUÍMICOS}

\section{Resumo}

O objetivo deste estudo foi verificar as relações espectrais e bioquímicas, em escala de folha, entre espécies arbóreas indicadoras de diferentes formações e fácies geológicas da Estação Ecológica de Mogi-Guaçu, São Paulo (Brasil), através de uma abordagem sazonal. Verificou-se também se espécies indicadoras de mesmo geoambiente apresentam comportamentos bioquímicos e espectrais similares, bem como se existe um momento sazonal mais adequado para a discriminação espectral dessas espécies. Complementarmente, analisou-se quando os resultados da análise de mistura espectral com múltiplos membros-finais (MESMA) podem estar correlacionados às variações intra e interespecíficas em pigmentos, compostos estruturais e água foliar. Dados espectrais $(0,35$ a 2,5 $\mu \mathrm{m}$; FieldSpec® 3 Hi-Res) e bioquímicos (clorofilas a e b, carotenoides + xantofilas, antocianinas, celulose, hemicelulose, lignina insolúvel e água foliar) foram coletados de folhas fotossinteticamente ativas da copa de três indivíduos das cinco espécies, alvo do estudo, nos períodos chuvoso e seco do ano de 2012. Análises de variância (ANOVA/teste F) e de médias (Tukey) foram aplicadas aos dados bioquímicos dos diferentes momentos sazonais. A prévia divisão do espectro em regiões espectrais (VIS: 0,4-0,7 $\mu \mathrm{m}$; NIR: 0,7-1,3 $\mu \mathrm{m}$; SWIR: 1,3-2,45 $\mu \mathrm{m}$ ), a normalização dos dados através da remoção do contínuo (CR) e o uso de diferentes métricas para seleção de membros-finais (EAR-MASA-CoB (EMC) e Iterative Endmember Selection (IES)) foram testados, nas análises MESMA dos dados espectrais. Análises de regressão entre as variações intra e interespecíficas de compostos bioquímicos e as exatidões específicas da classificação MESMA foram realizadas e testadas via teste F. As espécies-alvo foram muito bem classificadas em ambos os momentos sazonais analisados. Exatidões do produtor ou do usuário não foram inferiores à $87,5 \%$, dentre os melhores resultados de classificação MESMA. O sucesso de desmistura espectral 
entre essas espécies mostrou estar intimamente ligado à alta variabilidade bioquímica observada em suas folhas. As variações intra e interespecíficas em compostos bioquímicos puderam ser observadas e correlacionadas às suas variações espectrais. As características bioquímicas e espectrais dessas espécies, indicadoras de diferentes formações e fácies geológicas, não puderam ser consideradas conjuntamente como reflexo dos ambientes que habitam, mas de suas intrínsecas formas de adaptação e sobrevivência às determinadas condições edafogeológicas e ambientais.

\subsection{Introdução}

A compreensão dos aspectos relacionados à reflectância das copas de árvores e dos desafios envolvidos em sua classificação espectral começa no nível foliar (Castro-Esau e Kalacska, 2008). A configuração geral do espectro óptico de folhas, no entanto, é resultante das cinco maiores feições de absorção relacionadas à transição de elétrons em clorofilas, na região do visível, e à flexão e alongamento das ligações O-H em água e outros compostos químicos no infravermelho (Curran, 1989). Essas feições encobrem em torno de 42 menores feições de absorção associadas a diversos compostos bioquímicos (Curran, 1989), que têm sido estudadas com a aplicação de análises de regressão bioquímico-espectrais, índices espectrais ou análises de profundidade de feições de absorção (p.ex., Curran, 1989; Chappelle et al., 1992; Blackburn, 1998a, 1998b e 2007; Asner, 1998; Kokaly e Clark, 1999; Curran et al., 2001; Sims e Gamon, 2002; Gitelson e Merzlyak, 2003; Gitelson et al., 2006; Gitelson, 2012).

Contudo, mesmo que química e espectralmente as folhas das espécies não se pareçam, o grau de variabilidade bioquímica e espectral (intra e interespecífica) é o que determina a possibilidade de identificação remota de espécies (Asner, 2008). As variações bioquímicas entre pigmentos, água, nutrientes e carbono foliar, embora ainda pouco entendidas entre espécies tropicais (Asner, 2008; Asner e Martin, 2008), expressam diretamente as variações das propriedades espectrais foliares (Asner, 2008). Assim, um 
passo necessário para o avanço das pesquisas em química de dossel via sensoriamento remoto é o desenvolvimento de relações quantitativas entre química foliar e propriedades espectrais (Asner e Martin, 2008), tendo em vista que uma análise quantitativa interespecífica deve considerar as variações intraespecíficas de espectros (Price, 1994).

Embora ainda não se tenha comprovado efetivamente que as variações espectrais interespecíficas de indivíduos arbóreos superem as intraespecíficas e vice-versa (Rivard et al., 2008), existe um corpo emergente de evidências (p.ex., Clark et al., 2005; Gamon et al., 2005; Asner, 2008; Asner e Martin, 2009), que tem sustentado a hipótese de que o sensoriamento remoto hiperespectral entre os trópicos detecta não somente espécies, mas propriedades funcionais e estruturais que variam de acordo com espécies ou grupos funcionais (Gamon, 2008). As pesquisas em discriminação espectral de espécies em ecossistemas tropicais, com elevada diversidade química e espectral, iniciaram-se por volta dos anos 2000 e chegaram a resultados notáveis em escala de folha (p.ex., Cochrane, 2000; Fung et al., 2003; Castro-Esau et al., 2004; Clark et al., 2005; Castro-Esau et al., 2006; Rivard et al., 2008; Ferét \& Asner, 2011; Hesketh e Sánchez-Azofeifa, 2012; Prospere et al., 2014).

Parte dos estudos sobre o tema enfoca a discriminação espectral de grupos funcionais - termo que mais recentemente tem sido adotado para classificar espécies com respostas similares a múltiplos (ou específicos) fatores ambientes (Lavorel et al., 1997; Reich et al., 2003). Observe-se que espécies invasoras também representam tipos funcionais e ópticos distintos na paisagem (Ustin e Gamon, 2010) e, assim, trabalhos como os de Asner et al. (2006 e 2008), voltados à discriminação de espécies invasoras, indiretamente consideram a questão funcional. Há, finalmente, trabalhos que abordam a diferenciação de espécies de hábitos variados (p.ex., Castro-Esau et al., 2004; Kalacska et al., 2007; Sánchez-Azofeifa et al., 2009), ou de diferentes estágios sucessionais (p.ex., Alvarez-Añorve et al., 2012). Hesketh e Sánchez-Azofeifa (2012), por sua vez, estudaram as variações espectrais, em escala de folha, de espécies de árvores e lianas, em diferentes ambientes (matas seca e úmida) e períodos sazonais (seco e chuvoso) na América Central. 
Os autores observaram que os tipos funcionais, árvores e lianas, respondem diferentemente às variações em sazonalidade e, portanto, foram bem classificadas em ambos os períodos. Devido à intensidade dessas variações, uma tentativa de classificação entre períodos sazonais falhou. Expondo a necessidade de análises bioquímicas foliares para reforçar o que foi observado espectralmente, os autores concluem que a exploração de relações bioquímico-espectrais em diferentes gradientes temporais e geográficos deve ser prioridade em futuras investigações.

A literatura consultada parece, no entanto, não contemplar estudos em terrenos tropicais com enfoque na discriminação espectral em escala de folha de espécies associadas a diferentes formações e fácies geológicas. A importância da discriminação espectral dessas espécies está no acesso remoto às informações geológicas das áreas vegetadas do planeta, que representam a maior parte da superfície terrestre. Nessas áreas as características espectrais ópticas dos depósitos minerais e tipos de rochas não podem ser acessadas diretamente, objetivando, dentre outros, o mapeamento geológico e a prospecção mineral (Ustin et al., 1999). Assim, como previsto por Sabins et al. (1999), a disponibilidade de dados hiperespectrais vem como um estímulo a novas investigações geobotânicas. O melhor entendimento do comportamento espectral de espécies associadas a diferentes formações e fácies geológicas, considerando a variabilidade bioquímica, fisiológica e morfológica presente no dossel, pode ser atingido utilizando-se dados hiper e ultraespectrais, podendo contribuir sobremaneira a estudos geológicos específicos em áreas vegetadas.

Dessa forma, o objetivo deste estudo é verificar as relações espectrais e bioquímicas, em escala de folha, entre espécies arbóreas indicadoras de diferentes ambientes geológicos da Estação Ecológica de Mogi-Guaçu, São Paulo (Brasil), através de uma abordagem sazonal (períodos chuvoso e seco do ano). Espera-se, assim, verificar se espécies associadas a mesmo geoambiente apresentam comportamentos bioquímicos e espectrais similares, bem como se existe um momento sazonal mais adequado para discriminação espectral dessas espécies. A prévia divisão do espectro eletromagnético 
óptico em intervalos espectrais, a normalização dos dados através da remoção do contínuo e o uso de diferentes métricas para seleção de membros-finais são testados, em uma análise de mistura espectral com múltiplos membros-finais (MESMA; Roberts et al., 1998a). Complementarmente, será verificado quando a variação em composição química foliar pode estar correlacionada com os resultados da classificação espectral MESMA.

\subsection{Materiais e Métodos}

\subsubsection{Espécies-alvo do estudo}

As cinco espécies-alvo deste estudo foram definidas por suas associações de ocorrência com diferentes ambientes geológicos da Estação Ecológica de Mogi-Guaçu (EEMG), no município de Mogi-Guaçu, Estado de São Paulo (SP), Brasil (Figura 4.1).

Como foi apresentado no capítulo 3, na EEMG, Calophyllum brasiliense Cambess.e Inga vera Willd. subsp. affinis (DC.) T. D. Penn. apresentam distribuições associadas à mata ciliar com influência fluvial (terras baixas) na planície ordinária de inundação, sobre sedimentos quaternários, com domínio de material pelítico (frações argila e silte) (geoambiente I). Qualea grandiflora Mart. e Tabebuia ochracea (Cham.) Standl., ocorrentes na fisionomia cerradão, estão distribuídas nas áreas de interflúvio (colinas e plateaus) da Formação Aquidauana com altas porcentagens das frações areia fina, média e grossa, e escasso silte (geoambiente III). Os solos onde essas espécies ocorrem também são pobres em nutrientes, com alto teor de alumínio. A espécie Cedrela fissilis Vell. apresenta ocorrência apenas na mata ciliar sem influência sazonal (terras altas), indicando as bordas do afloramento local da Formação Aquidauana, notadamente dique e paleodique erodidos por solapamento pelo rio Mogi-Guaçu. Essa porção da Formação Aquidauana tem granulometria mais grossa, com distinta presença das frações de areia grossa e muito grossa, praticamente ausentes nos sedimentos dos outros geoambientes, além da baixa porcentagem das frações silte e areia fina (geoambiente IV) (Figura 4.1). Informações ecológicas das espécies alvo do presente estudo estão descritas na Tabela 4.1. 


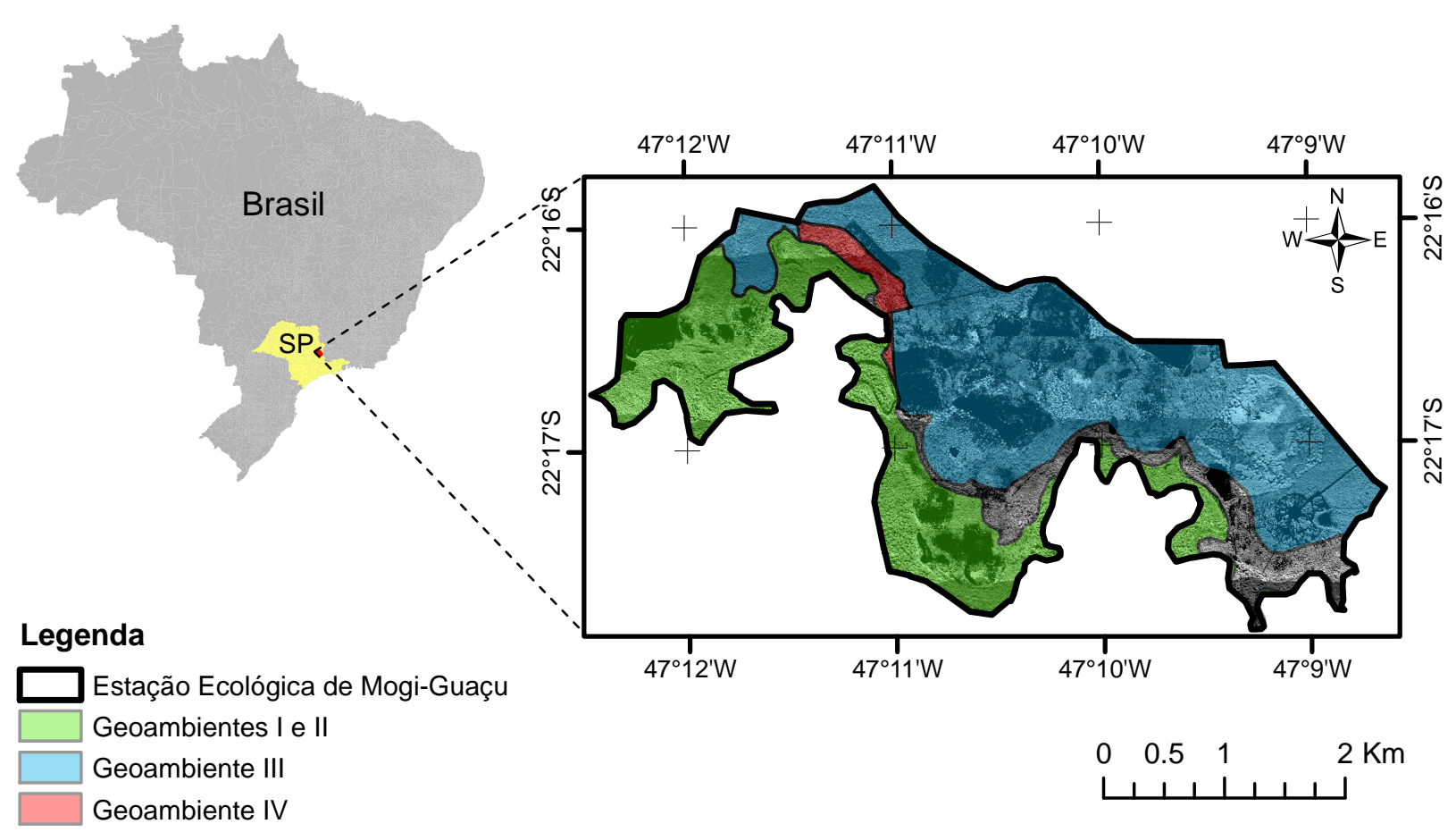

Mosaico ProSpecTIR-VS - canal: $841 \mathrm{~nm}$

Figura 4.1. Localização da área de estudo e geoambientes de ocorrência das espécies-alvo do estudo: Calophyllum brasiliense e Inga vera subsp. affinis (geoambiente I), Qualea grandiflora e Tabebuia ochracea (geoambiente III) e Cedrela fissilis (geoambiente IV).

Tabela 4.1. Informações ecológicas das espécies-alvo do estudo. $P E R=$ perenifólia; $D E C=$ decídua; $\mathrm{BDC}$ = brevidecídua; GLA = glabra; $\mathrm{PUB}=$ pubescente; $\mathrm{IAF}=$ índice de área foliar (Digital Plant Canopy Imager, CID Bio-science, Camas, WA, Estados Unidos) dos indivíduos amostrados no período seco (jun.-jul./2012).

\begin{tabular}{|c|c|c|c|c|c|c|}
\hline \multirow[b]{2}{*}{ Espécie-alvo } & \multirow{2}{*}{$\begin{array}{c}\text { Sigla } \\
\text { utilizada }\end{array}$} & \multicolumn{2}{|c|}{ Tolerância } & \multirow[b]{2}{*}{ Deciduidade } & \multirow[b]{2}{*}{ Folha } & \multirow[b]{2}{*}{ IAF } \\
\hline & & $\begin{array}{c}\text { Água } \\
\text { superficial }\end{array}$ & $\begin{array}{c}\text { Iluminação } \\
\text { direta }\end{array}$ & & & \\
\hline $\begin{array}{l}\text { Calophyllum brasiliense } \\
\text { Camb. }\end{array}$ & CABR & $\operatorname{sim}$ & não & PER & GLA & $1,39 \pm 0,19$ \\
\hline Cedrela fissilis Vell. & CEFI & não & $\operatorname{sim}$ & DEC & $\begin{array}{l}\text { GLA/ } \\
\text { PUB }\end{array}$ & $0,32 \pm 0,10$ \\
\hline $\begin{array}{l}\text { Inga vera Willd. subsp. affinis } \\
\text { (DC.) T. D. Penn. }\end{array}$ & INVE & $\operatorname{sim}$ & $\operatorname{sim}$ & PER & $\begin{array}{l}\text { GLA/ } \\
\text { PUB }\end{array}$ & $0,89 \pm 0,32$ \\
\hline Qualea grandiflora Mart. & QUGR & não & $\operatorname{sim}$ & BDC/DEC & GLA & $2,40 \pm 0,22$ \\
\hline $\begin{array}{l}\text { Tabebuia ochracea (Cham.) } \\
\text { Standl. }\end{array}$ & TAOC & não & $\operatorname{sim}$ & BDC/DEC & PUB & $1,22 \pm 0,50$ \\
\hline
\end{tabular}

\subsubsection{Coleta e armazenamento de amostras foliares}

Primeiramente foram selecionados três indivíduos de cada espécie-alvo que ocupassem o dossel, apresentando folhas fotossinteticamente ativas, e que satisfizessem a logística de rápida coleta e o transporte para a base da EEMG, onde as amostras foram processadas. Foram coletados ramos com folhas verdes da copa de cada indivíduo com 
auxílio de profissional especializado em escalagem e poda. Na base da EEMG, próxima ao local das coletas, foram feitas as medidas espectrais e de peso fresco de folha, bem como o armazenamento refrigerado das amostras para realização de análise bioquímica pós-campo e armazenamento seco para pesagem pós-estufa e mensuração da água foliar. Procurou-se não exceder o máximo de três horas entre a coleta, o transporte e as medidas dos espectros e do peso foliar (pré-estufa). As folhas foram mantidas nos ramos até o momento das mensurações, a fim de conservar ao máximo suas características bioquímicas. A coleta das folhas foi realizada do ápice à base dos ramos com o intuito de incluir nas análises as variações em tamanho e coloração, decorrentes principalmente da idade foliar. Esses procedimentos foram realizados nos períodos chuvoso (fevereiro/dezembro) e seco (junho/julho) do ano de 2012.

\subsubsection{Mensurações bioquímicas}

Parte das folhas coletadas (15 amostras; três indivíduos/espécie-alvo) foi armazenada em sacos de papel e, na base da EEMG, utilizando balança de precisão, foram anotados os pesos das folhas (pré-estufa). O material foi conservado e transportado em ambiente arejado e, no Centro Pluridisciplinar de Pesquisas Químicas, Biológicas e Agrícolas (CPQBA) da Universidade de Campinas (UNICAMP), recebeu secagem em estufa $\left(40^{\circ} \mathrm{C}-72 \mathrm{~h}\right)$ para posterior dosadagem da água foliar com pesagem pós-estufa. Outra parte das folhas (15 amostras, três indivíduos/espécie-alvo) foi armazenada em sacos plásticos postos em caixas térmicas com gelo, mantendo a temperatura entre $0^{\circ} \mathrm{C}$ a $-10^{\circ} \mathrm{C}$ no transporte para o laboratório de Fisiologia Vegetal da UNICAMP, onde foram conservadas em freezer, naquele intervalo de temperatura, até a execução das análise bioquímicas. Foram extraídos dados dos pigmentos foliares clorofilas a e b $(\mu \mathrm{g} / \mathrm{mg})$, carotenoides + xantofilas $(\mu \mathrm{g} / \mathrm{mg})$ e antocianina $(\Delta / \mathrm{mg})$; bem como dos compostos estruturais celulose $(\mathrm{mg} / \mathrm{g})$, hemicelulose $(\mathrm{mg} / \mathrm{g})$ e lignina insolúvel (\%). Os métodos utilizados para extração desses dados foram baseados em Holm (1954) e Updegraff (1969). 


\subsubsection{Mensurações espectrais}

Foram coletadas cinco folhas por indivíduo amostrado de cada espécie-alvo ( $n=75$, 15 folhas/ espécie-alvo), representando a variedade em tamanho e coloração de suas folhas. Os espectros foram obtidos com espectrorradiômetro ultraespectral portátil FieldSpec® 3 Hi-Res (Analytical Spectral Devices, Bolder, CO, Estados Unidos). Esse equipamento opera na faixa do espectro eletromagnético óptico entre 0,35 e 2,5 $\mu \mathrm{m}$, com resoluções espectrais de $3 \mathrm{~nm}(0,35-0,7 \mu \mathrm{m}), 8,5 \mathrm{~nm}(0,7-1,4 \mu \mathrm{m})$ e $6,5 \mathrm{~nm}(\sim 2,1 \mu \mathrm{m})$, e intervalo espectral de 1,4 e 2,0 nm. Os espectros foram obtidos da porção adaxial (superior) das folhas, com exclusão da nervura central. Para tanto, foram utilizados sonda para plantas e clipe de folhas, que, juntos, permitem a obtenção ortogonal de espectros em condições idênticas de iluminação e com reduzida influência atmosférica, considerando o contato da sonda. Posteriormente, os espectros coletados tiveram suas reflectâncias absolutas recuperadas e os offsets entre sensores foram corrigidos com a utilização de rotinas do software PRISM (Kokaly, 2011). Devido à baixa razão sinal-ruído das bandas localizadas no início e no fim dos espectros coletados, foram excluídas aquelas entre 0,35 e 0,4 $\mu$ m e entre 2,45 e $2,5 \mu \mathrm{m}$.

\subsubsection{Análise das variações bioquímicas entre espécies-alvo e momentos sazonais}

As concentrações dos compostos foliares clorofila a, clorofila b, carotenoides + xantofilas, antocianina, celulose, hemicelulose, lignina insolúvel e água tiveram suas variações analisadas via ANOVA one way (teste $F$ ) utilizando-se o pacote estatístico $R(R$ Development Core Team, 2008). Foram testadas as hipóteses nulas de inexistências de variações dos compostos bioquímicos entre espécies em determinado momento sazonal, bem como de não haver variação de determinado composto bioquímico entre momentos sazonais. Testes de médias de Tukey foram aplicados a todos os conjuntos de dados estatisticamente diferentes com nível de 5\% de significância (via ANOVA/teste F), a fim de comparar os contrastes entre duas médias. Nesse teste a hipótese nula testada foi a de que 
a média do tratamento i é igual à média do tratamento i', com pelo menos $5 \%$ de significância. A Diferença Mínima Significativa (DMS), do teste de Tukey, utiliza a amplitude total estudentizada (q) tabelada para determinado nível de significância, número de tratamentos e grau de liberdade do resíduo, além do quadrado médio do resíduo e o número de tratamentos.

\subsubsection{Análise de mistura espectral com múltiplos membros-finais}

\subsubsection{Elaboração das bibliotecas espectrais}

Primeiramente, os dados espectrais do visível ao infravermelho ondas curtas (VSWIR; 0,4-2,45 $\mu \mathrm{m}$ ) foram separados nos intervalos espectrais, adaptados de Asner (1998): visível (VIS; 0,4-0,7 $\mu \mathrm{m}$ ), infravermelho próximo (NIR; 0,7-1,3 $\mu \mathrm{m}$ ) e infravermelho ondas curtas (SWIR; 1,3-2,45 $\mu \mathrm{m}$ ). Esses dados tiveram seu contínuo removido (CR), a fim de normalizar as diferenças de brilho e realçar as feições de absorção presentes nos intervalos espectrais (Clark e Roush, 1984). Dessa forma, dezesseis bibliotecas espectrais globais (contendo os espectros de todas as classes, 75 espectros/biblioteca) foram geradas para o estudo, considerando os dois momentos sazonais estudados, os quatro intervalos de dados e os dois tipos de espectro, original de reflectância ou normalizado (CR). Essas bibliotecas são designadas e diferenciadas nas análises de mistura espectral como dado utilizado: VSWIR, VSWIR(CR), VIS, VIS(CR), NIR, NIR(CR), SWIR e SWIR(CR), do período chuvoso e do período seco.

Foram gerados metadados para as bibliotecas espectrais globais, referidas acima, utilizando o ViperTools (Roberts et al., 2007). Esses contêm informações necessárias aos processamentos subsequentes, embora possam ser inseridos dados quaisquer de importância à pesquisa, referentes a cada espectro. Os metadados foram compostos pelos seguintes campos: nome do espectro, classe, espécie, formação de ocorrência natural, período sazonal de coleta do espectro, escala e fonte dos dados, intervalo espectral, tipo do espectro, se de reflectância ou normalizado, e brilho. 
As bibliotecas espectrais foram, então, separadas aleatoriamente (de forma randomizada) em bibliotecas espectrais de treinamento e bibliotecas espectrais de validação. Um limite proporcional de 50\% de espectros para cada biblioteca (Roth et al., 2012) foi utilizado, ou seja, as bibliotecas de treinamento foram compostas por sete espectros de cada classe/espécie $(n=35)$ e as de validação por oito $(n=40)$.

Matrizes quadradas, armazenadas em uma imagem Band Sequential (BSQ), foram geradas para cada biblioteca de treinamento, contendo informações extraídas dos espectros e necessárias aos diferentes processos de seleção de membros-finais. Essas informações são: Erro quadrático médio - EQM (banda 1), ângulo espectral (2), frações brilhantes (3) e escuras (4) e restrição dos dados (5), se requerida pelo usuário (Roberts et al., 2007). Um limiar entre - 0,5 e 1,05 foi definido às frações dos membros-finais a serem selecionados (Dennison e Roberts, 2003; Roth et al., 2012) e diferentes restrições de EQM foram empiricamente testadas, a fim de acessar resultados com melhor exatidão na classificação espectral, sobre dados de reflectância e dados com CR. Testes iniciais foram realizados, baseando-se nos valores utilizados em trabalhos anteriores, embora sua maioria sobre dados de imageamento; ou seja, EQM $\leq 0,025$ para os dados originais de reflectância (Dennison e Roberts, 2003; Youngentob de 2011; Roth, 2012) e EQM $\leq 0,060$ para os dados com CR (Youngentob, 2011). Os EQM máximos (ótimos) à classificação espectral foliar das espécies-alvo deste estudo foram 0,035 para dados de reflectância e 0,075 para aqueles com CR.

\subsubsection{Seleção de membros-finais}

Membros-finais (MF) são espectros que melhor representam as classes analisadas e, portanto, são considerados puros (Adams et al., 1993). As métricas de seleção de MF EAR-MASA-CoB - designadas conjuntamente como EMC (Roberts et al., 2007) e o algoritmo Iterative Endmember Selection - IES (Schaaf et al., 2011) foram testados sobre as oito bibliotecas de treinamento, de cada período sazonal analisado. A distinção de MF via 
EMC foi realizada para cada classe selecionando-se os espectros com valor mínimo de Endmember Average RMSE (EAR) (Dennison e Roberts, 2003), valor mínimo de Minimum Average Spectral Angle (MASA) (Dennison et al., 2004) e valor máximo de Cont-Based Index (CoBIndex) (Roberts et al., 2003; Clark, 2005). Assim, um máximo de três MF foi selecionado para cada classe via EMC.

A seleção de MF via IES foi realizada utilizando rotina em Interactive Data Language - IDL (Schaaf et al., 2011; Roth et al., 2012). Os conjuntos de MF foram selecionados de forma automatizada, adicionando e subtraindo espectros até que o maior coeficiente Kappa fosse atingido, considerando a classificação dos espectros de treinamento por candidatos a MF (Schaaf et al., 2011). Quando o procedimento automatizado falhou, por não selecionar ao menos um MF para uma determinada classe, MF dessa classe faltante, selecionados via EMC, foram inseridos nas bibliotecas IES de MF. Quando houve a necessidade dessa intervenção, a técnica passou a ser designada no estudo como IES*.

\subsubsection{Modelagem espectral com dois membros-finais}

As dezesseis bibliotecas espectrais de validação ( $n=40 / c a d a)$ foram modeladas pelas bibliotecas de MF, geradas separadamente pelos métodos EMC e IES (IES*), utilizando rotina IDL para modelagem MESMA (Multiple Endmember Spectral Mixture Analysis; Roberts et al., 1998) com dois MF (Roberts et al., 2012). A técnica conhecida como análise de mistura espectral (SMA) modela os espectros contidos em uma biblioteca como uma combinação linear de espectros puros (MF), determinando sua relativa proporção dentro de um espectro misto (Adams et al., 1993). Contudo, diferentemente de outras técnicas SMA, que comportam apenas um MF por classe, MESMA permite que o tipo e o número de MF variem dentro de uma única classe (incorporando as variações espectrais intraespecíficas) e, assim, essa técnica gera modelos lineares utilizando diferentes conjuntos de MF a partir de bibliotecas de até centenas de espectros (Roberts et al., 1998a). 
A exatidão dos resultados de modelagem espectral via MESMA foi analisada através das métricas exatidão global (\%) e coeficiente Kappa. Testes de ANOVA one-way foram realizados sobre os coeficientes Kappa dos diferentes tratamentos. Essas análises foram aplicadas a fim de se testarem as hipóteses nulas de que os coeficientes Kappa não variam estatisticamente entre as classificações de dados VSWIR, VIS, NIR e SWIR, de reflectância ou com CR, e entre as métricas de seleção de MF EMC e IES (IES*). Essas análises foram realizadas tanto de forma unitemporal, considerando os dados de um único período sazonal, quanto multitemporal (período seco vs. período chuvoso). Essa última abordagem permitiu verificar se há um melhor momento sazonal à discriminação espectral das espécies-alvo se durante a época das chuvas ou na época de estiagem.

\subsubsection{Análises de mistura espectral entre as classes de espécies-alvo}

As exatidões do produtor e do usuário, de cada classe de espécie-alvo, foram analisadas para os melhores resultados de classificação global por intervalo espectral e período sazonal analisados. Essas análises foram baseadas na premissa de que um erro de comissão (expresso na exatidão do usuário) é definido como a inclusão de um espectro (ou pixel ou área) em uma categoria à qual ele não pertence, enquanto um erro de omissão (exatidão do produtor) é a exclusão de um espectro da categoria à qual ele realmente pertence, isto é, que cada erro representa a omissão de um espectro em sua categoria correta e a comissão desse espectral na categoria errada (Congalton, 1991; Congalton e Green, 1999).

Para tanto, foram analisadas as significâncias (via análise de variância e teste $F$ ) das variações em exatidão específica entre os períodos sazonais estudados, intervalos espectrais e espécies-alvo. Análises pareadas (entre duas classes) de mistura espectral também foram realizadas, a fim de testar a hipótese nula de que os erros de classificação espectral entre pares de espécies-alvo não são estatisticamente diferentes entre os diferentes intervalos espectrais e entre os dois períodos sazonais estudados. Quando as 
variações foram estatisticamente significantes $(\alpha=0,05)$, o teste de médias de Tukey foi aplicado para identificar qual(is) tratamento(s) é(são) estatisticamente diferente(s) dos outros tratamentos, com significância mínima de 5\%.

\subsubsection{Influência das variações bioquímicas na desmistura espectral das espécies-alvo}

Quando se pensa em analisar a importância das variações bioquímicas nas respostas espectrais das espécies e, consequentemente, em sua desmistura espectral, primeiramente, deve se considerar que diferentes compostos bioquímicos interagem diretamente com a energia eletromagnética em um determinado intervalo espectral. Também, além das variações interespecíficas, as variações intraespecíficas de compostos bioquímicos podem ser essenciais à discriminação espectral, considerando sua possível influência na pureza dos espectros a serem desmisturados. Dessa forma, a análise de causalidade parte do pressuposto de que altas variações interespecíficas de determinado composto bioquímico devem influenciar positivamente as classificações espectrais das espécies, enquanto elevadas variações intraespecíficas de dado composto influenciam negativamente a desmistura espectral das espécies, em um determinado intervalo espectral.

Para tanto, análises de correlação foram realizadas entre as variações inter e intraespecíficas de compostos bioquímicos (representadas pelos desvios padrão da média de cada tratamento em relação à média da população e das amostras dentro de cada tratamento, respectivamente) e as exatidões específicas de classificação (exatidões do produtor, referentes aos erros de omissão espectral), através da análise do coeficiente de correlação momento-produto de Pearson (r). Foram selecionados os pares de métricas com $r \geq|0,4|$, que corresponderam às correlações moderadas e fortes: i) diretamente proporcionais, variação interespecífica do composto - exatidão específica de classificação; e ii) indiretamente proporcionais, variação intraespecífica de determinado composto - exatidão específica de classificação. Além disso, foram estudadas apenas as possíveis relações de 
causalidade direta: pigmentos foliares vs. exatidões de classificação do VIS e do VSWIR e compostos estruturais e água foliar vs. exatidões do NIR, SWIR e VSWIR.

De posse das maiores correlações de Pearson, modelos de regressão linear com o máximo de três variáveis independentes foram gerados e testados estatisticamente, através da análise de variância da regressão via teste $\mathrm{F}$. Considerando a(s) variável(is) independente(s) $X_{i}$ (desvios padrões inter ou intraespecíficos de compostos bioquímicos) e a variável dependente $Y$ (exatidões do produtor do correspondente intervalo espectral), as hipóteses nulas testadas foram as de que todos os coeficientes da equação de regressão são iguais a zero $\left(\beta_{0}=\beta_{1}=\beta_{i}=0\right)$.

\subsection{Resultados}

\subsubsection{Variações bioquímicas entre espécies e momentos sazonais}

As hipóteses nulas que assumem a inexistência de variações de compostos bioquímicos entre as espécies-alvo, no período chuvoso, foram rejeitadas $(\alpha=0,05)$ para todos os pigmentos foliares e aceitas para os componentes estruturais e água foliar, excluindo-se a celulose (rejeitada com $0,1 \%$ de significância). No período seco, no entanto, apenas os teores de carotenoides + xantofilas não apresentaram variações estatisticamente significantes $(\alpha=0,05)$ entre as espécies-alvo (Tabela 4.2). 
Tabela 4.2. Análise de variância (teste F) de compostos bioquímicos foliares entre as espécies-alvo, para os diferentes períodos estudados, sendo que $H_{0}$ assume a inexistência de variação estatisticamente significante de determinado composto entre as espécies estudadas.

\begin{tabular}{|c|c|c|c|c|}
\hline ANOVA & \multicolumn{2}{|c|}{ Período chuvoso } & \multicolumn{2}{|c|}{ Período seco } \\
\hline Composto bioquímico & $\mathrm{H}_{0}$ & valor de $p$ & $\mathrm{H}_{0}$ & valor de $p$ \\
\hline Clorofila a $(\mu \mathrm{g} / \mathrm{mg})$ & Rejeitada $^{\star \star \star}$ & $3,73 e-04$ & Rejeitada* & $1,46 \mathrm{e}-02$ \\
\hline Clorofila $b(\mu \mathrm{g} / \mathrm{mg})$ & Rejeitada* & $2,20 \mathrm{e}-02$ & Rejeitada** & $8,01 \mathrm{e}-03$ \\
\hline Carotenoides + xantofilas $(\mu \mathrm{g} / \mathrm{mg})$ & Rejeitada* & $3,07 \mathrm{e}-02$ & Aceita* $^{*}$ & $5,34 \mathrm{e}-02$ \\
\hline Antocianina $(\Delta / \mathbf{m g})$ & Rejeitada $^{* \star *}$ & $2,14 \mathrm{e}-04$ & Rejeitada** $^{* *}$ & $2,06 e-03$ \\
\hline Celulose $(\mathrm{mg} / \mathrm{g})$ & Rejeitada*** & $9,05 e-05$ & Rejeitada** & $8,37 e-03$ \\
\hline Hemicelulose $(\mathrm{mg} / \mathrm{g})$ & Aceita* $^{*}$ & $1,24 \mathrm{e}-01$ & Rejeitada*** & $3,81 \mathrm{e}-04$ \\
\hline Lignina insolúvel (\%) & Aceita* & $6,52 e-02$ & Rejeitada $^{* \star *}$ & $7,28 \mathrm{e}-06$ \\
\hline Água (\%) & Aceita* & $1,92 \mathrm{e}-01$ & Rejeitada*** & $8,71 \mathrm{e}-06$ \\
\hline
\end{tabular}

${ }^{\star * *} F$ significativo a $0,1 \%$ de probabilidade.

${ }^{* *}$ F significativo a $1 \%$ de probabilidade.

${ }^{*} F$ significativo a $5 \%$ de probabilidade.

Os valores médios, referentes a cada espécie-alvo, dos compostos bioquímicos hemicelulose $(\alpha=0,01)$, lignina insolúvel $(\alpha=0,05)$ e água foliar $(\alpha=0,05)$ apresentaram diferenças estatisticamente significantes entre os períodos sazonais estudados. Enquanto os teores de lignina insolúvel (valores médios: período chuvoso - PC =60,26\%; período seco $-\mathrm{PS}=18,95 \%)$ e de água foliar (PC = 38,49\%; PS = 24,25\%) decresceram do período chuvoso ao período seco, os teores de hemicelulose aumentaram $(\mathrm{PC}=4,42 \%$; $\mathrm{PS}=$ 7,83\%) significativamente.

Dentre os compostos analisados, destacam-se aqueles que apresentaram variações significantes com pelo menos $0,1 \%$ de significância na diferenciação química de espécies, descritos na Tabela 4.2 acima. TAOC apresentou valores muito elevados de clorofila a no período chuvoso (Figura 4.2-A). Esses valores foram estatisticamente superiores $(\alpha=0,01)$ àqueles observados para todas as outras espécies-alvo, que, por sua vez, não demonstram contrastes significantes entre si. INVE no período chuvoso apresentou valores de antocianina também superiores a todas as outras quatro espécies-alvo $(\alpha=0,05$ em relação à QUGR e $\alpha=0,01$ às outras espécies), enquanto QUGR apresentou valores de antocianina superiores $(\alpha=0,05)$ aos observados para CABR, CEFI e TAOC (Figura 4.2-B). Ainda no período chuvoso, TAOC e CABR apresentaram os maiores valores de celulose, sendo que os valores de TAOC foram superiores $(\alpha=0,05)$ aos observados para CABR (Figura 4.2-C). 
Os valores de celulose de TAOC foram significantemente ainda mais elevados $(\alpha=0,01)$ se comparados aos referentes à CEFI, INVE, QUGR. A celulose em CABR foi também superior ao observado em CEFI $(\alpha=0,05)$ e em QUGR e INVE $(\alpha=0,01)$, respectivamente.

No período seco, destacaram-se as variações entre espécies em hemicelulose, lignina insolúvel e água. Valores de hemicelulose foram significantemente inferiores $(\alpha=$ $0,01)$ nas folhas de INVE, quando comparados à quantidade desse composto nas outras quatro espécies-alvo. Embora QUGR e TAOC sejam as únicas espécies de Cerrado "sensu stricto" e representativas do mesmo geoambiente, QUGR apresentou valores de hemicelulose inferiores $(\alpha=0,05)$ aos observados em TAOC na época de estiagem (Figura 4.2-D). Um comportamento diferente é observado naquelas duas espécies, quando analisados os teores de lignina insolúvel (Figura 4.2-E). Ambas apresentaram os menores teores desse composto, sem variação estatisticamente significante $(\alpha=0,05)$ entre elas. Seus teores de lignina insolúvel foram inferiores $(\alpha=0,01)$ a todas as outras espécies-alvo (CABR, CEFI e INVE; espécies florestais). O teor de lignina em CEFI também foi inferior ao observado em CABR, considerando $\alpha=0,05$. Os teores de água de TAOC, no período seco, foram estatisticamente inferiores $(\alpha=0,01)$ àqueles das folhas de QUGR, CABR, INVE e CEFI, respectivamente (Figura 4.2-F). CEFI também apresentou baixos teores de água foliar; esses foram inferiores aos observados em folhas de QUGR e CABR $(\alpha=0,01)$ e de INVE $(\alpha=0,05)$. INVE ainda apresentou teores de água foliar estatisticamente inferiores $(\alpha=$ 0,05) à QUGR. 
A

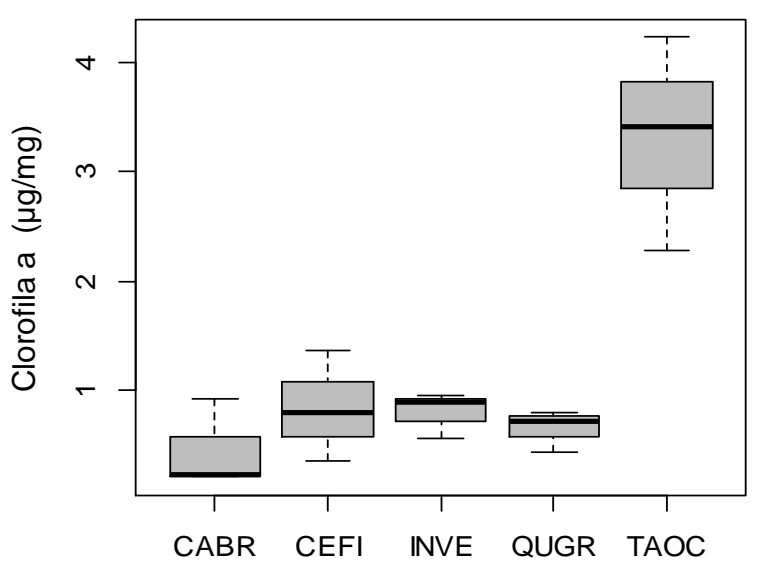

C

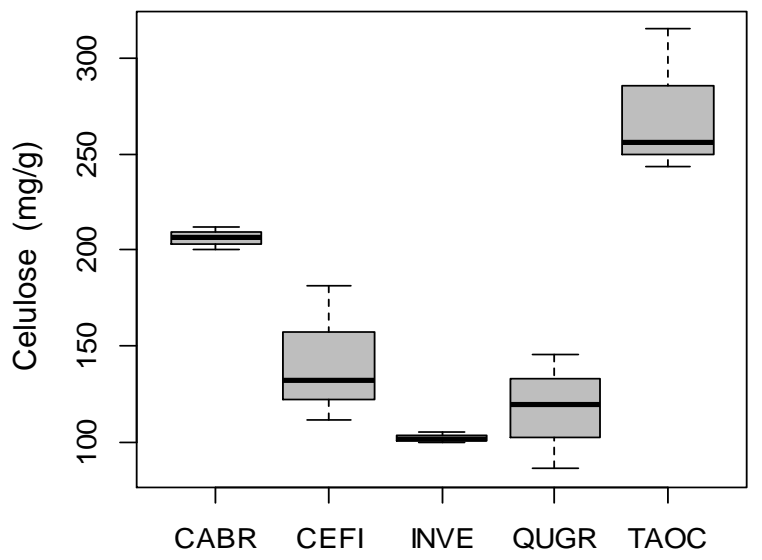

$\mathrm{E}$

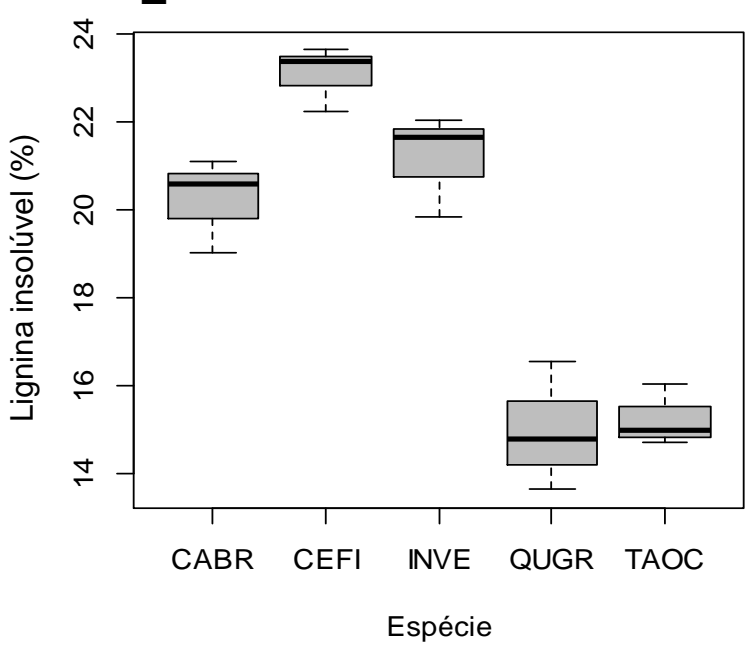

B
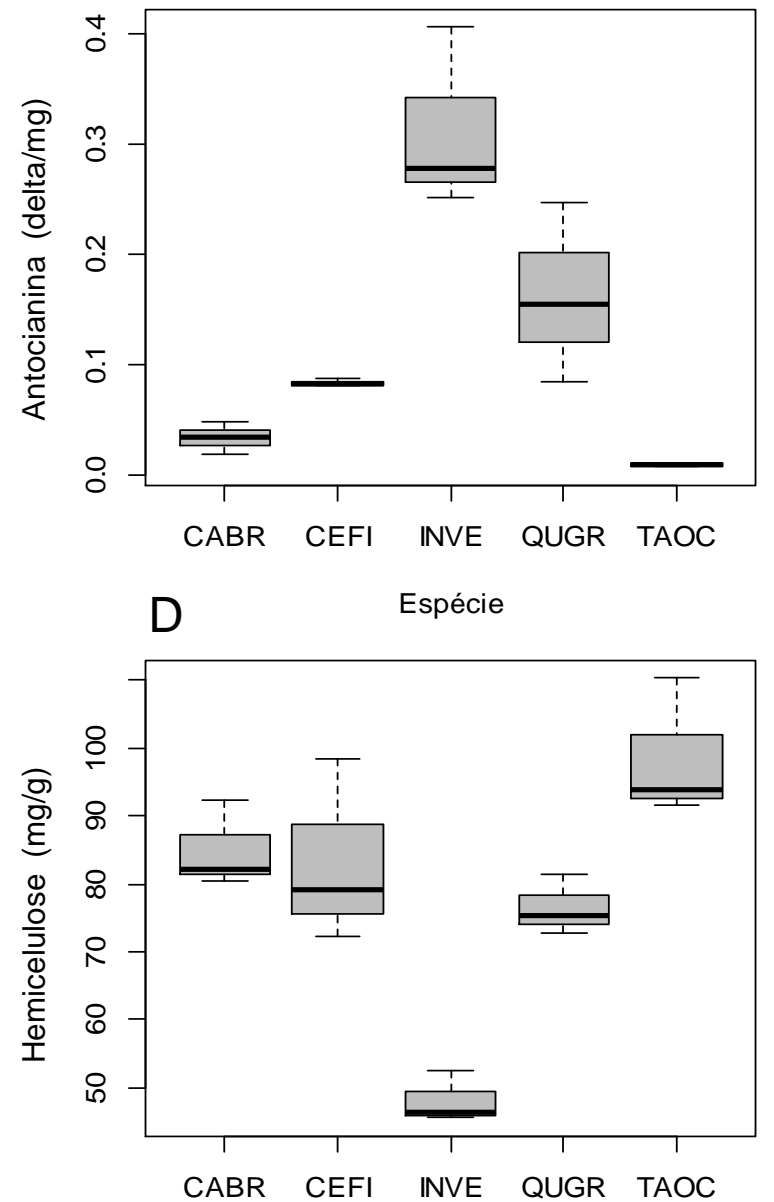

$\mathrm{F}$

Espécie

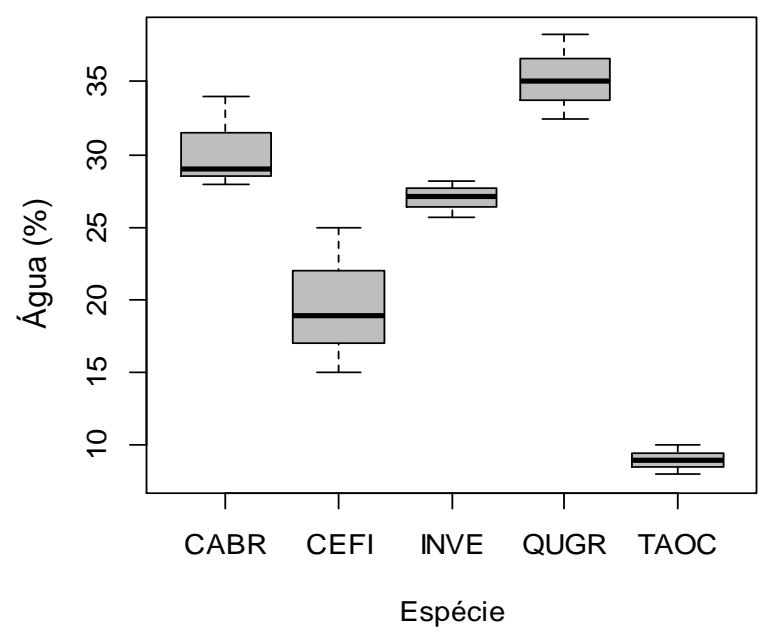

Figura 4.2. Variações de compostos bioquímicos entre espécies-alvo, estatisticamente significantes a $0,1 \%$ : Clorofila a $(\mu \mathrm{g} / \mathrm{mg})$, período chuvoso - PC (A); Antocianina $(\Delta / \mathrm{mg})-\mathrm{PC}(\mathrm{B})$; Celulose $(\mathrm{mg} / \mathrm{g})-$ PC (C); Hemicelulose (mg/g), período seco - PS (D); Lignina insolúvel (\%) - PS (E) e Água (\%) - PS $(\mathrm{F})$.

Ao analisar as variações em compostos bioquímicos entre os períodos chuvoso e seco, por espécie-alvo, foi possível verificar que não há um único composto que variou 
significantemente (ou não variou) em todas elas (Tabela 4.3). Do período chuvoso ao seco, entre os pigmentos foliares, destacam-se o aumento $(\alpha=0,001)$ em clorofila $b$ apenas nas folhas de INVE e a diminuição $(\alpha=0,05)$ em carotenoides + xantofilas nas folhas de CEFI. Variações significativas de compostos estruturais, entre períodos, foram observadas em mais espécies-alvo. As folhas de todas elas apresentaram aumento em hemicelulose e redução em lignina do período chuvoso ao seco. Essas variações só não foram significativas, com pelo menos 5\% de significância, nas folhas de INVE (hemicelulose) e de QUGR (lignina).

Tabela 4.3. Significância das variações de compostos bioquímicos entre os períodos chuvoso (C) e seco $(S)$ nas folhas das espécies-alvo: período de maior concentração $(P)$ e valor de $p$ do teste $F$ (ANOVA).

\begin{tabular}{|c|c|c|c|c|c|c|c|c|c|c|}
\hline \multirow{2}{*}{$\begin{array}{c}\text { ANOVA } \\
\text { Composto } \\
\text { bioquímico }\end{array}$} & \multicolumn{2}{|r|}{ CABR } & \multicolumn{2}{|r|}{ CEFI } & \multicolumn{2}{|r|}{ INVE } & \multicolumn{2}{|c|}{ QUGR } & \multicolumn{2}{|r|}{ TAOC } \\
\hline & $\mathbf{P}$ & $p$ & $\mathbf{P}$ & $p$ & $\mathbf{P}$ & $p$ & $\mathbf{P}$ & $p$ & $\mathbf{P}$ & $p$ \\
\hline Clorofila a $(\mu \mathrm{g} / \mathrm{g})$ & $S$ & 0,155 & $\mathrm{C}$ & 0,794 & $S$ & $0,003^{* *}$ & $\mathrm{C}$ & 0,897 & $\mathrm{C}$ & $0,017^{*}$ \\
\hline Clorofila b $(\mu \mathrm{g} / \mathrm{g})$ & C & 0,951 & $\mathrm{~S}$ & 0,081 & $S$ & $2,35 \mathrm{E}-05^{\star * *}$ & C & 0,255 & $S$ & 0,272 \\
\hline $\begin{array}{l}\text { Carotenoides }+ \\
\text { xantofilas }(\mu \mathrm{g} / \mathrm{g})\end{array}$ & C & 0,920 & C & $0,021^{*}$ & $S$ & 0,063 & C & 0,362 & C & 0,293 \\
\hline $\begin{array}{l}\text { Antocianina } \\
\text { (delta/mg) }\end{array}$ & $S$ & 0,826 & $S$ & $0,048^{*}$ & C & $0,008^{* *}$ & C & 0,097 & $S$ & $0,003^{* *}$ \\
\hline Celulose (mg/g) & $\mathrm{C}$ & 0,533 & $S$ & 0,651 & $S$ & $0,001^{* * *}$ & $S$ & 0,052 & $\mathrm{C}$ & $0,044^{*}$ \\
\hline Hemicelulose $(\mathrm{mg} / \mathrm{g})$ & $\mathrm{S}$ & $0,003^{* *}$ & $S$ & $0,005^{\star \star}$ & $S$ & 0,060 & $\mathrm{~S}$ & $0,004^{* *}$ & $\mathrm{~S}$ & $0,008^{* *}$ \\
\hline Lignina insolúvel (\%) & C & $4,10 \mathrm{E}-05^{\star \star *}$ & C & $1,48 \mathrm{E}-04^{\star \star \star}$ & C & $3,33 \mathrm{E}-04^{\star \star *}$ & C & 0,082 & C & $0,001^{* \star *}$ \\
\hline Água (\%) & $C$ & $0,008^{* *}$ & $\mathrm{C}$ & $0,004^{\star \star}$ & $C$ & 0,119 & $\mathrm{~S}$ & 0,399 & $C$ & $1,15 \mathrm{E}-05^{\star \star *}$ \\
\hline
\end{tabular}

Os dados integrais de pigmentos, compostos estruturais e água foliar, por indivíduo/espécie-alvo e de ambos os momentos sazonais, são apresentados no Apêndice C. 


\subsubsection{Classificações espectrais MESMA com dois membros-finais}

\subsubsection{Exatidões globais}

A classificação das espécies-alvo utilizando espectros originais de reflectância VSWIR e MF selecionados via IES apresentou a maior exatidão global $(90,0 \%)$ e coeficiente Kappa $(0,875)$, para o período chuvoso. A segunda e a terceira melhores classificações espectrais utilizando dados desse período foram atingidas, respectivamente, com espectros VSWIR $(C R)$ e métrica IES de seleção de MF (exatidão global = 82,5\% e coeficiente Kappa = 0,781), e com espectros SWIR e MF selecionados através da métrica IES* $(80,0 \%$ e 0,750$)$. Os piores resultados foram observados para os dados VIS(CR) independentemente da métrica utilizada para seleção de MF (50,0\% e 0,375) (Figura 4.3).

Não foram observadas diferenças estatisticamente significantes $(\alpha=0,05)$ entre as classificações das espécies-alvo com diferentes intervalos espectrais (VIS, NIR, SWIR e VSWIR). A remoção de contínuo dos espectros, que deve realçar feições de absorção presentes no intervalo de dados, também não influenciou significantemente $(\alpha=0.05)$ os resultados das classificações espectrais, quando comparadas àquelas realizadas utilizandose os dados originais de reflectância. Os coeficientes Kappa das classificações por MF selecionados via EMC e via IES (IES*) também não foram estatisticamente significantes com, pelo menos, $5 \%$ de significância. 

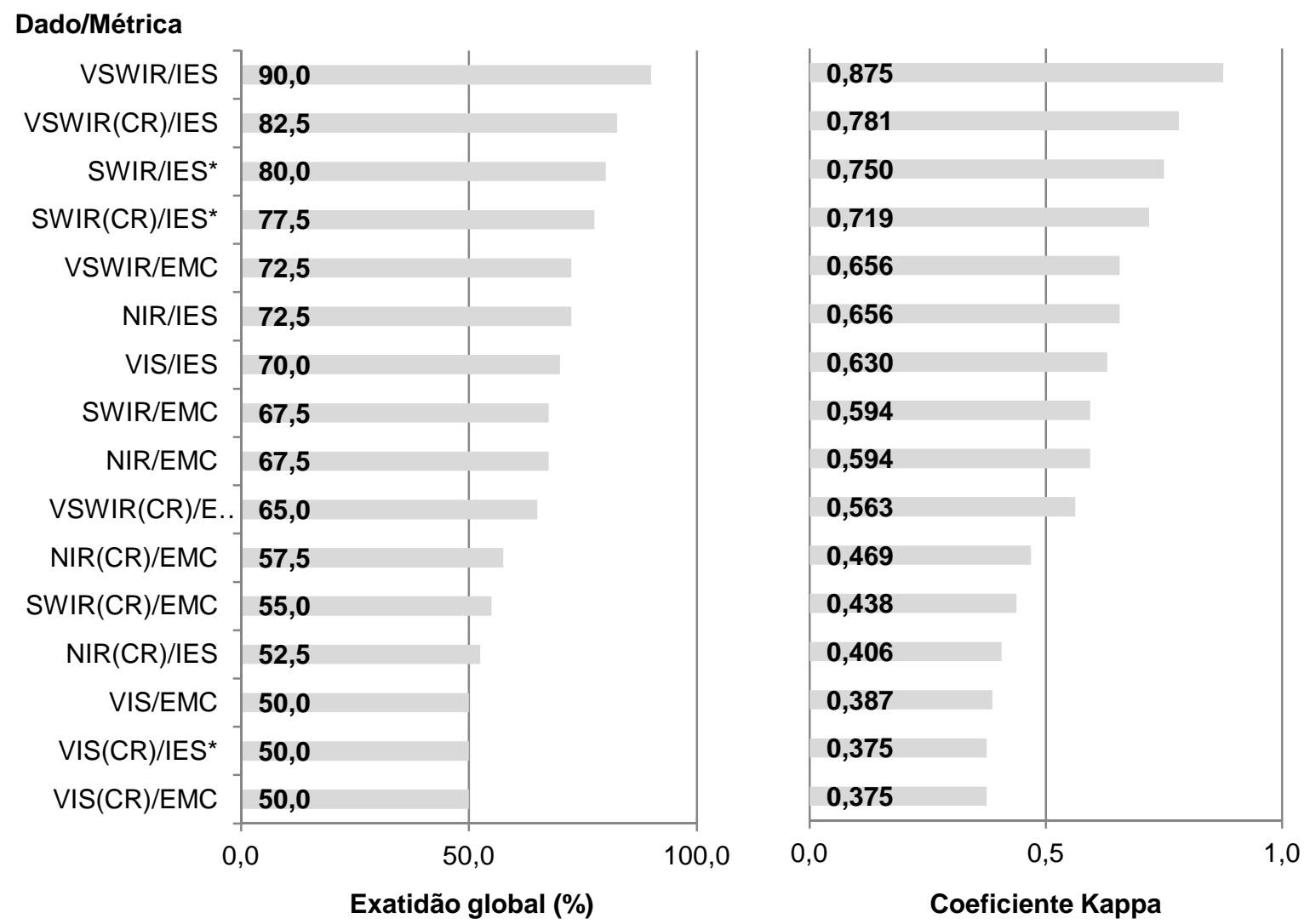

Figura 4.3. Exatidão global (\%) e coeficiente Kappa das classificações MESMA com dois membrosfinais aplicadas aos dados espectrais foliares de cinco espécies arbóreas, coletados no período chuvoso. Dados VIS, NIR, SWIR e VSWIR, em reflectância ou com o contínuo removido (CR), e métrica para seleção de membros-finais EMC ou IES(IES*). Dados apresentados de forma ranqueada do maior para o menor coeficiente Kappa.

A mais alta exatidão global $(85,0 \%)$ e mais alto coeficiente Kappa $(0,814)$ obtidos nas classificações das cinco espécies-alvo no período seco ocorreram utilizando-se os dados VSWIR(CR) e MF selecionados via EMC. Como pode ser observado na Figura 4.4, a classificação espectral realizada sobre os dados SWIR(CR)/IES apresentou resultados globais semelhantes ao anterior (exatidão global $=85,0 \%$ e coeficiente Kappa $=0,813$ ). As classificações das espécies-alvo com dados VIS(CR)/EMC e NIR(CR)/EMC apresentaram os piores resultados do período seco; ambas atingiram $42,5 \%$ de exatidão global e coeficiente Kappa de 0,294.

Contudo, diferenças estatisticamente significantes $(\alpha=0,05)$ não foram encontradas entre os coeficientes Kappa obtidos sobre os diferentes intervalos espectrais utilizados (VIS, NIR, SWIR e VSWIR). O uso de dados em reflectância ou de dados com o contínuo removido também não interferiu significantemente $(\alpha=0.05)$ nos resultados de classificação 
de espécies, no período seco. As classificações espectrais utilizando MF selecionados via EMC ou via IES (IES*) também não apresentaram diferenças estatisticamente diferentes ( $\alpha$ $=0.05)$ sobre os dados do período seco.
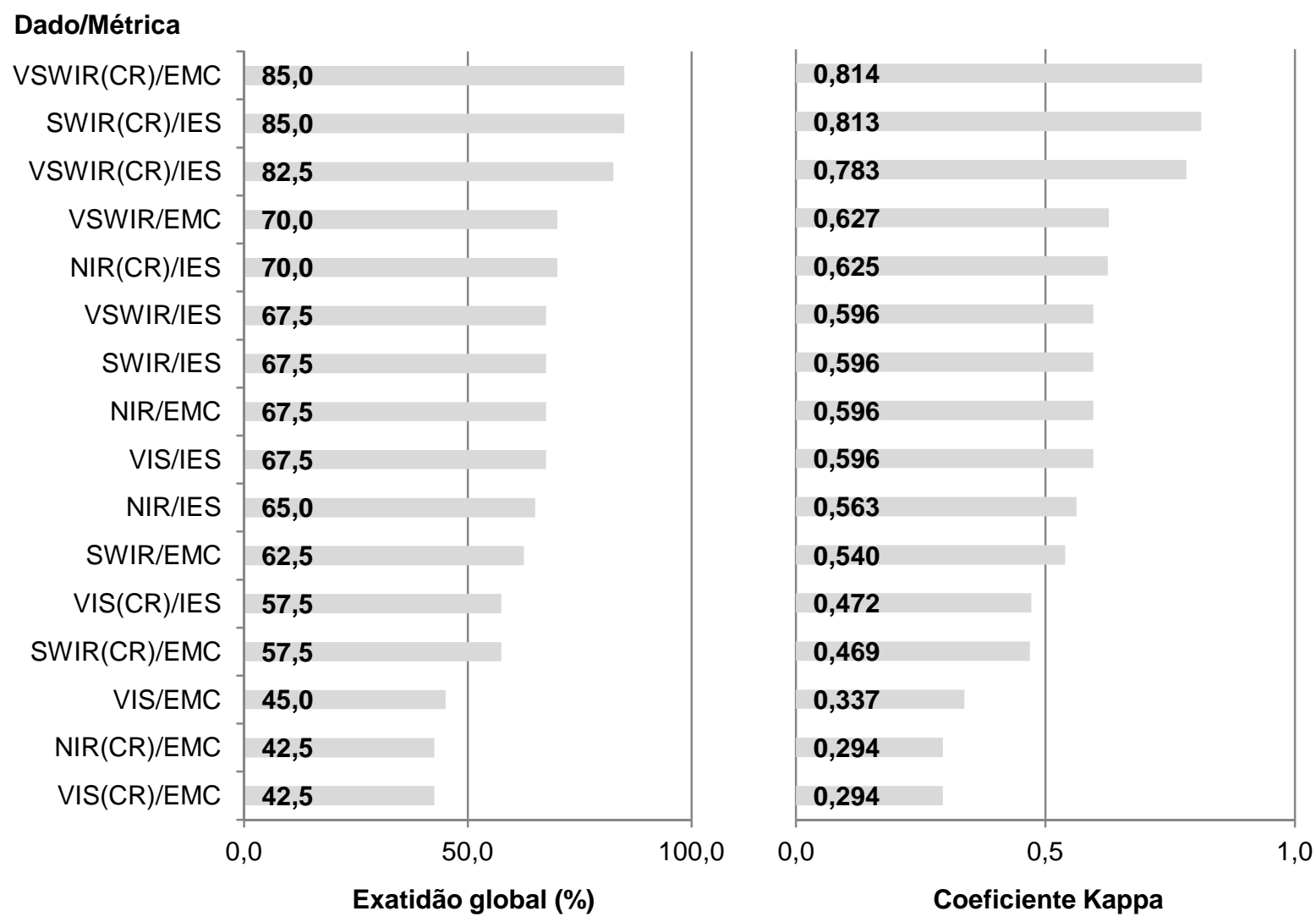

Figura 4.4. Exatidão global (\%) e coeficiente Kappa das classificações MESMA com dois membrosfinais aplicadas aos dados espectrais foliares de cinco espécies arbóreas, coletados no período seco. Dados VIS, NIR, SWIR e VSWIR, em reflectância ou com o contínuo removido (CR), e métricas para seleção de membros-finais EMC ou IES(IES*). Dados apresentados de forma ranqueada do maior para o menor coeficiente Kappa.

Enquanto a mais alta exatidão global e o mais alto coeficiente Kappa, entre as classificações das espécies-alvo, foram atingidos com os dados VSWIR/IES do período chuvoso, a segunda e a terceira melhores classificações espectrais das espécies-alvo foram atingidas sobre dados do período seco (VSWIR(CR)/EMC e SWIR(CR)/IES, respectivamente).

A hipótese nula que assume não haver um melhor momento sazonal para a classificação espectral das cinco espécies-alvo em escala de folha foi aceita com, pelo menos, $5 \%$ de significância; ou seja, variações estatisticamente significantes não foram 
observadas entre os coeficientes Kappa das classificações realizadas com dados do período chuvoso e do período seco. As variações dos coeficientes Kappa entre momentos sazonais também foram insignificantes $(\alpha=0.05)$, quando analisados os diferentes intervalos espectrais separadamente (VIS - período chuvoso vs. VIS - período seco, NIR - período chuvoso vs. NIR - período seco, SWIR - período chuvoso vs. SWIR - período seco e VSWIR - período chuvoso vs. VSWIR - período seco).

\subsubsection{Exatidões específicas e relações de mistura espectral entre espécies-alvo}

Considerando as mais altas e mais equilibradas exatidões do produtor (EP) e do usuário (EU), Calophyllum brasiliense (CABR), Cedrela fissilis (CEFI) e Qualea grandiflora (QUGR) apresentaram seus melhores resultados de classificação com espectros do período chuvoso, utilizando-se dados SWIR e métrica IES* para seleção de MF (CABR e QUGR) e dados VSWIR/IES (CEFI). Inga vera subsp. affinis (INVE) e Tabebuia ochracea (TAOC) foram mais bem classificadas com espectros $\operatorname{VSWIR}(C R)$ do período seco e MF selecionados através da métrica EMC (Tabela 4.4). Contudo, apenas TAOC apresentou variações estatisticamente significantes $(\alpha=0,05)$ entre as exatidões específicas atingidas com dados do período chuvoso e do período seco. Enquanto, nas classificações de espectros do período seco essa classe apresentou EU média de 93,75\% (variância = $52,08 \%)$, no período chuvoso apresentou EU média de 72,98\% (126,98\%), indicando que neste período mais espectros oriundos de outras classes foram erroneamente classificados como sendo de TAOC. A hipótese nula de que não há variação entre as exatidões específicas de classificação realizadas sobre os diferentes intervalos espectrais foi aceita ( $\alpha$ $=0,05)$, para ambos os momentos sazonais. 
Tabela 4.4. Exatidões do produtor (EP) e do usuário (EU), em porcentagem, para cada classe (espécie-alvo) do estudo, obtidas sobre os melhores resultados globais por região espectral (VSWIR, VIS, NIR, SWIR) e período sazonal (chuvoso e seco).

\begin{tabular}{|c|c|c|c|c|c|c|c|c|c|c|}
\hline \multicolumn{11}{|c|}{ Período chuvoso } \\
\hline \multirow{2}{*}{ Dado/Método } & \multicolumn{2}{|c|}{ CABR } & \multicolumn{2}{|c|}{ CEFI } & \multicolumn{2}{|c|}{ INVE } & \multicolumn{2}{|c|}{ QUGR } & \multicolumn{2}{|c|}{ TAOC } \\
\hline & EP & EU & EP & EU & EP & EU & EP & EU & EP & EU \\
\hline VSWIR/IES & 87,5 & 87,5 & 87,5 & 87,5 & 100,0 & 88,9 & 75,0 & 100,0 & 100,0 & 88,9 \\
\hline$\overline{\text { SWIR/IES }}{ }^{*}$ & 87,5 & 100,0 & 12,5 & 50,0 & 100,0 & 66,7 & 100,0 & 100,0 & 100,0 & 72,7 \\
\hline NIR/IES & 62,5 & 83,3 & 100,0 & 66,7 & 75,0 & 85,7 & 37,5 & 75,0 & 87,5 & 63,6 \\
\hline VIS/IES & 87,5 & 87,5 & 62,5 & 62,5 & 100,0 & 72,7 & 50,0 & 80,0 & 50,0 & 66,7 \\
\hline \multicolumn{11}{|c|}{ Período seco } \\
\hline \multirow{2}{*}{ Dado/Método } & \multicolumn{2}{|c|}{ CABR } & \multicolumn{2}{|c|}{ CEFI } & \multicolumn{2}{|c|}{ INVE } & \multicolumn{2}{|c|}{ QUGR } & \multicolumn{2}{|c|}{ TAOC } \\
\hline & EP & EU & EP & EU & EP & EU & EP & $\overline{E U}$ & EP & EU \\
\hline VSWIR(CR)/EMC & 87,5 & 70,0 & 75,0 & 85,7 & 100,0 & 100,0 & 62,5 & 83,3 & 100,0 & 100,0 \\
\hline SWIR(CR)/IES & 87,5 & 87,5 & 62,5 & 100,0 & 100,0 & 88,9 & 87,5 & 70,0 & 87,5 & 87,5 \\
\hline NIR(CR)/IES & 75,0 & 85,7 & 62,5 & 55,6 & 75,0 & 66,7 & 62,5 & 55,6 & 75,0 & 100,0 \\
\hline VIS/IES & 62,5 & 100,0 & 75,0 & 50,0 & 50,0 & 80,0 & 62,5 & 55,6 & 87,5 & 87,5 \\
\hline
\end{tabular}

Constatou-se que apenas no período seco os erros de classificação espectral são significantemente diferentes $(\alpha=0,05)$ entre pares de espécies-alvo. Destacam-se, por suas significâncias, as maiores taxas de mistura espectral entre CEFI e QUGR $(14,10 \%$ de seus espectros) e entre CABR e QUGR (12,53\%), bem como as ausências de mistura de espectral entre INVE e TAOC e entre QUGR e TAOC (Tabela 4.5). As variações em mistura espectral de pares de espécies-alvo entre as classificações de dados do período chuvoso e do período seco não foram estatisticamente significantes $(\alpha=0,05)$. 
Tabela 4.5. Média $(\bar{X})$ (desvio padrão $(\sigma)$ ) e estimativa de contraste entre médias das taxas de mistura espectral entre pares de classes, provenientes das classificações MESMA de espectros do período seco.

\begin{tabular}{|c|c|c|c|c|c|c|c|c|c|c|c|}
\hline $\begin{array}{l}\text { Pares } \\
\text { de } \\
\text { classes }\end{array}$ & $\bar{X}(\sigma)$ & $\begin{array}{l}\text { CEFI- } \\
\text { QUGR }\end{array}$ & $\begin{array}{l}\text { CABR- } \\
\text { QUGR }\end{array}$ & $\begin{array}{l}\text { CEFI- } \\
\text { INVE }\end{array}$ & $\begin{array}{l}\text { INVE- } \\
\text { QUGR }\end{array}$ & $\begin{array}{l}\text { CEFI- } \\
\text { TAOC }\end{array}$ & $\begin{array}{l}\text { CABR- } \\
\text { TAOC }\end{array}$ & $\begin{array}{c}\text { CABR- } \\
\text { CEFI }\end{array}$ & $\begin{array}{l}\text { CABR } \\
\text {-INVE }\end{array}$ & $\begin{array}{l}\text { INVE- } \\
\text { TAOC }\end{array}$ & $\begin{array}{l}\text { QUGR- } \\
\text { TAOC }\end{array}$ \\
\hline $\begin{array}{l}\text { CEFI- } \\
\text { QUGR }\end{array}$ & $\begin{array}{c}14,10 \\
( \pm 5,99)\end{array}$ & $x$ & & & & & & & & & \\
\hline $\begin{array}{l}\text { CABR- } \\
\text { QUGRR }\end{array}$ & $\begin{array}{c}12,53 \\
( \pm 5,10)\end{array}$ & 1,58 & $x$ & & & & & & & & \\
\hline $\begin{array}{l}\text { CEFI- } \\
\text { INVE }\end{array}$ & $\begin{array}{c}7,83 \\
( \pm 9,39)\end{array}$ & 6,28 & 4,70 & $x$ & & & & & & & \\
\hline $\begin{array}{l}\text { INVE- } \\
\text { QUGR }\end{array}$ & $\begin{array}{c}7,83 \\
( \pm 5,98)\end{array}$ & 6,28 & 4,70 & 0,00 & $x$ & & & & & & \\
\hline $\begin{array}{l}\text { CEFI- } \\
\text { TAOC }\end{array}$ & $\begin{array}{c}6,28 \\
( \pm 5,10)\end{array}$ & 7,83 & 6,25 & 1,55 & 1,55 & $x$ & & & & & \\
\hline $\begin{array}{l}\text { CABR- } \\
\text { TAOC }\end{array}$ & $\begin{array}{c}3,15 \\
( \pm 3,64)\end{array}$ & 10,95 & 9,38 & 4,68 & 4,68 & 3,13 & $x$ & & & & \\
\hline $\begin{array}{l}\text { CABR- } \\
\text { CEFI }\end{array}$ & $\begin{array}{c}1,58 \\
( \pm 3,15)\end{array}$ & $12,53^{*}$ & 10,95 & 6,25 & 6,25 & 4,70 & 1,58 & $x$ & & & \\
\hline $\begin{array}{l}\text { CABR- } \\
\text { INVE }\end{array}$ & $\begin{array}{c}1,58 \\
( \pm 3,15)\end{array}$ & $12,53^{*}$ & 10,95 & 6,25 & 6,25 & 4,70 & 1,58 & 0,00 & $x$ & & \\
\hline $\begin{array}{l}\text { INVE- } \\
\text { TAOC }\end{array}$ & $\begin{array}{c}0,00 \\
( \pm 0,00)\end{array}$ & $14,10^{*}$ & $12,53^{*}$ & 7,83 & 7,83 & 6,28 & 3,15 & 1,58 & 1,58 & $x$ & \\
\hline $\begin{array}{l}\text { QUGR- } \\
\text { TAOC }\end{array}$ & $\begin{array}{c}0,00 \\
( \pm 0,00)\end{array}$ & $14,10^{*}$ & $12,53^{*}$ & 7,83 & 7,83 & 6,28 & 3,15 & 1,58 & 1,58 & 0,00 & $\mathrm{x}$ \\
\hline
\end{tabular}

${ }^{*}$ Médias estatisticamente diferentes via teste de Tukey $(\alpha=0,05)$.

\subsubsection{Influência das variações bioquímicas na desmistura espectral das espécies-alvo}

A análise de causalidade indicou que os erros específicos de omissão espectral observados nas classificação de dados VIS, do período chuvoso, e de dados SWIR e VSWIR, do período seco, podem ser explicados pelas variações em compostos químicos e água nas folhas das espécies-alvo (Tabela 4.6). As EP obtidas com dados VIS, do período chuvoso, pudem ser explicadas linearmente pelas variações interespecíficas dos compostos clorofila b e antocianina e intraespecífica de carotenoides + xantofilas $\left(R^{2}\right.$ ajustado $=1,0 ; p=$ 0,01). Já no período seco, as EP obtidas nas classificações com dados SWIR demostraram possível dependência linear das variações intraespecíficas em hemicelulose e em água foliar $\left(R^{2}\right.$ ajustado $\left.=0,95 ; p=0,02\right)$ e as EP obtidas com dados VSWIR, das variações intraespecíficas em antocianina e interespecíficas em hemicelulose $\left(R^{2}\right.$ ajustado $=0,99 ; p=$ $0,01)$. 
Tabela 4.6. Regressões lineares, com significância de $\mathrm{F}$ acima de $5 \%$, de melhor ajuste e menor erro padrão, por período de amostragem. Considerando as relações de causalidade das variações intra e interespecíficas de compostos bioquímicos $-X_{i}$ (desvio padrão considerado/ coeficiente de correlação de Pearson com a variável $Y$ ) nas exatidões do produtor (EP) - Y, obtidas nas classificações MESMA com dois membros-finais, utilizando-se dados do visível (VIS), infravermelho ondas curtas (SWIR) e todo espectro óptico (VSWIR).

\begin{tabular}{|c|c|c|c|c|c|c|}
\hline \multirow{12}{*}{ 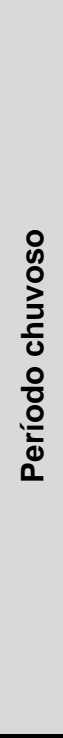 } & $\mathbf{Y}$ & EP-VIS & \multirow{12}{*}{ 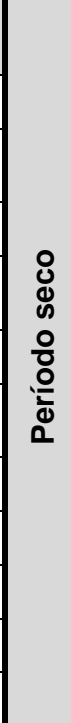 } & $\mathbf{Y}$ & EP-SWIR & EP-VSWIR \\
\hline & $\beta_{0}$ & 41,92 & & $\beta_{0}$ & 112,17 & 88,20 \\
\hline & $x_{1}$ & $\begin{array}{c}\text { Clorofila B } \\
\text { (DP-INTER/0.89) } \\
\end{array}$ & & $x_{1}$ & $\begin{array}{c}\text { Hemicelulose } \\
\text { (DP-INTRA/-0.87) }\end{array}$ & $\begin{array}{c}\text { Antocianina } \\
\text { (DP-INTRA/-0.93) }\end{array}$ \\
\hline & $\beta_{1}$ & 200,65 & & $\beta_{1}$ & $-2,34$ & $-792,37$ \\
\hline & $X_{2}$ & $\begin{array}{c}\text { Carotenoides + xantofilas } \\
\text { (DP-INTRA/-0,74) }\end{array}$ & & $X_{2}$ & $\begin{array}{c}\text { Água } \\
\text { (DP-INTRA/-0,86) }\end{array}$ & $\begin{array}{c}\text { Hemicelulose } \\
\text { (DP-INTRA/0,87) }\end{array}$ \\
\hline & $\beta_{2}$ & $-77,05$ & & $\beta_{2}$ & $-5,73$ & 1,29 \\
\hline & $X_{3}$ & $\begin{array}{c}\text { Antocianina } \\
(\text { DP-INTER/0,69) }\end{array}$ & & $X_{3}$ & & \\
\hline & $\beta_{3}$ & 276,14 & & $\beta_{3}$ & & \\
\hline & $\varepsilon$ & 0,52 & & $\varepsilon$ & 2,98 & 1,90 \\
\hline & $\mathbf{R}^{2}$ & 1,00 & & $\mathbf{R}^{2}$ & 0,98 & 0,99 \\
\hline & $R^{2}$ ajust. & 1,00 & & $R^{2}$ ajust. & 0,95 & 0,99 \\
\hline & Signif. F & 0,01 & & Signif. F & 0,02 & 0,01 \\
\hline
\end{tabular}

\subsection{Discussão}

Embora as variações das exatidões globais entre os períodos seco e chuvoso para os diferentes intervalos espectrais não tenham sido estatisticamente significantes $(\alpha=0,05)$, observou-se que as mais altas exatidões globais de classificações VIS, NIR e VSWIR foram atingidas utilizando-se dados do período chuvoso, enquanto a melhor classificação no SWIR ocorreu com espectros do período seco. Essa observação correlaciona-se com as maiores significâncias de variação em pigmentos foliares (excetuando-se clorofila b) e celulose observadas no período chuvoso, em comparação ao período seco, bem como à insignificância das variações dos compostos estruturais hemicelulose e lignina e da água foliar naquele período. As variações desses últimos compostos, que interagem com a energia incidente no IR, passaram a ser altamente significantes $(\alpha=0,001)$ entre as espécies-alvo no período seco. Hemicelulose, lignina e água foliar foram os únicos compostos bioquímicos que apresentaram variações significativas entre os períodos estudados. 
De forma geral, o conjunto de espécies-alvo foi muito bem classificado em ambos os momentos sazonais e isso parece ser reflexo da alta variação em química foliar observada entre as espécies, o que indica a existência de diferentes comportamentos fisiológicos entre elas durante o período das chuvas e o de estiagem. Fato semelhante já foi observado em espécies de hábitos variados em florestas secas e úmidas da América Central (Hesketh e Sánchez-Azofeifa, 2012). Foi possível verificar que não existem padrões distintos em composição bioquímica e resposta espectral entre as espécies indicadoras dos diferentes geoambientes da EEMG. Assim, mesmo que os pares de espécies CABR e INVE e QUGR e TAOC possam ser considerados pares de tipos funcionais distintos, por estarem associados a diferentes condições edafogeológicas (Lavorel et al., 1997; Reich et al., 2003); química e espectralmente esses pares de espécies não representam grupos com diferenciados padrões fisiológicos e fenológicos. Assim como entre ambientes, a distinção de espécies em grupos funcionais também se dá entre "estratégias" dentro de habitats (Reich et al., 2003). No cerrado "sensu lato", mais especificamente, as condições edáficas de solos pobres em nutrientes, com toxicidade por alumínio, bem como os eventuais episódios de fogo, têm sido associados à elevada variedade de estratégias fenológicas observada entre as espécies nativas do bioma (Eiten, 1972).

Apenas o teor de lignina insolúvel, no período seco, indicou uma distinção química entre tipos funcionais. Enquanto as espécies de cerrado - QUGR e TAOC, presentes nas áreas de interflúvio da EEMG - apresentaram baixos (e semelhantes) teores desse composto estrutural, as espécies de floresta estacional semidecidual - CABR, CEFI e INVE, que ocorrem nas matas ciliares da EEMG - apresentaram teores mais elevados (e semelhantes) de lignina insolúvel em suas folhas. Essa observação é contrastante ao observado por Asner (1998), que encontrou teores muito variáveis em lignina e celulose entre espécies de cerrado.

Embora tenha sido observado nas espécies higrófitas, CABR e INVE, um aumento no teor de clorofila a no período seco, não foram constatadas (em ambos os períodos) diferenças significativas em concentração desse composto entre elas, conjuntamente, e o 
outro grupo funcional ou CEFI. Apenas TAOC, no período chuvoso, apresentou concentração superior desse composto em relação às outras espécies. Outros aspectos importantes, e que também ratificam a existência de estratégias fenológicas distintas entre espécies de mesmo grupo-alvo, foram: i) o acúmulo de água observado nas folhas de QUGR no período seco, quando todas as outras espécies incluindo TAOC (também de cerrado) apresentaram redução do teor de água foliar, em comparação ao período das chuvas (variação sem significância estatística $(\alpha=0,05)$ apenas para INVE); ii) o aumento significativo em clorofila a $(\alpha=0,01)$ e b $(\alpha=0,001)$ observado para INVE, no período seco, o que não foi observado para CABR - ambas as espécies ocupam áreas com sedimentos e solos pelíticos e alagáveis no período chuvoso.

Muitas das variações químicas intra e interespecíficas puderam ser correlacionadas aos resultados de classificação espectral e aos espectros foliares das espécies-alvo (Figura 4.5). No período chuvoso, CABR foi a espécie melhor classificada na região do VIS, apresentou a menor reflectância média de espectros entre, aproximadamente, 0,5 e 0,7 $\mu \mathrm{m}$ (Figura 4.5-A) e a maior variação espectral interclasse nessa mesma região (Figura 4.5-C). Ao mesmo tempo, a quantidade de clorofila $b$ em suas folhas foi a mais elevada e estatisticamente superior à CEFI $(\alpha=0,05)$ e à INVE $(\alpha=0,01)$. As mais altas concentrações (e com maior variação intraclasse) de antocianina observadas para INVE e QUGR, ainda no período chuvoso, podem ter refletido nos maiores desvios padrão intraclasse observados para os espectros de ambas as espécies na região de 0,53 $\mu \mathrm{m}$ (Figura 4.5-B). Essas apresentaram alta taxa de mistura espectral, com 18,8\% de seus espectros erroneamente classificados entre si. Essa mistura espectral só não foi mais alta que aquela observada para as espécies CEFI e TAOC (25,5\%), que apresentaram alta similaridade espectral no primeiro terço do espectro visível $(\sim 0,4-0,5 \mu \mathrm{m})$ (Figura 4.5-A a 4.5-C). As mais altas concentrações de carotenoides + xantofilas também foram observadas naquelas espécies, embora apenas CEFI tenha se destacado significantemente perante as outras espécies, em relação à concentração desses compostos. 
No período seco, quando as variações em mistura espectral entre pares de espécies, passaram a ser significativas, outras relações químicas e espectrais puderam ser estabelecidas. Observou-se que as classes de espécies que apresentaram maior mistura espectral entre si não pertencem aos mesmos grupos-alvo (tipos funcionais). As maiores taxas de mistura espectral entre CEFI e QUGR puderam ser explicadas por suas maiores variações espectrais intraespecíficas, observadas para quase todo o espectro eletromagnético nesse período (Figura 4.5-E). A similaridade dos espectros médios no SWIR (Figura 4.5-D) e dos desvios padrões interespecíficos, principalmente na região de 1,9 $\mu \mathrm{m}$ (Figura 4.5-F), de CABR e QUGR - espécies que apresentam juntas a segunda maior taxa de mistura espectral do período seco - também indicam a dificuldade de se distinguir espectralmente essas duas espécies. As folhas de CABR e QUGR foram aquelas que apresentaram menor reflectância no SWIR e maior teor de água no período de estiagem. Contudo, ao analisar os desvios padrão intraclasse dessas espécies-alvo (Figura 4.5-E), diferentemente de QUGR, CABR apresentou a menor variação intraclasse no SWIR, o que pode ter garantido seu melhor resultado de classificação nesse período, dentre os resultados obtidos por intervalo espectral. 

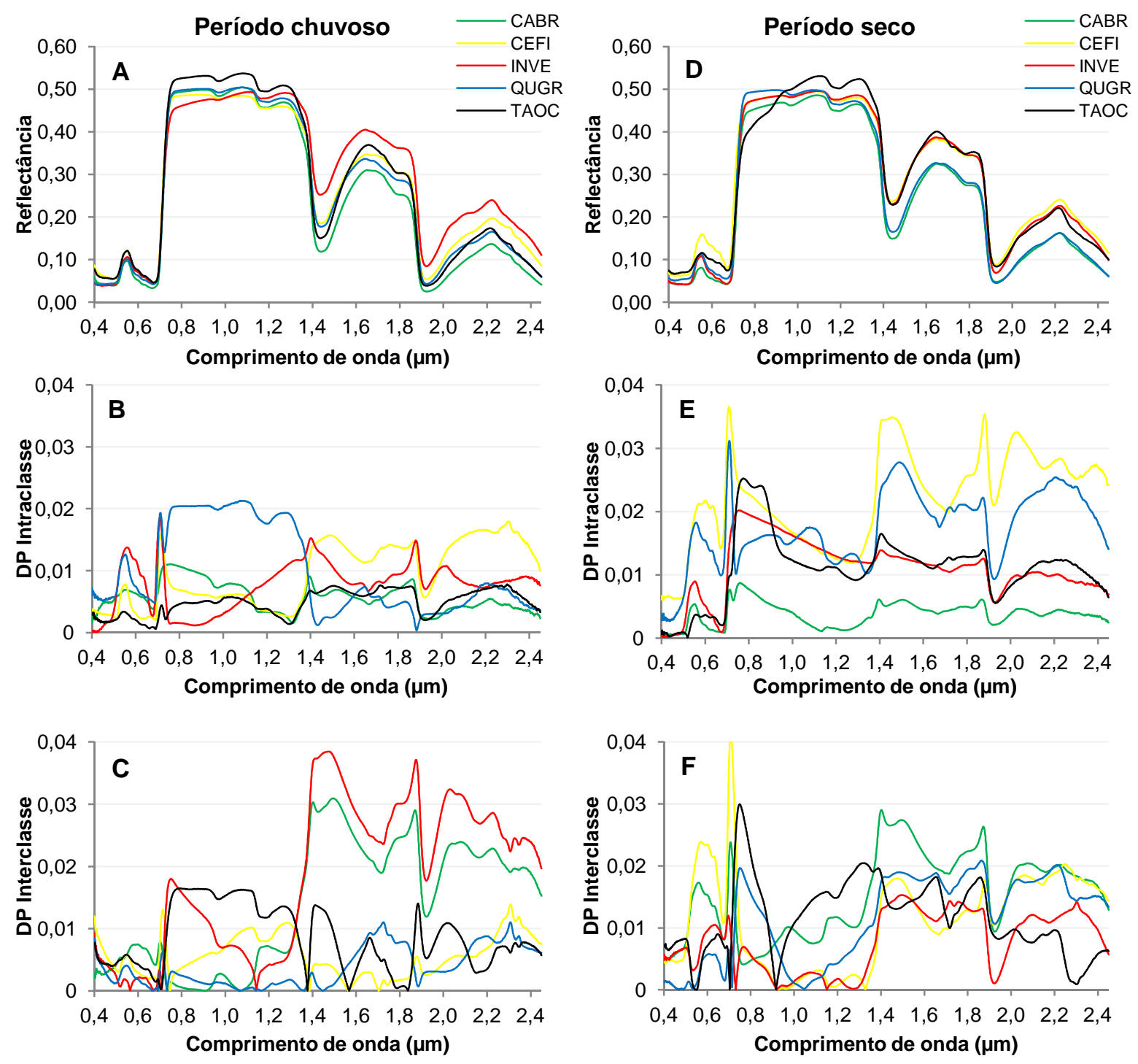

Figura 4.5. Espectros médios por classe de espécie-alvo, desvios padrões intraclasse, considerando os espectros médios de cada indivíduo/espécie, e desvios padrões interclasse, considerando o espectro médio da espécie em relação à média da população, apresentados respectivamente sobre os dados do período chuvoso ( $A, B$ e $C$ ) e do período seco (D, E e F).

Como discutido por Asner (2008), o estabelecimento de relações de causalidade entre um determinado composto bioquímico e as características espectrais de espécies deve levar em consideração as potenciais influências, mesmo que indiretas, de outros compostos bioquímicos. As análises de regressão, que consideraram as variações de diversos compostos como fatores causais no sucesso de classificação espectral das espécies-alvo, indicaram que linearmente as relações só são significativas quando já existe uma variação acentuada do determinado composto, entre as espécies-alvo. No período chuvoso, quando as variações entre espécies em compostos estruturais (hemicelulose e 
lignina) e água foliar não foram estatisticamente significantes, não foram estabelecidas correlações lineares de causalidade entre eles e as exatidões do produtor (EP) obtidas sobre dados SWIR e VSWIR. Neste período, relações lineares significativas só foram observadas para as EP obtidas como dados VIS, quando todos os pigmentos apresentavam variações significantes entre espécies (Figura 4.6-A). A importância da integração de mais de um composto como fator preponderante à discriminação espectral de espécies é particularmente importante na região do VIS, pois todos os pigmentos apresentam sobreposição de feições de absorção (Asner, 2008). Além disso, diferentemente do que talvez se possa imaginar, as variações em clorofila b entre espécies, são mais significantes do que em clorofila a (Gates, 1965).

A falta de modelos explicativos (e significativos) da classificação espectral no NIR pode ser explicada pela não observância, no estudo, de variações quantitativas de características morfoanatômicas das folhas das espécies-alvo. A reflectância nesse intervalo espectral é resultado do menor ou maior espalhamento de fótons produzido pelas interfaces parede celular-espaços gasosos (função da espessura das paredes e do teor de água) no mesófilo esponjoso (Wooley, 1971; Gausman, 1985; Grant, 1987), e externamente, em linhas gerais, pela espessura da cutícula e presença de tricomas (Billings e Morris, 1951; Gausman et al., 1972; Grant, 1987). No SWIR a água tende a obscurecer outras feições de absorção por compostos estruturais e, portanto, mesmo que esses últimos tenham influência na discriminação de espécies, a importância das variações em água mostra-se significativa (Figura 4.6-B). Isso ocorre de forma óbvia por se tratar de uma análise com folhas verdes (Fourty et al., 1996). Contudo, mesmo que as feições de absorção por celulose, lignina e hemicelulose sejam sobrepostas, seus efeitos individuais podem ser visíveis no espectro (Kokaly, 2009).

A alta variabilidade interespecífica observada no período seco, tanto em pigmentos foliares como em compostos da parede celular e em água, possibilitou o estabelecimento de relações lineares de causalidade para as EP de classificação VSWIR nesse período. De acordo com Price (1992), o comportamento e separabilidade espectral da vegetação são 
descritos por um pequeno número de variáveis independentes. Particularmente ao conjunto de espécies estudadas, as variações intraespecíficas em antocianina e interespecíficas em hemicelulose demonstram uma possível explicação do sucesso de classificação das espécies-alvo no período, considerando todo o espectro óptico (Figura 4.6-C). Cabe ressaltar que essa classificação foi a única que utilizou espectros com o contínuo removido, entre as melhores de ambos os períodos. Essa prévia normalização dos dados pode ter auxiliado no realce das menores feições associadas àqueles compostos, que foram os que mais variaram entre as espécies estudadas. A variação entre as concentrações mínima e máxima (entre espécies) de antocianina foi a maior, para o período, entre os pigmentos foliares $(337,2 \%$, seguida por clorofila b com $175,3 \%$ de variação), bem como a variação em hemicelulose, superior entre os componentes estruturais $(104,7 \%$, seguida por lignina insolúvel com 54,0\%). 

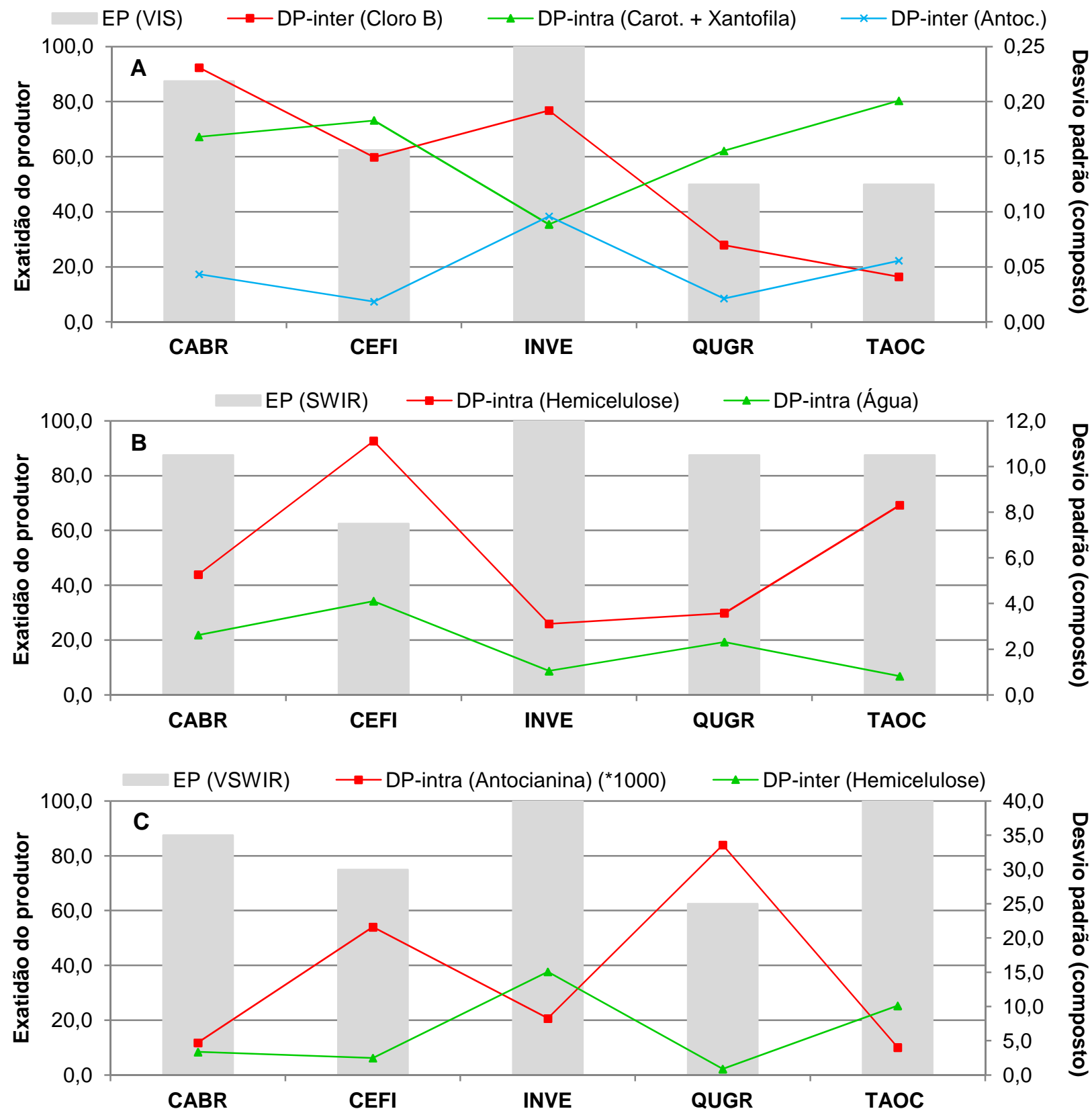

Figura 4.6. Relações entre as variáveis dependentes (exatidão do produtor (EP) da classificação MESMA para determinada região espectral) e independentes (desvios padrão intra ou interespecíficos de compostos bioquímicos): A) EPs da classificação espectral utilizando o intervalo do visível (VIS) e variações em pigmentos foliares que os expressam, no período chuvoso; B) EP do infravermelho ondas curtas (SWIR) e variações em composto estrutural e água, do período seco; C) EP da classificação espectral utilizando todo o intervalo óptico (VSWIR) e compostos que expressam aqueles resultados, no período seco. Cloro = clorofila; Carot $=$ carotenoides; Antoc $=$ antocianina.

Aspectos como idade dos indivíduos e das folhas, tendo em vista para essa última os variados regimes de deciduidade e brotamento, e que também influenciam a energia refletida (p.ex., Alvarez-Añorve, 2008; Roberts et al., 1998b) não foram levados em consideração no estudo. Contudo a elevada diversidade estrutural e química das folhas de 
espécies do bioma Cerrado - aspecto que já foi discutido por Eiten (1972) e por Asner (1998), por exemplo - contribuiu para a discriminação espectral das espécies-alvo, não sendo esse o desafio encontrado. A elevada diversidade bioquímico-espectral, também constatada no presente estudo, dificultou, no entanto, o reconhecimento de padrões fisiológicos e/ou fenológicos que pudesse ser encontrados entre as espécies indicadoras de mesmo geoambiente. Grupos ecológicos em tolerância à inundação ou à iluminação direta também não refletiram padrões químicos e ópticos, indicando que também há estratégias diferenciadas dentro desses nichos, como observado por Alvarez-Añorve (2008) e AlvarezAñorve et al. (2012) em diferentes grupos sucessionais.

\subsection{Conclusões}

As espécies indicadoras de diferentes formações e fácies geológicas da Estação Ecológica de Mogi-Guaçu (EEMG), no Estado de São Paulo, Brasil, foram muito bem classificadas, em escala de folha, em ambos os momentos sazonais analisados, o chuvoso e o seco. Não foi constatada, assim, a existência de um melhor momento sazonal para a discriminação espectral das cinco espécies-alvo do presente estudo. Não foram observadas variações estatisticamente significantes entre as classificações MESMA, seja com espectros originais de reflectância e com o contínuo removido, utilizando diferentes métricas para seleção de membros-finais (EAR-MASA-CoB - EMC e Iterative Endmember Selection IES) ou diferentes intervalos espectrais (VIS, NIR, SWIR e VSWIR), em ambos os momentos sazonais analisados. O melhor resultado de classificação foi obtido utilizando-se dados VSWIR, em reflectância e do período chuvoso, e métrica IES para seleção de membros-finais (exatidão global $=90,0 \%$ e coeficiente Kappa $=0,875$ ), seguido pela classificação realizada com dados VSWIR, com o contínuo removido e do período seco, e membros-finais selecionados via EMC (87,5\% e 0,814, respectivamente). Esse sucesso de classificação espectral, observado em ambos os momentos sazonais, parece ser reflexo da alta variação em compostos foliares observada entre as espécies. Essa alta variabilidade 
química, que se correlaciona à alta variabilidade espectral, sugeriu a existência de diferentes estratégias fisiológicas e fenológicas, considerando as análises sazonais.

Foi possível verificar que não existem padrões distintos em composição bioquímica e resposta espectral entre as espécies indicadoras dos diferentes geoambientes da EEMG. Assim, mesmo que os pares de espécies Calophyllum brasiliense (CABR) e Inga vera subsp. affinis (INVE) e Qualea grandiflora (QUGR) e Tabebuia ochracea (TAOC) possam ser considerados pares de tipos funcionais distintos, por estarem associadas a diferentes condições edafogeológicas, química e espectralmente essas espécies não representam grupos funcionais com diferenciados padrões fisiológicos e fenológicos. Mais do que pertencerem ao mesmo ambiente, as estratégias fisiológicas de cada uma superam qualquer tentativa de classificação funcional, inclusive ao se abordarem outras características ecológicas, como tolerância à iluminação direta e à inundação sazonal. Apenas o teor de lignina insolúvel foliar, no período seco, apresentou diferenças significantes entre espécies exclusivas de cerrado e espécies de floresta estacional semidecidual.

As intensas e significativas variações intra e interespecíficas em compostos bioquímicos foliares, observadas entre as espécies-alvo, puderam ser visualizadas em seus espectros. Quando significantes entre espécies, essas variações mostraram influenciar os resultados das análises de mistura espectral com múltiplos membros-finais, como pôde ser observado, por exemplo, nas variações em compostos estruturais e água foliar no período seco, que possivelmente culminaram em diferentes taxas de mistura espectral entre pares de espécies-alvo. Essas foram significantemente diferentes apenas no período seco. O par de espécies QUGR e Cedrela fissilis (CEFI) apresentou a maior taxa de mistura espectral, seguido por QUGR e CABR. Nesse período, também não foram observados erros em classificação espectral entre TAOC e INVE e entre TAOC e QUGR.

Os resultados obtidos nesta pesquisa são relevantes à geobotânica entre os trópicos, pois indicam, entre outras questões, que dentro de seus habitats cada espécie apresenta comportamentos fisiológicos, fenológicos e espectrais distintos. Assim, espécies 
associadas a mesmo ambiente geológico não representam, conjuntamente, tipos ópticos distintos na paisagem. Esse aspecto deve ser levado em consideração no mapeamento geobotânico em escala de copas individuais, uma vez que maiores erros de classificação espectral podem ocorrer entre espécies associadas a diferentes condições edafogeológicas e, não, como se poderia esperar, entre espécies associadas a um mesmo ambiente.

\subsection{Referências bibliográficas}

Adams, J. B., Smith, M. O., \& Gillespie, A. R. (1993). Imaging spectroscopy: Interpretation based on spectral mixture analysis. In C. M. Pieters, \& P. A. J. Englert (Eds.), Remote geochemical analyses: Elemental and mineralogical composition (pp. 145-166). Cambridge: Cambridge University Press.

Alvarez-Añorve, M. Y., Quesada, M., Sánchez-Azofeifa, G. A., Avila-Cabadilla, L. D., \& Gamon, J. A. (2012). Functional regeneration and spectral reflectance of trees during succession in a highly diverse tropical dry forest ecosystem. American journal of botany, 99(5), 816-826.

Alvarez-Añorve, M., Quesada, M., \& de la Barrera, E. (2008). Remote Sensing and Plant Functional Groups. In: M. Kalacska, \& G. A. Sanchez-Azofeifa (Orgs.). Hyperspectral remote sensing of tropical and subtropical forests (pp. 27-45), New York: Taylor \& Francis Group.

Asner, G. P. (1998). Biophysical and biochemical sources of variability in canopy reflectance. Remote Sensing of Environment, 64(3), 234-253.

Asner, G. P., \& Martin, R. E. (2008). Spectral and chemical analysis of tropical forests: Scaling from leaf to canopy levels. Remote Sensing of Environment, 112(10), 3958-3970.

Asner, G. P., Jones, M. O., Martin, R. E., Knapp, D. E., \& Hughes, R. F. (2008). Remote sensing of native and invasive species in Hawaiian forests. Remote Sensing of Environment, 112(5), 1912-1926.

Asner, G. P., Martin, R. E., Carlson, K. M., Rascher, U., \& Vitousek, P. M. (2006). Vegetation-climate interactions among native and invasive species in Hawaiian rainforest. Ecosystems, 9(7), 1106-1117.

Asner, G.P. \& Martin, R.E. (2009). Airborne spectranomics: Mapping canopy chemical and taxonomic diversity in tropical forests. Frontiers in Ecology and the Environment, 7, 269276.

Asner, G.P. (2008). Hyperspectral Remote Sensing of Canopy Chemistry, Physiology, and Biodiversity in Tropical Rainforests. In: M. Kalacska, \& G. A. Sanchez-Azofeifa (Orgs.). Hyperspectral remote sensing of tropical and subtropical forests (pp. 261-296), New York: Taylor \& Francis Group.

Billings, W. D., \& Morris, R. J. (1951). Reflection of visible and infrared radiation from leaves of differing ecological groups. American Journal of Botany, 38,327-331.

Blackburn, G. A. (1998a). Spectral indices for estimating photosynthetic pigment concentrations: a test using senescent tree leaves. International Journal of Remote Sensing, 19(4), 657-675. 
Blackburn, G. A. (1998b). Quantifying chlorophylls and carotenoids at leaf and canopy scales: An evaluation of some hyperspectral approaches. Remote sensing of environment, 66(3), 273-285.

Blackburn, G.A. (2007). Hyperspectral remote sensing of plant pigments. Journal of Experimental Botany, 58(4), 855-867.

Castro-Esau, K. L., \& Kalacska, M. (2008). Tropical Dry Forest Phenology and Discrimination of Tropical Tree Species Using Hyperspectral Data. In: M. Kalacska, \& Sanchez-Azofeifa, G. A. (Orgs.) Hyperspectral remote sensing of tropical and subtropical forests (pp. 0125), New York: Taylor \& Francis Group.

Castro-Esau, K. L., Sánchez-Azofeifa, G. A., Rivard, B., Wright, S. J., \& Quesada, M. (2006). Variability in leaf optical properties of Mesoamerican trees and the potential for species classification. American Journal of Botany, 93(4), 517-530.

Castro-Esau, K., Sánchez-Azofeifa, G. A., \& Caelli, T. (2004). Discrimination of lianas and trees with leaf-level hyperspectral data. Remote Sensing of Enviroment, 90(3), 353-372.

Chappelle, E. W., Kim, M. S., \& McMurtrey III, J. E. (1992). Ratio analysis of reflectance spectra (RARS): an algorithm for the remote estimation of the concentrations of chlorophyll a, chlorophyll b, and carotenoids in soybean leaves. Remote Sensing of Environment, 39(3), 239-247.

Clark, M. L, Roberts, D. A., \& Clark, D. B. (2005). Hyperspectral discrimination of tropical rain forest tree species at leaf to crown scales. Remote Sensing of Environment, 96, 375-398.

Clark, M. L. (2005). An assessment of Hyperspectral and Lidar Remote Sensing for the Monitoring of Tropical Rain Forest Trees. PhD. Thesis, Department of Geography, University of California, Santa Barbara. (UMI No. 3186829).

Clark, R. N., \& Roush, T. L. (1984). Reflectance spectroscopy: Quantitative analysis techniques for remote sensing applications. Journal of Geophysical Research, 89, 63296340.

Cochrane, M. A. (2000). Using vegetation reflectance variability for species level classification of hyperspectral data. International Journal of Remote Sensing, 21(10), 2075-2087.

Congalton, R. G. (1991). A review of assessing the accuracy of classifications of remotely sensed data. Remote sensing of environment, 37(1), 35-46.

Congalton, R. G., \& Green, K. (1999). Assessing the accuracy of remotely sensed data: principles and practices. Boca Raton: CRC press.

Curran, P. J. (1989). Remote sensing of foliar chemistry. Remote sensing of Environment, $30(3), 271-278$.

Dennison, P. E., \& Roberts, D. A. (2003). Endmember selection for multiple endmember spectral mixture analysis using endmember average RMSE. Remote Sensing of Environment, 87, 123-135.

Dennison, P. E., Halligan, K. Q. \& Roberts, D. A. (2004). A comparison of error metrics and constraints for multiple endmember spectral mixture analysis and spectral angle mapper. Remote Sensing of Environment, 93, 359-367.

Eiten, G. (1963). Habitat flora of Fazenda Campininha. Anais do $1^{\circ}$ Simpósio sobre Cerrado (pp. 157-202). São Paulo: Universidade de São Paulo.

Eiten, G. (1972). The cerrado vegetation of Brazil. Botanical Review, 38, 201-341.

Féret, J.B., \& Asner, G.P. (2011). Spectroscopic classification of tropical forest species using radiative transfer modeling. Remote Sensing of Environment, 115, 2415-2422. 
Fourty, T., Baret, F., Jacquemoud, S., Schmuck, G., \& Verdebout, J. (1996). Leaf optical properties with explicit description of its biochemical composition: direct and inverse problems. Remote sensing of Environment, 56(2), 104-117.

Fung, T., Yan Ma, H. F., \& Siu, W. L. (2003). Band selection using hyperspectral data of subtropical tree species. Geocarto International, 18(4), 3-11.

Gamon, J. A., Kitajima, K., Mulkey, S. S., Serrano, L., \& Wright, S. J. (2005). Diverse Optical and Photosynthetic Properties in a Neotropical Dry Forest during the Dry Season: Implications for Remote Estimation of Photosynthesis. Biotropica, 37(4), 547-560.

Gamon, J.A. (2008). Tropical Remote Sensing - Opportunities and Challenges. In: M. Kalacska, \& G. A. Sanchez-Azofeifa (Orgs.) Hyperspectral remote sensing of tropical and subtropical forests (pp. 297-304), New York: Taylor \& Francis Group.

Gates, D. M., Keegan, H. J., Schleter, J. C., \& Weidner, V. R. (1965). Spectral properties of plants. Applied optics, 4(1), 11-20.

Gausman, H. W. (1985). Plant leaf properties in visible and near infrared light. Lubbock: Texas Tech Press.

Gausman, H. W., Allen, W. A., \& Wiegand, C. L. (1972). Plant factors affecting electromagnetic radiation. Soil and Water Conservation Research Division, Agricultural Research Service, US Department of Agriculture.

Gitelson, A. A. (2012). Nondestructive Estimation of Foliar Pigment (Chlorophylls, Carotenoids, and Anthocyanins) Contents: Evaluating a Semianalytical Three-Band Model. In P.S. Thenkabail, J.G. Lyon, \& A. Huete (Orgs.), Hyperspectral Remote Sensing of Vegetation (pp. 141-165). New York: CRC Press.

Gitelson, A. A., \& Merzlyak, M. N. (2003). Relationships between leaf chlorophyll content and spectral reflectance and algorithms for non-destructive chlorophyll assessment in higher plant leaves. Journal of plant physiology, 160(3), 271-282.

Gitelson, A. A., Keydan, G. P., \& Merzlyak, M. N. (2006). Three-band model for noninvasive estimation of chlorophyll, carotenoids, and anthocyanin contents in higher plant leaves. Geophysical Research Letters, 33. L11402.

Grant, L. (1987). Diffuse and specular characteristics of leaf reflectance. Remote Sensing of Environment, 22(2), 309-322.

Hesketh, M., \& Sánchez-Azofeifa, G. A. (2012). The effect of seasonal spectral variation on species classification in the Panamanian tropical forest. Remote Sensing of Environment, 118, 73-82.

Holm, G. (1954). Chlorophyll mutations in barley. Acta Agricuturae Scandinavica, 4, 457-461.

Instituto Florestal do Estado de São Paulo. (2010). Áreas protegidas do Instituto Florestal: Estação Ecológica de Mogi-Guaçu. Recuperado em 20 de agosto de 2010, de http://www.iflorestal.sp.gov.br/areas_protegidas/index.asp

Kalacska, M. et al. 2007. Hyperspectral discrimination of tropical dry forest lianas and trees: Comparative data reduction approaches at the leaf and canopy levels. Remote Sensing of Environment, 109, 406-415.

Kokaly, R. F. (2011). PRISM: Processing routines in IDL for spectroscopic measurements. Recuperado em 15 de janeiro de 2013, de http://pubs.usgs.gov/of/2011/1155/

Kokaly, R. F., \& Clark, R. N. (1999). Spectroscopic determination of leaf biochemistry using band-depth analysis of absorption features and stepwise multiple linear regression. Remote Sensing of Environment, 67(3), 267-287. 
Kokaly, R. F., Asner, G. P., Ollinger, S. V., Martin, M. E., \& Wessman, C. A. (2009). Characterizing canopy biochemistry from imaging spectroscopy and its application to ecosystem studies. Remote Sensing of Environment, 113, S78-S91.

Lavorel, S., Mclntyre, S., Landsberg, J., \& Forbes, T. D. A. (1997). Plant functional classifications: from general groups to specific groups based on response to disturbance. Trends in Ecology \& Evolution, 12(12), 474-478.

Price, J. C. (1992). Variability of high resolution crop reflectance spectra. International Journal of Remote Sensing, 14, 2593-2610.

Price, J. C. (1994). How unique are spectral signatures?. Remote Sensing of Environment, 49(3), 181-186.

Prospere, K., McLaren, K., \& Wilson, B. (2014). Plant Species Discrimination in a Tropical Wetland Using In Situ Hyperspectral Data. Remote Sensing, 6(9), 8494-8523.

R Development Core Team (2008). R: A language and environment for statistical computing. $R$ Foundation for Statistical Computing, Vienna, Austria. Recuperado em 23 de junho de 2013, de http://www.R-project.org/

Reich, P. B., Wright, I. J., Cavender-Bares, J., Craine, J. M., Oleksyn, J., Westoby, M. et al. (2003). The evolution of plant functional variation: traits, spectra, and strategies. International Journal of Plant Sciences, 164(S3), S143-S164.

Ribeiro, J. F., \& Walter, B. M. T. (2008). As principais fitofisionomias do Bioma Cerrado. In S.M. Sano, S. P. Almeida, \& J. F. Ribeiro (Eds.). Cerrado: ecologia e flora (pp. 153-212). Planaltina: EMBRAPA-CPAC.

Rivard, B., Sánchez-Azofeifa, G. A., Foley, S., \& Calvo-Alvarado, J. C. (2008). Species classification of Tropical tree leaf reflectance and dependence on selection of spectral bands. In: M. Kalacska, \& Sanchez-Azofeifa, G. A. (Orgs.) Hyperspectral remote sensing of tropical and subtropical forests (pp. 141-159), New York: Taylor \& Francis Group.

Roberts, D. A., Dennison, P. E., Gardner, M., Hetzel, Y. L., Ustin, S. L., \& Lee, C. (2003). Evaluation of the potential of Hyperion for fire danger assessment by comparison to the Airborne Visible Infrared Imaging Spectrometer. IEEE Transactions on Geoscience and Remote Sensing, 41, 1297-1310.

Roberts, D. A., Gardner, M., Church, R., Ustin, S., Scheer, G., \& Green, R. O. (1998a). Mapping Chaparral in the Santa Monica Mountains using multiple endmember spectral mixture models. Remote Sensing of Environment, 65, 267-279.

Roberts, D. A., Halligan, K. Q., \& Dennison, P. E. (2007). ViperTools. Recuperado em 12 de fevereiro de 2013, de http://www.vipertools.org/

Roberts, D. A., Nelson, B. W., Adams, J. B., \& Palmer, F. (1998b). Spectral changes with leaf aging in Amazon caatinga. Trees, 12(6), 315-325.

Roberts, D. A., Quattrochi, D. A., Hulley, G. C., Hook, S. J. \& Green, R. O. (2012). Synergies between VSWIR and TIR data for the urban environment: An evaluation of the potential for the Hyperspectral Infrared Imager (HysplRI) Decadal Survey mission. Remote Sensing of Environment, 117, 83-101.

Roth, K. L., Dennison, P. E. \& Roberts, D. A. (2012). Comparing endmember selection techniques for accurate mapping of plant species and land cover using imaging spectrometer data. Remote Sensing of Environment, 127, 139-152.

Sabins, F. F. (1999). Remote sensing for mineral exploration. Ore Geology Reviews, 14(3), 157-183 
Sánchez-Azofeifa, G. A., Castro, K., Wright, S. J., Gamon, J., Kalacska, M., Rivard, B. et al. (2009). Differences in leaf traits, leaf internal structure, and spectral reflectance between two communities of lianas and trees: implications for remote sensing in tropical environments. Remote Sensing of Environment, 113(10), 2076-2088.

Schaaf, A. N., Dennison, P. E., Fryer, G. K., Roth, K. L., \& Roberts, D. A. (2011). Mapping plant functional types at three spatial resolutions using multiple endmember spectral mixture analysis. GIScience and Remote Sensing, 48, 324-344.

Sims, D. A., \& Gamon, J. A. (2002). Relationships between leaf pigment content and spectral reflectance across a wide range of species, leaf structures and developmental stages. Remote sensing of environment, 81(2), 337-354.

Updegraff, D. M. (1969). Semimicro determination of cellulose in biological materials. Analytical Biochemistry, 32(3), 420-424.

Ustin, S. L., \& Gamon, J. A. (2010). Remote sensing of plant functional types. New Phytologist, 186(4), 795-816.

Ustin, S. L., Smith, M. O., Jacquemoud, S., Verstraete, M. M., Govaerts, Y. (1999). Geobotany: vegetation mapping for Earth Sciences. In: A. N. Rencz (Org.). Remote sensing for the Earth Sciences, $3^{\text {rd }}$ ed (pp. 189-233). New York: John Wiley and sons.

Woolley, J. T. (1971). Reflectance and transmittance of light by leaves. Plant Physiology, 47, 656-662.

Youngentob, K. N., Roberts, D. A., Held, A. A., Dennison, P. E., Jia, X., \& Lindenmayer, D. B. (2011). Mapping two Eucalyptus subgenera using multiple endmember spectral mixture analysis and continuum-removed imaging spectrometry data. Remote Sensing of Environment, 115(5), 1115-1128. 


\section{ANÁLISE DE MISTURA ESPECTRAL EM ESCALA DE COPA ENTRE ESPÉCIES INDICADORAS GEOLÓGICAS E MAPEAMENTO DE FRAÇÕES ESPECTRAIS}

\section{Resumo}

O objetivo deste estudo foi testar a possibilidade de mapeamento de espécies arbóreas neotropicais, associadas a diferentes formações e fácies geológicas da Estação Ecológica de Mogi-Guaçu, São Paulo, Brasil, bem como analisar a mistura espectral, em escala de copa, entre essas espécies e e entre elas e outras classes de vegetação da paisagem, utilizando dados hiperespectrais (do visível ao infravermelho ondas curtas - VSWIR; 530$2.352 \mathrm{~nm}$ ) com resolução espacial de 1,0 m. Para tanto, a técnica Multiple Endmember Spectral Mixture Analysis (MESMA) foi aplicada em diferentes etapas de análise espectral e de mapeamento baseado em pixel. Foram testadas, nas análises de mistura espectral com dois membros-finais (MF), a prévia divisão do espectro eletromagnético óptico em diferentes regiões espectrais, a normalização dos dados através da remoção do contínuo $(\mathrm{CR})$ e o uso de diferentes métricas para seleção de MF: EAR-MASA-CoB (conjuntamente designadas como EMC) e Iterative Endmember Selection (IES). Testes de restrição de frações e Erro Quadrático Médio (EQM) também foram realizados nos dados originais de reflectância e com o contínuo removido. Cedrela fissilis (CEFI), Inga vera subsp. affinis (INVE) e Qualea grandiflora (QUGR), foram discriminadas entre si, com exatidão global de 70,59\%, utilizando-se dados VSWIR com CR e MF selecionados via IES. Contudo, a importância da primeira parte do espectro (VIS-NIR1; 530-919 nm) na discriminação espectral dessas espécies foi evidente, CEFI e INVE foram melhor discriminadas utilizando apenas esses dados. No início do período seco (época de obtenção das imagens), enquanto os espectros das copas de CEFI destacam-se pela elevada presença da fração de vegetação não fotossintética (NPV) e de sombra, as copas de INVE distinguem-se por suas elevadas frações de vegetação fotossinteticamente ativa (GV) e baixas frações de NPV e de sombra. Esse fato é coerente com a deciduidade, morfologia e angulação foliar dessas espécies. QUGR foi a espécie-alvo de melhor discriminação quando incluídas nas análises de mistura 
espectral outras oito classes de vegetação presentes na paisagem. Isso indica que dentre as oito outras classes, há algumas de maior similaridade espectral com CEFI e INVE. A falta de comissão espectral e a relativa baixa omissão espectral atingidas por QUGR, na modelagem espectral com dois MF, resultou em um mapeamento satisfatório de sua fração espectral na modelagem da imagem com três MF. A dispersão dos valores médios de sua fração não chegam a atingir 50\% nos pixels e nas copas de outras classes, na avaliação das imagens de frações geradas via MESMA. A imagem classificada da fração de QUGR indicou claramente a ocorrência das colinas e platôs da Formação Aquidauana na EEMG, às quais essa espécie está localmente associada e é considerada indicadora.

\subsection{Introdução}

A prospecção mineral e o mapeamento geológico de terrenos cobertos por vegetação, via sensoriamento remoto óptico, podem ser auxiliados pela geobotânica. A observação das relações entre a cobertura vegetal e o meio físico vem, decerto, desde as origens de nossa espécie, embora concretamente tenha sido citada apenas no século IV a.C., por Teofrasto, discípulo de Aristóteles (Kruckeberg, 2002), e sistematizada por Georgius Agrícola, em 1556, quando observou haver senescência precoce e nanismo de plantas ocorrentes sobre corpos de minérios (Ustin et al., 1999). A difusão da geobotânica teve notável impulso com a disponibilização de imagens de sensoriamento remoto multiespectral na década de 70, suscitando estudos como o de Arden e Westra (1977), que compara a aplicabilidade da técnica através de fotografias aéreas e de imagens do sensor Multi Spectral Scanner-MSS, do satélite Landsat 1, na Geórgia (EUA).

Contudo, enquanto nas regiões temperadas, onde as variações florísticas são relativamente baixas, o estresse químico da vegetação é o que geralmente caracteriza a variabilidade geobotânica, nas regiões subtropicais a equatoriais, altamente biodiversas, as variações florísticas e fisionômicas constituem a principal fonte de informação para essa área de pesquisa (Almeida et al., 2009). Nesses ambientes, o estresse da vegetação deve 
ser observado apenas sobre intensas anomalias geoquímicas, causando toxicidade nos solos ou condições secundárias adversas à vegetação, como sobre exsudações de hidrocarbonetos (p.ex., Lammoglia e Souza Filho, 2013).

Além da dificuldade de obtenção de dados de campo no interior de florestas tropicais, o sensoriamento remoto permite a observação em escala de paisagem de variações da vegetação, bem como o estabelecimento de suas relações com as propriedades edáficas e geológicas subjacentes (Higgins et al., 2014). Resultados positivos de associação de variações florísticas e fisionômicas à geologia local, em ambientes tropicais e por meio de dados multiespectrais, têm sido descritos principalmente na vegetação amazônica (p.ex., Tuomisto et al., 2003a-c; Higgins et al., 2011, 2012 e 2014). No bioma Cerrado (savana tropical brasileira) são observados estudos geobotânicos voltados à caracterização de mineralizações e processos mineralizantes (p. ex., Almeida-Filho e Castelo Branco, 1992; Almeida-Filho et al., 1996; Almeida-Filho e Vitorello; 1997), bem como de microexsudações de hidrocarbonetos (p.ex., Souza Filho, 2008). No entanto, parecem faltar na literatura estudos como aqueles observados na Amazônia, com enfoque na detecção de variações florísticas e fisionômicas que possam ser associadas a litologias comuns. Esses dados podem servir como fonte de informação ao mapeamento geológico dos terrenos onde ocorre o bioma Cerrado, que é o segundo maior da América do Sul (Ferreira et al., 2004) e ocupa cerca de $21 \%$ do território brasileiro (Klink e Machado, 2005).

Como foi previsto por Sabins (1999), a disponibilidade de sensores hiperespectrais tem também encorajado novas investigações geobotânicas em ambientes tropicais, incluindo aquelas sem o intuito de prospectar minérios, processos mineralizantes ou exsudações de hidrocarbonetos. Vitousek et al. (2009), por exemplo, correlacionaram variações em nitrogênio no dossel e em altura da vegetação, com a integração de dados Light Detection And Ranging (LIDAR), à idade do substrato - de 300 a 4 milhões de anos -, no Havaí (EUA). No entanto, as informações que podem ser obtidas através do sensoriamento remoto hiperespectral vão além do exposto, até o momento, em geobotânica. 
A evolução das técnicas em sensoriamento hiperespectral (ou espectroscopia de imageamento) na discriminação espectral e no mapeamento de plantas em nível específico ocorreu principalmente nos estudos que envolvem espécies exóticas e invasoras (p.ex., Underwood et al., 2003; Asner \& Vitousek; 2005; Miao et al., 2006; Tsai et al., 2007; Hestir et al., 2008; Somers e Asner, 2013 e 2014). Além da importância ecológica de seu mapeamento, essas espécies constituem tipos ópticos distintos nas paisagens (Ustin e Gamon, 2010). Pesquisas em discriminação espectral de espécies nativas entre os trópicos iniciaram-se por volta dos anos 2000, sendo o trabalho de Cochrane (2000), em escala de folha e na Amazônia, o primeiro registro na literatura. Contudo, a discriminação espectral em escala de copas individuais, possível apenas com sensores remotos de resolução espacial fina, só veio a acontecer em 2005, por Clark et al. (2005) na Costa Rica. Cabem destacar também trabalhos subsequentes, como os de Kalacska et al. (2007), Ferét e Asner (2013) e Somers e Asner (2014).

Como foi constatado por diversos autores, a caracterização espectral e o mapeamento de espécies em comunidades altamente biodiversas não constituem uma tarefa fácil (Clark et al., 2005; Castro-Esau et al., 2006; Zhang et al., 2006; Lucas et al., 2008). Além disso, essa elevada diversidade intra e interespecífica observada em formações tropicais é ainda pouco entendida pela comunidade científica (Asner, 2008; Asner e Martin, 2008). Assim, acredita-se que o sucesso do mapeamento de uma dada espécie, nesses ambientes, é determinado por sua singularidade espectral (Asner e Martin, 2009), a qual pode também ser descrita como um tipo óptico distinto, resultante de sua diferenciação estrutural, bioquímica, fisiológica e fenológica, diante das outras espécies presentes na paisagem (Gamon, 2008; Ustin e Gamon, 2010).

Embora já se tenha um número razoável de aplicações bem sucedidas em discriminação e em mapeamento de espécies, via espectroscopia de imageamento de resolução espacial fina, parecem faltar na literatura trabalhos com enfoque em espécies indicadoras geológicas. Assim, o objetivo deste estudo é testar a possibilidade de mapeamento de espécies arbóreas neotropicais, associadas a diferentes formações e fácies 
geológicas da Estação Ecológica de Mogi-Guaçu, no sudeste do Brasil, bem como analisar a mistura espectral, em escala de copa, entre essas espécies e entre elas e outras classes de vegetação da paisagem, através da técnica Multiple Endmember Spectral Mixture Analysis (MESMA; Roberts et al., 1998). Para tanto, testou-se a prévia divisão do espectro eletromagnético óptico em intervalos espectrais, a normalização dos dados através da remoção do contínuo e o uso de dois diferentes métricas para seleção de membros-finais.

\subsection{Materiais e Métodos}

\subsubsection{Espécies-alvo do estudo}

As três espécies-alvo deste estudo foram definidas por suas associações de ocorrência com diferentes ambientes geológicos da Estação Ecológica de Mogi-Guaçu (EEMG), no município de Mogi-Guaçu, Estado de São Paulo (SP), Brasil. Como foi apresentado no Capítulo 3, Qualea grandiflora Mart., espécie nativa do Cerrado, é observada nas áreas de interflúvio (colinas e platôs) da Formação Aquidauana, sobre solos com altas porcentagens das frações areia fina, média e grossa, e escasso silte. Cedrela fissilis Vell. é espécie de Floresta Estacional Semidecidual (FES) Submontana e ocorre nas bordas da Formação Aquidauna, notadamente nas margens erodidas pelo rio Mogi-Guaçu, onde a presença das frações granulométricas areias grossa e muito grossa são discriminantes, além da baixa porcentagem das frações silte e areia fina. Inga vera subsp. affinis (DC.) T.D. Penn., espécies de FES Aluvial, ocorre sobre sedimentos quaternários, com amplo domínio das frações argila e silte, notadamente na planície de inundação do rio Mogi-Guaçu (Depósitos Aluvionares).

\subsubsection{Aquisição e pré-processamento de dados hiperespectrais}

Os dados hiperespectrais ProSpecTIR - VS (SpecTIR - Reno, NV, EUA/ FotoTerra São Paulo, SP, BRA) foram obtidos no dia 8 de junho de 2010 por um conjunto de dois sensores. O primeiro opera com intervalo de amostragem de $~ 2,9 \mathrm{~nm}$ entre 400 e $970 \mathrm{~nm}$, 
resultando em 121 bandas, e o segundo entre 970 e $2.450 \mathrm{~nm}$ com intervalo de amostragem de $~ 8,5 \mathrm{~nm}$, totalizando 236 bandas. Dezessete faixas de voo (leste-oeste) foram adquiridas, com variação em elevação solar de $36,38^{\circ}$ a $26,17^{\circ}$ e ângulo azimutal de $325,43^{\circ}$ e $312,01^{\circ}$, a uma altura de $\sim 1.350 \mathrm{~m}$, com $\sim 320 \mathrm{~m}$ de largura e campo de visada instantâneo no terreno (GIFOV, pixel) de 1,0 m (Figura 5.1).

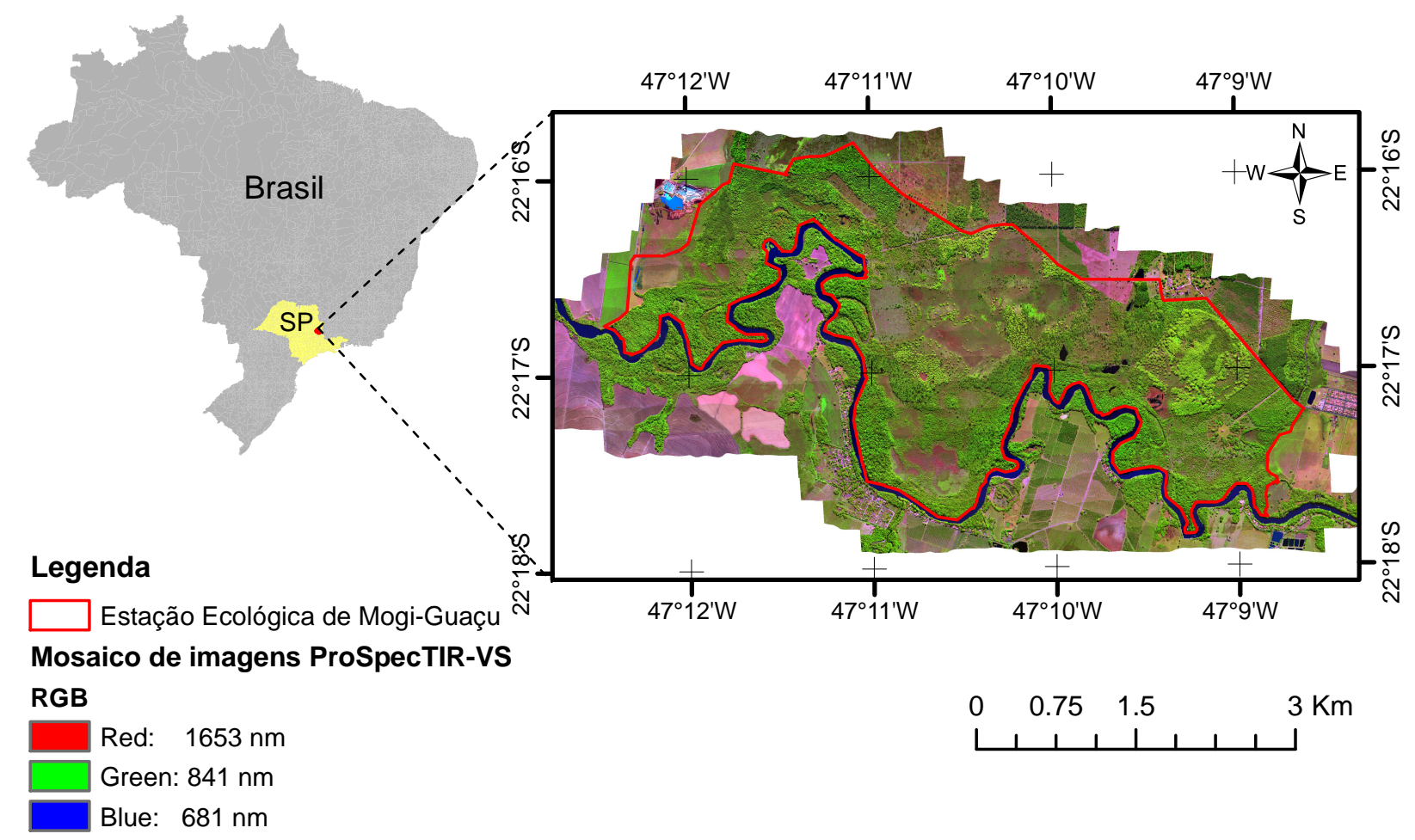

Figura 5.1. Mosaico de imagens hiperespectrais ProSpecTIR-VS obtidas para o estudo na Estação Ecológica de Mogi-Guaçu, São Paulo, Brasil.

A correção atmosférica foi realizada sobre os dados de radiância, no software ACORN 5 (Imspec LLC - Palmdale, CA, EUA). Foram estimados e utilizados na correção o vapor de água e a água líquida presentes nas imagens, a fim de suprimir os efeitos de água líquida da superfície. As derivações de vapor de água foram feitas utilizando as bandas localizadas em 940 e $1140 \mathrm{~nm}$. Não foram realizadas supressões de artefatos, de forma a preservar os dados de reflectância.

Amostras de solos superficiais foram coletadas em estradas não pavimentadas, com amostragem coberta por todas as faixas de voo. Coordenadas geográficas dos pontos de 
amostragem foram obtidas com GPS de navegação. Dados espectrais de laboratório foram coletados das amostras utilizando sonda de contato e o espectrômetro FieldSpec 3 Hi-Res. (ASD Inc. - Boulder, CO, EUA). Esse equipamento opera com resoluções espectrais de 3 $\mathrm{nm}(350-700 \mathrm{~nm}), 8,5 \mathrm{~nm}(700-1.400 \mathrm{~nm})$ e $6,5 \mathrm{~nm}(2.100 \mathrm{~nm})$, e intervalo de amostragem de 1,4 e 2,0 $\mathrm{nm}$. Os espectros obtidos foram tratados para a recuperação da reflectância absoluta e correção de offset entre sensores, bem como para a obtenção de dados médios de cada ponto amostral, através de rotinas PRISM (Kokaly, 2011) no software ENVI 4.8. (Exelis Visual Information Solutions Inc. - Boulder, CO, EUA). Essas medidas espectrais de solos foram utilizadas para o realce espectral das dezesssete faixas de imageamento, atmosfericamente corrigidas, através da convolução dos dados laboratoriais com as características espectrais das imagens, no software ACORN 5. As dezessete imagens foram georreferenciadas utilizando dados de voo Geographic Look Table (GLT) e, então, agrupadas em um mosaico.

A razão sinal-ruído dos dados foi analisada para cada banda. Selecionadas por sua alta razão sinal-ruído, 216 bandas do visível (VIS) ao infravermelho ondas curtas (SWIR) foram mantidas para o processamento. Aquelas localizadas no início do VIS e no final do SWIR, na região de offset entre os sensores, bem como nas regiões de forte absorção por água foram excluídas do conjunto de dados (Figura 5.2).

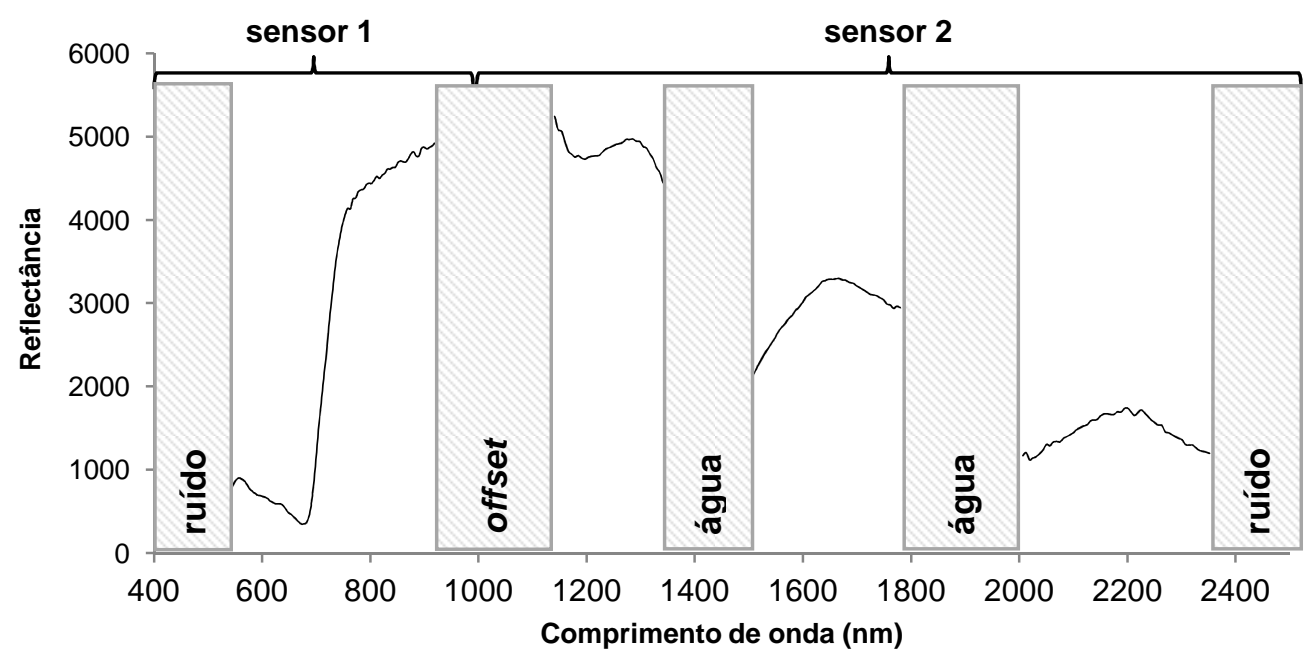

Figura 5.2. Regiões espectrais excluídas dos dados (áreas hachuradas) e mantidas para o processamento (espectro/ linha) dos dados ProSpecTIR-VS. 
Uma razão de bandas simples $(S R=\rho 797.3 / \rho 681.5 \mathrm{~nm}$; Jordan, 1969) foi realizada sobre os dados ProSpecTIR-VS para geração e aplicação de máscara sobre o mosaico, a fim de se trabalhar apenas com os dados de vegetação. Todas as superfícies com valores de SR inferiores a 0,5 foram mascaradas, permanecendo na análise apenas a vegetação mais densa. Os conjuntos de dados VSWIR (216 canais; de $530 \mathrm{~nm}$ a $2.352 \mathrm{~nm}$ ), VIS-NIR1 (82 canais; 530-919 nm) e NIR2-SWIR (134 canais; 1.141-2.352 nm) tiveram seu contínuo removido (CR) (Clark e Roush, 1984), a fim de testar se a prévia normalização dos dados pode influenciar positivamente os resultados de classificação espectral. Assim, seis diferentes subconjuntos espectrais foram considerados para a aplicação da técnica MESMA: VSWIR e VSWIR(CR); VIS-NIR1 e VIS-NIR1(CR); NIR2-SWIR e NIR2-SWIR(CR).

\subsubsection{Obtenção das amostras de referência e bibliotecas espectrais}

Em dezembro de 2012 e em setembro de 2013 foram realizadas coletas de coordenadas geográficas das copas de indíviduos das três espécies-alvo com a utilização de GPS diferencial Trimble 5700 (Trimble Navigation Ltd. - Sunnyvale, CA, EUA). A utilização desse equipamento e técnica mostrou-se necessária por se tratar de um trabalho em nível específico dentro de mosaicos florestais densos e com alta diversidade na composição de seus dosséis. A distância entre o receptor da base e o receptor móvel foi inferior a 4,5 km. Enquanto a base foi instalada em campo aberto, a antena do receptor móvel foi acoplada à haste extensível, com cabo de transmissão de dados de $30 \mathrm{~m}$, e elevada ao dossel com auxílio de profissional especializado em escalagem de árvores. Os pontos foram coletados com constelação mínima de oito satélites e precisão sempre abaixo de 1,0 m. A correção diferencial foi realizada utilizando dados da Rede Brasileira de Monitoramento Contínuo dos Sistemas GNSS/IBGE, a partir das estações de Campinas (SPCA) e de São Paulo (POLI), ambas localizadas no Estado de São Paulo e com abrangências que envolvem a EEMG. 
Somadas àquelas três classes de espécie-alvo, foram adicionadas, ao processo de modelagem espectral das imagens, outras oito classes de vegetação representativas da paisagem: espécies arbóreas de cerradão, espécies arbóreas de mata ciliar, Citrus spp. (frutas cítricas), Dendrocalamus sp. (bambú), Eucalyptus spp. (eucaliptos), Poaceae spp. (gramíneas nativas e exóticas), Pinus spp. (pinheiros) e Saccharum spp. (cana-de-açúcar). Os dados de referência das duas classes de formações arbóreas nativas foram coletados nas copas de outras espécies presentes no dossel, com apoio também de base vetorial de parcelas e transectos (apresentados no capítulo 3), onde as espécies-alvo não foram amostradas. As outras classes tiveram suas coordenadas coletadas em campo, com GPS de navegação. Com base nesses dados, em fotointerpretação e em análise espectral das imagens, regiões de interesse representadas por polígonos de até 9,0 $\mathrm{m}^{2}$ foram obtidas sobre as copas das classes. Foram extraídos os espectros médios de cada polígono, para cada um dos seis dados de entrada (Tabela 5.1).

Tabela 5.1. Classe, sigla utilizada no estudo e número de espectros extraídos de seis imagens: VSWIR (530-2.352 nm), VIS-NIR1 (530-919 nm) e NIR2-SWIR (1.141-2.352 nm), de reflectância e com contínuo removido, para realização das diferentes análises propostas.

\begin{tabular}{|c|c|c|c|c|}
\hline \multirow{14}{*}{ 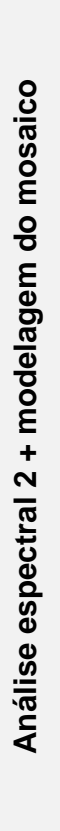 } & \multirow{5}{*}{ 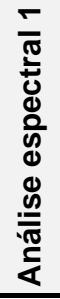 } & Classe & Sigla & Número de espectros \\
\hline & & Cedrela fissilis & CEFI & 22 \\
\hline & & Inga vera subsp. affinis & INVE & 31 \\
\hline & & Qualea grandiflora & QUGR & 28 \\
\hline & & \multicolumn{2}{|c|}{ Biblioteca global } & 81 \\
\hline & & espécies de cerradão & CERspp & 18 \\
\hline & & Citrus spp. & CITspp & 20 \\
\hline & & Dendrocalamus sp. & DENDsp & 20 \\
\hline & & Eucalyptus spp. & EUCspp & 20 \\
\hline & & espécies de mata ciliar & MACIspp & 28 \\
\hline & & Pinus spp. & PINspp & 20 \\
\hline & & Poaceae spp. & POAspp & 20 \\
\hline & & Sacharum spp. & SACspp & 20 \\
\hline & & \multicolumn{2}{|c|}{ Biblioteca global } & 328 \\
\hline
\end{tabular}




\subsubsection{Geração e extração de informações das bibliotecas espectrais}

Metadados foram gerados para cada espectro das bibliotecas globais, utilizando o ViperTools (Roberts et al., 2007). Esses dados, que incluem informações como a classe à qual o espectro pertence e seu brilho, são necessários às etapas subsequentes de seleção de espectros considerados puros. As bibliotecas globais foram divididas aleatoriamente em bibliotecas espectrais de treinamento e de validação. Um limite absoluto de 10 espectros por classe foi definido às bibliotecas de treinamento, a fim de se ter um treinamento mais equilibrado e, também, preservar um número aceitável de espectros ao processo de validação (Roth et al., 2012).

Matrizes quadradas foram geradas para as bibliotecas de treinamento. Informações de erro quadrático médio (EQM), ângulo espectral, membros-finais brilhantes e escuros e tipo de restrição de dados foram extraídas e armazenadas matricialmente em uma imagem BSQ. Após diversos testes de otimização dos resultados de modelagem espectral, limiares de fração de membros-finais e restrições de EQM, permissíveis à classificação, foram definidos entre -0,05 e 1,05 e EQM $\leq$ 0,025, para os dados de reflectância, e entre -0,01 e 1,01 e $E Q M \leq 0,065$ os dados com o contínuo removido.

\subsubsection{Seleção de membros-finais}

Membros-finais (MF) são espectros de determinada classe considerados "puros" (não mistos) e utilizados na classificação dos espectros de validação, bem como na modelagem dos pixels da imagem (Adams et al., 1993). A seleção de MF foi realizada por dois processos distintos, a fim de se poder optar por resultados de classificação mais exatos. As métricas de seleção de MF EAR, MASA e CoB - conjuntamente designadas como EMC (Roberts et al., 2007) e Iterative Endmember Selection - IES (Schaaf et al., 2011), foram testadas sobre as bibliotecas globais de treinamento, proveniente dos seis dados de entrada (intervalo espectral/ tipo de espectro). 
Utilizando as métricas EMC no ViperTools (Roberts et al., 2007), a seleção de MF foi realizada para cada classe através da seleção de espectros com valor mínimo de Endmember Average RMSE (EAR) (Dennison e Roberts, 2003), valor mínimo de Minimum Average Spectral Angle (MASA) (Dennison et al., 2004) e valor máximo de Cont-Based Index (CoBlndex) (Roberts et al., 2003; Clark, 2005). Por ser selecionado apenas um espectro por métrica, as bibliotecas de MF geradas via EMC foram compostas por, no máximo, três espectros por classe. A seleção de membros-finais via IES foi realizada utilizando rotina em Interactive Data Language - IDL (Schaaf et al., 2011; Roth et al., 2012). Os conjuntos de membros-finais foram selecionados de forma automatizada, por processo de adição e subtração de espectros, candidatos a MF, em uma classificação dos espectros de treinamento, até que o maior coeficiente Kappa fosse atingido (Schaaf et al., 2011). Quando obtida a melhor classificação espectral dentro daquele conjunto de dados, a biblioteca IES de MF foi gerada.

\subsubsection{Análise de mistura espectral com múltiplos membros-finais}

\subsubsection{Classificação espectral com dois membros-finais}

O processo de classificação espectral com dois MF (MF de dada classe e MF de sombra fotométrica) foi realizado para as três classes de espécie-alvo, a fim de analisar a mistura espectral entre elas, bem como para as onze classes de vegetação como procedimento prévio à seleção das imagens e conjuntos de MF a serem utilizados na obtenção das imagens de fração espectral das espécies-alvo. Nos dois processos, as bibliotecas de validação foram classificadas separadamente pelas bibliotecas de MF selecionadas pelos métodos EMC e IES, utilizando rotina IDL para modelos de dois MF (Roth et al., 2012). Os resultados de classificação espectral foram analisados através das métricas exatidão global (\%) e coeficiente Kappa. As variações em coeficiente Kappa das classificações realizadas utilizando diferentes intervalos espectrais, tipos de espectros e métodos para seleção de MF foram testadas via ANOVA (teste F). Foram consideradas 
significantes as variações ocorrentes entre tratamentos com, pelo menos, $5 \%$ de significância estatística.

Também tiveram suas variações analisadas estatisticamente (ANOVA/teste F) as exatidões específicas de classificação - exatidão do produtor (relativa aos erros de omissão de espectros) e exatidão do usuário (erros de comissão espectral) - e as taxas de mistura espectral entre pares de espécies-alvo. Nessas últimas foram considerados, dentre todos seus espectros de validação, aqueles erroneamente classificados entre si.

\subsubsection{Obtenção de imagens de fração espectral das espécies-alvo}

As modelagens espectrais de imagens foram baseadas nos melhores resultados específicos obtidos pelas classes de espécie-alvo, na classificação espectral das onze classes de vegetação com dois MF (etapa anterior). De posse dos melhores resultados, no ViperTools (Roberts et al., 2007), os pixels das imagens selecionadas foram modelados por três membros finais: MF da classe de espécie-alvo, MF de outra classe de vegetação e sombra fotométrica. Os múltiplos MF utilizados nessa etapa foram aqueles que classificaram corretamente os espectros de validação de sua classe, na etapa anterior. As restrições de dados (limiar de frações e EQM máximo) definidos nas classificações com dois MF foram mantidos no processo de modelagem das imagens.

Como parte do pós-processamento, as imagens foram normalizadas pela extração da fração de sombra, permanecendo no produto apenas as frações de vegetação verde (GV). A fração de sombra inclui também efeitos de iluminação secundária, que variam com a elevação solar, o azimute, a inclinação do terreno e o aspecto e rugosidade da superfície (Adams et al., 1986; Smith et al., 1990a and 1990b). Nesse processo de normalização, cada fração de GV foi divida pela soma de todas as frações GV em modelos com dois MF. Dessa forma, os pixels modelados foram normalizados como uma composição de duas frações de GV (MF da classe-alvo + MF de outra classe de vegetação) que juntas totalizam 100\% (Smith et al., 1990a; Dennison and Roberts, 2003). 
As imagens de fração normalizadas foram avaliadas tanto em escala de copa $(n=$ 247) como de pixel ( $n=1.036)$. Para tanto, foram utilizadas as regiões de interesse, previamente definidas para extração dos dados espectrais para compor as bibliotecas espectrais, que representam com confiança de campo os alvos estudados. Quando mais de um tipo de dado/métrica de seleção de MF apresentou bons resultados de classificação específica para determinada espécie-alvo, aquele mais adequado ao seu mapeamento foi selecionado nessa etapa pela análise da abundância subpixel média de sua fração em suas copas. A fim de otimizar o mapeamento das frações das três espécies-alvo, essas imagens foram classificadas (em duas classes) utilizando um valor de corte determinado, a partir do valor máximo da fração de espécie-alvo observado à copa de outra classe de vegetação.

\subsection{Resultados}

\subsubsection{Análise de mistura espectral entre espécies-alvo}

O melhor resultado de discriminação espectral entre as três espécies, alvo do estudo, foi atingido quando utilizados dados VSWIR com o contínuo removido (CR) e membros-finais (MF) selecionados via IES, apresentando coeficiente Kappa de 0,551 e exatidão global de 70,59\% (Figura 5.3). Embora a média dos coeficientes Kappa obtidos nas classificações de dados VIS-NIR1 $(0,435 \pm 0,090)$ tenha sido superior às médias das classificações de dados VSWIR $(0,429 \pm 0,112)$ e NIR2-SWIR $(0,262 \pm 0,110)$, suas variações não foram estatisticamente significantes com, pelo menos, $5 \%$ de significância. Esses coeficientes também não apresentaram variações significativas $(\alpha=0,05)$ entre as classificações de espectros originais de reflectância ou com prévia remoção do contínuo, bem como entre as classificações utilizando MF selecionados via EMC ou via IES. 


\section{Dado/Métrica}

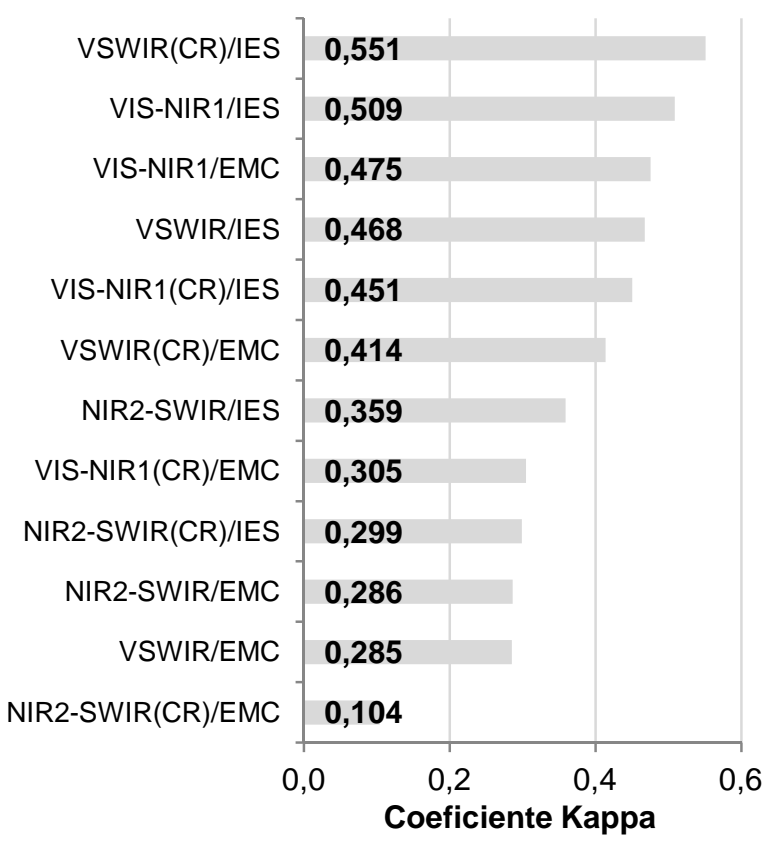

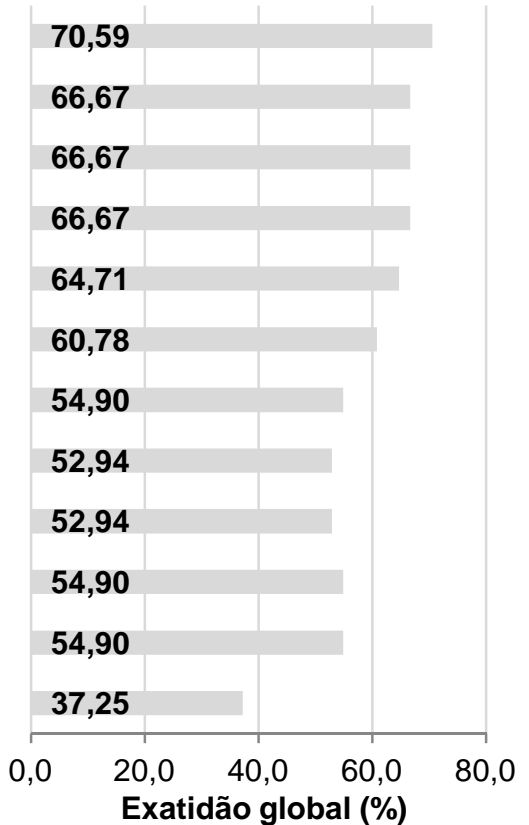

Figura 5.3. Coeficientes Kappa e exatidões globais (\%) das classificações MESMA com dois membros-finais, obtidos sobre diferentes dados espectrais e métricas para seleção de membrosfinais, ranqueados do maior ao menor coeficiente Kappa.

Quando analisadas as mais altas e balanceadas exatidões específicas de classificação das espécies-alvo, foi possível verificar que Cedrela fissilis (CEFI) foi mais bem classificada utilizando-se dados de reflectância VIS-NIR1 e MF selecionados via EMC, apresentando exatidão do produtor (EP) de 66,67\% e exatidão do usuário (EU) de 88,89\%. Inga vera subsp. affinis (INVE) também foi mais bem classificada com dados VIS-NIR1 de reflectância, mas utilizando MF selecionados via IES (EP = 80,95\% e EU =89,47\%). Qualea grandiflora (QUGR) apresentou as mais altas e balanceadas exatidões específicas (EP = $72,22 \%$ e EU $=68,42 \%$ ) na classificação de dados VSWIR com contínuo removido e utilizando MF selecionados via IES. Apenas as exatidões do usuário, referentes aos erros de comissão espectral, variaram de forma significativa $(\alpha=0,05)$ entre as classes de espéciesalvo, mais especificamente entre INVE e QUGR. Enquanto INVE apresentou EU média (desvio padrão) de 69,18\% ( \pm 12,60\%), QUGR apresentou EU média de 56,93\% ( \pm 10,02\%).

A hipótese nula de que não há variações estatisticamente significantes $(\alpha=0,05)$ em exatidão específica (EP ou EU) nas classificações com diferentes intervalos espectrais foi aceita para as três classes de espécies-alvo. Esse fato também foi observado entre 
classificações com espectros originais de reflectância e com o contínuo removido. Contudo, a hipótese nula de que não há variações significantes em EU quando utilizados MF selecionados via EMC e via IES foi rejeitada $(\alpha=0,05)$ para INVE. Essa classe apresentou EU média de $61,14 \% \pm 9,77 \%$ com MF selecionados via EMC e EU média de $77,22 \% \pm$ 9,93\% quando os MF utilizados foram selecionados via IES.

CEFI teve todos seus espectros de validação modelados por MF, independentemente do intervalo espectral, tipo de espectro e métrica de seleção de MF utilizados. Dentre os espectros de validação de INVE, 9,52\% deles não foram modelados nas classificações VSWIR(CR)/EMC e NIR2-SWIR/IES e 4,76\% nas classificações VISNIR1/IES e VIS-NIR1(CR)/EMC. QUGR, por sua vez, teve 5,56\% de seus espectros de validação não modelados nas classificações NIR2-SWIR/IES, NIR2-SWIR(CR)/EMC e NIR2$\mathrm{SWIR}(\mathrm{CR}) / \mathrm{IES}$. Diferenças estatisticamente significantes $(\alpha=0,05)$ foram observadas nas porcentagens de espectros não modelados por MF da classe QUGR, entre as classificações realizadas com diferentes intervalos espectrais. Essa classe teve todos os seus espectros de validação VIS-NIR1 e VSWIR modelados por MF nas variadas classificações MESMA.

Diferenças estatísticas, com pelo menos $5 \%$ de significância, foram encontradas entre as taxas de mistura espectral CEFI-INVE e CEFI-QUGR nas classificações de dados VIS-NIR1 e VSWIR (Figura 5.4). Utilizando dados VIS-NIR1, uma média de 7,58\% ( \pm 8,02\%) dos espectros de validação de CEFI e INVE foi erroneamente classificada entre essas classes, enquanto que $24,17 \%( \pm 9,57 \%)$ dos espectros de validação de CEFI e QUGR foram mal classificados entre si. Nas classificações de dados VSWIR a taxa média de mistura espectral entre CEFI e INVE foi de $11,36 \%$ ( $\pm 3,81 \%$ ) e entre CEFI e QUGR de $20,83 \%( \pm 4,19 \%)$. 


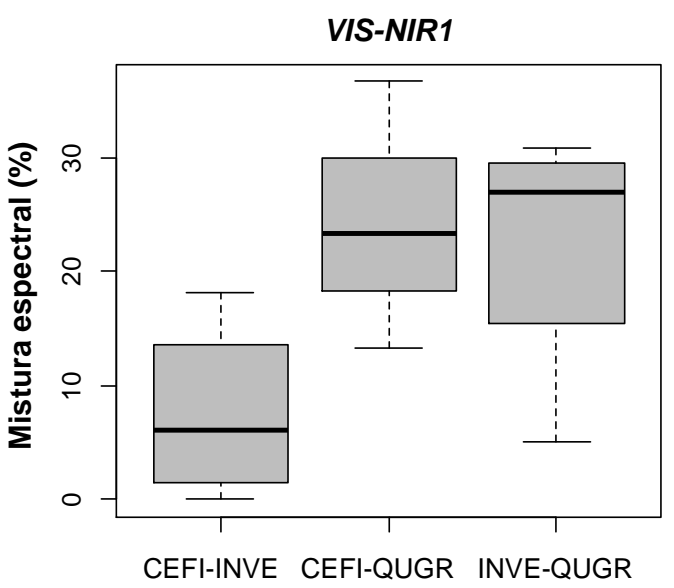

Par de classes

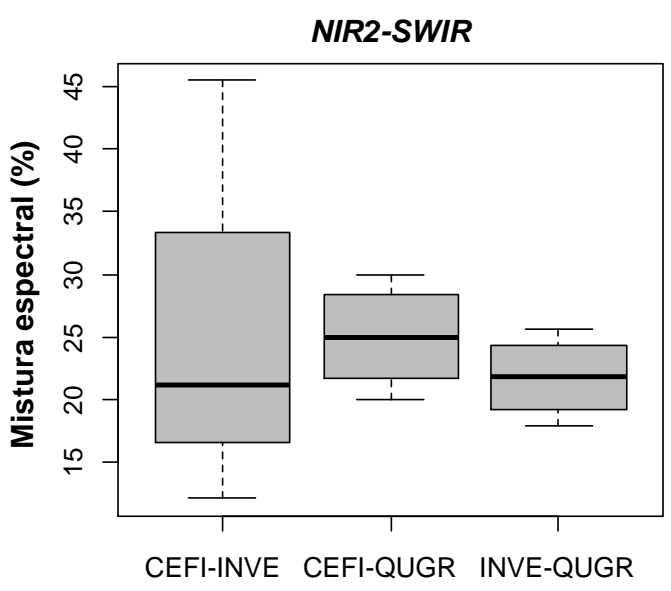

Par de classes

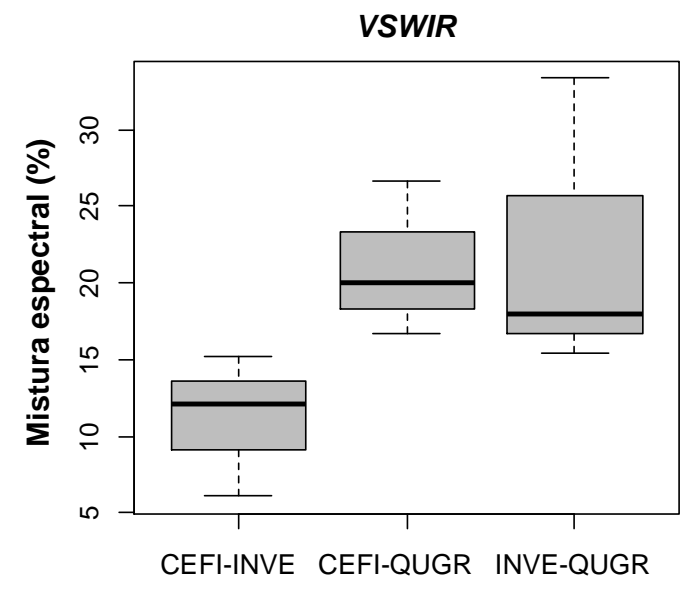

Par de classes

Figura 5.4. Taxas de mistura espectral observadas entre as classes de espécie-alvo, Cedrela fissilis (CEFI), Inga vera subsp. affinis (INVE) e Qualea grandiflora (QUGR), nas classificações espectrais de dados VIS-NIR1, NIR2-SWIR e VSWIR. As linhas centrais horizontais indicam as medianas das populações, as bordas inferior e superior das caixas o intervalo entre 25 e $75 \%$ da distribuição dos dados da população e as linhas extremas horizontais os valores mínimo e máximo do conjunto de dados (não considerados os outliers).

\subsubsection{Análise de mistura espectral entre espécies-alvo e outras classes de vegetação}

Quando foram consideradas nas análises de mistura espectral outras oito classes de vegetação, incluindo espécies e formações representativas da paisagem, os coeficientes Kappa e exatidões globais das classificações espectrais foram inferiores àqueles observados na análise de mistura espectral das três espécies-alvo. A melhor classificação MESMA, para as onze classes de vegetação, foi atingida utilizando-se dados VSWIR, com contínuo removido, e MF selecionados via IES (coeficiente Kappa $=0,397$ e exatidão global $=45,26 \%)$. O coeficiente Kappa médio das classificações de dados VSWIR foi superior 
$(0,336 \pm 0,055)$ ao observado para dados NIR2-SWIR $(0,300 \pm 0,048)$ e VIS-NIR1 $(0,235 \pm$ 0,088). Contudo, diferenças estatisticamente significantes $(\alpha=0,05)$ não foram observadas entre as classificações realizadas com diferentes intervalos espectrais, nem entre dados de reflectância e com o contínuo removido, nem entre as classificações com MF selecionados via EMC e via IES.

As exatidões do produtor (EP) atingidas por CEFI foram estatisticamente inferiores ( $\alpha$ $=0,05)$ em comparação com aquelas atingidas por INVE e QUGR, fato não observado para as exatidões do usuário (EU). A hipótese nula que assume a inexistência de variações significantes em EP quando utilizados diferentes intervalos espectrais, no processo de classificação, foi rejeitada $(\alpha=0,05)$ para INVE. Essa classe apresentou EP média de $57,14 \% \pm 12,29 \%$ nas classificações realizadas com dados VSWIR, 25,0\% $\pm 9,02 \%$ com dados VIS-NIR1 e 44,05\% \pm 14,22\% nas classificações de dados NIR2-SWIR. No entanto, essa hipótese foi aceita para as outras duas classes de espécies-alvo. As EPs obtidas por CEFI nas classificações de espectros com o contínuo removido foram estatisticamente superiores $(30,56 \pm 16,39 \%)$ às obtidas nas classificações de espectros originais de reflectância $(11,11 \% \pm 12,55 \%)$. Essas diferenças também não foram observadas nas outras duas classes-alvo.

As mais altas e balanceadas exatidões específicas de classificação (EP e EU) observadas para CEFI não chegaram a atingir 50,0\% (EP $=41,67 \%$ e EU $=45,45 \%$, sobre dados VSWIR(CR)/IES e VSWIR(CR)/EMC). INVE foi mais bem classificada utilizando dados VSWIR de reflectância, com MF selecionados via EMC $(E P=61,90 \%$ e EU $=$ $59,09 \%$ ) e via IES (EP $=71,43 \%$ e EU $=48,39 \%$ ). QUGR foi mais classificada com dados $\operatorname{VSWIR}(\mathrm{CR}) / \mathrm{EMC}(\mathrm{EP}=61,11 \%$ e $\mathrm{EU}=100,00 \%)$.

\subsubsection{Modelagem espectral de imagens hiperespectrais}

Observou-se que QUGR apresentou o melhor potencial de mapeamento entre as espécies-alvo na EEMG. A abundância (subpixel) média de sua fração nos pixels de suas 
copas de referência $(0,53 \pm 0,23)$, bem como a abundância média de sua fração em suas copas $(0,52 \pm 0,24)$, foram inferiores ao observado para CEFI $(0,58 \pm 0,23$ e $0,57 \pm 0,21$, respectivamente) e INVE $(0,62 \pm 0,22$ e 0,62 $\pm 0,19$, respectivamente). Contudo, excetuando-se valores atípicos (outliers), as abundâncias máximas da fração de QUGR observada nas copas e pixels de outras classes não ultrapassaram 0,49 e 0,45 , respectivamente, o que não foi observado nas imagens de frações de CEFI e INVE. Nelas, diversas classes apresentaram valores elevados $(\geq 0,50)$ de suas frações tanto em escala de pixel (seis classes para CEFI e sete para INVE) como de copa (duas para CEFI e quatro para INVE) (Tabela 5.2).

Tabela 5.2. Avaliação das imagens de frações de Cedrela fissilis (CEFI; VSWIR(CR)/IES), Inga vera subsp. affinis (INVE; VSWIR/IES) e Qualea grandiflora (QUGR; VSWIR(CR)/EMC). Porcentagem de pixels (\%PM) e copas (\%CM) modelados e respectivos valores médios $(\bar{X})$ (desvios-padrão $(\sigma))$ da fração de espécie-alvo às classes do estudo.

\begin{tabular}{|c|c|c|c|c|c|c|c|c|c|c|c|c|}
\hline \multirow{3}{*}{ Classe } & \multicolumn{4}{|c|}{ VSWIR(CR)/IES } & \multicolumn{4}{|c|}{ VSWIR/IES } & \multicolumn{4}{|c|}{ VSWIR(CR)/EMC } \\
\hline & \multicolumn{4}{|c|}{ Abundância da fração CEFI } & \multicolumn{4}{|c|}{ Abundância da fração INVE } & \multicolumn{4}{|c|}{ Abundância da fração QUGR } \\
\hline & $\%$ PM & $\bar{X}(\sigma)$ & $\% \mathrm{CM}$ & $\bar{X}(\sigma)$ & \%PM & $\bar{X}(\sigma)$ & $\% \mathrm{CM}$ & $\bar{X}(\sigma)$ & \%PM & $\bar{X}(\sigma)$ & $\% \mathrm{CM}$ & $\bar{X}(\sigma)$ \\
\hline CEFI & 100,0 & $\begin{array}{c}0,58 \\
(0,23)\end{array}$ & 100,0 & $\begin{array}{c}0,57 \\
(0,21)\end{array}$ & 100,0 & $\begin{array}{c}0,38 \\
(0,19)\end{array}$ & 100,0 & $\begin{array}{c}0,37 \\
(0,18)\end{array}$ & 96,8 & $\begin{array}{c}0,22 \\
(0,15)\end{array}$ & 100,0 & $\begin{array}{c}0,24 \\
(0,14)\end{array}$ \\
\hline CERspp & 96,3 & $\begin{array}{c}0,39 \\
(0,19)\end{array}$ & 100,0 & $\begin{array}{c}0,38 \\
(0,16)\end{array}$ & 94,4 & $\begin{array}{c}0,35 \\
(0,22)\end{array}$ & 95,0 & $\begin{array}{c}0,34 \\
(0,19)\end{array}$ & 81,5 & $\begin{array}{c}0,22 \\
(0,18)\end{array}$ & 70,0 & $\begin{array}{c}0,22 \\
(0,14)\end{array}$ \\
\hline CITspp & 87,0 & $\begin{array}{c}0,27 \\
(0,18)\end{array}$ & 100,0 & $\begin{array}{c}0,25 \\
(0,14)\end{array}$ & 89,0 & $\begin{array}{c}0,28 \\
(0,24)\end{array}$ & 100,0 & $\begin{array}{c}0,27 \\
(0,20)\end{array}$ & 49,0 & $\begin{array}{c}0,21 \\
(0,17)\end{array}$ & 100,0 & $\begin{array}{c}0,18 \\
(0,12)\end{array}$ \\
\hline DENDsp & 100,0 & $\begin{array}{c}0,36 \\
(0,18)\end{array}$ & 100,0 & $\begin{array}{c}0,36 \\
(0,13)\end{array}$ & 96,3 & $\begin{array}{c}0,47 \\
(0,16)\end{array}$ & 100,0 & $\begin{array}{c}0,47 \\
(0,08)\end{array}$ & 99,1 & $\begin{array}{c}0,19 \\
(0,12)\end{array}$ & 100,0 & $\begin{array}{c}0,19 \\
(0,06)\end{array}$ \\
\hline EUCspp & 100,0 & $\begin{array}{c}0,21 \\
(0,14)\end{array}$ & 100,0 & $\begin{array}{c}0,21 \\
(0,09)\end{array}$ & 100,0 & $\begin{array}{c}0,25 \\
(0,17)\end{array}$ & 100,0 & $\begin{array}{c}0,26 \\
(0,13)\end{array}$ & 99,0 & $\begin{array}{c}0,29 \\
(0,20)\end{array}$ & 100,0 & $\begin{array}{c}0,29 \\
(0,16)\end{array}$ \\
\hline INVE & 100,0 & $\begin{array}{c}0,35 \\
(0,18)\end{array}$ & 100,0 & $\begin{array}{c}0,35 \\
(0,14)\end{array}$ & 100,0 & $\begin{array}{c}0,62 \\
(0,22)\end{array}$ & 100,0 & $\begin{array}{c}0,63 \\
(0,19)\end{array}$ & 100,0 & $\begin{array}{c}0,24 \\
(0,16)\end{array}$ & 100,0 & $\begin{array}{c}0,25 \\
(0,14)\end{array}$ \\
\hline MACIspp & 91,3 & $\begin{array}{c}0,32 \\
(0,21)\end{array}$ & 95,0 & $\begin{array}{c}0,31 \\
(0,17)\end{array}$ & 95,3 & $\begin{array}{c}0,29 \\
(0,20)\end{array}$ & 95,0 & $\begin{array}{c}0,29 \\
(0,17)\end{array}$ & 66,1 & $\begin{array}{c}0,18 \\
(0,14)\end{array}$ & 60,0 & $\begin{array}{c}0,17 \\
(0,11)\end{array}$ \\
\hline PINspp & 78,2 & $\begin{array}{c}0,16 \\
(0,10)\end{array}$ & 100,0 & $\begin{array}{c}0,16 \\
(0,07)\end{array}$ & 92,0 & $\begin{array}{c}0,27 \\
(0,21)\end{array}$ & 100,0 & $\begin{array}{c}0,27 \\
(0,18)\end{array}$ & 44,8 & $\begin{array}{c}0,17 \\
(0,13)\end{array}$ & 96,4 & $\begin{array}{c}0,16 \\
(0,08)\end{array}$ \\
\hline POAspp & 100,0 & $\begin{array}{c}0,31 \\
(0,21)\end{array}$ & 96,4 & $\begin{array}{c}0,31 \\
(0,16)\end{array}$ & 93,1 & $\begin{array}{c}0,37 \\
(0,27)\end{array}$ & 100,0 & $\begin{array}{c}0,36 \\
(0,27)\end{array}$ & 90,1 & $\begin{array}{c}0,27 \\
(0,14)\end{array}$ & 78,6 & $\begin{array}{c}0,27 \\
(0,12)\end{array}$ \\
\hline QUGR & 100,0 & $\begin{array}{c}0,43 \\
(0,18)\end{array}$ & 100,0 & $\begin{array}{c}0,43 \\
(0,16)\end{array}$ & 98,7 & $\begin{array}{c}0,33 \\
(0,21)\end{array}$ & 100,0 & $\begin{array}{c}0,33 \\
(0,17)\end{array}$ & 96,2 & $\begin{array}{c}0,53 \\
(0,23)\end{array}$ & 95,0 & $\begin{array}{c}0,52 \\
(0,24)\end{array}$ \\
\hline SACspp & 100,0 & $\begin{array}{c}0,22 \\
(0,16)\end{array}$ & 100,0 & $\begin{array}{c}0,22 \\
(0,11)\end{array}$ & 100,0 & $\begin{array}{c}0,31 \\
(0,19)\end{array}$ & 100,0 & $\begin{array}{c}0,31 \\
(0,15)\end{array}$ & 90,6 & $\begin{array}{c}0,20 \\
(0,13)\end{array}$ & 100,0 & $\begin{array}{c}0,19 \\
(0,09)\end{array}$ \\
\hline
\end{tabular}

Ao considerar também os valores atípicos (outliers) nas análises de abundância máxima das frações de espécies-alvo, nas copas de outras classes, um valor máximo de 
0,79 da fração de CEFI foi observado na copa de QUGR, de 0,82 da fração de INVE no dossel de POAspp e de 0,62 da fração QUGR na copa de EUCspp. As imagens de frações das três espécies-alvo classificadas, de acordo com os valores máximos de suas frações nas copas de outras classes, são apresentadas abaixo. Os pixels considerados, com maior confiabilidade, como CEFI foram os modelados com mais de $80 \%$ de sua fração (Figura 5.5), os pixels considerados como INVE foram os modelados com no mínimo $85 \%$ de sua fração (Figura 5.6) e os considerados como representantes das copas de QUGR foram os modelados com $65 \%$ ou mais de sua fração (Figura 5.7).

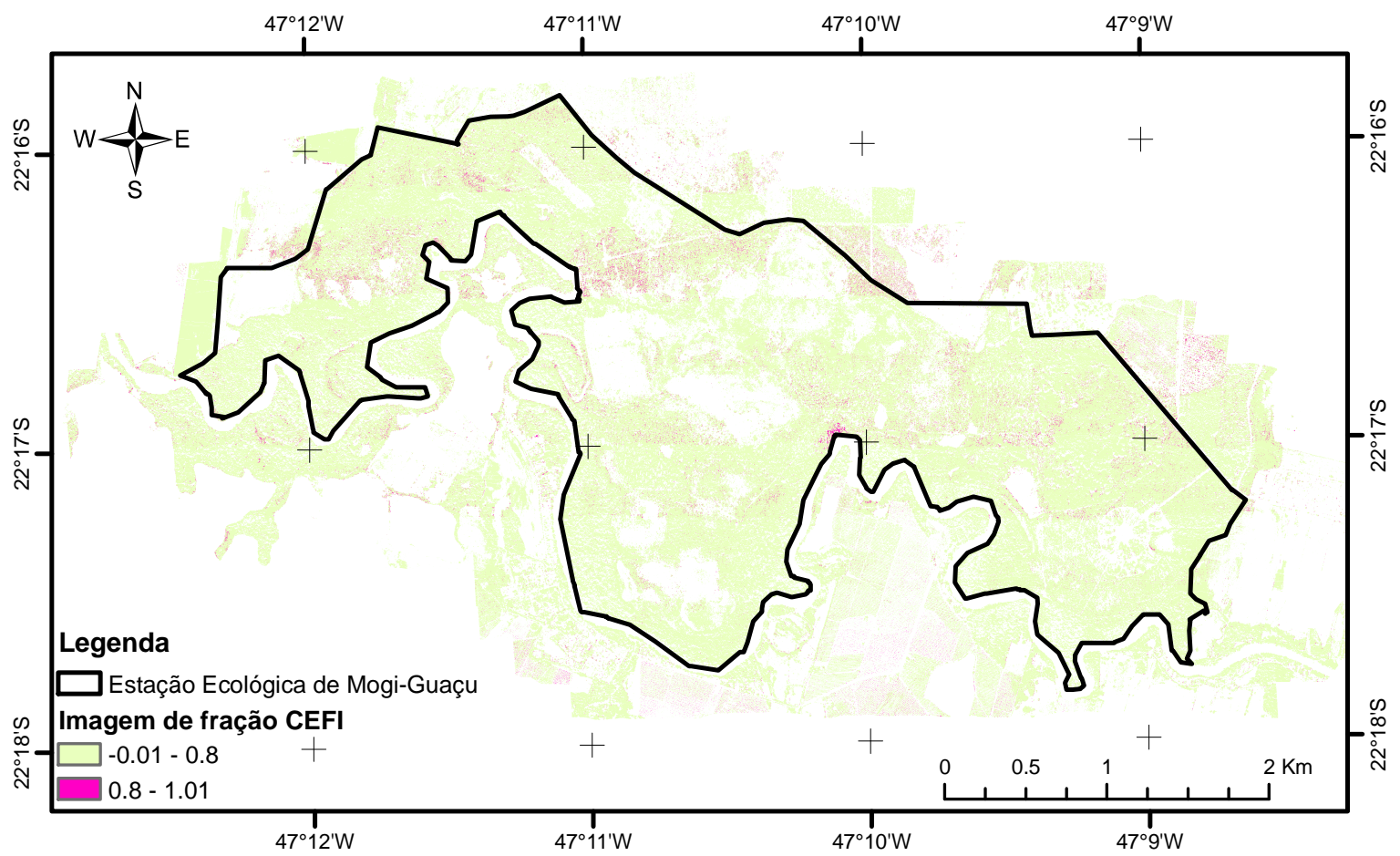

Figura 5.5. Imagem classificada de fração espectral de Cedrela fissilis (CEFI), na Estação Ecológica de Mogi-Guaçu, São Paulo, Brasil: pixels com menos de $80 \%$ de sua fração em verde e com mais de $80 \%$ de sua fração em magenta. 


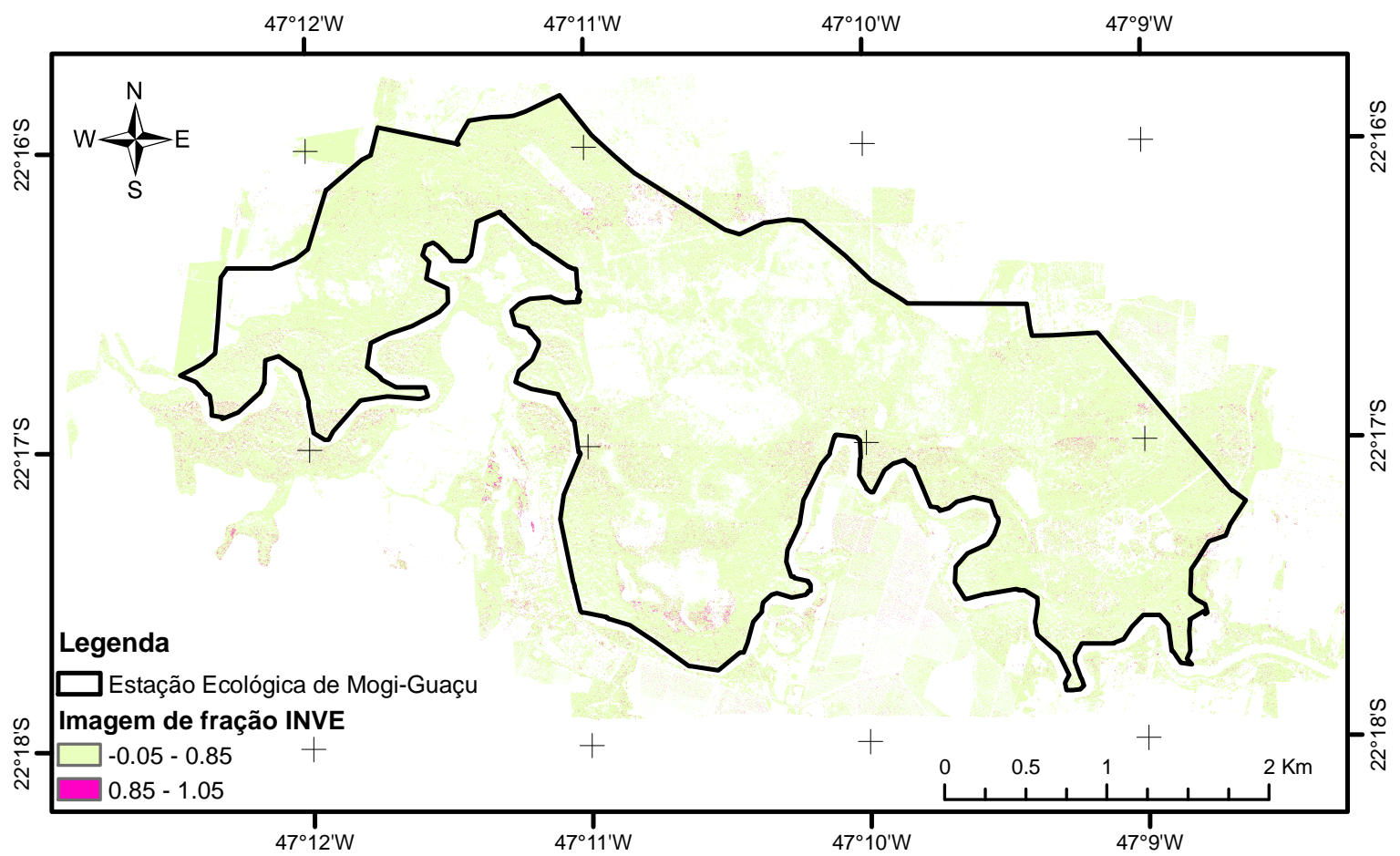

Figura 5.6. Imagem classificada de fração espectral de Inga vera subsp. affinis (INVE), na Estação Ecológica de Mogi-Guaçu, São Paulo, Brasil: pixels com menos de $85 \%$ de sua fração em verde e com mais de $85 \%$ de sua fração em magenta.

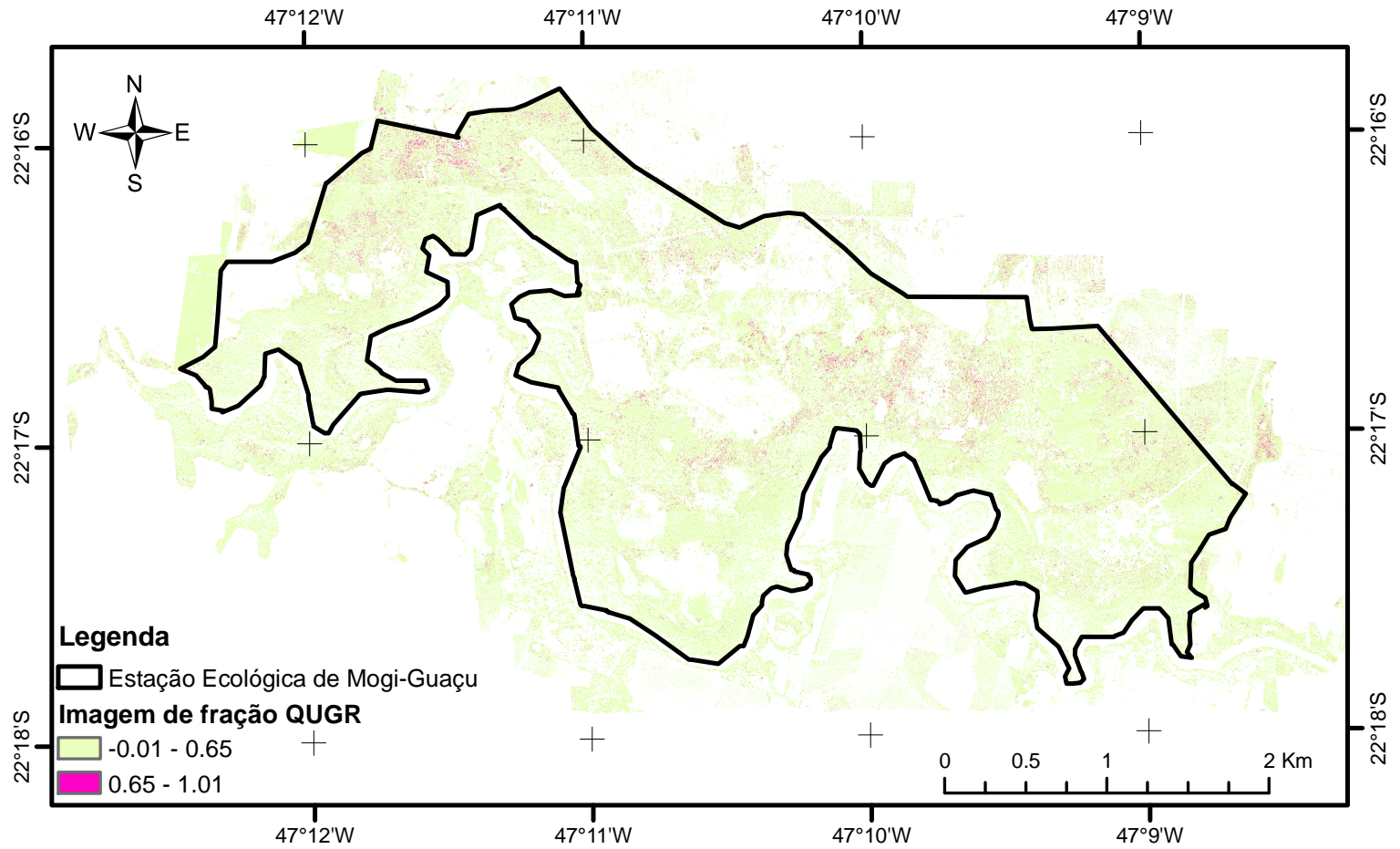

Figura 5.7. Imagem classificada de fração espectral de Qualea grandiflora (QUGR), na Estação Ecológica de Mogi-Guaçu, São Paulo, Brasil: pixels com menos de $65 \%$ de sua fração em verde e com mais de $65 \%$ de sua fração em magenta. 


\subsection{Discussão}

A discriminação espectral em escala de copa das três espécies-alvo, indicadoras de diferentes formações e fácies geológicas da área de estudo, mostrou-se dependente da maior variabilidade interespecífica de energia refletida no intervalo VIS-NIR1 (530-919 nm). A esse intervalo espectral estão associadas feições de absorção por clorofilas e outros pigmentos foliares, bem como efeitos de espalhamento interno (p.ex., células do mesófilo esponjoso), área e ângulo de inserção foliar. Devido à sazonalidade da região e à data de obtenção dos dados espectrais, no início do período seco, as variações em senescência e abscisão foliar entre as espécies-alvo podem ter realçado a importância desse intervalo espectral - onde as clorofilas e os outros pigmentos foliares apresentam feições de absorção. Contudo, enquanto a melhor discriminação espectral de Cedrela fissilis (CEFI) e Inga vera subsp. affinis (INVE) foi atingida com dados originais de reflectância desse intervalo, Qualea grandiflora (QUGR) foi mais bem discriminada utilizando dados VSWIR (530-2.352 nm) e com o contínuo removido. Além disso, as taxas de mistura espectral entre CEFI-INVE foram estatisticamente inferiores às apresentadas para CEFI-QUGR, quando analisados os resultados de classificação VIS-NIR1 e VSWIR.

Os espectros médios obtidos nas copas dessas espécies mostram que no primeiro intervalo as diferenças entre CEFI e INVE são marcantes. Enquanto INVE apresenta maior fração de vegetação verde (GV), as copas de CEFI demonstram maior presença de vegetação não fotossintética (NPV) e de sombra (SHADE) (Figura 5.8). Além das maiores concentrações de clorofilas a e b observadas nas folhas de INVE no período seco, frente às outras espécies-alvo (ver capítulo 4), INVE é perenifólia e seus folíolos apresentam disposição geralmente planófila ( 90 , em relação ao zênite), como observado em campo. Ainda, suas folhas compostas apresentam raque alada - estrutura foliar plana (fotossinteticamente ativa), entre os folíolos -, que confere à espécie maior área foliar. CEFI apresenta dossel descontínuo, é decídua - com pico de abscisão foliar entre os meses de maio e julho (Santos e Takaki, 2005) - e seus folíolos, ao menos na área de estudo, 
apresentam angulação superior a $90^{\circ}$. QUGR, que pode ser considerada decídua ou brevidecídua (p.ex., Lenza e Klink, 2006; Silvério e Lenza, 2010), apresenta perda e brotação de folhas concentradas no final do período seco. Suas folhas jovens tendem a se apresentar eretas, enquanto as maduras tendem a inclinações superiores a $90^{\circ}$. A concentração de água em suas folhas no período seco, bem como o baixo teor de lignina, distinto em relação às outras espécies estudadas (ver capítulo 4), podem ter corroborado na melhor discriminação espectral dessa espécie ao se utilizar dados VSWIR com contínuo removido.

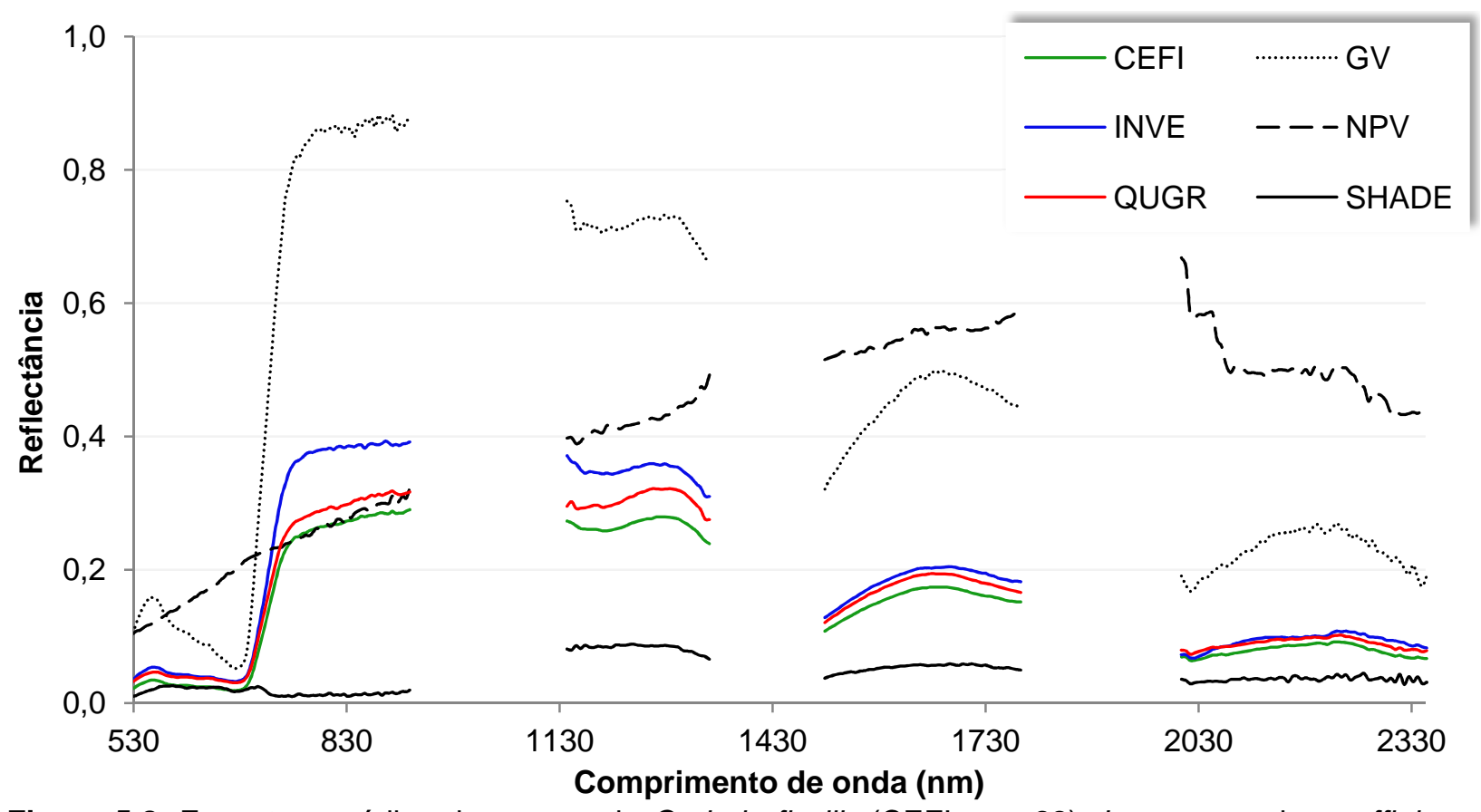

Figura 5.8. Espectros médios das copas de Cedrela fissilis (CEFI, $\mathrm{n}=22$ ), Inga vera subsp. affinis (INVE, $n=31$ ) e Qualea grandiflora (QUGR, $n=28$ ) e membros-finais de vegetação verde $(G V)$, vegetação não fotossintética (NPV) e sombra (SHADE), obtidos no mosaico de imagens ProSpecTIRVS da Estação Ecológica de Mogi-Guaçu, São Paulo, Brasil.

Assim como foi observado em diferentes trabalhos de classificação espectral de espécies (p.ex., Castro-Esau et al., 2006; Hesketh e Sánchez-Azofeifa, 2012), a exatidão global das melhores classificações MESMA decresceu (25,33\%) com o aumento do número de classes. Além disso, a inclusão de classes não específicas na análise, como as gramíneas nativas e exóticas (POAspp) e as outras espécies de cerradão (CERspp) e de mata ciliar (MAClspp), contribuiu ao aumento da variabidade intraclasse, reduzindo as 
exatidões específicas e globais das classificações. Cabe ressaltar que há compartilhamento de espécies generalistas no dossel dessas duas últimas classes de vegetação.

Embora nas classificações espectrais entre as espécies-alvo CEFI e INVE tenham sido mais bem discriminadas do que QUGR, quando se consideraram outras classes de vegetação no processo de classificação espectral das espécies-alvo, QUGR foi a de melhor discriminação. Os erros de omissão espectral foram estatisticamente superiores em CEFI, o que pode estar correlacionado à alta variabilidade intraespecífica das copas da espécie que, no momento de aquisição dos dados, encontrava-se em processo de senescência e abscisão foliar, como discorrido anteriormente. Nessa análise, INVE foi mais bem discriminada utilizando-se dados VSWIR e NIR2-SWIR, indicando que dentre as novas classes há aquelas com características espectrais semelhantes às que melhor distinguiam a espécie no intervalo VIS-NIR1 de dados. Esse fato é mais bem explicitado quando observada a fração da espécie no dossel das outras classes. DENDsp, espécie com maior abundância média da fração INVE, tanto em escala de copa como de dossel, apresenta também em sua composição espectral elevada presença de GV e baixa de NPV e de sombra (ver Anexo A).

A maior taxa de mistura espectral observada no par de espécies CEFI-QUGR permaneceu nas análises posteriores, até às imagens de fração espectral. QUGR foi a classe que apresentou erroneamente maior abundância média da fração de CEFI, tanto em escala de copa como de pixel. A terceira classe com maior abundância da fração CEFI, em ambas as escalas, foi CERspp. Embora CEFI seja espécie de Floresta Estacional Semidecidual (FES), suas características espectrais são semelhantes às de espécies de cerrado "sensu stricto" (CSS). Cedrela fissilis e Zeyheria tuberculosa são as únicas espécies de FES consideradas indicadoras da Formação Aquidauana na área de estudo, assim como as exclusivas de cerrado (ver capítulo 3).

A ausência de comissão espectral e a baixa omissão espectral atingidas concomitantemente pela classe QUGR na modelagem espectral com dois MF, refletiram em um mapeamento satisfatório de sua fração espectral, na modelagem baseada em pixel com 
três MF. A abundância máxima de sua fração observada nas copas de outras classes, considerada atípica (outlier), foi de apenas 62\% (em EUCspp; espécies de eucalipto) e a dispersão dos valores médios de sua fração não chegaram a atingir $50 \%$ nos pixels e copas de outras classes. A Figura 5.9, que mostra simultaneamente as frações das três espécies indicadoras, indica a ocorrência das concentrações de pixels modelados, e posteriormente classificados, como QUGR sobre as colinas e platôs da Formação Aquidauana na EEMG, às quais a espécie está localmente associada (ver capítulo 3). Há virtual ausência de pixels classificados como QUGR na baixada dominada pelos sedimentos quaternários, exceto importante concentração no extremo oeste da EEMG. Essa exceção, entretanto, parece dever-se mais à imprecisão do contato geológico do que a falhas na hipótese de trabalho e no conjunto de processamentos. Esse local, por dificuldade de acesso, deixou de ser visitado em campo e o contato foi traçado utilizando cartas topográficas 1:10.000. Qualea grandiflora (QUGR) é considerada, assim, uma eficiente espécie indicadora, na área de estudo, da Formação Aquidauana, especialmente das colinas e platôs que ocorrem nos terrenos dessa unidade geológica. 


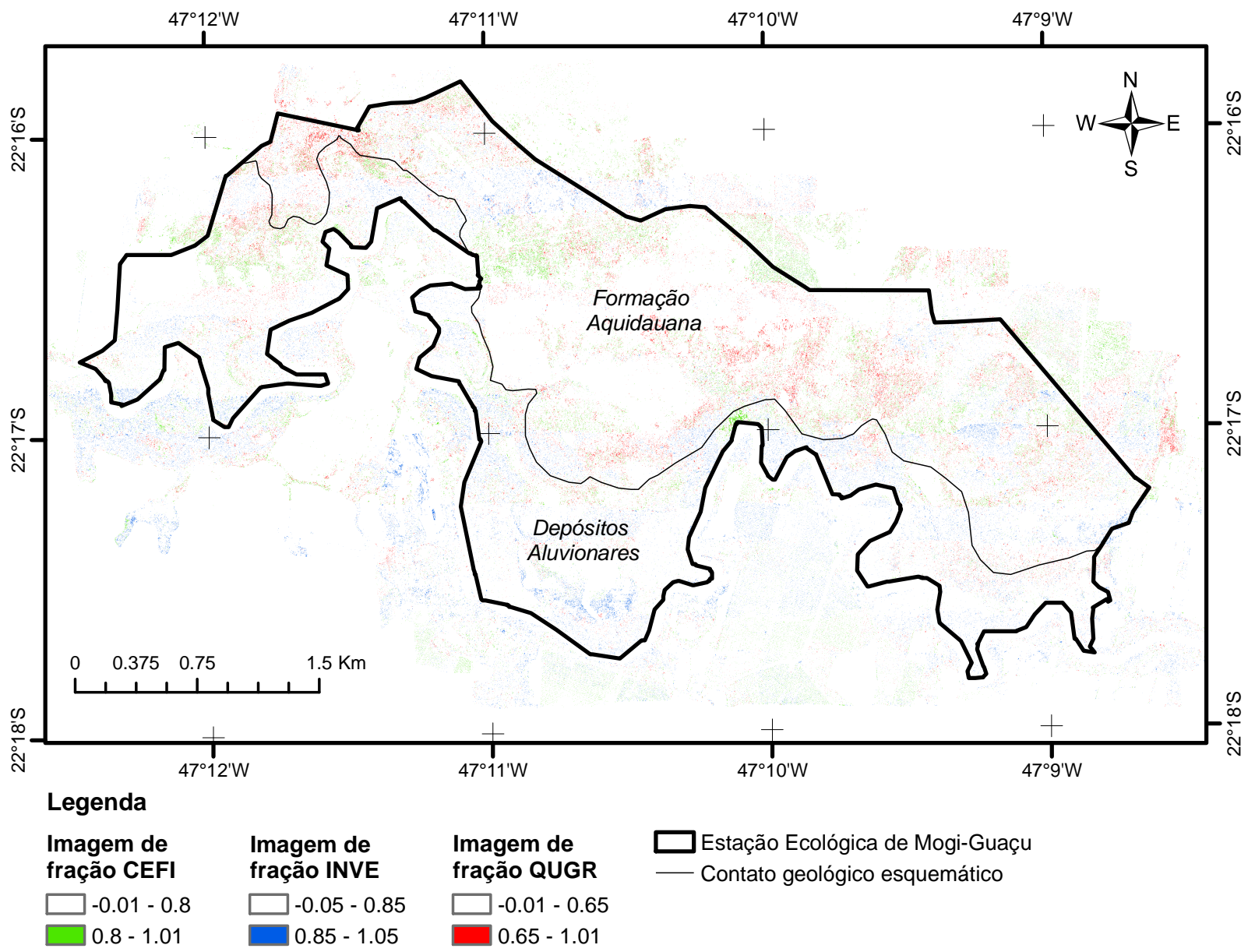

Figura 5.9. Frações espectrais de Cedrela fissilis (CEFI - em verde, $\geq 0,80$ ), Inga vera subsp. affinis (INVE - em azul, $\geq 0,85$ ) e Qualea grandiflora (QUGR - em vermelho, $\geq 0,65$ ), na Estação Ecológica de Mogi-Guaçu, São Paulo, Brasil. Contato geológico esquemático (capítulo 3), em escala aproximada de 1:10.000.

Os resultados também demonstraram que as análises MESMA, que permitem múltiplos MF por classe, minimizaram a influência das diferenças de brilho entre faixas de imageamento. Contudo, para que sejam superadas essas diferenças, decorrentes da geometria de iluminação e de visada, há a necessidade de ampla distribuição (entre as faixas imageadas) de amostras de treinamento de cada espécie-alvo. Esse fato influenciou principalmente os resultados observados em CEFI. Essa espécie, por ser a mais rara e de distribuição mais agregada entre as estudadas, teve suas amostras de referência naturalmente restritas a poucas faixas de voo. A aplicação da técnica Shade normalization foi também essencial na atenuação de efeitos secundários de iluminação, considerando os 
ângulos azimutal e zenital solar, e suas variações entre a aquisição da primeira à última faixa de imageamento, bem como as diferenças em rugosidade dos alvos estudados.

Utilizando dados de alta resolução espectral e espacial, a discriminação espectral em escala de copa de espécies arbóreas nativas em ambientes tropicais é recente. Desde sua primeira aplicação com sucesso registrada na literatura consultada (Clark et al., 2005), diversas técnicas têm sido implementadas e aperfeiçoadas com o intuito maior de se obter um mapeamento efetivo dessas espécies. Essa constitui uma difícil tarefa, devido à alta diversidade química e estrutural observada nos dosséis de florestas tropicais e subtropicais (Asner, 2008). A técnica MESMA vem também evoluindo ao longo dos anos, passando da criação de novas técnicas para seleção de MF (p.ex., Schaaf et al., 2011; Roth et al., 2012), à utilização de dados tratados previamente (p.ex., Somers et al., 2010; Youngentob et al., 2011), à consideração de dados multitemporais na discriminação de espécies (p.ex., Somers e Asner, 2013), e, também, à modificação do método, objetivando o aperfeiçoamento das estimativas subpixels de fração (p.ex., Somers e Asner, 2014).

Destacam-se também técnicas que aliam dados LIDAR aos hiperespectrais, de alta resolução espacial. Essa abordagem multissensores tem apresentado resultados notáveis para o mapeamento de espécies tropicais (p.ex., Colgan et al., 2012; Baldeck et al., 2014) e deve ser considerada em futuras investigações. Baldeck et al. (2014), por exemplo, mapearam mais de 500.000 copas de árvores e arbustos de savana na África do Sul, através de dados Hi-FIS (384,8-1.054,3 nm) e LIDAR. Os autores utilizaram modelo de classificação para 15 classes de espécies (mais classe de outras vegetações), com ampla distribuição na paisagem. Esse modelo foi composto por dois Support Vector Machine, o primeiro em escala de pixel e o segundo em escala de copa. A exatidão do processamento foi de aproximadamente $76 \%$. Algumas daquelas classes não chegaram a ser observadas na área e a que agrupava todas as outras vegetações foi a de maior predição. Os autores observaram que nove espécies, dentre elas as sete mais comuns na paisagem, apresentavam distribuições associadas à variação topográfica. Paralelamente, analisaram a distribuição das comunidades de plantas utilizando nonmetric multidimensional scaling 
(NMDS) e análise de agrupamento hierárquica sobre o mapeamento realizado. Onze grupos foram escolhidos para representar as comunidades de plantas presentes na paisagem e, para cada um, uma espécie indicadora foi selecionada. Contudo, cinco comunidades de plantas representaram $91 \%$ da paisagem. $21,2 \%$ das variações em composição de espécies das cinco comunidades puderam ser explicadas por variáveis topográficas, obtidas e geradas a partir de modelo digital de elevação. Os autores concluíram que outros fatores relacionados aos solos devem apresentar grande importância na distribuição daquelas comunidades. No entanto, a influência geológica não foi discutida por eles.

Como previsto por Sabins (1999), o sensoriamento remoto hiperespectral veio como um estímulo a novas pesquisas geobotânicas, como a aqui apresentada. Os resultados desse estudo mostraram-se encorajadores a futuras investigações. A área estudada apresenta variação geológica relativamente monótona e, mesmo assim, com a definição acurada de espécies associadas aos ambientes geológicos subjacentes, um mapeamento geobotânico em nível específico foi atingido. O sucesso da aplicação sugere que em ambientes geológicos mais diferenciados, como sobre depósitos metálicos e suas encaixantes, se mostre ainda mais viável. Nessas áreas, onde pode ocorrer alta concentração de compostos químicos de elevada toxicidade, espera-se uma maior seleção de espécies. Além disso, a detecção de tendências em suas distribuições espaciais devem ser facilitadas em imagens hiperespectrais de resolução espacial fina. Acredita-se que, com o aumento da disponibilidade de dados dessa ordem, bem como com a evolução das técnicas de processamento desses dados em amplo e rápido desenvolvimento, as pesquisas geobotânicas por sensoriamento remoto em ambientes tropicais poderão ser tratadas em nível específico e em escala de copas individuais.

\subsection{Conclusões}

Esse estudo demonstrou a possibilidade de discriminação espectral, em escala de copa, de espécies neotropicais indicadoras de formações e fácies geológicas na Estação 
Ecológica de Mogi-Guaçu (EEMG), São Paulo, Brasil, utilizando dados hiperespectrais (VSWIR; 530-2.352 nm) de alta resolução espacial e técnica de processamento Multiple Endmember Spectral Mixture Analysis (MESMA). Cedrela fissilis (CEFI), Inga vera subsp. affinis (INVE) e Qualea grandiflora (QUGR) foram discriminadas entre si com exatidão global de $70,59 \%$ e coeficiente Kappa de 0,551. Essa exatidão máxima foi atingida utilizando-se dados VSWIR com o contínuo removido (CR) e membros-finais (MF) selecionados via Iterative Endmember Selection (IES). Contudo, considerando todos os diferentes tratamentos analisados, CEFI foi mais bem discriminada com dados VIS-NIR1 (530-919 nm) originais de reflectância e MF selecionados via EAR-MASA-CoB (EMC), apresentando exatidão do produtor (EP) de $66,67 \%$ e exatidão do usuário (EU) de $88,89 \%$. INVE também foi mais bem classificada utilizando-se dados VIS-NIR1 em reflectância, mas com MF selecionados via IES (EP $=80,95 \%$ e EU $=89,47 \%$ ). Já QUGR foi mais bem discriminada com dados VSWIR com CR, e utilizando MF selecionados via IES (EP $=72,22 \%$ e EU $=$ $68,42 \%)$. As taxas de mistura espectral entre CEFI e INVE foram estatisticamente inferiores àquelas entre CEFI e QUGR nas classificações de dados VIS-NIR1 e VSWIR. No início do período seco, época de obtenção das imagens, enquanto os espectros das copas de CEFI apresentavam elevada fração de vegetação não fotossintética (NPV) e de sombra, as copas de INVE destacavam-se por suas elevadas frações de vegetação fotossinteticamente ativa (GV) e baixas frações de NPV e de sombra. A elevada taxa de mistura espectral entre espécies indicadoras da Formação Aquidauna (CEFI e QUGR) e a maior discriminação espectral, entre as espécies-alvo, daquela associada à sequência Depósitos Aluvionares (INVE) podem ser explicadas por suas características morfofisiológicas e fenológicas. As espécies associadas às diferentes formações geológicas são distintas em termos de deciduidade. Enquanto CEFI e QUGR são caducifólias, INVE é perenifólia.

Embora a discriminação espectral de CEFI e INVE tenha sido superior entre as espécies-alvo, quando incluídas nas análises de mistura espectral outras oito classes de vegetação presentes na paisagem, QUGR foi a espécie-alvo de melhor discriminação. Isso indicou que há espécies com maior similaridade espectral com CEFI e INVE, dentre as 
outras classes de vegetação. Os melhores resultados de discriminação espectral dessas espécies na paisagem ocorreram utilizando diferentes dados de entrada. CEFI, que não chegou a apresentar $50 \%$ de exatidão nessa análise, teve sua melhor classificação realizada com dados VSWIR(CR)/IES (EP $=41,67 \%$ e EU $=45,45 \%$ ). INVE foi mais bem classificada com dados VSWIR/IES (EP $=71,43 \%$ e EU $=48,39 \%$ ) e QUGR com dados VSWIR(CR)/EMC (EP $=61,11 \%$ e EU $=100,00 \%)$. A falta de comissão espectral e a relativa baixa omissão espectral, conferidas à QUGR na modelagem espectral com dois MF, refletiram em um mapeamento satisfatório de sua fração na desmistura espectral do mosaico de imagens, com três MF. A dispersão dos valores médios de sua fração não chegaram a atingir $50 \%$ nos pixels e copas de outras classes e a abundância subpixel máxima de sua fração, considerada atípica (outlier), observada nas copas de outras classes, foi de apenas 62\%. Desse modo, o mapeamento final de QUGR mostrou de forma clara a ocorrência da espécie sobre as colinas e platôs da Formação Aquidauana na área de estudo. A pesquisa teve sucesso, assim, tanto em considerá-la espécie indicadora daqueles ambientes e daquela unidade geológica como em mapeá-la remotamente.

Os resultados desse estudo mostraram-se encorajadores a futuras investigações. A discriminação espectral, em escala de copas individuais, e mapeamento de espécies arbóreas neotropicais com o intuito de correlacionar suas distribuições espaciais à geologia local parece ser uma abordagem inédita. A aplicação da técnica pode ser ainda mais promissora em terrenos com presença de mineralizações ou processos mineralizantes pela maior diversidade geológica presente e, possivelmente, maior seleção de espécies por adaptabilidade. Com o aumento da disponibilidade de dados de alta resolução espectral e espacial, bem como com a evolução das técnicas de processamento desses dados, acredita-se que a geobotânica por sensoriamento remoto em escala específica e de copas individuais poderá avançar notadamente. 


\subsection{Referências bibliográficas}

Adams, J. B., Smith, M. O., \& Gillespie, A. R. (1993). Imaging spectroscopy: Interpretation based on spectral mixture analysis. In C. M. Pieters, \& P. A. J. Englert (Eds.), Remote geochemical analysis: Elemental and mineralogical composition (pp. 145-166). Cambridge: Press Syndicate of the University of Cambridge.

Adams, J. B., Smith, M. O., \& Johnson, P. E. (1986). Spectral mixture modeling: A new analysis of rock and soil types at the Viking Lander 1 site.Journal of Geophysical Research: Solid Earth (1978-2012), 91(B8), 8098-8112.

Almeida, T. I. R., Souza Filho, C. R., Juliani, C., \& Branco, F. C. (2009). Application of Remote Sensing to Geobotany to Detect Hydrothermal Alteration Facies in Epithermal High Sulfidation Gold Deposits in the Amazon Region. In: R. Bedell, S. Simmons, E. Grunsky, \& A. Crósta. (Orgs.). SEG Reviews in Economic Geology - Remote Sensing and Spectral Geology, 1 ed. (pp. 135-142). Society of Economic Geologists.

Almeida-Filho, R, \& Castelo Branco, R. M. G. (1992). Location of kimberlites using Landsat Thematic Mapper images and aerial photographs: the Redondão diatreme, Brazil. International Journal of Remote Sensing, 13, 1449-1457.

Almeida-Filho, R., \& Vitorello, I. (1997). Remote sensing data integration in the definition of hydrotermally altered areas in vegetated terrain, central Brazil. International Journal of Remote Sensing, 18(8), 1835-1842.

Almeida-Filho, R., Vitorello, I., \& Correia, V. R. (1996). Use of Landsat Thematic Mapper imagery as mineral prospecting tool in the tin province of Goias, Brazil. Geocarto International, 11(1), 61-69.

Arden Jr, D. D., \& Westra, R. N. (1977). Remote sensing of geobotanical relations in Georgia. Technical Report (NASA-CR-150709) 103p.

Asner, G. P. (2008). Hyperspectral remote sensing of canopy chemistry, physiology, and biodiversity in tropical rainforests. In M. Kalacska, \& G. A. Sanchez-Azofeifa (Eds.), Hyperspectral remote sensing of tropical and subtropical forests (pp. 261-296). Boca Raton: CRC Press Taylor \& Francis Group.

Asner, G. P., \& Martin, R. E. (2008). Spectral and chemical analysis of tropical forests: scaling from leaf to canopy levels. Remote Sensing of Environment, 112, 3958-3970.

Asner, G. P., \& Martin, R. E. (2009). Airborne spectranomics: mapping canopy chemical and taxonomic diversity in tropical forests. Frontiers in Ecology and the Environment, 7(5), 269-276.

Baldeck, C. A., Colgan, M. S., Féret, J. B., Levick, S. R., Martin, R. E., \& Asner, G. P. (2014). Landscape-scale variation in plant community composition of an African savanna from airborne species mapping. Ecological Applications, 24(1), 84-93.

Castro-Esau, K. L., Sánchez-Azofeifa, G. A., Rivard, B., Wright, S. J., \& Quesada, M. (2006). Variability in leaf optical properties of Mesoamerican trees and the potential for species classification. American Journal of Botany, 93(4), 517-530.

Clark, M. L, Roberts, D. A., \& Clark, D. B. (2005). Hyperspectral discrimination of tropical rain forest tree species at leaf to crown scales. Remote Sensing of Environment, 96, 375-398.

Clark, M. L. (2005). An assessment of Hyperspectral and Lidar Remote Sensing for the Monitoring of Tropical Rain Forest Trees. PhD. Thesis, Department of Geography, University of California, Santa Barbara. (UMI No. 3186829).

Clark, R. N., \& Roush, T. L. (1984). Reflectance spectroscopy: Quantitative analysis techniques for remote sensing applications. Journal of Geophysical Research, 89, 63296340. 
Cochrane, M. A. (2000). Using vegetation reflectance variability for species level classification of hyperspectral data. International Journal of Remote Sensing, 21(10), 2075-2087.

Colgan, M. S., Baldeck, C. A., Féret, J. B., \& Asner, G. P. (2012). Mapping savanna tree species at ecosystem scales using support vector machine classification and BRDF correction on airborne hyperspectral and LiDAR data. Remote Sensing, 4(11), 34623480.

Dennison, P. E., \& Roberts, D. A. (2003). Endmember selection for multiple endmember spectral mixture analysis using endmember average RMSE. Remote Sensing of Environment, 87, 123-135.

Dennison, P. E., Halligan, K. Q. \& Roberts, D. A. (2004). A comparison of error metrics and constraints for multiple endmember spectral mixture analysis and spectral angle mapper. Remote Sensing of Environment, 93, 359-367.

Eiten, G. (1963). Habitat flora of Fazenda Campininha. Anais do $1^{\circ}$ Simpósio sobre Cerrado (pp. 157-202). São Paulo: Universidade de São Paulo.

Féret, J., \& Asner, G. P. (2013). Tree species discrimination in tropical forests using airborne imaging spectroscopy. Geoscience and Remote Sensing, IEEE Transactions on, 51(1), 73-84.

Gamon, J.A. 2008. Tropical Remote Sensing - Opportunities and Challenges. In: M. Kalacska, \& G. A. Sanchez-Azofeifa (Orgs.) Hyperspectral remote sensing of tropical and subtropical forests (pp. 297-304), New York: Taylor \& Francis Group.

Hesketh, M., \& Sánchez-Azofeifa, G. A. (2012). The effect of seasonal spectral variation on species classification in the Panamanian tropical forest.Remote Sensing of Environment, 118, 73-82.

Hestir, E. L., Khanna, S., Andrew, M. E., Santos, M. J., Viers, J. H., Greenberg, J. A., Rajapakse, S. S., \& Ustin, S.L. (2008). Identification of invasive vegetation using hyperspectral remote sensing in the California Delta ecosystem. Remote Sensing of Environment, 112, 4034-4047.

Higgins, M. A., Asner, G. P., Perez, E., Elespuru, N., \& Alonso, A. (2014). Variation in photosynthetic and nonphotosynthetic vegetation along edaphic and compositional gradients in northwestern Amazonia. Biogeosciences, 11(3), 3505-3513.

Higgins, M. A., Asner, G. P., Perez, E., Elespuru, N., Tuomisto, H., Ruokolainen, K., et al. (2012). Use of Landsat and SRTM data to detect broad-scale biodiversity patterns in Northwestern Amazonia. Remote Sensing, 4(8), 2401-2418.

Higgins, M. A., Ruokolainen, K., Tuomisto, H., Llerena, N., Cardenas, G., Phillips, O. L., et al. (2011). Geological control of floristic composition in Amazonian forests. Journal of Biogeography, 38(11): 2136-2149.

Instituto Florestal do Estado de São Paulo. (2010). Áreas protegidas do Instituto Florestal: Estação Ecológica de Mogi-Guaçu. Recuperado de http://www.iflorestal.sp.gov.br/areasprotegidas/index.asp

Jordan, C. F. (1969). Derivation of leaf-area index from quality of light on the forest floor. Ecology, 50, 663-666.

Kalacska, M., Bohlman, S., Sanchez-Azofeifa, G. A., Castro-Esau, K., \& Caelli, T. (2007). Hyperspectral discrimination of tropical dry forest lianas and trees: Comparative data reduction approaches at the leaf and canopy levels.Remote Sensing of Environment, 109(4), 406-415.

Kokaly, R. F. (2011). PRISM: Processing routines in IDL for spectroscopic measurements. Recuperado em 15 de janeiro de 2013, de http://pubs.usgs.gov/of/2011/1155/ 
Kruckeberg, A. R. (2002). Geology and plant life: the effects of landforms and rock types on plants. Seatle: University of Washington Press. 360p.

Lammoglia, T., \& de Souza Filho, C. R. (2013). Unraveling Hydrocarbon Microseepages in Onshore Basins Using Spectral-Spatial Processing of Advanced Spaceborne Thermal Emission and Reflection Radiometer (ASTER) Data. Surveys in Geophysics, 34(3), 349373.

Lenza, E., \& Klink, C. A. (2006). Comportamento fenológico de espécies lenhosas em um cerrado sentido restrito de Brasília, DF. Revista Brasileira de Botânica, 29(4), 627-638.

Lucas, R., Mitchell, A., \& Bunting, P. (2008). Hyperspectral data for assessing carbon dynamics and biodiversity of forests In M. Kalacska, \& G. A. Sanchez-Azofeifa (Eds.), Hyperspectral remote sensing of tropical and subtropical forests (pp. 47-86). Boca Raton: CRC Press Taylor \& Francis Group.

Miao, X., Gong, P., Swope, S., Pu, R., Carruthers, R., Anderson, G. L., Heaton, J. L. \& Tracy, C. R. (2006). Estimation of yellow starthistle abundance through CASI-2 hyperspectral imagery using linear spectral mixture models. Remote Sensing of Environment, 101(3), 329-341.

Paradella, W. R., Da Silva, M. F. F., \& Rosa, N. D. A. (1994). A geobotanical approach to the tropical rain forest environment of the Carajás Mineral Province (Amazon Region, Brazil), based on digital TM-Landsat and DEM data. International Journal of Remote Sensing, 15(8), 1633-1648.

Ribeiro, J.F., \& Walter, B.M.T. (2008). As principais fitofisionomias do Bioma Cerrado. In S.M. Sano, S. P. Almeida, \& J. F. Ribeiro (Eds.). Cerrado: ecologia e flora (pp. 153-212). Planaltina: EMBRAPA-CPAC.

Roberts, D. A., Dennison, P. E., Gardner, M., Hetzel, Y. L., Ustin, S. L., \& Lee, C. (2003). Evaluation of the potential of Hyperion for fire danger assessment by comparison to the Airborne Visible Infrared Imaging Spectrometer. IEEE Transactions on Geoscience and Remote Sensing, 41, 1297-1310.

Roberts, D. A., Gardner, M., Church, R., Ustin, S., Scheer, G., \& Green, R. O. (1998). Mapping Chaparral in the Santa Monica Mountains using multiple endmember spectral mixture models. Remote Sensing of Environment, 65, 267-279.

Roberts, D. A., Halligan, K. Q., \& Dennison, P. E. (2007). ViperTools. Recuperado em 12 de fevereiro de 2013, de http://www.vipertools.org/

Roth, K. L., Dennison, P. E. \& Roberts, D. A. (2012). Comparing endmember selection techniques for accurate mapping of plant species and land cover using imaging spectrometer data. Remote Sensing of Environment, 127, 139-152.

Sabins, F. F. (1999). Remote sensing for mineral exploration. Ore Geology Reviews, 14(3), 157-183.

Santos, D. L. D., \& Takaki, M. (2005). Fenologia de Cedrela fissilis Vell.(Meliaceae) na região rural de Itirapina, SP, Brasil. Acta Botanica Brasilica, 19(3), 625-632.

Schaaf, A. N., Dennison, P. E., Fryer, G. K., Roth, K. L., \& Roberts, D. A. (2011). Mapping plant functional types at three spatial resolutions using multiple endmember spectral mixture analysis. GIScience and Remote Sensing, 48, 324-344.

Serviço Geológico do Brasil - CPRM. (2006). Geologia e recursos minerais do estado de São Paulo: sistema de informações geográficas (SIG). Mapas Geológicos Estaduais. Escala 1:750.000. Programa Geologia do Brasil. São Paulo: CPRM, 1 CD-ROM.

Silvério, D. V., \& Lenza, E. (2010). Fenologia de espécies lenhosas em um cerrado típico no Parque Municipal do Bacaba, Nova Xavantina, Mato Grosso, Brasil. Biota Neotropica, 10(3), 205-216. 
Smith, M. O., Ustin, S. L., Adams, J. B., \& Gillespie, A. R. (1990a). Vegetation in deserts: I. A regional measure of abundance from multispectral images. Remote sensing of Environment, 31(1), 1-26.

Smith, M. O., Ustin, S. L., Adams, J. B., \& Gillespie, A. R. (1990b). Vegetation in deserts: II. Environmental influences on regional abundance. Remote sensing of Environment, 31(1), 27-52.

Somers, B., \& Asner, G. P. (2013). Multi-temporal hyperspectral mixture analysis and feature selection for invasive species mapping in rainforests. Remote Sensing of Environment, 136, 14-27.

Somers, B., \& Asner, G. P. (2014). Tree species mapping in tropical forests using multitemporal imaging spectroscopy: Wavelength adaptive spectral mixture analysis. International Journal of Applied Earth Observation and Geoinformation, 31, 57-66.

Somers, B., Delalieux, S., Verstraeten, W. W., van Aardt, J. A. N., Albrigo, G., \& Coppin, P. (2010). An automated waveband selection technique for optimized hyperspectral mixture analysis. International Journal of Remote Sensing, 31, 5549-5568.

Souza Filho, C. R., Augusto, V., Oliveira, W. J., \& Lammoglia, T. (2008). Detecção de exsudações de hidrocarbonetos por geobotânica e sensoriamento remoto multi-temporal: estudo de caso no Remanso do Fogo (MG). Revista Brasileira de Geociências, 38(2), 228-243.

Tsai, F., Lin, E. E., \& Yoshino, K. (2007). Spectrally segmented principal component analysis of hyperspectral imagery for mapping invasive plant species. International Journal of Remote Sensing, 28(5), 1023-1039.

Tuomisto, H., Poulsen, A. D., Ruokolainen, K., Moran, R. C., Quintana, C., Celi, J., \& Cañas, G. (2003b). Linking floristic patterns with soil heterogeneity and satellite imagery in Ecuadorian Amazonia. Ecological Applications, 13(2), 352-371.

Tuomisto, H., Poulsen, A. D., Ruokolainen, K., Moran, R. C., Quintana, C., Celi, J., \& Cañas, G. (2003). Linking floristic patterns with soil heterogeneity and satellite imagery in Ecuadorian Amazonia. Ecological Applications, 13(2), 352-371.

Tuomisto, H., Ruokolainen, K., \& Yli-Halla, M. (2003c). Dispersal, environment, and floristic variation of western Amazonian forests. Science, 299(5604), 241-244.

Tuomisto, H., Ruokolainen, K., Aguilar, M., \& Sarmiento, A. (2003a). Floristic patterns along a 43-km long transect in an Amazonian rain forest. Journal of Ecology, 91(5), 743-756.

Underwood, E. C., Ustin, S. L., \& Di Pietro, D. (2003). Mapping nonnative plants using hyperspectral imagery, Remote Sensing of Environment, 86, 150-161.

Ustin, S. L., \& Gamon, J. A. (2010). Remote sensing of plant functional types. New Phytologist, 186(4), 795-816.

Ustin, S. L., Smith, M. O., Jacquemoud, S., Verstraete, M. M., Govaerts, Y. (1999). Geobotany: vegetation mapping for Earth Sciences. In: A. N. Rencz (Org.). Remote sensing for the Earth Sciences, $3^{\text {rd }}$ ed (pp. 189-233). New York: John Wiley and sons.

Vitousek, P., Asner, G. P., Chadwick, O. A., \& Hotchkiss, S. (2009). Landscape-level variation in forest structure and biogeochemistry across a substrate age gradient in Hawaii. Ecology, 90(11), 3074-3086.

Zhang, J., Rivard, B., Sánchez-Azofeifa, A., \& Castro-Esau, K. (2006). Intra-and inter-class spectral variability of tropical tree species at La Selva, Costa Rica: Implications for species identification using HYDICE imagery. Remote Sensing of Environment, 105(2), 129-141. 


\section{CONSIDERAÇÕES FINAIS}

A geologia aflorante na Estação Ecológica de Mogi-Guaçu, São Paulo, Brasil, é composta por sedimentos e rochas sedimentares comuns, sem qualquer característica geoquímica especial. Dessa forma, a identificação de espécies arbóreas indicadoras de variações sutis em textura de solos e sedimentos, associadas à geologia local, é uma abordagem que mostrou ser viável em ambientes altamente biodiversos como a área estudada. No entanto, há de se considerar que outros fatores edáficos também podem ser associados à distribuição daquelas espécies. As espécies amostradas exclusivamente sobre a sequência Depósitos Aluvionares (na planície de inundação) mostraram-se associadas a ambientes com sedimentos pelíticos (argila e silte), e também sazonalmente inundados (função também de altitude e nível do freático) e de alta fertilidade. De forma contrastante, as espécies exclusivas de cerrado, amostradas apenas sobre a Formação Aquidauana (nas colinas e platôs), demonstraram estar associadas a ambientes com solos essencialmente arenosos e com muito baixos teores de silte, e também com ausência de inundação sazonal (função também de altitude) e de baixa fertilidade. O meio físico é composto por diversos fatores condicionantes que, de forma conjunta, constituem ambientes favoráveis à ocorrência de uma dada espécie e desfavoráveis a outras.

A aplicação de análises multivariadas, como os Self-Organizing Maps, foi essencial para observação das relações entre fisionomias florestais, espécies arbóreas e o meio físico

que habitam. O grande passo para o estabelecimento seguro de associação entre a florística e a geologia local foi o estudo do comportamento das variáveis de interesse nos domínios formados a partir de diversos fatores do sistema. A existência de relações entre unidades amostrais, independentemente se analisadas apenas as variáveis granulométricas ou todas as observadas no sistema estudado, comprovou que a textura de solos e sedimentos é um parâmetro fundamental na formação de microambientes, onde são observadas fisionomias e espécies florestais únicas. Cabe ressaltar que estudos presentes na literatura a respeito de análises granulométricas e que, em geral, não encontraram 
correlação entre textura de solos e vegetação, utilizam apenas três (raramente cinco) classes granulométricas, com exceção do trabalho de Soares (2012), citado nessa tese. A segregação da fração areia em cinco classes (mais argila e silte) foi essencial ao estudo e às relações estabelecidas. Enquanto os geoambientes da Formação Aquidauana apresentam concentrações discriminantes de areia fina, média, grossa e muito grossa, os depósitos de diques marginais da sequência Depósitos Aluvionares foram caracterizados, principalmente, por suas distintas concentrações de areia muito fina.

Tratando-se de ambientes geológicos comuns - sem a presença de solos particulares como ocorre frequentemente sobre mineralizações metálicas, por exemplo -, espécies consideradas indicadoras de sutis variações edafogeológicas podem ser raras e apresentar distribuição agregada, considerando-se os fatores condicionantes à sua germinação, estabelecimento e sobrevivência. Assim, a discriminação remota de plantas em nível de copas individuais aplicada à geobotânica em ambientes geologicamente monótonos é, em princípio, dificultada. Além da baixa densidade amostral, que pode ser insuficiente à aplicação, as espécies selecionadas provavelmente não serão aquelas dominantes na paisagem e, tampouco, aquelas emergentes de copas globosas e amplas, o que facilitaria os processos de obtenção de dados de referência nas imagens e de mapeamento. Ressalte-se que a discriminação espectral em escala de copas individuais e o mapeamento de espécies nativas em ambientes tropicais, seja ele florestal ou savânico, têm sido realizados com aquelas dominantes na paisagem (p.ex. Clark et al, 2005 e Baldeck et al., 2014).

A aplicação da técnica apresenta ainda mais dificuldades, uma vez que o recobrimento de uma área com variações geológicas por imagens de alta resolução espacial, requeridas ao processo, se dará com a mosaicagem de múltiplas faixas de imageamento. Sendo assim, o sucesso da aplicação também é dependente das características de aquisição desses dados. Mesmo que sua obtenção seja no nadir e próxima ao meio-dia solar, haverá variação na geometria de iluminação entre a aquisição da primeira à última faixa de voo. Quanto maior a área a ser imageada maior deverá ser essa 
variação. A obtenção de uma faixa de imageamento tranversal (Raymond Kokaly, informação verbal) ou mesmo a aplicação de modelo para correção de BRDF (Bidirectional Reflectance Distribution Function) (p.ex., Colgan, 2012) podem servir à normalização das diferenças em brilho entre as imagens e devem ser consideradas em futuros esforços de pesquisa. Esse fato é importante, pois as características espectrais singulares de dada espécie, geralmente muito sutis, devem ser superiores a possíveis variações espectrais entre faixas de imageamento. Caso contrário sua fração espectral tende a ser erroneamente superior a outros pixels da(s) faixa(s) de voo onde seus espectros de treinamento foram coletados.

Devido às características das populações das seis espécies definidas "in loco" como indicadoras de formações e fácies geológicas, apenas cinco delas puderam ser estudadas espectralmente em escala de folha e três em escala de copa. Zeyheria tuberculosa não foi considerada nas análises de mistura espectral e bioquímica, em escala de folha, em função de sua raridade no dossel florestal e alta deciduidade. Nas datas de coleta de material do período seco, apenas dois de seus indivíduos que ocupam o dossel não estavam completamente sem folhas. Assim, a espécie não atingiu suficiência amostral para essa análise. Z. tuberculosa, Calophyllum brasiliense e Tabebuia ochracea não puderam ser consideradas nos processamentos em escala de copa. Suas distribuições, naturalmente restritas a uma ou a poucas faixas de imageamento, influenciaram os resultados de mistura espectral e mapeamento de frações, em análise prévia. A baixa densidade amostral (espectros coletados nas imagens), considerando a raridade e as características de copa dos indivíduos amostrados, também preponderou na exclusão dessas espécies nessa análise e no mapeamento de frações espectrais.

Embora os fatores que influenciam a resposta espectral sejam diferentes entre escalas de trabalho (Roberts et al., 2004), Cedrela fissilis e Qualea grandiflora apresentaram as maiores taxas de mistura espectral tanto em escala de folha quanto de copa. A alta variabilidade bioquímica e espectral observada nas folhas das espécies-alvo sugeriu a existência de diferentes estratégias fisiológicas e fenológicas entre elas, inclusive quando 
habitam o mesmo ambiente. Mesmo que pares de espécies associadas a determinado geoambiente possam ser considerados tipos funcionais distintos, espectralmente eles não representam tipos ópticos diferenciados na paisagem. Assim, no mapeamento geobotânico em nível específico, espécies indicadoras de diferentes fácies geológicas podem apresentar maiores erros de classificação espectral entre si do que espécies associadas a mesmo geoambiente. Essa alta variabilidade química e espectral observada nas folhas das copas de espécies-alvo corrobora a conclusão de que não há um melhor momento sazonal para discriminação espectral dessas espécies em escala de folha. Nessa escala, todas elas foram bem discriminadas em ambos os momentos sazonais, o de chuvas e o de estiagem.

Diferentemente do observado em escala de folha, em escala de copa as variações fenológicas, em termos de senescência e abscisão foliar, parecem constituir importante fator à discriminação espectral de espécies indicadoras de diferentes formações geológicas. Enquanto Inga vera subsp. affinis (associada aos sedimentos quaternários) é perenifólia, $C$. fissilis e Q. grandiflora (associadas à Formação Aquidauna) são caducifólias, com domínio de folhas senescentes, e também em processo de abscisão foliar em $C$. fissilis, no momento de aquisição dos dados hiperespectrais. Essas últimas apresentaram maior taxa de mistura espectral em escala de copa, tanto nas análises de dados VIS-NIR1 (530-919 nm), quanto VSWIR (530-2.352 nm).

C. fissilis e I. vera subsp. affinis apresentaram maior taxa de mistura espectral com outras classes de vegetação presentes na paisagem, do que $Q$. grandiflora. Como foi discutido anteriormente, $C$. fissilis é espécie rara e, portanto, teve seu mapeamento influenciado pelas diferenças espectrais entre faixas de imageamento. I. vera subsp. affinis, de forma contrária, é espécie abundante, de distribuição ampla e teve suas amostras de treinamento coletadas em diversas faixas de imageamento. Contudo, além de ocorrer pontualmente fora da sequência Depósitos Aluvionares, onde há também deposição de sedimentos pelíticos, I. vera subsp. affinis apresentou elevada mistura espectral com espécies da paisagem que apresentam alta abundância de fração de vegetação 
fotossinteticamente ativa e baixa de frações de vegetação não fotossinteticamente ativa e de sombra.

O sucesso de mapeamento da fração de $Q$. grandiflora pode ser atribuído também à mais ampla distribuição e abundância da espécie (e das amostras de treinamento) na área estudada; mas, apresenta como essência a singularidade espectral da espécie frente à diversidade espectral presente na paisagem. Em seu mapeamento final, observou-se que a espécie apresenta clara associação com as colinas e platôs da Formação Aquidauna, além da virtual ausência de pixels modelados por sua fração onde ocorrem os sedimentos quaternários (Depósitos Aluvionares). Esse fato demonstra o sucesso da pesquisa, tanto em considerá-la indicadora geológica como em discriminá-la remotamente.

A aplicação da técnica provavelmente será mais promissora em terrenos com mineralizações ou processos mineralizantes, onde haverá maior diversidade geológica e contraste geoquímico e, possivelmente, maior seleção de espécies por adaptabilidade. Isso deve facilitar a definição "in loco" e a detecção remota de espécies indicadoras, em paisagens altamente biodiversas.

$\mathrm{Na}$ área de estudo, os paleoleitos mostraram ser os ambientes mais anômalos para a colonização e sobrevivência de espécies arbóreas. A parcela 10, por exemplo, teve a unidade amostral (ua) A alocada sobre paleodique enquanto as ua B e C foram alocadas sobre paleoleito. A primeira apresentou abundância de 52 indivíduos e riqueza de 19 espécies, enquanto as outras duas apresentaram abundância de 37 e 33 indivíduos, respectivamente, e riqueza de oito espécies, cada uma. Juntas as ua 10-B e 10-C (800 $\left.\mathrm{m}^{2}\right)$ apresentaram apenas 11 espécies. O transecto 1 também foi alocado sobre paleodique e paleoleito. Ambos os ambientes apresentaram abundância de 19 indivíduos, contudo o primeiro (ua $A, B, C$ e D; $200 \mathrm{~m}^{2}$ ) apresentou riqueza de 11 espécies e o segundo ( $F, G, H, I$ e J; $250 \mathrm{~m}^{2}$ ) de apenas seis. Apenas $C$. brasiliense foi amostrada e observada apenas nos paleoleitos, demonstrando que as outras não estão restritas àquelas condições. Aquela espécie, no entanto, apresenta distribuição agregada no interior dos paleoleitos e, como foi discutido, não pôde ser considerada nas análises em escala de copa e mapeamento. 
Além de uma possível maior seleção de espécies em ambientes geoquimicamente anômalos, alterações morfofisiológicas no dossel podem ser observadas, devido à alta concentração de compostos tóxicos, ou à presença de condições secundárias, ambas adversas à vegetação. Nos paleoleitos, além da formação de ambientes fluviolacustres no período das chuvas, seus solos e sedimentos essencialmente pelíticos apresentam elevada acidez e baixa oxigenação. Assim, variações bioquímicas podem ser observadas em seu dossel florestal, em escala de paisagem (Figura 6.1). Como apresentado em Amaral et al. (2012), nessa escala, a vegetação sobre paleoleitos apresenta menores quantidades de clorofilas, quando comparada à vegetação adjacente.

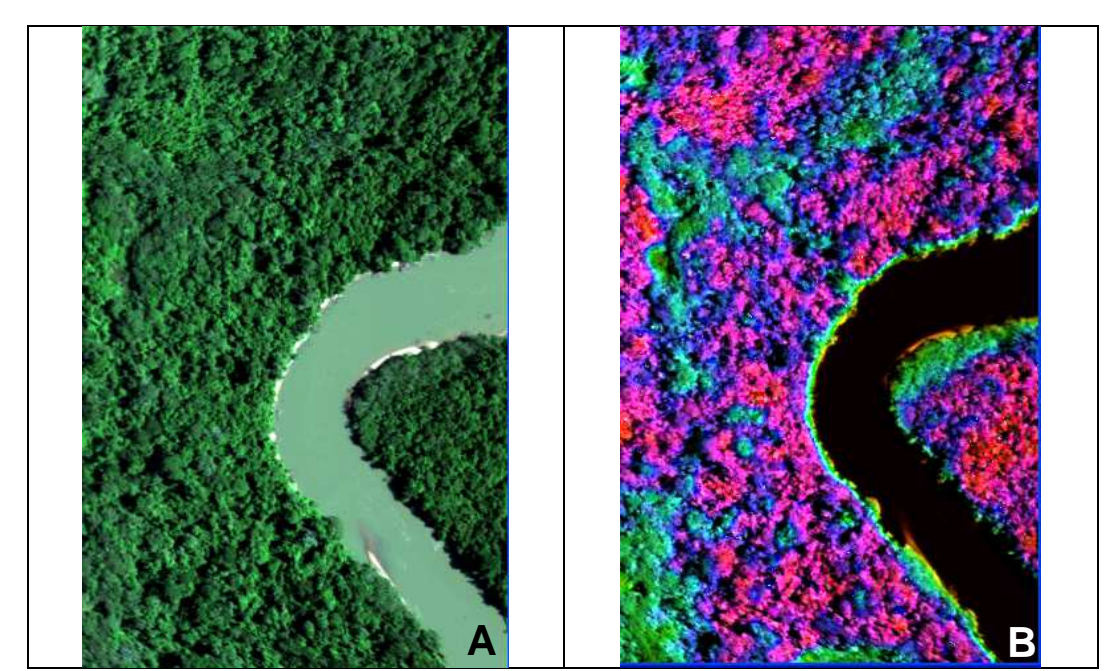

Figura 6.1. Trecho de Floresta Estacional Semidecidual às margens do rio Mogi-Guaçu, na área de estudo. A) em composição colorida em cores naturais (canais $686 \mathrm{~nm}, 553 \mathrm{~nm}, 479 \mathrm{~nm}$, em RGB); B) em cor sintética, razão simples $\rho 740 / 0677 \mathrm{~nm}$ (realce para clorofila a). Ver variação espectral da vegetação evidenciando paleoleito (à esquerda do rio), em relação aos terrenos adjacentes.

A observação de anomalias geobotânicas em escala de paisagem, associada aos resultados observados em escala de copa e de folha, demostram claramente a dependência da escala de trabalho na resposta espectral da vegetação analisada, bem como em suas associações com o meio físico e a geologia. Em escala de paisagem, o alvo estudado inclui, não apenas espécies de ocorrências restritas a determinada condição edafogeológica, mas também espécies generalistas que ocasionalmente se estabeleceram nesse ambiente. Assim, devido às condições adversas aí encontradas, as generalistas deverão expressar respostas morfofisiológicas e espectrais anômalas, em relação ao restante de sua 
população. Por outro lado, ao se trabalhar com espécies indicadoras, foi possível compreender em escala de folha que cada uma delas apresenta um comportamento intrínseco de adaptação ao ambiente que habita e, portanto, não há um padrão espectral, fisiológico, morfológico ou mesmo fenológico entre espécies indicadoras de mesma fácies geológica. Em escala de copa, entretanto, similaridades em composição espectral e em deciduidade puderam ser observadas entre espécies com ocorrências associadas à mesma formação geológica. O mapeamento de espécies indicadoras, baseado em pixel, permitiu concluir que aquelas de distribuição ampla, mas restritamente associadas a uma unidade geológica, podem ser mapeadas em imagens hiperespectrais de resolução espacial fina e indicar a ocorrência daquele geoambiente. Para tanto, ela deve ser espectralmente singular na paisagem. Assim, em escala de paisagem, ou mesmo quando os alvos são espécies generalistas, é possível afirmar que variações espectrais intraespecíficas também constituem fator de prospecção geobotânica. Contrariamente a essa alegação, ao se tratar de espécies indicadoras, adaptadas ao ambiente em questão, a homogeneidade intraespecífica e a distinção interespecífica são características-chave ao sucesso do mapeamento geobotânico.

Com o aumento da disponibilidade de dados de alta resolução espectral e espacial, bem como com a evolução das técnicas de processamento desses dados, que se encontram em amplo e rápido desenvolvimento, acredita-se que as pesquisas geobotânicas por sensoriamento remoto em ambientes tropicais podem ser adotadas e desenvolvidas em escala copas individuais. Isso se aplica tanto a pesquisas de discriminação interespecífica de espécies indicadoras, quanto as que visam às variações intraespecíficas em espécies generalistas.

Além da geobotânica, cabe ressaltar que o mapeamento de espécies em escala de copas individuais pode subsidiar os estudos em diversidade arbórea e bioquímica de dossel de formações tropicais, o monitoramento de espécies ameaçadas de extinção, o planejamento de manejo de espécies com potencial econômico (como aquelas potenciais em produtos não madeireiros), bem como os estudos ecológicos e fitogeográficos que visam 
ao entendimento de outros fatores condicionantes à distribuição de espécies, sejam eles pedológicos, topográficos, climáticos ou relacionados a distúrbios naturais ou antrópicos.

\subsection{Referências bibliográficas}

Amaral, C. H., Almeida, T. I. R., Souza Filho, C. R., Botelho, M., Alves, M. N., \& Penatti, N. C. (2012). Correlation between the variations of clay content in soils and sediments and the spectral behavior of superjacent vegetation using spectir hyperspectral images. In IEEE $4^{\text {th }}$ Workshop on Hyperspectral Image and Signal Processing (pp.01-04). Shanghai, China.

Baldeck, C. A., Colgan, M. S., Féret, J. B., Levick, S. R., Martin, R. E., \& Asner, G. P. (2014). Landscape-scale variation in plant community composition of an African savanna from airborne species mapping. Ecological Applications, 24(1), 84-93.

Clark, M. L, Roberts, D. A., \& Clark, D. B. (2005). Hyperspectral discrimination of tropical rain forest tree species at leaf to crown scales. Remote Sensing of Environment, 96, 375-398.

Colgan, M. S., Baldeck, C. A., Féret, J. B., \& Asner, G. P. (2012). Mapping savanna tree species at ecosystem scales using support vector machine classification and BRDF correction on airborne hyperspectral and LiDAR data. Remote Sensing, 4(11), 34623480.

Roberts, D. A., Ustin, S. L., Ogunjemiyo, S., Greenberg, J., Dobrowski, S. Z., Chen, J. et al. (2004). Spectral and structural measures of northwest forest vegetation at leaf to landscape scales. Ecosystems, 7(5), 545-562.

Soares, C. T. (2012). Geobotânica por sensoriamento remoto em florestas de Restinga sobre sedimentos holocênicos, Iguape-SP. Dissertação de Mestrado, Instituto de Geociências, Universidade de São Paulo, São Paulo. 


\section{APÊNDICES}

\section{Apêndice A - Espécies arbustivo-arbóreas amostradas no estudo}

\section{Amostragem por parcelas}

Tabela 1. Espécies amostradas na Parcela 01 , densidade absoluta ( $\mathrm{n}^{0}$ indivíduos/ha; DA), dominância absoluta (área basal/ha; DoA), frequência absoluta (unidade amostral presente/ $\mathrm{n}^{\circ}$ unidades amostrais (3); FA), Índice de Valor de Importância (somatório de densidade, dominância e frequência relativas; IVI).

\begin{tabular}{|c|c|c|c|c|}
\hline Espécie & DA & DoA & FA & IVI \\
\hline Protium heptaphyllum (Aubl.) Marchand & 133,3 & 3,69 & 100,00 & 37,16 \\
\hline Qualea grandiflora Mart. & 125,0 & 2,75 & 66,67 & 29,43 \\
\hline Rapanea guianensis Aubl. & 150,0 & 1,52 & 100,00 & 27,55 \\
\hline Alchornea sidifolia Mull. Arg. & 91,7 & 2,26 & 100,00 & 26,22 \\
\hline Zanthoxylum riedelianum Engl. & 100,0 & 2,01 & 100,00 & 25,69 \\
\hline Syzygium cumini (L.) Skeels & 116,7 & 1,25 & 100,00 & 23,27 \\
\hline Melia azedarach L. & 50,0 & 2,32 & 100,00 & 22,88 \\
\hline Xylopia aromatica (Lam.) Mart. & 83,3 & 0,67 & 100,00 & 17,38 \\
\hline Psidium guajava L. & 66,7 & 0,22 & 100,00 & 13,65 \\
\hline Dimorphandra mollis Benth. & 25,0 & 0,84 & 66,67 & 10,91 \\
\hline Eugenia brasiliensis Lam. & 41,7 & 0,22 & 66,67 & 9,2 \\
\hline Nectandra megapotamica (Spreng.) Mez & 25,0 & 0,48 & 66,67 & 9,1 \\
\hline Bauhunia forficata Link & 16,7 & 0,16 & 66,67 & 6,7 \\
\hline Mangifera indica L. & 16,7 & 0,47 & 33,33 & 6,1 \\
\hline Indeterminada 1 & 25,0 & 0,10 & 33,33 & 4,91 \\
\hline Pinus elliottii Engel. & 8,3 & 0,24 & 33,33 & 4,17 \\
\hline Schinus terebinthifolia Raddi & 8,3 & 0,16 & 33,33 & 3,76 \\
\hline Cordia ecalyculata Vell. & 8,3 & 0,06 & 33,33 & 3,27 \\
\hline Schizolobium parahyba (Vell.) S.F. Blake & 8,3 & 0,05 & 33,33 & 3,2 \\
\hline Ficus guaranitica Schodat & 8,3 & 0,04 & 33,33 & 3,18 \\
\hline Myrtaceae 1 & 8,3 & 0,04 & 33,33 & 3,14 \\
\hline Gochnatia pulchra Cabrera & 8,3 & 0,02 & 33,33 & 3,06 \\
\hline Casearia sylvestris Sw. & 8,3 & 0,02 & 33,33 & 3,04 \\
\hline Nectandra rigida (Kunth) Ness & 8,3 & 0,02 & 33,33 & 3,04 \\
\hline
\end{tabular}


Tabela 2. Espécies amostradas na Parcela 02 , densidade absoluta ( $\mathrm{n}^{0}$ indivíduos/ha; DA), dominância absoluta (área basal/ha; DoA), frequência absoluta (unidade amostral presente/ ${ }^{\circ}$ unidades amostrais (3); FA), Índice de Valor de Importância (somatório de densidade, dominância e frequência relativas; IVI).

\begin{tabular}{l|c|c|c|c}
\multicolumn{1}{c|}{ Espécie } & DA & DoA & FA & IVI \\
\hline Alchornea sidifolia Mull. Arg & 325,0 & 11,41 & 100,00 & 94,46 \\
\hline Protium heptaphyllum (Aubl.) Marchand & 208,3 & 2,30 & 100,00 & 41,98 \\
\hline Eucalyptus robusta Sm. & 58,3 & 4,42 & 100,00 & 36,77 \\
\hline Euterpe edulis Mart. & 175,0 & 0,84 & 66,67 & 28,4 \\
\hline Nectandra rigida (Kunth) Ness & 25,0 & 0,94 & 66,67 & 14,08 \\
\hline Dicksonia sellowiana (Presl.) Hook. & 41,7 & 0,30 & 66,67 & 12,87 \\
\hline Copaifera langsdorffii Desf. & 25,0 & 0,82 & 33,33 & 9,84 \\
\hline Myrtaceae 2 & 16,7 & 0,06 & 66,67 & 9,33 \\
\hline Pera glabrata (Schott) Baill. & 25,0 & 0,22 & 33,33 & 7,15 \\
\hline Guapira opposita Vell. & 25,0 & 0,14 & 33,33 & 6,78 \\
\hline Rapanea guianensis Aubl. & 25,0 & 0,08 & 33,33 & 6,54 \\
\hline Casearia sylvestris Sw. & 25,0 & 0,07 & 33,33 & 6,48 \\
\hline Ocotea corymbosa (Meisn.) Mez & 8,3 & 0,39 & 33,33 & 6,29 \\
\hline Machaerium nyctitans (Vell.) Benth & 8,3 & 0,08 & 33,33 & 4,89 \\
\hline Eugenia brasiliensis Lam. & 8,3 & 0,07 & 33,33 & 4,83 \\
\hline Ficus guaranitica Schodat & 8,3 & 0,03 & 33,33 & 4,67 \\
\hline Vochysia tucanorum Mart. & 8,3 & 0,03 & 33,33 & 4,64 \\
\hline
\end{tabular}


Tabela 3. Espécies amostradas na Parcela 03, densidade absoluta ( $\mathrm{n}^{0}$ indivíduos/ha; DA), dominância absoluta (área basal/ha; DoA), frequência absoluta (unidade amostral presente/ ${ }^{\circ}$ unidades amostrais (3); FA), Índice de Valor de Importância (somatório de densidade, dominância e frequência relativas; IVI).

\begin{tabular}{l|c|c|c|c}
\multicolumn{1}{c|}{ Espécie } & DA & DoA & FA & IVI \\
\hline Rapanea guianensis Aubl. & 483,3 & 3,46 & 100,00 & 57,73 \\
\hline Qualea grandiflora Mart. & 158,3 & 1,93 & 100,00 & 27,57 \\
\hline Protium heptaphyllum (Aubl.) Marchand & 25,0 & 3,51 & 100,00 & 27,27 \\
\hline Ficus guaranitica Schodat & 108,3 & 2,23 & 100,00 & 25,83 \\
\hline Dimorphandra mollis Benth. & 100,0 & 1,95 & 100,00 & 23,76 \\
\hline Gochnatia pulchra Cabrera & 158,3 & 0,86 & 100,00 & 21,73 \\
\hline Indeterminada 3 & 116,7 & 1,22 & 100,00 & 20,9 \\
\hline Zanthoxylum riedelianum Engl. & 25,0 & 0,32 & 100,00 & 9,8 \\
\hline Roupala brasiliensis Klotzsch & 58,3 & 0,24 & 66,67 & 9,49 \\
\hline Eriotheca pubescens (Mart. \& Zucc.) Schott \& Endl. & 33,3 & 0,25 & 66,67 & 7,86 \\
\hline Copaifera langsdorffii Desf. & 16,7 & 0,44 & 66,67 & 7,77 \\
\hline Vochysia tucanorum Mart. & 25,0 & 0,29 & 66,67 & 7,51 \\
\hline Melastomataceae 1 & 33,3 & 0,15 & 66,67 & 7,31 \\
\hline Luehea divaricata Mart. & 16,7 & 0,68 & 33,33 & 6,97 \\
\hline Myrcia tomentosa (Aubl.) DC. & 25,0 & 0,11 & 66,67 & 6,52 \\
\hline Schinus terebinthifolia Raddi & 25,0 & 0,10 & 66,67 & 6,46 \\
\hline Tabebuia aurea (Silva Manso) Benth. \& Hook f. ex S. Moore & 16,7 & 0,15 & 66,67 & 6,2 \\
\hline Platypodium elegans Vogel & 16,7 & 0,12 & 66,67 & 6,03 \\
\hline Indeterminada 2 & 25,0 & 0,06 & 33,33 & 4,14 \\
\hline Tabebuia ochracea (Cham.) Standl. & 8,3 & 0,09 & 33,33 & 3,18 \\
\hline Ocotea pulchela Mart. & 8,3 & 0,07 & 33,33 & 3,08 \\
\hline Caryocar brasiliense Camb. & 8,3 & 0,04 & 33,33 & 2,88 \\
\hline & & & & \\
\hline
\end{tabular}


Tabela 4. Espécies amostradas na Parcela 04, densidade absoluta ( $\mathrm{n}^{0}$ indivíduos/ha; DA), dominância absoluta (área basal/ha; DoA), frequência absoluta (unidade amostral presente/ $\mathrm{n}^{\circ}$ unidades amostrais (3); FA), Índice de Valor de Importância (somatório de densidade, dominância e frequência relativas; IVI).

\begin{tabular}{l|c|c|c|c}
\multicolumn{1}{c|}{ Espécie } & DA & DoA & FA & IVI \\
\hline Sapium glandulatum (Vell.) Pax & 208,3 & 6,18 & 100,00 & 45,77 \\
\hline Rapanea guianensis Aubl. & 266,7 & 2,50 & 100,00 & 34,69 \\
\hline Luehea divaricata Mart. & 125,0 & 2,59 & 100,00 & 25,1 \\
\hline Schinus terebinthifolius Raddi & 200,0 & 1,16 & 100,00 & 24,48 \\
\hline Enterolobium contortisiliquum (Vell.) Morong & 16,7 & 4,68 & 33,33 & 22,34 \\
\hline Zanthoxylum riedelianum Engl. & 83,3 & 1,22 & 100,00 & 16,53 \\
\hline Machaerium nyctitans (Vell.) Benth & 50,0 & 0,52 & 100,00 & 11,33 \\
\hline Eugenia brasiliensis Lam. & 66,7 & 0,44 & 66,67 & 10,28 \\
\hline Psidium guajava L. & 66,7 & 0,25 & 66,67 & 9,48 \\
\hline Bathysa nicholsoni K. Schum. & 25,0 & 0,43 & 100,00 & 9,19 \\
\hline Euphorbiaceae 1 & 25,0 & 0,55 & 66,67 & 7,78 \\
\hline Casearia sylvestris Sw. & 41,7 & 0,14 & 66,67 & 7,28 \\
\hline Nectandra rigida (Kunth) Ness & 16,7 & 0,55 & 66,67 & 7,19 \\
\hline Nectandra megapotamica (Spreng.) Mez & 25,0 & 0,34 & 66,67 & 6,94 \\
\hline Syagrus romanzoffiana (Cham.) Glassman & 25,0 & 0,66 & 33,33 & 6,37 \\
\hline Annona cacans Warm. & 16,7 & 0,07 & 66,67 & 5,24 \\
\hline Myrciaria tenella O. Berg & 16,7 & 0,06 & 66,67 & 5,19 \\
\hline Alchornea sidifolia Mull. Arg. & 8,3 & 0,45 & 33,33 & 4,34 \\
\hline Protium heptaphyllum (Aubl.) Marchand & 16,7 & 0,15 & 33,33 & 3,67 \\
\hline Zanthoxylum rhoifolium Lam. & 16,7 & 0,11 & 33,33 & 3,52 \\
\hline Xylopia aromatica (Lam.) Mart. & 16,7 & 0,09 & 33,33 & 3,45 \\
\hline Tabebuia aurea (Silva Manso) Benth. \& Hook f. ex S. & 8,3 & 0,22 & 33,33 & 3,39 \\
\hline Moore & 16,7 & 0,06 & 33,33 & 3,31 \\
\hline Guarea guidonia (L.) Sleumer & 8,3 & 0,17 & 33,33 & 3,18 \\
\hline Platypodium elegans Vogel & 8,3 & 0,15 & 33,33 & 3,1 \\
\hline Tapirira guianensis Aubl. & 8,3 & 0,13 & 33,33 & 3,03 \\
\hline Annona crassiflora Mart. & 8,3 & 0,11 & 33,33 & 2,93 \\
\hline Cecropia hololeuca Miq. & 8,3 & 0,11 & 33,33 & 2,91 \\
\hline Machaerium stipitatum (DC.) Vogel & 8,3 & 0,07 & 33,33 & 2,77 \\
\hline Indeterminada 4 & 8,3 & 0,04 & 33,33 & 2,62 \\
\hline Copaifera langsdorffii Desf. & 0,03 & 33,33 & 2,6 \\
\hline Pouteria ramiflora (Mart.) Radlk. & & & \\
\hline & & & \\
\hline
\end{tabular}


Tabela 5. Espécies amostradas na Parcela 05 , densidade absoluta ( $\mathrm{n}^{0}$ indivíduos/ha; DA), dominância absoluta (área basal/ha; DoA), frequência absoluta (unidade amostral presente/ ${ }^{\circ}$ unidades amostrais (3); FA), Índice de Valor de Importância (somatório de densidade, dominância e frequência relativas; IVI).

\begin{tabular}{l|c|c|c|c}
\multicolumn{1}{c|}{ Espécie } & DA & DoA & FA & IVI \\
\hline Gallesia integrifolia (Spreng.) Harms & 200,0 & 27,24 & 100,00 & 96,16 \\
\hline Melastomataceae 2 & 300,0 & 2,60 & 100,00 & 50,65 \\
\hline Alchornea sidifolia Mull. Arg. & 75,0 & 7,99 & 100,00 & 37,38 \\
\hline Eugenia uniflora L. & 75,0 & 0,58 & 100,00 & 20,25 \\
\hline Eugenia brasiliensis Lam. & 58,3 & 0,42 & 100,00 & 17,99 \\
\hline Guarea guidonia (L.) Sleumer & 50,0 & 0,23 & 66,67 & 13,13 \\
\hline Erythrina verna Vell. & 16,7 & 1,64 & 66,67 & 12,58 \\
\hline Inga marginata Willd & 8,3 & 1,61 & 33,33 & 8,13 \\
\hline Centrolobium tomentosum Guillemin ex Benth. & 8,3 & 0,48 & 33,33 & 5,51 \\
\hline Casearia sy/vestris Sw. & 16,7 & 0,06 & 33,33 & 5,49 \\
\hline Psychotria carthagenensis Jacq. Sensu L. B. Sm. & 16,7 & 0,03 & 33,33 & 5,43 \\
\hline Nectandra rigida (Kunth) Ness & 8,3 & 0,10 & 33,33 & 4,62 \\
\hline Cyclolobium vecchii A. Samp. ex Hoehne & 8,3 & 0,08 & 33,33 & 4,58 \\
\hline Genipa americana L. & 8,3 & 0,08 & 33,33 & 4,58 \\
\hline Ocotea pulchela Mart. & 8,3 & 0,07 & 33,33 & 4,56 \\
\hline Guapira opposita Vell. & 8,3 & 0,05 & 33,33 & 4,52 \\
\hline Garcinia gardineriana (Planch \& Triana) Zappi & 8,3 & 0,02 & 33,33 & 4,45 \\
\hline
\end{tabular}


Tabela 6. Espécies amostradas na Parcela 06, densidade absoluta ( $\mathrm{n}^{0}$ indivíduos/ha; DA), dominância absoluta (área basal/ha; DoA), frequência absoluta (unidade amostral presente $/ \mathrm{n}^{\circ}$ unidades amostrais (3); FA), Índice de Valor de Importância (somatório de densidade, dominância e frequência relativas; IVI).

\begin{tabular}{|c|c|c|c|c|}
\hline Espécie & DA & DoA & FA & IVI \\
\hline Cyclolobium vecchii A. Samp. ex Hoehne & 133,3 & 5,57 & 100,00 & 29,3 \\
\hline Eugenia brasiliensis Lam. & 191,7 & 3,08 & 100,00 & 28,65 \\
\hline Hymenaea courbaril var. stilbocarpa (Hayne) Y.T. Lee \& Langenh & 25,0 & 9,81 & 66,67 & 27,93 \\
\hline Cariniana estrellensis (Raddi) Kuntze & 16,7 & 7,01 & 66,67 & 20,81 \\
\hline Gallesia integrifolia (Spreng.) Harms & 16,7 & 5,24 & 66,67 & 16,78 \\
\hline Guarea guidonia (L.) Sleumer & 91,7 & 1,58 & 100,00 & 16,61 \\
\hline Trichilia catigua A. Juss. & 108,3 & 0,57 & 100,00 & 15,73 \\
\hline Eugenia uniflora L. & 100,0 & 0,87 & 100,00 & 15,7 \\
\hline Eugenia florida DC. & 100,0 & 0,62 & 100,00 & 15,13 \\
\hline Genipa americana L. & 50,0 & 2,21 & 66,67 & 12,76 \\
\hline Ocotea puberula (Rich.) Ness & 50,0 & 0,21 & 100,00 & 9,87 \\
\hline Machaerium stipitatum (DC.) Vogel & 16,7 & 1,04 & 66,67 & 7,21 \\
\hline Erythrina verna Vell. & 8,3 & 1,59 & 33,33 & 6,05 \\
\hline Alchornea sidifolia Mull. Arg. & 16,7 & 0,52 & 66,67 & 6,02 \\
\hline Copaifera langsdorffii Desf. & 16,7 & 0,41 & 66,67 & 5,75 \\
\hline Inga vera Willd. Subsp. affinis (DC.) T.D. Penn. & 16,7 & 0,24 & 66,67 & 5,36 \\
\hline Myrciaria tenella O. Berg & 16,7 & 0,18 & 66,67 & 5,24 \\
\hline Euterpe edulis Mart. & 16,7 & 0,17 & 66,67 & 5,21 \\
\hline Nectandra rigida (Kunth) Ness & 16,7 & 0,12 & 66,67 & 5,11 \\
\hline Croton floribundus Spreng. & 8,3 & 1,12 & 33,33 & 4,97 \\
\hline Nectandra megapotamica (Spreng.) Mez & 25,0 & 0,09 & 33,33 & 4,05 \\
\hline Lonchocarpus guillemineanus (Tul.) Malme & 8,3 & 0,56 & 33,33 & 3,69 \\
\hline Endlicheria paniculata (Spreng.) J.F. Macbr & 16,7 & 0,06 & 33,33 & 3,28 \\
\hline Machaerium nyctitans (Vell.) Benth & 8,3 & 0,31 & 33,33 & 3,11 \\
\hline Astronium graveolens Jacq. & 8,3 & 0,26 & 33,33 & 3,01 \\
\hline Syagrus romanzoffiana (Cham.) Glassman & 8,3 & 0,11 & 33,33 & 2,66 \\
\hline Rapanea guianensis Aubl. & 8,3 & 0,08 & 33,33 & 2,6 \\
\hline Myrtaceae 1 & 8,3 & 0,06 & 33,33 & 2,56 \\
\hline Zanthoxylum riedelianum Engl. & 8,3 & 0,04 & 33,33 & 2,52 \\
\hline Maytenus muelleri Schwacke & 8,3 & 0,04 & 33,33 & 2,51 \\
\hline Acacia polyphylla DC. & 8,3 & 0,02 & 33,33 & 2,47 \\
\hline Guapira opposita Vell. & 8,3 & 0,02 & 33,33 & 2,46 \\
\hline Melastomataceae 2 & 8,3 & 0,02 & 33,33 & 2,46 \\
\hline Psychotria carthagenensis Jacq. Sensu L.B.Sm. & 8,3 & 0,02 & 33,33 & 2,45 \\
\hline
\end{tabular}


Tabela 7. Espécies amostradas na Parcela 07, densidade absoluta ( $\mathrm{n}^{0}$ indivíduos/ha; DA), dominância absoluta (área basal/ha; DoA), frequência absoluta (unidade amostral presente $/ \mathrm{n}^{\circ}$ unidades amostrais (3); FA), Índice de Valor de Importância (somatório de densidade, dominância e frequência relativas; IVI).

\begin{tabular}{|c|c|c|c|c|}
\hline Espécie & DA & DoA & FA & IVI \\
\hline Hymenaea courbaril var. stilbocarpa (Hayne) Y.T. Lee \& Langenh & 33,3 & 6,89 & 66,67 & 26,62 \\
\hline Astronium graveolens Jacq. & 150,0 & 1,25 & 100,00 & 23,87 \\
\hline Meliaceae 1 & 150,0 & 1,14 & 100,00 & 23,52 \\
\hline Copaifera langsdorffii Desf. & 41,7 & 4,61 & 66,67 & 20,92 \\
\hline Ocotea corymbosa (Meisn.) Mez & 66,7 & 2,49 & 100,00 & 19,07 \\
\hline Gallesia integrifolia (Spreng.)Harms & 41,7 & 2,87 & 66,67 & 15,92 \\
\hline Croton floribundus Spreng. & 50,0 & 2,01 & 66,67 & 14,27 \\
\hline Machaerium villosum Vogel & 16,7 & 2,80 & 66,67 & 13,2 \\
\hline Acacia polyphylla DC. & 33,3 & 1,39 & 100,00 & 12,59 \\
\hline Zanthoxylum riedelianum Engl. & 41,7 & 0,64 & 100,00 & 11,27 \\
\hline Eugenia brasiliensis Lam. & 58,3 & 0,32 & 66,67 & 10,27 \\
\hline Annonaceae 1 & 25,0 & 0,73 & 100,00 & 9,87 \\
\hline Zeyheria tuberculosa(Vell.) Bureau & 25,0 & 0,19 & 100,00 & 8,32 \\
\hline Cedrela fissilis Vell. & 16,7 & 1,66 & 33,33 & 8,18 \\
\hline Esenbeckia febrifuga (A. St.-Hil.)A. Juss. Ex Mart & 33,3 & 0,12 & 66,67 & 7,18 \\
\hline Myrtaceae 3 & 25,0 & 0,13 & 66,67 & 6,39 \\
\hline Nectandra megapotamica (Spreng.) Mez & 16,7 & 0,38 & 66,67 & 6,27 \\
\hline Endlicheria paniculata (Spreng.) J.F. Macbr & 8,3 & 1,06 & 33,33 & 5,64 \\
\hline Ixora gardneriana Benth. & 16,7 & 0,12 & 66,67 & 5,52 \\
\hline Trichilia catigua A. Juss. & 16,7 & 0,11 & 66,67 & 5,5 \\
\hline Enterolobium contortisiliquum (Vell.) Morong & 8,3 & 0,95 & 33,33 & 5,33 \\
\hline Indeterminada 6 & 25,0 & 0,34 & 33,33 & 5,24 \\
\hline Ocotea puberula (Rich.) Ness & 8,3 & 0,82 & 33,33 & 4,93 \\
\hline Ocotea odorifera (Vell.) Rohwer & 16,7 & 0,43 & 33,33 & 4,66 \\
\hline Roupala brasiliensis Klotzsch & 8,3 & 0,41 & 33,33 & 3,78 \\
\hline Syagrus romanzoffiana (Cham.) Glassman & 8,3 & 0,39 & 33,33 & 3,72 \\
\hline Myrciaria tenella O. Berg & 16,7 & 0,08 & 33,33 & 3,66 \\
\hline Indeterminada 5 & 8,3 & 0,15 & 33,33 & 3,01 \\
\hline Maclura tinctoria (L.) D. Don ex Steud. & 8,3 & 0,13 & 33,33 & 2,97 \\
\hline Cariniana estrellensis (Raddi) Kuntze & 8,3 & 0,13 & 33,33 & 2,95 \\
\hline Patagonula americana L. & 8,3 & 0,04 & 33,33 & 2,71 \\
\hline Aloysia virgata (Ruiz \& Pav.) Juss & 8,3 & 0,03 & 33,33 & 2,66 \\
\hline
\end{tabular}


Tabela 8. Espécies amostradas na Parcela 08, densidade absoluta ( $\mathrm{n}^{0}$ indivíduos/ha; DA), dominância absoluta (área basal/ha; DoA), frequência absoluta (unidade amostral presente $/ \mathrm{n}^{\circ}$ unidades amostrais (3); FA), Índice de Valor de Importância (somatório de densidade, dominância e frequência relativas; IVI).

\begin{tabular}{l|c|c|c|c}
\multicolumn{1}{c|}{ Espécie } & DA & DoA & FA & IVI \\
\hline Vochysia tucanorum Mart. & 325,0 & 8,34 & 100,00 & 69,97 \\
\hline Sapium glandulatum (Vell.) Pax & 116,7 & 7,10 & 100,00 & 44,38 \\
\hline Ocotea corymbosa (Meisn.) Mez & 58,3 & 1,74 & 100,00 & 18,57 \\
\hline Qualea grandiflora Mart. & 58,3 & 0,86 & 100,00 & 15,32 \\
\hline Ocotea puberula (Rich.) Ness & 25,0 & 1,68 & 33,33 & 10,84 \\
\hline Copaifera langsdorffii Desf. & 8,3 & 2,12 & 33,33 & 10,81 \\
\hline Fabaceae 1 & 25,0 & 0,87 & 66,67 & 9,92 \\
\hline Indeterminada 7 & 16,7 & 0,60 & 66,67 & 8,09 \\
\hline Rapanea guianensis Aubl. & 41,7 & 0,41 & 33,33 & 7,81 \\
\hline Bignoniaceae 1 & 25,0 & 0,22 & 66,67 & 7,51 \\
\hline Rubiaceae 1 & 25,0 & 0,18 & 66,67 & 7,34 \\
\hline Campomanesia guazumifolia (Cambess.) & 25,0 & 0,12 & 66,67 & 7,12 \\
\hline Cordia ecalyculata Vell. & 25,0 & 0,06 & 66,67 & 6,92 \\
\hline Enterolobium gummiferum (Mart.) J.F. Macbr & 16,7 & 0,21 & 66,67 & 6,64 \\
\hline Protium heptaphyllum (Aubl.) Marchand & 16,7 & 0,09 & 66,67 & 6,17 \\
\hline Casearia sylvestris Sw. & 16,7 & 0,06 & 66,67 & 6,06 \\
\hline Fabaceae 2 & 8,3 & 0,75 & 33,33 & 5,69 \\
\hline Roupala brasiliensis Klotzsch & 25,0 & 0,24 & 33,33 & 5,5 \\
\hline Tabebuia ochracea (Cham.) Standl. & 16,7 & 0,13 & 33,33 & 4,24 \\
\hline Acrocomia aculeata (Jacq.) Lodd. Ex Mart. & 8,3 & 0,32 & 33,33 & 4,13 \\
\hline Alchornea sidifolia Mull. Arg. & 16,7 & 0,06 & 33,33 & 3,99 \\
\hline Ficus guaranitica Schodat & 16,7 & 0,04 & 33,33 & 3,92 \\
\hline Nectandra rigida (Kunth) Ness & 8,3 & 0,17 & 33,33 & 3,56 \\
\hline Eugenia brasiliensis Lam. & 8,3 & 0,17 & 33,33 & 3,56 \\
\hline Nectandra megapotamica (Spreng.) Mez & 8,3 & 0,14 & 33,33 & 3,44 \\
\hline Melastomataceae 2 & 8,3 & 0,08 & 33,33 & 3,21 \\
\hline Melastomataceae 3 & 8,3 & 0,07 & 33,33 & 3,18 \\
\hline Myrciaria tenella O. Berg & 8,3 & 0,05 & 33,33 & 3,12 \\
\hline Senna macranthera (DC. Ex Collad.) H.S. Irwin \& Barneby & 8,3 & 0,02 & 33,33 & 2,99 \\
\hline Xylopia aromatica (Lam.) Mart. & 8,3 & 0,02 & 33,33 & 2,99 \\
\hline Gochnatia pulchra Cabrera & 8,3 & 0,02 & 33,33 & 2,99 \\
\hline & & & \\
\hline
\end{tabular}


Tabela 9. Espécies amostradas na Parcela 09, densidade absoluta ( $\mathrm{n}^{0}$ indivíduos/ha; DA), dominância absoluta (área basal/ha; DoA), frequência absoluta (unidade amostral presente/ $\mathrm{n}^{\circ}$ unidades amostrais (3); FA), Índice de Valor de Importância (somatório de densidade, dominância e frequência relativas; IVI).

\begin{tabular}{l|c|c|c|c}
\multicolumn{1}{c|}{ Espécie } & DA & DoA & FA & IVI \\
\hline Gallesia integrifolia (Spreng.)Harms & 683,3 & 10,44 & 100,00 & 102,29 \\
\hline Copaifera langsdorffii Desf. & 41,7 & 8,79 & 33,33 & 32,47 \\
\hline Inga vera Willd. Subsp. affinis (DC.) T.D. Penn. & 41,7 & 5,20 & 100,00 & 29,98 \\
\hline Melastomataceae 2 & 125,0 & 1,13 & 100,00 & 25,92 \\
\hline Nectandra megapotamica (Spreng.) Mez & 33,3 & 3,71 & 100,00 & 25,03 \\
\hline Endlicheria paniculata (Spreng.) J.F. Macbr & 41,7 & 4,03 & 66,67 & 22,83 \\
\hline Alchornea sidifolia Mull. Arg. & 33,3 & 0,34 & 66,67 & 11,65 \\
\hline Casearia sylvestris Sw. & 33,3 & 0,27 & 66,67 & 11,43 \\
\hline Melastomataceae 3 & 33,3 & 0,21 & 66,67 & 11,28 \\
\hline Cyclolobium vecchii A. Samp. ex Hoehne & 16,7 & 0,91 & 33,33 & 7,92 \\
\hline Euphorbiaceae 1 & 8,3 & 0,18 & 33,33 & 5,1 \\
\hline Cecropia pachystachya Trécul & 8,3 & 0,05 & 33,33 & 4,74 \\
\hline Vochysia tucanorum Mart. & 8,3 & 0,03 & 33,33 & 4,68 \\
\hline Eugenia brasiliensis Lam. & 8,3 & 0,03 & 33,33 & 4,67 \\
\hline
\end{tabular}


Tabela 10. Espécies amostradas na Parcela 10, densidade absoluta ( $\mathrm{n}^{\circ}$ indivíduos/ha; DA), dominância absoluta (área basal/ha; DoA), frequência absoluta (unidade amostral presente $/ \mathrm{n}^{\circ}$ unidades amostrais (3); FA), Índice de Valor de Importância (somatório de densidade, dominância e frequência relativas; IVI).

\begin{tabular}{l|c|c|c|c}
\hline \multicolumn{1}{c|}{ Espécie } & DA & DoA & FA & IVI \\
\hline Calophylum brasiliensis Cambess. & 216,7 & 5,56 & 66,67 & 40,45 \\
\hline Cyclolobium vecchii A. Samp. ex Hoehne & 83,3 & 6,85 & 100,00 & 33,31 \\
\hline Inga vera Willd. Subsp. affinis (DC.) T.D. Penn. & 25,0 & 9,18 & 66,67 & 30,34 \\
\hline Trichilia catigua A. Juss. & 141,7 & 1,23 & 100,00 & 25,48 \\
\hline Eugenia brasiliensis Lam. & 125,0 & 1,61 & 100,00 & 24,76 \\
\hline Eugenia uniflora L. & 108,3 & 0,46 & 100,00 & 20,35 \\
\hline Alchornea sidifolia Mull. Arg. & 91,7 & 1,99 & 33,33 & 16,68 \\
\hline Cariniana estrellensis (Raddi) Kuntze & 16,7 & 4,80 & 33,33 & 16,09 \\
\hline Euphorbiaceae 1 & 25,0 & 2,86 & 33,33 & 12,23 \\
\hline Genipa americana L. & 16,7 & 1,52 & 33,33 & 8,16 \\
\hline Nectandra megapotamica (Spreng.) Mez & 16,7 & 0,73 & 33,33 & 6,26 \\
\hline Aspidosperma cylindrocarpon Müll. Arg. & 8,3 & 0,92 & 33,33 & 5,91 \\
\hline Acacia polyphylla DC. & 8,3 & 0,86 & 33,33 & 5,76 \\
\hline Myrtaceae 4 & 16,7 & 0,49 & 33,33 & 5,69 \\
\hline Guapira opposita Vell. & 25,0 & 0,14 & 33,33 & 5,65 \\
\hline Pseudobombax grandiflorum (Cav.) A. Robyns & 16,7 & 0,37 & 33,33 & 5,39 \\
\hline Machaerium stipitatum (DC.) Vogel & 8,3 & 0,59 & 33,33 & 5,09 \\
\hline Nectandra rigida (Kunth) Ness & 8,3 & 0,45 & 33,33 & 4,75 \\
\hline Vochysia tucanorum Mart. & 8,3 & 0,25 & 33,33 & 4,27 \\
\hline Copaifera langsdorffii Desf. & 8,3 & 0,22 & 33,33 & 4,22 \\
\hline Duguetia lanceolata A. St.-Hil. & 8,3 & 0,20 & 33,33 & 4,16 \\
\hline Myrciaria tenella O. Berg & 8,3 & 0,04 & 33,33 & 3,78 \\
\hline Ocotea odorifera (Vell.) Rohwer & 8,3 & 0,04 & 33,33 & 3,78 \\
\hline Indeterminada 8 & 8,3 & 0,02 & 33,33 & 3,72 \\
\hline Euterpe edulis Mart. & 8,3 & 0,02 & 33,33 & 3,72 \\
\hline
\end{tabular}




\section{Amostragem por transectos}

Tabela 11. Espécies amostradas no Transecto 01 e número de indivíduos amostrados nas subunidades edafogeológicas (N).

\begin{tabular}{|c|c|}
\hline Espécie & $\mathbf{N}$ \\
\hline \multicolumn{2}{|l|}{ Subunidades $A / B / C / D$} \\
\hline Esenbeckia febrifuga (A. St.-Hil.) A. Juss. Ex Mart & 3 \\
\hline Eugenia brasiliensis Lam. & 3 \\
\hline Zeyheria tuberculosa (Vell.) Bureau & 3 \\
\hline Cedrela fissilis Vell. & 2 \\
\hline Luehea divaricata Mart. & 2 \\
\hline Aloysia virgata (Ruiz \& Pav.) Juss & 1 \\
\hline Annona cacans Warm. & 1 \\
\hline Copaifera langsdorffii Desf. & 1 \\
\hline Enterolobium contortisiliquum (Vell.) Morong & 1 \\
\hline Mollinedia widgrenii DC & 1 \\
\hline Ocotea corymbosa (Meisn.) Mez & 1 \\
\hline \multicolumn{2}{|l|}{ Subunidade $\mathbf{E}$} \\
\hline Alchornea sidifolia Mull. Arg. & 1 \\
\hline Copaifera langsdorffii Desf. & 1 \\
\hline Guarea guidonia (L.) Sleumer & 1 \\
\hline Inga vera Willd. Subsp. affinis (DC.) T.D. Penn. & 1 \\
\hline Nectandra rigida (Kunth) Ness & 1 \\
\hline \multicolumn{2}{|l|}{ Subunidades $F / G / H / I / J$} \\
\hline Trichilia catigua A. Juss. & 7 \\
\hline Inga vera Willd. subsp. affinis (DC.) T.D. Penn. & 4 \\
\hline Eugenia uniflora L. & 3 \\
\hline Eugenia brasiliensis Lam. & 2 \\
\hline Indeterminada 1 & 2 \\
\hline Calophylum brasiliensis Cambess. & 1 \\
\hline
\end{tabular}


Tabela 12. Espécies amostradas no Transecto 02 e número de indivíduos amostrados nas subunidades edafogeológicas (N).

\begin{tabular}{|c|c|}
\hline Espécie & $\mathbf{N}$ \\
\hline \multicolumn{2}{|l|}{ Subunidades $A / D / G$} \\
\hline Trichilia catigua A. Juss. & 4 \\
\hline Alchornea sidifolia Mull. Arg. & 2 \\
\hline Indeterminada 5 & 2 \\
\hline Eugenia brasiliensis Lam. & 1 \\
\hline Indeterminada 2 & 1 \\
\hline Inga vera Willd. Subsp. affinis (DC.) T.D. Penn. & 1 \\
\hline \multicolumn{2}{|l|}{ Subunidades $B / H / / / J$} \\
\hline Gallesia integrifolia (Spreng.) Harms & 4 \\
\hline Indeterminada 3 & 3 \\
\hline Indeterminada 6 & 3 \\
\hline Trichilia catigua A. Juss. & 3 \\
\hline Casearia sylvestris Sw. & 2 \\
\hline Eugenia uniflora L. & 2 \\
\hline Acacia polyphylla DC. & 1 \\
\hline Campomanesia guazumifolia (Cambess.) & 1 \\
\hline Cariniana legalis (Mart.) Kuntze & 1 \\
\hline Cecropia hololeuca Miq. & 1 \\
\hline Guapira opposita Vell. & 1 \\
\hline Indeterminada 2 & 1 \\
\hline Mollinedia widgrenii DC & 1 \\
\hline \multicolumn{2}{|l|}{ Subunidade C } \\
\hline Indeterminada 4 & 1 \\
\hline Indeterminada 5 & 1 \\
\hline Trichilia catigua A. Juss. & 1 \\
\hline \multicolumn{2}{|l|}{ Subunidades E/F } \\
\hline Indeterminada 6 & 3 \\
\hline Alchornea sidifolia Mull. Arg. & 2 \\
\hline Acacia polyphylla DC. & 1 \\
\hline Ficus sp. & 1 \\
\hline Indeterminada 1 & 1 \\
\hline Trichilia catigua A. Juss. & 1 \\
\hline
\end{tabular}


Tabela 13. Espécies amostradas no Transecto 03 e número de indivíduos amostrados nas subunidades edafogeológicas (N).

\begin{tabular}{l|l}
\hline \multicolumn{1}{c}{ Espécie } & N \\
\hline Subunidades A/B/C/D/E & 3 \\
\hline Cyclolobium vecchii A. Samp. ex Hoehne & 2 \\
\hline Casearia sy/vestris Sw. & 2 \\
\hline Eugenia uniflora L. & 2 \\
\hline Guarea guidonia (L.) Sleumer & 2 \\
\hline Indeterminada 4 & 2 \\
\hline Indeterminada 5 & 1 \\
\hline Alchornea sidifolia Mull. Arg. & 1 \\
\hline Croton floribundus Spreng. & 1 \\
\hline Euterpe edulis Mart. & 1 \\
\hline Gallesia integrifolia (Spreng.) Harms & 1 \\
\hline Indeterminada 2 & 1 \\
\hline Indeterminada 3 & 1 \\
\hline Mollinedia widgrenii DC & 1 \\
\hline Ocotea corymbosa (Meisn.) Mez & 1 \\
\hline Ocotea puberula (Rich.) Ness & 1 \\
\hline Sebastiania klotzchiana (Müll Arg.) Müll Arg. & \\
\hline Subunidades F/G/H/I/J & 5 \\
\hline Cyclolobium vecchii A. Samp. ex Hoehne & 1 \\
\hline Gallesia integrifolia (Spreng.) Harms & 1 \\
\hline Nectandra rigida (Kunth) Ness & 1 \\
\hline Guapira opposita Vell. & 1 \\
\hline Alchornea sidifolia Mull. Arg. & 1 \\
\hline Copaifera langsdorffii Desf. & 1 \\
\hline Eugenia brasiliensis Lam. & 1 \\
\hline Eugenia uniflora L. & 1 \\
\hline Indeterminada 5 & 1 \\
\hline Ocotea pulchela Mart. & 1 \\
\hline Trichilia catigua A. Juss. & 1 \\
\hline & \\
\hline
\end{tabular}


Tabela 14. Espécies amostradas no Transecto 04 e número de indivíduos amostrados nas subunidades edafogeológicas (N).

\begin{tabular}{|c|c|}
\hline ate & $\mathbf{N}$ \\
\hline \multicolumn{2}{|l|}{ Subunidades A/D } \\
\hline Ocotea puberula (Rich.) Ness & 2 \\
\hline Cariniana estrellensis (Raddi) Kuntze & 1 \\
\hline Croton floribundus Spreng. & 1 \\
\hline Cupania vernalis Cambess. & 1 \\
\hline Indeterminada 4 & 1 \\
\hline Machaerium villosum Vogel & 1 \\
\hline Mollinedia widgrenii DC & 1 \\
\hline Zanthoxylum riedelianum Engl. & 1 \\
\hline \multicolumn{2}{|l|}{ Subunidades $B / G / H / I / J$} \\
\hline Croton floribundus Spreng. & 6 \\
\hline Annona cacans Warm. & 2 \\
\hline Cedrela fissilis Vell. & 2 \\
\hline Hymenaea courbaril var. stilbocarpa (Hayne) Y.T. Lee \& Langenh & 2 \\
\hline Cariniana estrellensis (Raddi) Kuntze & 1 \\
\hline Copaifera langsdorffii Desf. & 1 \\
\hline Cordia ecalyculata Vell. & 1 \\
\hline Endlicheria paniculata (Spreng.) J.F. Macbr & 1 \\
\hline Eugenia brasiliensis Lam. & 4 \\
\hline Indeterminada 2 & 1 \\
\hline Indeterminada 7 & 1 \\
\hline Machaerium villosum Vogel & 1 \\
\hline Myrciaria tenella O. Berg & 1 \\
\hline Ocotea odorifera (Vell.) Rohwer & 1 \\
\hline Piptadenia gonoacantha (Mart.) Macbr. & 1 \\
\hline Syagrus romanzoffiana (Cham.) Glassman & 1 \\
\hline \multicolumn{2}{|l|}{ Subunidades $\mathrm{C} / \mathrm{E} / \mathrm{F}$} \\
\hline Croton floribundus Spreng. & 3 \\
\hline Cariniana estrellensis (Raddi) Kuntze & 1 \\
\hline Cedrela fissilis Vell. & 1 \\
\hline Copaifera langsdorffii Desf. & 1 \\
\hline Cordia ecalyculata Vell. & 1 \\
\hline Erythrina verna Vell. & 1 \\
\hline Esenbeckia febrifuga (A. St.-Hil.) A. Juss. Ex Mart & 1 \\
\hline Eugenia brasiliensis Lam. & 1 \\
\hline Euterpe edulis Mart. & 1 \\
\hline Indeterminada 2 & 1 \\
\hline Machaerium villosum Vogel & 1 \\
\hline Ocotea corymbosa (Meisn.) Mez & 1 \\
\hline Ocotea odorifera (Vell.) Rohwer & 1 \\
\hline Protium heptaphyllum (Aubl.) Marchand & 1 \\
\hline Zeyheria tuberculosa (Vell.) Bureau & 1 \\
\hline
\end{tabular}




\section{Apêndice B - Fertilidade e granulometria dos solos e sedimentos amostrados}

Dados químicos de solos

Tabela 1. Dados químicos de solos das unidades amostrais (UA) das dez parcelas do estudo: $\mathrm{pH}$ (acidez ativa), $\mathrm{H}+\mathrm{Al}$ (acidez potencial, mmolc/dm3), MO (matéria orgânica, g/dm ${ }^{3}$ ), SB (soma de bases, mmolc/ $\mathrm{dm}^{3}$ ), CTC (capacidade de troca catiônica, mmolc/dm ${ }^{3}$ ), V\% (saturação por bases, \%), $\mathrm{P}$ (fósforo, $\mathrm{mg} / \mathrm{dm}^{3}$ ), $\mathrm{K}$ (potássio, mmolc/ $\mathrm{dm}^{3}$ ), Ca (cálcio, mmolc/ $\mathrm{dm}^{3}$ ), $\mathrm{Mg}$ (magnésio, mmolc/ $/ \mathrm{dm}^{3}$ ), Al (alumínio, mmolc/dm ${ }^{3}$ ).

\begin{tabular}{|c|c|c|c|c|c|c|c|c|c|c|c|}
\hline UA & $\mathrm{pH}$ & $\mathrm{H}+\mathrm{Al}$ & MO & SB & CTC & V\% & $\mathbf{P}$ & $\mathrm{K}$ & $\mathrm{Ca}$ & Mg & Al \\
\hline \multicolumn{12}{|c|}{ Parcela 01} \\
\hline A & 4,1 & 42,0 & 22,0 & 3,9 & 46,2 & 8,0 & 4,0 & 0,9 & 2,0 & 1,0 & 13,0 \\
\hline B & 4,0 & 42,0 & 21,0 & 6,6 & 48,9 & 13,0 & 5,0 & 1,6 & 4,0 & 1,0 & 13,0 \\
\hline C & 4,2 & 42,0 & 21,0 & 8,0 & 50,3 & 16,0 & 4,0 & 2,0 & 3,0 & 3,0 & 12,0 \\
\hline \multicolumn{12}{|c|}{ Parcela 02} \\
\hline A & 3,8 & 185,0 & 61,0 & 6,7 & 191,4 & 4,0 & 7,0 & 0,7 & 4,0 & 2,0 & 41,0 \\
\hline B & 3,7 & 281,0 & 96,0 & 9,3 & 290,8 & 3,0 & 10,0 & 1,3 & 4,0 & 4,0 & 54,0 \\
\hline C & 3,2 & 429,0 & 97,0 & 11,5 & 440,4 & 3,0 & 18,0 & 1,5 & 5,0 & 5,0 & 63,0 \\
\hline \multicolumn{12}{|c|}{ Parcela 03} \\
\hline A & 4,0 & 64,0 & 24,0 & 3,8 & 68,2 & 6,0 & 3,0 & 0,8 & 2,0 & 1,0 & 25,0 \\
\hline B & 4,0 & 58,0 & 22,0 & 3,6 & 61,6 & 6,0 & 3,0 & 0,6 & 2,0 & 1,0 & 23,0 \\
\hline C & 4,0 & 58,0 & 24,0 & 4,8 & 62,8 & 8,0 & 4,0 & 0,8 & 2,0 & 2,0 & 20,0 \\
\hline \multicolumn{12}{|c|}{ Parcela 04} \\
\hline A & 4,1 & 52,0 & 25,0 & 14,0 & 66,2 & 21,0 & 4,0 & 1,1 & 9,0 & 3,0 & 13,0 \\
\hline B & 4,1 & 47,0 & 21,0 & 33,3 & 80,3 & 41,0 & 2,0 & 0,8 & 30,0 & 2,0 & 13,0 \\
\hline $\mathbf{C}$ & 4,7 & 25,0 & 23,0 & 29,5 & 54,5 & 54,0 & 4,0 & 0,7 & 23,0 & 6,0 & 2,0 \\
\hline \multicolumn{12}{|c|}{ Parcela 05} \\
\hline A & 4,4 & 34,0 & 19,0 & 14,5 & 48,8 & 30,0 & 6,0 & 0,6 & 10,0 & 4,0 & 6,0 \\
\hline B & 4,8 & 31,0 & 24,0 & 22,6 & 53,4 & 42,0 & 7,0 & 0,9 & 14,0 & 8,0 & 2,0 \\
\hline C & 4,4 & 42,0 & 25,0 & 21,7 & 21,7 & 34,0 & 10,0 & 0,7 & 18,0 & 3,0 & 5,0 \\
\hline \multicolumn{12}{|c|}{ Parcela 06} \\
\hline A & 4,4 & 88,0 & 39,0 & 29,1 & 29,1 & 25,0 & 8,0 & 4,2 & 16,0 & 9,0 & 17,0 \\
\hline B & 4,0 & 135,0 & 52,0 & 27,0 & 27,0 & 17,0 & 10,0 & 2,2 & 19,0 & 5,0 & 33,0 \\
\hline C & 5,1 & 52,0 & 55,0 & 78,2 & 78,2 & 60,0 & 11,0 & 8,1 & 48,0 & 22,0 & 2,0 \\
\hline \multicolumn{12}{|c|}{ Parcela 07} \\
\hline $\mathbf{A}$ & 4,8 & 38,0 & 40,0 & 54,4 & 54,4 & 59,0 & 10,0 & 2,6 & 38,0 & 14,0 & 2,0 \\
\hline B & 5,1 & 34,0 & 39,0 & 65,6 & 65,6 & 66,0 & 9,0 & 2,9 & 46,0 & 16,0 & 1,0 \\
\hline C & 4,6 & 42,0 & 33,0 & 33,0 & 33,0 & 44,0 & 6,0 & 2,4 & 19,0 & 11,0 & 2,0 \\
\hline \multicolumn{12}{|c|}{ Parcela 08} \\
\hline $\mathbf{A}$ & 4,0 & 88,0 & 38,0 & 8,9 & 97,3 & 9,0 & 3,0 & 1,4 & 4,0 & 3,0 & 23,0 \\
\hline B & 4,1 & 80,0 & 34,0 & 6,4 & 86,0 & 7,0 & 3,0 & 0,9 & 3,0 & 2,0 & 21,0 \\
\hline $\mathbf{C}$ & 4,1 & 80,0 & 31,0 & 5,6 & 85,2 & 7,0 & 3,0 & 1,1 & 2,0 & 2,0 & 20,0 \\
\hline \multicolumn{12}{|c|}{ Parcela 09} \\
\hline A & 4,5 & 58,0 & 31,0 & 22,8 & 80,8 & 28,0 & 9,0 & 0,6 & 17,0 & 5,0 & 8,0 \\
\hline B & 4,4 & 72,0 & 25,0 & 13,6 & 85,2 & 16,0 & 11,0 & 0,5 & 10,0 & 3,0 & 10,0 \\
\hline C & 4,2 & 88,0 & 29,0 & 12,4 & 100,8 & 12,0 & 13,0 & 0,6 & 9,0 & 2,0 & 21,0 \\
\hline \multicolumn{12}{|c|}{ Parcela 10} \\
\hline A & 5,5 & 34,0 & 55,0 & 132,2 & 166,5 & 79,0 & 16,0 & 6,1 & 102,0 & 24,0 & 1,0 \\
\hline B & 4,3 & 98,0 & 38,0 & 27,2 & 125,4 & 22,0 & 13,0 & 2,6 & 98,0 & 5,0 & 26,0 \\
\hline C & 4,4 & 80,0 & 37,0 & 7,8 & 87,4 & 9,0 & 13,0 & 0,8 & 80,0 & 1,0 & 35,0 \\
\hline
\end{tabular}


Tabela 2. Dados químicos de solos das unidades amostrais (UA) dos quatro transectos do estudo: $\mathrm{pH}$ (acidez ativa), $\mathrm{H}+\mathrm{Al}$ (acidez potencial, mmolc/dm3), MO (matéria orgânica, $\mathrm{g} / \mathrm{dm}^{3}$ ), SB (soma de bases, $\mathrm{mmolc} / \mathrm{dm}^{3}$ ), CTC (capacidade de troca catiônica, mmolc/ $\mathrm{dm}^{3}$ ), V\% (saturação por bases, \%), $\mathrm{P}$ (fósforo, $\mathrm{mg} / \mathrm{dm}^{3}$ ), $\mathrm{K}$ (potássio, $\mathrm{mmolc} / \mathrm{dm}^{3}$ ), $\mathrm{Ca}$ (cálcio, mmolc/ $\mathrm{dm}^{3}$ ), $\mathrm{Mg}$ (magnésio, mmolc/ $\mathrm{dm}^{3}$ ), Al (alumínio, mmolc/dm ${ }^{3}$ ), Cu (cobre, $\mathrm{mg} / \mathrm{dm}^{3}$ ), Fe (ferro, $\mathrm{mg} / \mathrm{dm}^{3}$ ), Mn (manganês, $\mathrm{mg} / \mathrm{dm}^{3}$ ) e Zn (zinco, $\left.\mathrm{mg} / \mathrm{dm}^{3}\right)$.

\begin{tabular}{|c|c|c|c|c|c|c|c|c|c|c|c|c|c|c|c|}
\hline UA & $\mathrm{pH}$ & $\mathrm{H}+\mathrm{Al}$ & MO & SB & CTC & V\% & $\mathbf{P}$ & $\mathrm{K}$ & $\mathrm{Ca}$ & $\mathrm{Mg}$ & Al & $\mathrm{Cu}$ & $\mathrm{Fe}$ & Mn & $\mathrm{Zn}$ \\
\hline \multicolumn{16}{|c|}{ Transecto 01} \\
\hline A & 3,9 & 64,0 & 27,0 & 8,4 & 72,4 & 12,0 & 8,0 & 1,4 & 4,0 & 3,0 & 23,0 & 0,7 & 89,0 & 5,2 & $\overline{, 3}$ \\
\hline B & 4,0 & 98,0 & 41,0 & 35,2 & 133,2 & 26,0 & 12,0 & 5,2 & 20,0 & 10,0 & 12,0 & 0,7 & 60,0 & 20,6 & 0,6 \\
\hline C & 4,0 & 109,0 & 55,0 & 49,9 & 158,9 & 31,0 & 18,0 & 2,9 & 32,0 & 15,0 & 10,0 & 1,1 & 101,0 & 49,4 & 2,2 \\
\hline D & 3,8 & 109,0 & 27,0 & 12,4 & 121,4 & 10,0 & 10,0 & 1,4 & 8,0 & 3,0 & 23,0 & 0,9 & 118,0 & 7,5 & 0,9 \\
\hline$E$ & 3,7 & 121,0 & 35,0 & 10,5 & 131,5 & 8,0 & 16,0 & 1,5 & 6,0 & 3,0 & 27,0 & 1,3 & 191,0 & 8,8 & 1,2 \\
\hline$F$ & 3,8 & 121,0 & 39,0 & 5,9 & 126,9 & 5,0 & 25,0 & 0,9 & 3,0 & 2,0 & 36,0 & 1,9 & 149,0 & 2,6 & 0,9 \\
\hline $\mathbf{G}$ & 3,7 & 135,0 & 51,0 & 13,1 & 148,1 & 9,0 & 23,0 & 1, & 10,0 & 2,0 & 32,0 & 1,5 & 66,0 & 6,5 & 1,3 \\
\hline $\mathrm{H}$ & 3,8 & 135,0 & 42,0 & 7,1 & 142,1 & 5, & 26,0 & 1 , & 4,0 & 2,0 & 35,0 & 1,5 & 141,0 & 3,7 & 0,9 \\
\hline$I$ & 3,8 & 150,0 & 44,0 & 8,0 & 158,0 & 5,0 & 23,0 & 1, & $\pi$ & 2,0 & 48,0 & 1,7 & 126,0 & 4,9 & 0,7 \\
\hline $\mathbf{J}$ & 3,9 & 135,0 & 36,0 & 4,7 & 139,7 & 3,0 & 21 , & $\overline{0}$ & 3 & 1 & 33,0 & 15 & & 3,5 & 0,5 \\
\hline \multicolumn{16}{|c|}{ Transecto 02} \\
\hline A & 4,0 & 109,0 &, 0 & ,2 & 9,2 & 7,0 & 3,0 & , & 3,0 & ,0 &, 0 & ,2 & 216,0 & 8,8 & 8 \\
\hline B & 4,5 & 52,0 & 29,0 & 58,1 & 110,1 & 53,0 & 18,0 & 1,1 & 47,0 & 10,0 & 1,0 & 1,2 & 91,0 & 52,9 & 1,6 \\
\hline C & 4,8 & 4 & 30,0 & 87,7 & 134,7 & 65,0 & 27,0 & 1,7 & 67,0 & 19,0 & 1,0 & 1,4 & 97,0 & 35,0 & 2,0 \\
\hline D & 4,3 & 64,0 & 24,0 & 33,5 & 97,5 & 34,0 & 19 & 1,5 & 27,0 & 5 , & 9,0 & 1,7 & 102,0 & 19,6 & 1,5 \\
\hline$E$ & 4,2 & 72,0 & 19,0 & 17,7 & 89,7 & 20,0 & 13 & 0,7 & 15,0 & 2 , & 14,0 & 1,6 & 0,0 & 25,3 & 1,9 \\
\hline $\mathrm{F}$ & 4,2 & 72 & 23,0 & 26,2 & 98,2 & 27,0 & 14 & 1, & 21 . & 4 & 10,0 & 1,8 & 129,0 & 28,0 & 2,6 \\
\hline G & 4,3 & 8 & 34,0 & 42,2 & 122,2 & 35,0 & 16 & 1,2 & 35,0 & 6 , & 8,0 & 1,9 & 241,0 & 31,4 & 3,0 \\
\hline $\mathrm{H}$ & 4,4 & & 13,0 & 25,5 & 72,5 & 35,0 & 11 , & & 000 & & 3,0 & 1,2 & 102,0 & 11,0 & 1,4 \\
\hline$I$ & 4,6 & 42,0 & 17,0 & 34,8 & 76,8 & 45,0 & 13,0 & 0,8 & 25,0 & 9, & 2,0 & 1,3 & 93,0 & 17,0 & 2,1 \\
\hline $\mathbf{J}$ & 4,8 & 22,0 & 15,0 & 40,1 & 62,1 & 65,0 & 10,0 & 1,1 & 30,0 & 9, & 0,0 & 0,8 & 62,0 & 11,7 & 1,6 \\
\hline \multicolumn{16}{|c|}{ Transecto 03} \\
\hline A & 4,0 & 42,0 & 13,0 & 8,6 & 0,6 & 17,0 & 8 , & 0,6 & 6,0 & 2,0 & 0 & 1 & 96 & 26,2 & 1,9 \\
\hline B & 3,9 & 520 & 13,0 & 7,6 & 59 , & 13,0 & 8, & 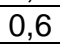 & 5, & & 15,0 & 1,3 & 92 & 20,6 & 1,9 \\
\hline C & 3,9 & & & 9,8 & 7 & 13 & 8, & 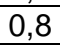 & 6 & & 16,0 & & & 57,8 & 2,3 \\
\hline D & 4,0 & & 1 & 11,9 & 6 & 17,0 & 8,0 & 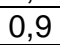 & - & & 10,0 & 1,2 & 0 & 31,0 & 1,7 \\
\hline$E$ & 4,1 & 58,0 & 20,0 & 17,1 & 75,1 & 23,0 & 11,0 & 1 , & 12,0 & 4 & 10,0 & 1,4 & 101,0 & 46,6 & 2,0 \\
\hline$F$ & 4,1 & & 27,0 & 29,4 & & 31,0 & 110 & & 21,0 & & 10,0 & 1,3 & & 41,2 & 2,4 \\
\hline $\mathbf{G}$ & 4,1 & & 23,0 & 20,6 & 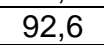 & 22,0 & 19 & 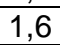 & 16,0 & 3 & 13,0 & 1,9 & 77,0 & 27,8 & 3,3 \\
\hline H & 3,8 & 109 & 18 & 5,8 & 114,8 & 5,0 & 10 & 0 & 4 & & 28,0 & & & 19,4 & 1,7 \\
\hline$I$ & 3,8 & & 21 & 10,9 & 82, & 13 & 11 & 0 & & & 22,0 & 7 & & 34,2 & 2,2 \\
\hline $\mathbf{J}$ & 3,9 & 88,0 & 22,0 & 10,4 & 98,4 & 11,0 & 14,0 & 1,4 & 7,0 & 2,0 & 22,0 & 1,8 & 129,0 & 20,5 & 3,4 \\
\hline \multicolumn{16}{|c|}{ Transecto 04} \\
\hline A & 3,8 & 98,0 & 28,0 & 9,7 & 107,7 & 9,0 & 13,0 & 1,7 & 5,0 & 3,0 & 17,0 & 0,9 & 108,0 & 24,8 & 0,3 \\
\hline B & 4,0 & 98,0 & 38,0 & 25,7 & & 21,0 & 9,0 & 1 & 17,0 & 7 & 12,0 & 07 & & 43,1 & 0,5 \\
\hline C & 4,1 & 8 & 38,0 & 40,1 & 128,1 & 31,0 & 11, & 2 & 25,0 & 13,0 & 8,0 & 0,7 & 74,0 & 33,8 & 0,5 \\
\hline D & 3,9 & 98,0 & 34,0 & 18,2 & 116,2 & 16,0 & 9,0 & 2,2 & 8,0 & 8,0 & 19,0 & 0,9 & 110,0 & 22,3 & 0,2 \\
\hline$E$ & 3,9 & 109 & 40 & 28,8 & 137,8 & 21,0 & 12 & & 15 & 12 & 16,0 & 15 & 109,0 & 25,3 & 0,4 \\
\hline$F$ & 3,9 & 98,0 & 37,0 & 29,1 & 127,1 & 23,0 & 12 & 2 , & 15,0 & 12,0 & 14,0 & 1,2 & 94,0 & 36,0 & 0,6 \\
\hline $\mathbf{G}$ & 3,7 & & 34,0 & 16,8 & 114,8 & 15 & 10 & & 8, & 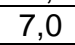 & 19,0 & 1,1 & & 35,2 & 0,5 \\
\hline H & 3,6 & 109,0 & 30,0 & 11,4 & 120,4 & 9,0 & 9,0 & 1, & 6, & 4,0 & 20,0 & 1,2 & 100,0 & 29,6 & 0,5 \\
\hline$I$ & 3,8 & 109,0 & 37,0 & 12,3 & 121,3 & 10,0 & 10,0 & 1,3 & 6, & 5, & 19,0 & 1,0 & 77,0 & 39,5 & 0,4 \\
\hline $\mathbf{J}$ & 3,6 & 121,0 & 38,0 & 14,4 & 135,4 & 11,0 & 11,0 & 1,4 & 9,0 & 4,0 & 22,0 & 1,1 & 98,0 & 29,8 & 0,6 \\
\hline
\end{tabular}


Dados granulométricos de solos

Tabela 3. Dados granulométricos de solos das unidades amostrais (UA) das dez parcelas do estudo, em porcentagem.

\begin{tabular}{|c|c|c|c|c|c|c|c|}
\hline UA & Argila & Silte & Areia muito fina & Areia fina & Areia média & Areia grossa & Areia muito grossa \\
\hline \multicolumn{8}{|c|}{ Parcela 01} \\
\hline A & 19,1 & 5,9 & 4,0 & 27,2 & 37,2 & 5,6 & 1,0 \\
\hline B & 18,1 & 5,8 & 4,7 & 26,4 & 37,4 & 6,7 & 0,9 \\
\hline C & 17,4 & 5,9 & 5,7 & 27,3 & 36,5 & 5,8 & 1,4 \\
\hline \multicolumn{8}{|c|}{ Parcela 02} \\
\hline $\mathbf{A}$ & 63,5 & 18,2 & 1,9 & 7,1 & 7,7 & 1,3 & 0,2 \\
\hline B & 46,0 & 25,9 & 4,9 & 9,2 & 10,0 & 2,9 & 1,2 \\
\hline C & 44,7 & 50,2 & 1,4 & 1,2 & 1,1 & 0,7 & 0,7 \\
\hline \multicolumn{8}{|c|}{ Parcela 03} \\
\hline $\mathbf{A}$ & 23,8 & 20,5 & 8,8 & 25,0 & 18,3 & 2,9 & 0,7 \\
\hline B & 17,6 & 14,5 & 7,3 & 30,4 & 25,1 & 4,3 & 0,8 \\
\hline $\mathbf{C}$ & 18,1 & 13,3 & 7,6 & 30,7 & 25,2 & 4,5 & 0,6 \\
\hline \multicolumn{8}{|c|}{ Parcela 04} \\
\hline $\mathbf{A}$ & 12,4 & 13,5 & 8,4 & 31,8 & 29,3 & 3,7 & 0,9 \\
\hline B & 8,5 & 14,9 & 7,6 & 34,1 & 29,9 & 4,2 & 0,9 \\
\hline C & 13,1 & 15,2 & 10,7 & 32,2 & 24,4 & 3,6 & 0,8 \\
\hline \multicolumn{8}{|c|}{ Parcela 05} \\
\hline A & 13,6 & 15,6 & 16,3 & 43,1 & 10,4 & 0,9 & 0,1 \\
\hline B & 20,5 & 22,9 & 16,8 & 31,7 & 6,9 & 0,7 & 0,4 \\
\hline C & 15,5 & 17,8 & 18,2 & 41,4 & 6,1 & 0,6 & 0,3 \\
\hline \multicolumn{8}{|c|}{ Parcela 06} \\
\hline A & 58,3 & 37,2 & 1,7 & 1,5 & 0,7 & 0,3 & 0,2 \\
\hline B & 60,2 & 35,5 & 1,3 & 1,2 & 0,6 & 0,5 & 0,7 \\
\hline $\mathrm{C}$ & 57,4 & 37,6 & 1,5 & 1,6 & 0,9 & 0,5 & 0,6 \\
\hline \multicolumn{8}{|c|}{ Parcela 07} \\
\hline $\mathbf{A}$ & 22,4 & 10,0 & 3,8 & 11,3 & 25,0 & 21,0 & 6,5 \\
\hline B & 22,2 & 9,5 & 4,3 & 12,9 & 23,3 & 20,1 & 7,7 \\
\hline C & 19,2 & 11,2 & 4,7 & 14,2 & 25,3 & 18,6 & 6,7 \\
\hline \multicolumn{8}{|c|}{ Parcela 08} \\
\hline A & 34,3 & 11,7 & 6,1 & 21,3 & 21,0 & 4,5 & 1,1 \\
\hline B & 35,4 & 10,3 & 5,7 & 18,6 & 21,1 & 7,2 & 1,7 \\
\hline $\mathrm{C}$ & 36,2 & 11,5 & 5,6 & 18,1 & 20,7 & 6,5 & 1,4 \\
\hline \multicolumn{8}{|c|}{ Parcela 09} \\
\hline A & 43,5 & 47,1 & 5,7 & 2,1 & 0,7 & 0,4 & 0,5 \\
\hline B & 43,8 & 49,1 & 4,7 & 1,6 & 0,6 & 0,2 & 0,2 \\
\hline C & 43,7 & 50,4 & 3,9 & 0,9 & 0,3 & 0,3 & 0,5 \\
\hline \multicolumn{8}{|c|}{ Parcela 10} \\
\hline $\mathbf{A}$ & 53,6 & 38,2 & 3,9 & 2,5 & 0,7 & 0,6 & 0,6 \\
\hline B & 67,1 & 32,2 & 0,3 & 0,2 & 0,1 & 0,0 & 0,0 \\
\hline C & 61,9 & 36,1 & 1,1 & 0,6 & 0,2 & 0,1 & 0,0 \\
\hline
\end{tabular}


Tabela 4. Dados granulométricos de solos das unidades amostrais (UA) dos quatro transectos do estudo, em porcentagem.

\begin{tabular}{|c|c|c|c|c|c|c|c|}
\hline UA & Argila & Silte & Areia muito fina & Areia fina & Areia média & Areia grossa & Areia muito grossa \\
\hline \multicolumn{8}{|c|}{ Transecto 01} \\
\hline A & 43,0 & 8,0 & 3,9 & 10,4 & 18,5 & 12,9 & 3,4 \\
\hline B & 46,0 & 8,2 & 2,9 & 8,5 & 15,7 & 13,1 & 5,7 \\
\hline C & 48,5 & 10,0 & 4,2 & 9,5 & 14,7 & 9,6 & 3,5 \\
\hline $\mathbf{D}$ & 47,5 & 7,8 & 3,7 & 9,7 & 15,1 & 9,9 & 6,3 \\
\hline $\mathbf{E}$ & 42,7 & 10,6 & 2,8 & 8,8 & 17,9 & 12,1 & 5,0 \\
\hline $\mathbf{F}$ & 67,2 & 31,7 & 0,2 & 0,2 & 0,4 & 0,1 & 0,2 \\
\hline $\mathbf{G}$ & 64,1 & 34,8 & 0,2 & 0,3 & 0,3 & 0,2 & 0,2 \\
\hline $\mathbf{H}$ & 66,2 & 33,1 & 0,1 & 0,2 & 0,2 & 0,1 & 0,1 \\
\hline I & 62,4 & 36,8 & 0,2 & 0,2 & 0,3 & 0,1 & 0,0 \\
\hline $\mathbf{J}$ & 64,0 & 35,6 & 0,1 & 0,1 & 0,1 & 0,1 & 0,0 \\
\hline \multicolumn{8}{|c|}{ Transecto 02} \\
\hline A & 51,9 & 40,5 & 5,3 & 1,3 & 0,5 & 0,3 & 0,3 \\
\hline B & 12,4 & 13,2 & 19,8 & 47,5 & 6,8 & 0,1 & 0,1 \\
\hline C & 39,8 & 48,3 & 9,1 & 1,3 & 0,7 & 0,3 & 0,4 \\
\hline D & 38,3 & 45,2 & 13,3 & 1,8 & 0,8 & 0,5 & 0,2 \\
\hline $\mathbf{E}$ & 35,2 & 40,2 & 20,4 & 3,5 & 0,4 & 0,2 & 0,1 \\
\hline $\mathbf{F}$ & 34,0 & 40,9 & 19,9 & 4,4 & 0,4 & 0,3 & 0,1 \\
\hline $\mathbf{G}$ & 31,0 & 37,5 & 23,6 & 7,0 & 0,4 & 0,3 & 0,1 \\
\hline $\mathbf{H}$ & 17,1 & 18,6 & 31,1 & 32,7 & 0,4 & 0,0 & 0,0 \\
\hline I & 16,0 & 19,4 & 24,6 & 38,4 & 1,4 & 0,1 & 0,0 \\
\hline $\mathbf{J}$ & 16,6 & 18,0 & 20,1 & 40,5 & 4,5 & 0,2 & 0,0 \\
\hline \multicolumn{8}{|c|}{ Transecto 03} \\
\hline A & 18,8 & 20,8 & 28,6 & 30,9 & 0,7 & 0,1 & 0,0 \\
\hline B & 19,7 & 23,2 & 31,6 & 25,0 & 0,3 & 0,1 & 0,1 \\
\hline C & 23,8 & 30,2 & 29,5 & 15,7 & 0,6 & 0,2 & 0,0 \\
\hline D & 18,4 & 24,2 & 30,1 & 25,7 & 1,3 & 0,4 & 0,1 \\
\hline $\mathbf{E}$ & 23,5 & 27,5 & 28,6 & 19,7 & 0,5 & 0,1 & 0,0 \\
\hline $\bar{F}$ & 28,9 & 37,5 & 20,8 & 9,9 & 2,2 & 0,6 & 0,1 \\
\hline $\mathbf{G}$ & 32,2 & 38,6 & 22,4 & 6,2 & 0,4 & 0,2 & 0,1 \\
\hline $\mathbf{H}$ & 30,8 & 40,0 & 21,9 & 6,9 & 0,3 & 0,1 & 0,0 \\
\hline I & 28,1 & 38,9 & 20,9 & 10,4 & 1,4 & 0,2 & 0,1 \\
\hline $\mathbf{J}$ & 35,3 & 42,1 & 18,1 & 3,7 & 0,5 & 0,2 & 0,1 \\
\hline \multicolumn{8}{|c|}{ Transecto 04} \\
\hline A & 34,4 & 9,5 & 3,5 & 11,2 & 22,6 & 16,3 & 2,4 \\
\hline B & 30,7 & 6,8 & 3,0 & 12,8 & 26,3 & 16,6 & 3,9 \\
\hline $\mathrm{C}$ & 42,0 & 6,4 & 3,0 & 10,8 & 20,6 & 13,9 & 3,2 \\
\hline D & 32,5 & 8,1 & 3,1 & 11,7 & 25,2 & 15,9 & 3,4 \\
\hline $\mathbf{E}$ & 42,4 & 8,6 & 3,1 & 9,9 & 20,8 & 13,0 & 2,2 \\
\hline $\mathbf{F}$ & 36,3 & 9,4 & 3,2 & 10,8 & 22,3 & 14,8 & 3,2 \\
\hline $\mathbf{G}$ & 32,9 & 5,4 & 3,1 & 10,6 & 24,6 & 19,3 & 4,1 \\
\hline $\mathbf{H}$ & 24,6 & 8,4 & 3,3 & 12,9 & 28,6 & 17,6 & 4,5 \\
\hline I & 33,4 & 7,4 & 3,2 & 10,5 & 22,5 & 18,2 & 4,8 \\
\hline $\mathbf{J}$ & 32,3 & 6,8 & 3,2 & 12,8 & 25,2 & 16,0 & 3,6 \\
\hline
\end{tabular}


Dados granulométricos de sedimentos

Tabela 5. Dados granulométricos de sedimentos das unidades amostrais (UA) das dez parcelas do estudo, em porcentagem.

\begin{tabular}{|c|c|c|c|c|c|c|c|}
\hline UA & Argila & Silte & Areia muito fina & Areia fina & Areia média & Areia grossa & Areia muito grossa \\
\hline \multicolumn{8}{|c|}{ Parcela 01} \\
\hline $\mathbf{A}$ & 33,2 & 2,0 & 6,9 & 26,3 & 27,0 & 3,3 & 1,3 \\
\hline B & 30,3 & 8,5 & 6,5 & 24,0 & 25,2 & 4,2 & 1,4 \\
\hline C & 27,3 & 5,7 & 5,9 & 26,4 & 29,4 & 4,4 & 0,8 \\
\hline \multicolumn{8}{|c|}{ Parcela 02} \\
\hline A & 3,4 & 12,6 & 5,6 & 36,2 & 35,9 & 5,5 & 0,8 \\
\hline B & 8,5 & 12,4 & 5,9 & 32,3 & 32,6 & 7,1 & 1,2 \\
\hline C & 10,8 & 14,0 & 6,6 & 29,9 & 31,2 & 6,0 & 1,5 \\
\hline \multicolumn{8}{|c|}{ Parcela 03} \\
\hline A & 25,6 & 16,6 & 8,6 & 26,1 & 19,7 & 2,9 & 0,5 \\
\hline $\mathbf{B}$ & 24,9 & 16,0 & 10,6 & 25,8 & 18,5 & 3,6 & 0,7 \\
\hline $\mathbf{C}$ & 27,2 & 16,1 & 11,5 & 24,5 & 17,3 & 2,8 & 0,6 \\
\hline \multicolumn{8}{|c|}{ Parcela 04} \\
\hline $\mathbf{A}$ & 22,2 & 13,0 & 9,7 & 30,0 & 21,6 & 2,9 & 0,6 \\
\hline B & 21,5 & 13,3 & 8,7 & 30,5 & 22,2 & 2,9 & 0,9 \\
\hline C & 20,5 & 10,3 & 11,8 & 32,8 & 21,2 & 2,8 & 0,5 \\
\hline \multicolumn{8}{|c|}{ Parcela 05} \\
\hline A & 14,2 & 15,2 & 29,4 & 38,9 & 2,0 & 0,2 & 0,2 \\
\hline B & 19,1 & 19,9 & 32,7 & 27,3 & 0,7 & 0,1 & 0,1 \\
\hline $\mathbf{C}$ & 10,1 & 10,2 & 14,2 & 45,8 & 19,6 & 0,2 & 0,0 \\
\hline \multicolumn{8}{|c|}{ Parcela 06} \\
\hline A & 46,8 & 42,7 & 2,8 & 3,9 & 3,3 & 0,6 & 0,0 \\
\hline B & 55,3 & 34,2 & 3,0 & 4,0 & 2,8 & 0,5 & 0,1 \\
\hline C & 61,5 & 34,6 & 1,3 & 1,1 & 1,1 & 0,4 & 0,1 \\
\hline \multicolumn{8}{|c|}{ Parcela 07} \\
\hline A & 40,8 & 7,9 & 4,2 & 12,2 & 17,7 & 10,9 & 6,3 \\
\hline $\mathbf{B}$ & 44,9 & 7,0 & 4,9 & 10,9 & 17,0 & 12,0 & 3,3 \\
\hline C & 45,6 & 7,6 & 4,5 & 10,8 & 15,9 & 10,9 & 4,7 \\
\hline \multicolumn{8}{|c|}{ Parcela 08} \\
\hline A & 43,9 & 9,7 & 6,9 & 16,3 & 17,2 & 4,6 & 1,3 \\
\hline B & 44,8 & 11,8 & 6,5 & 15,7 & 15,4 & 4,6 & 1,3 \\
\hline C & 45,5 & 10,8 & 7,0 & 17,2 & 15,2 & 3,4 & 0,9 \\
\hline \multicolumn{8}{|c|}{ Parcela 09} \\
\hline A & 32,2 & 31,4 & 18,3 & 17,0 & 0,8 & 0,2 & 0,1 \\
\hline B & 46,8 & 46,7 & 4,6 & 1,3 & 0,5 & 0,1 & 0,1 \\
\hline C & 50,8 & 46,7 & 1,5 & 0,6 & 0,2 & 0,1 & 0,1 \\
\hline \multicolumn{8}{|c|}{ Parcela 10} \\
\hline A & 48,0 & 35,0 & 10,7 & 4,5 & 1,1 & 0,4 & 0,2 \\
\hline B & 39,1 & 42,1 & 11,8 & 6,1 & 0,6 & 0,2 & 0,1 \\
\hline C & 23,8 & 25,6 & 25,9 & 21,9 & 2,4 & 0,4 & 0,1 \\
\hline
\end{tabular}


Tabela 6. Dados granulométricos de sedimentos das unidades amostrais (UA) dos quatro transectos do estudo, em porcentagem.

\begin{tabular}{|c|c|c|c|c|c|c|c|}
\hline UA & Argila & Silte & Areia muito fina & Areia fina & Areia média & Areia grossa & Areia muito grossa \\
\hline \multicolumn{8}{|c|}{ Transecto 01} \\
\hline A & 56,7 & 6,4 & 3,9 & 9,2 & 13,5 & 8,0 & 2,3 \\
\hline B & 56,8 & 7,5 & 3,5 & 9,1 & 12,3 & 7,8 & 3,0 \\
\hline C & 19,1 & 8,1 & 3,6 & 21,6 & 34,2 & 10,1 & 3,2 \\
\hline D & 49,5 & 8,6 & 4,0 & 10,4 & 16,5 & 8,5 & 2,6 \\
\hline$E$ & 63,1 & 19,5 & 2,0 & 3,3 & 5,1 & 4,8 & 2,3 \\
\hline $\mathbf{F}$ & 65,5 & 26,5 & 1,1 & 1,7 & 2,0 & 1,3 & 2,0 \\
\hline $\mathbf{G}$ & 69,5 & 24,9 & 0,4 & 0,8 & 1,3 & 0,7 & 2,5 \\
\hline $\mathrm{H}$ & 71,9 & 20,9 & 0,6 & 1,3 & 1,8 & 1,0 & 2,4 \\
\hline I & 69,8 & 24,8 & 0,3 & 0,6 & 0,9 & 0,8 & 2,7 \\
\hline $\mathrm{J}$ & 66,6 & 29,4 & 0,3 & 0,6 & 0,8 & 0,8 & 1,6 \\
\hline \multicolumn{8}{|c|}{ Transecto 02} \\
\hline A & 26,6 & 42,2 & 14,4 & 14,6 & 1,6 & 0,6 & 0,1 \\
\hline B & 14,4 & 13,4 & 18,5 & 50,3 & 3,3 & 0,1 & 0,0 \\
\hline C & 29,4 & 41,0 & 22,2 & 6,6 & 0,2 & 0,1 & 0,3 \\
\hline D & 7,8 & 16,0 & 25,0 & 48,2 & 2,7 & 0,1 & 0,1 \\
\hline $\mathrm{E}$ & 16,1 & 21,2 & 18,1 & 32,6 & 11,6 & 0,2 & 0,1 \\
\hline $\mathbf{F}$ & 13,9 & 16,1 & 5,6 & 21,7 & 42,5 & 0,2 & 0,0 \\
\hline $\mathbf{G}$ & 18,5 & 22,0 & 25,0 & 33,7 & 0,7 & 0,0 & 0,0 \\
\hline $\mathrm{H}$ & 33,4 & 44,7 & 16,8 & 5,0 & 0,1 & 0,0 & 0,0 \\
\hline $\mathrm{I}$ & 34,0 & 46,9 & 15,3 & 3,6 & 0,2 & 0,0 & 0,0 \\
\hline $\mathrm{J}$ & 41,9 & 47,0 & 8,9 & 2,0 & 0,2 & 0,0 & 0,0 \\
\hline \multicolumn{8}{|c|}{ Transecto 03} \\
\hline $\mathbf{A}$ & 28,0 & 39,2 & 23,4 & 9,1 & 0,2 & 0,0 & 0,0 \\
\hline B & 24,5 & 28,3 & 31,0 & 15,9 & 0,2 & 0,0 & 0,0 \\
\hline C & 34,1 & 48,7 & 13,6 & 3,3 & 0,2 & 0,1 & 0,0 \\
\hline D & 30,5 & 41,9 & 20,6 & 6,9 & 0,2 & 0,0 & 0,0 \\
\hline$E$ & 27,3 & 36,7 & 24,1 & 10,9 & 0,8 & 0,1 & 0,0 \\
\hline $\mathbf{F}$ & 25,2 & 42,5 & 10,6 & 11,1 & 9,0 & 1,3 & 0,3 \\
\hline $\mathbf{G}$ & 26,8 & 42,6 & 15,0 & 10,2 & 4,7 & 0,6 & 0,1 \\
\hline $\mathrm{H}$ & 27,4 & 36,7 & 23,4 & 12,0 & 0,4 & 0,1 & 0,0 \\
\hline I & 34,9 & 47,2 & 11,7 & 4,5 & 1,5 & 0,3 & 0,0 \\
\hline $\mathrm{J}$ & 27,0 & 38,9 & 19,9 & 10,8 & 2,9 & 0,4 & 0,0 \\
\hline \multicolumn{8}{|c|}{ Transecto 04} \\
\hline $\mathbf{A}$ & 52,5 & 6,0 & 3,6 & 9,9 & 16,4 & 9,9 & 1,7 \\
\hline B & 51,1 & 5,3 & 3,1 & 10,3 & 18,0 & 10,8 & 1,4 \\
\hline C & 51,2 & 5,2 & 2,9 & 10,3 & 17,9 & 10,7 & 1,7 \\
\hline D & 50,6 & 5,6 & 3,2 & 10,0 & 18,3 & 10,5 & 1,7 \\
\hline$E$ & 55,5 & 7,0 & 3,3 & 9,8 & 15,0 & 8,1 & 1,3 \\
\hline $\mathbf{F}$ & 53,0 & 6,6 & 3,1 & 9,2 & 16,9 & 9,7 & 1,6 \\
\hline $\mathbf{G}$ & 53,9 & 6,7 & 3,1 & 8,1 & 14,8 & 11,2 & 2,1 \\
\hline $\mathrm{H}$ & 47,9 & 7,1 & 3,3 & 9,8 & 18,9 & 10,9 & 2,1 \\
\hline $\mathrm{I}$ & 46,8 & 6,1 & 2,9 & 10,1 & 19,4 & 12,3 & 2,4 \\
\hline $\mathbf{J}$ & 45,2 & 6,9 & 3,5 & 11,0 & 20,2 & 11,2 & 1,9 \\
\hline
\end{tabular}




\section{Apêndice C - Bioquímica foliar de espécies-alvo do estudo}

\section{Período chuvoso}

Tabela 1. Dados bioquímicos foliares das espécies-alvo do estudo, coletados no período chuvoso. Clorofila a (Cloro a), clorofila b (Cloro a) e carotenoides + xantofilas (Car. + Xant.) em $\mu \mathrm{g} / \mathrm{mg}$, antocianina (Antoc.) em $\Delta / \mathrm{mg}$, celulose (Celul.) e hemicelulose (Hemicel.) em $\mathrm{mg} / \mathrm{g}$, lignina insolúvel (Lig. insol.) e água em porcentagem.

\begin{tabular}{|c|c|c|c|c|c|c|c|c|}
\hline Ind. & Cloro a & Cloro b & Car. + Xant. & Antoc. & Celul. & Hemicel. & Lign. insol. & Água \\
\hline \multicolumn{9}{|c|}{ Calophyllum brasiliense (CABR) } \\
\hline 01 & 0,231 & 1,402 & 0,394 & 0,048 & 200,5 & 50,6 & 40,5 & 41,9 \\
\hline 02 & 0,934 & 0,347 & 0,757 & 0,018 & 211,6 & 46,7 & 43,2 & 43,0 \\
\hline 03 & 0,212 & 0,946 & 0,408 & 0,034 & 206,1 & 58,8 & 40,5 & 49,0 \\
\hline \multicolumn{9}{|c|}{ Cedrela fissilis (CEFI) } \\
\hline 01 & 1,372 & 0,348 & 1,242 & 0,081 & 181,6 & 40,6 & 50,1 & 37,1 \\
\hline 02 & 0,795 & 0,043 & 0,822 & 0,082 & 132,5 & 34,0 & 44,5 & 35,9 \\
\hline 03 & 0,364 & 0,023 & 0,897 & 0,087 & 111,3 & 30,9 & 46,4 & 37,6 \\
\hline \multicolumn{9}{|c|}{ Inga vera subsp. affinis (INVE) } \\
\hline 01 & 0,950 & 0,098 & 0,438 & 0,251 & 101,9 & 42,8 & 55,7 & 39,0 \\
\hline 02 & 0,560 & 0,041 & 0,280 & 0,278 & 99,7 & 39,7 & 67,2 & 51,0 \\
\hline 03 & 0,894 & 0,019 & 0,487 & 0,405 & 105,0 & 32,4 & 65,3 & 29,0 \\
\hline \multicolumn{9}{|c|}{ Qualea grandiflora (QUGR) } \\
\hline 01 & 0,723 & 0,596 & 0,541 & 0,155 & 145,5 & 53,3 & 196,5 & 32,0 \\
\hline 02 & 0,444 & 0,445 & 0,211 & 0,247 & 86,0 & 37,0 & 37,2 & 37,0 \\
\hline 03 & 0,806 & 0,688 & 0,540 & 0,085 & 119,7 & 44,9 & 132,8 & 28,0 \\
\hline \multicolumn{9}{|c|}{ Tabebuia ochracea (TAOC) } \\
\hline 01 & 4,226 & 0,729 & 0,737 & 0,011 & 255,9 & 60,5 & 25,4 & 40,8 \\
\hline 02 & 3,415 & 0,554 & 0,709 & 0,007 & 314,7 & 34,8 & 28,7 & 37,8 \\
\hline 03 & 2,287 & 0,273 & 0,298 & 0,009 & 243,3 & 56,0 & 29,7 & 38,1 \\
\hline
\end{tabular}




\section{Período seco}

Tabela 2. Dados bioquímicos foliares das espécies-alvo do estudo, coletados no período seco. Clorofila a (Cloro a), clorofila b (Cloro a) e carotenoides + xantofilas (Car. + Xant.) em $\mu \mathrm{g} / \mathrm{mg}$, antocianina (Antoc.) em $\Delta / \mathrm{mg}$, celulose (Celul.) e hemicelulose (Hemicel.) em $\mathrm{mg} / \mathrm{g}$, lignina insolúvel (Lig. insol.) e água em porcentagem.

\begin{tabular}{|c|c|c|c|c|c|c|c|c|}
\hline Ind. & Cloro a & Cloro b & Car. + Xant. & Antoc. & Celul. & Hemicel. & Lign. insol. & Água \\
\hline \multicolumn{9}{|c|}{ Calophyllum brasiliense (CABR) } \\
\hline 01 & 0,654 & 0,638 & 0,341 & 0,029 & 211,7 & 82,2 & 20,6 & 29,0 \\
\hline 02 & 1,017 & 0,916 & 0,543 & 0,037 & 204,9 & 80,5 & 21,1 & 28,0 \\
\hline 03 & 1,267 & 1,076 & 0,628 & 0,040 & 182,1 & 92,4 & 19,0 & 34,0 \\
\hline \multicolumn{9}{|c|}{ Cedrela fissilis (CEFI) } \\
\hline 01 & 1,090 & 0,867 & 0,575 & 0,125 & 149,8 & 98,5 & 22,3 & 19,0 \\
\hline 02 & 0,750 & 0,537 & 0,440 & 0,101 & 136,7 & 72,3 & 23,6 & 15,0 \\
\hline 03 & 0,394 & 0,327 & 0,356 & 0,154 & 173,1 & 79,0 & 23,4 & 25,0 \\
\hline \multicolumn{9}{|c|}{ Inga vera subsp. affinis (INVE) } \\
\hline 01 & 1,624 & 1,095 & 0,550 & 0,085 & 254,4 & 46,3 & 19,8 & 25,7 \\
\hline 02 & 1,702 & 1,102 & 0,706 & 0,066 & 213,5 & 45,6 & 22,0 & 27,1 \\
\hline 03 & 1,537 & 1,226 & 0,564 & 0,081 & 209,2 & 52,5 & 21,6 & 28,2 \\
\hline \multicolumn{9}{|c|}{ Qualea grandiflora (QUGR) } \\
\hline 01 & 0,402 & 0,237 & 0,255 & 0,023 & 169,2 & 75,3 & 14,8 & 32,5 \\
\hline 02 & 1,040 & 0,580 & 0,421 & 0,096 & 170,5 & 72,8 & 13,6 & 35,0 \\
\hline 03 & 0,433 & 0,427 & 0,232 & 0,026 & 157,5 & 81,4 & 16,5 & 38,2 \\
\hline \multicolumn{9}{|c|}{ Tabebuia ochracea (TAOC) } \\
\hline 01 & 1,326 & 0,902 & 0,476 & 0,025 & 190,8 & 93,8 & 14,7 & 9,0 \\
\hline 02 & 0,847 & 0,608 & 0,338 & 0,034 & 168,9 & 91,6 & 16,0 & 10,0 \\
\hline 03 & 0,943 & 0,659 & 0,395 & 0,028 & 221,5 & 110,2 & 15,0 & 8,0 \\
\hline
\end{tabular}




\author{
ANEXO \\ Anexo A - Mapping invasive species and spectral mixture relationships with \\ neotropical woody formations in southeastern Brazil \\ Cibele H. Amaral ${ }^{a}$, Dar A. Roberts ${ }^{b}$, Teodoro I. R. Almeida ${ }^{a}$, Carlos R. Souza Filho ${ }^{c}$

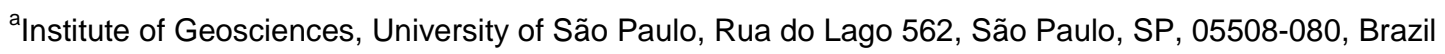 \\ ${ }^{b}$ Department of Geography, University of California Santa Barbara, 1832 Ellison Hall, Santa Barbara, CA 93106, \\ United States \\ ${ }^{c}$ Institute of Geosciences, University of Campinas, PO Box 6152, Campinas, SP, 13083-870, Brazil
}

Keywords: invasive species, Cerrado biome, hyperspectral data, multiple endmember spectral mixture analysis

\begin{abstract}
Biological invasion substantially contributes to the increasing extinction rates of native vegetative species. The remote identification and mapping of invasive species is critical for environmental monitoring. The spatial distribution of these species has been incorporated in global change scenarios. This study aims to assess the performance of a Multiple Endmember Spectral Mixture Analysis (MESMA) applied to imaging spectroscopy data for mapping Dendrocalamus $s p$. (bamboo) and Pinus elliottii L. (slash pine), which are invasive plant species, in a Brazilian neotropical landscape within the Cerrado biome. The work also investigates the spectral mixture between these exotic species and the native woody formations, including woodland savanna, submontane and alluvial seasonal semideciduous forests (SSF). Visible to Shortwave Infrared (VSWIR) imaging spectroscopy data at one-meter spatial resolution were atmospherically compensated and subset into the different spectral ranges (VIS-NIR1: 530-919 nm; and NIR2-SWIR: 1,141-2,352 nm). The data were further normalized via continuum removal (CR). Multiple endmember selection methods, including Interactive Endmember Selection (IES) and Endmember average root mean square error (EAR), Minimum average spectral angle (MASA) and Count-based (CoB) tools (jointly designated as EMC), were employed to create endmember libraries for the targeted vegetation classes. The performance of the MESMA was assessed at the pixel and crown scales. Statistically significant differences $(\alpha=0.05)$ were observed between overall accuracies that were obtained at various spectral ranges. The infrared
\end{abstract}


region (IR) was critical for detecting the vegetation classes through spectral data. The invasive species endmembers exhibited spectral patterns in the IR that were not observed for the native formations. Bamboo was characterized as having a high green vegetation (GV) fraction, lower non-photosynthetic vegetation (NPV) and a low shade fraction, while pine exhibited higher NPV and shade fractions. When analyzing the best two-endmember classification results per spectral range, additional invasive species spectra were omitted. The invasive species showed a statistically significant larger number of spectra erroneously assigned to the woodland savanna class versus the alluvial and submontane SSF classes. Consequently, the invasive species tend to be overestimated, especially in the woodland savanna. Bamboo was best classified using the VSWIR(CR) data with the EMC endmember selection method (User accuracy and Producer's accuracy $=98.11 \%$ and $72.22 \%$, respectively). Pine was best classified using NIR2-SWIR(CR) data with the IES selected endmembers $(97.06 \%$ and $62.26 \%$, respectively). The results obtained during the two-endmember modeling were fully translated into the three-endmember unmixed images. The sub-pixel invasive species abundance analysis reveals that MESMA performs well when unmixing the pixel-based images and mapping the invasive species fractions in a complex neotropical environment, even when analyzed both at pixel and crown scales with 1 -m spatial resolution data.

\section{Introduction}

Biological invasion has increased the extinction rates of native species (Vitousek et al., 1996). Some invasive species can modify ecosystems, introducing intolerable or unfavorable conditions for the survival and colonization of native species by changing the frequency and intensity of wildfires, ecosystem hydrology biogeochemical cycling and erosion rates (Beck et al., 2008). These species exhibit rapid dispersion and nonlinear dynamics; therefore, their synergy with other anthropogenic changes is a major challenge during global change (Burkett et al., 2005; Parry et al., 2007). Due to their importance, the extent and impact of colonization by invasive species must be included in scenarios of global change (Mooney and Hobbs, 2000).

Imaging spectroscopy has often been employed to map invasive species and linear Spectral Mixture Analysis (Adams et al., 1993) has been a widely used successful method for this purpose (e.g., Lass et al., 2004; Li et al., 2005; Ramsey III et al., 2005a and 2005b; Rosso et al., 2005; Underwood et al.; 2006; Hestir et al., 2008; Tits et al., 2012; Somers and Asner, 2013 and 2014). 
Multiple endmember spectral mixture analysis (MESMA; Roberts et al., 1998), which differs from traditional Spectral Mixture Analysis (SMA) by allowing the type and number of a single class endmembers to vary per pixel, has generate successful images of invasive species fractions based on various hyperspectral data. While using data from the Airborne Visible/Infrared Imaging Spectrometer (AVIRIS), Li et al. (2005) and Rosso et al. (2005) identified marshland that included invasive species, such as Spartina spp., in the San Francisco Bay, California (USA). Underwood et al. (2006) found exotic aquatic species in the central valley of California (USA) using data from the HyMap airborne sensor. Tits et al. (2012) identified Morella faya in Hawaii (USA) on AVIRIS and Hyperion images, also using MESMA.

Recent research indicates that pre-processing techniques can improve MESMA results. Somers and Asner (2013 and 2014) detected invasive species in Hawaii (USA) using unitemporal and multi-temporal Hyperion data and MESMA classification. The authors employed a separability index (SI) and found that selecting spectral features beforehand, while excluding adjacent bands with high correlations, increased the classification accuracy of MESMA. Youngentob et al. (2011) mapped two native subgenera of Eucalyptus in the Tumult region in New South Wales (AUS). The authors applied continuum removal to the spectra; this process normalizes the data and enhances the absorption features (Clark and Roush, 1984). Two Eucalyptus subgenera were detected more effectively by MESMA when using continuum-removed (CR) spectra compared to standard spectra.

Although largely explored in the northern hemisphere, the use of imaging spectroscopy to map invasive species in neotropical biomes in continental South America appears to be lacking. In addition, an understanding of how different pre-processing approaches can improve invasive species mapping using MESMA in these highly biodiverse landscapes is also lacking. Among these landscapes, the Cerrado (Brazilian savanna) is a hotspot for global biodiversity, even though only $2 \%$ of its area is legally protected; it has the richest savanna flora in the world (> 7,000 species) and a high level of endemism (Klink and Machado, 2005). Virtually all conservation units, such as biological reserves and parks, are currently being invaded by exotic species to varying degrees (Pivello, 2011). In addition to the areas with anthropic disturbances, the open physiognomies of the Cerrado, which allow direct sunlight to reach the lower strata, are under significant colonization pressure due to these invasive species (Pivello et al., 1999). 
In this context, this study aims to evaluate the performance of MESMA for the spectral detection and mapping of invasive species, particularly Dendrocalamus sp. (bamboo) and Pinus elliottii L. (slash pine), in the Mogi-Guaçu Ecological Park, São Paulo, Brazil. This area contains a wide variety of tree and shrub species, which produces considerable spectral variation in the airborne hyperspectral images acquired for the study. Within this larger goal, we test whether these invasive species could be spectrally detected in a landscape containing varied woody formations in the Cerrado biome to determine which formation shows the largest estimation errors for the targeted invasive species. We also evaluate possible accuracy improvements through independent visible-near infrared and infrared-shortwave infrared hyperspectral data subsets, both with and without continuum removal in MESMA classifications, while considering different endmember selection methods.

\section{Theory section}

\subsection{Continuum Removal}

The continuum is a convex hull consisting of straight line segments that connect the ends of the spectrum and/or reflectance peaks in that interval; it is modeled as a mathematical function and can be removed from segments or the entire spectrum to normalize the differences in brightness while highlighting the absorption features present in the interval (Clark and Roush, 1984). During continuum removal, the intersection points are normalized to 1.0 and the reflectance values of the absorption features begin to vary between 1.0 and zero. The continuum is removed (CR) by dividing the reflectance value $(\rho)$ at a given wavelength $(\lambda)$ by the reflectance value of the continuum $\left(\rho_{C} \lambda\right)$ at the same wavelength:

$C R=\frac{\rho \lambda}{\rho_{C} \lambda}$

In vegetation spectroscopy, continuum removal has been used primarily for analyzing absorption features located in the near infrared (NIR) and shortwave infrared (SWIR) regions, particularly when estimating the non-pigmented biochemical constituents of vegetation, such as nitrogen, lignin and cellulose (e.g., Kokaly and Clark, 1999; Curran et al., 2001; Kokaly, 2001; Huang et al., 2004; and Kokaly et al., 2009). This technique has also been applied to preprocess the hyperspectral data for the maps of invasive species in California (USA), as reported by Underwood et 
al. (2003) and Hestir et al. (2008). In these studies, the authors used this technique to enhance the spectral absorption features of intra-leaf water in the NIR region. Youngentob et al. (2011) also used the continuum-removed spectra to map the two subgenera of eucalyptus in New South Wales (AUS) using MESMA.

\subsection{Endmember selection methods}

Endmember selection involves identifying the types and numbers of endmembers and their spectral signatures from a spectral library (Somers et al., 2011). Several techniques that capture the smallest number of endmembers representing and modelling the spectral variability of a particular class have been developed for applications in MESMA (Roth et al., 2012).

Roberts et al. (2003) proposed a count-based (CoB) endmember selection in which the optimal endmember models the largest number of spectra within its class. The CoB index (CoBI) was subsequently proposed by Clark (2005) to rank the endmembers according to the ratio obtained between modeled spectra within its class (CoBln) and modeled spectra outside its class (CoBOut). Dennison and Roberts (2003a) developed the endmember average root mean square error (EAR), which uses each spectrum within a class to model all other spectra of that class through a linear SMA. EAR is equivalent to the average root mean square error (RMSE) for all models of a single endmember within the same class. The best endmember with the smallest EAR is selected:

$E_{A i}=\frac{\sum_{j=1}^{n} R M S E_{A i} A j}{n-1}$

where $A$ is a single class, $A_{i}$ is the spectrum being tested as an endmember, $A_{j}$ is a modeled spectrum, $\mathrm{n}$ is the total number of class A spectra and the term " $\mathrm{n}-1$ " refers to the auto-modeled spectrum. The minimum average spectral angle (MASA) method, which was created by Dennison et al. (2004), is similar to EAR but uses the spectral angle (Kruse et al., 1993) instead of the RMSE as the metric during endmember selection. The endmembers are selected based on the lowest MASA.

Although these techniques are commonly applied during endmember selection for MESMA applications, EAR, MASA and $\mathrm{CoB}$, which are grouped under the EMC designation, can fail because they only consider the intraclass spectral variability and do not account for the resulting interactions between the endmembers selected for the different classes (Roth et al., 2012). To address this issue, 
Schaaf et al. (2011) proposed an iterative endmember selection (IES) method that considers the interactions between endmembers selected for multiple classes during the selection process.

IES is a stepwise algorithm that initially tests all pairwise combinations to find the two endmembers that generate the highest Kappa coefficient in a MESMA classification within the global training library. Subsequently, additional potential endmembers are evaluated and a new endmember is added if the accuracy is improved based on Kappa. The endmembers selected in previous steps are also evaluated via subtraction to determine whether their removal improves the accuracy. After adding and subtracting the spectra, a final set of endmembers with the highest Kappa coefficient is obtained (Schaaf et al., 2011).

Roth et al. (2012) developed a hybrid technique that combines the EMC and IES methods to optimize the endmember selection process using IES. This technique is ideal for cases where endmembers are not selected for certain classes through the IES method. With this approach, the missing endmembers, which are selected by CoB, EAR (from EMC method) or another selection procedure, are forced into the IES selection process at a pre-defined step. The IES is then allowed to continue selecting additional endmembers, optimizing those previously selected by IES and by EMC.

\subsection{Multiple endmember spectral mixture analysis}

MESMA (Roberts et al., 1998) is a variant of spectral mixture analysis (SMA) that has been commonly used in the literature (Somers et al., 2011). SMA models the spectra of an image as a linear combination of "pure" spectra (endmembers) by determining their relative proportions within a "mixed" spectrum (Adams et al., 1993). A spectrum within the ground instantaneous field of view (GIFOV) (pixel) is modeled according to the best fit among the endmember fractions in the mixed spectrum. This modeling process uses the sum of the reflectance of a fixed set of endmembers multiplied by their fractional cover:

$$
\rho_{\lambda}^{\prime}=\sum_{i=1}^{N} f_{\mathrm{i}} * \rho_{\mathrm{i} \lambda}+\varepsilon_{\lambda}
$$

where $\rho_{\lambda}^{\prime}$ is the reflectance at a given wavelength $(\lambda), \rho_{i \lambda}$ is the reflectance of endmember $i$ at $\lambda, f_{\mathrm{i}}$ is the cover fraction of endmember $\mathrm{i}, \mathrm{N}$ is the total number of endmembers in the model and $\varepsilon_{\lambda}$ is the 
residual error of the model. The endmember fractions are typically constrained by a sum equal to 1.0 when assuming that a particular spectrum is $100 \%$ modeled by the endmembers during the analysis:

$$
\sum_{i=1}^{N} f_{i}=1
$$

The evaluation of the best-fit model uses the root mean square error (RMSE) and the residual error of the model $\left(\varepsilon_{\lambda}\right)$ :

$R M S E=\sqrt{\frac{\sum_{\lambda=1}^{M}\left(\varepsilon_{\lambda}\right)^{2}}{M}}$

where $M$ is the total number of bands.

To overcome the limitations observed in several SMA methods that only uses one endmember per class, MESMA allows the type and number of endmembers to vary (within a single class) per pixel (Roberts et al., 1998). The technique generates linear models using different sets of endmembers from spectral libraries consisting of up to hundreds of endmembers, and selects the model with the lowest RMSE for each pixel. In addition to being repeatable and portable between images, MESMA generates fraction images corresponding to each endmember spectrum (Roberts et al., 1998). With two endmembers, MESMA generates models between one of the endmembers from a particular class and the photometric shade endmember. This modeling has been used as a successful algorithm for classifying and mapping species plants and functional types, such as the shrubby vegetation (chaparral) in southeastern California, USA (Roberts et al., 1998; Dennison and Roberts, 2003a and 2003b; Roth et al., 2012), the boreal forest in Canada (Roberts et al., 1999), the aquatic and marsh vegetation in northeastern California, USA (Li et al., 2005; Rosso et al., 2005; Underwood et al., 2006), the temperate forest in New Hampshire, USA (Plourde et al., 2007), the montane vegetation in northern Utah, USA (Schaaf et al., 2011), the eucalyptus forest in New South Wales, Australia (Youngentob et al., 2011), and the montane rainforest in Hawaii, USA (Tits et al., 2012; Somers and Asner, 2013). Although the two-endmember models exhibit better separation between classes than those with three endmembers (Roberts et al., 1998), the three-endmember models can also generate 
accurate estimates of endmember fractions by spectrally unmixing the images (Roberts et al., 1998; Dennison and Roberts, 2003a and 2003b).

According to Roberts et al. (1998), the key to using multiple endmembers is to start with a series of potential two-endmember models and evaluate each model according to the selection criteria; candidate models can be built to incorporate more endmembers if necessary.

\section{Data and Methods}

\subsection{Study area}

The study area is located in the Mogi-Guaçu Ecological Park (MGEP), Mogi Guaçu city, São Paulo State, southeastern Brazil (Fig. 1). The area covers 1,230.5 ha and is located between latitudes

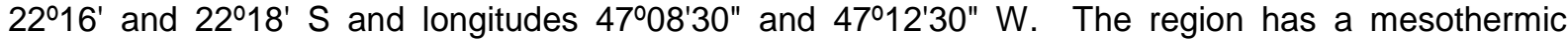
climate (CWA; Köppen climate classification) characterized by hot, humid summers and mild winters. Average daily temperatures are above $22^{\circ} \mathrm{C}$ during the summer and lower than $18^{\circ} \mathrm{C}$ during the winter. The topography is characterized by wide alluvial plains and hills with altitudes between 560 and $700 \mathrm{~m}$. The soils are primarily hydromorphic. The study area includes approximately $17 \mathrm{~km}$ of the Mogi-Guaçu river margins (Instituto Florestal do Estado de São Paulo, 2010).

The MGEP is within the Cerrado biome (Brazilian savanna) and displays both Cerrado "strictu sensu" (e.g., woodlands) and Atlantic forest formations (Eiten, 1963; Joly and Bicudo, 1999). The seasonal semideciduous forests (Atlantic forest) are physiognomically present within the Cerrado biome as riparian and gallery forests generally at the lowlands. The Woodland savanna formation (sclerophyllous woodland savanna) occupies the interfluve areas of the landscape (Eiten, 1963; Ribeiro and Walter, 2008). The study area has been severely impacted by the spread of exotic species introduced by the intense anthropic disturbance of the native vegetation and the close proximity of the experimental plantations in and around the natural reserve. These species, which include Dendrocalamus sp. (bamboo) and Pinus elliottii L. (slash pine), are mainly invading open and second growth forest terrains (Fig. 1), which are areas where these species have never been cultivated. 

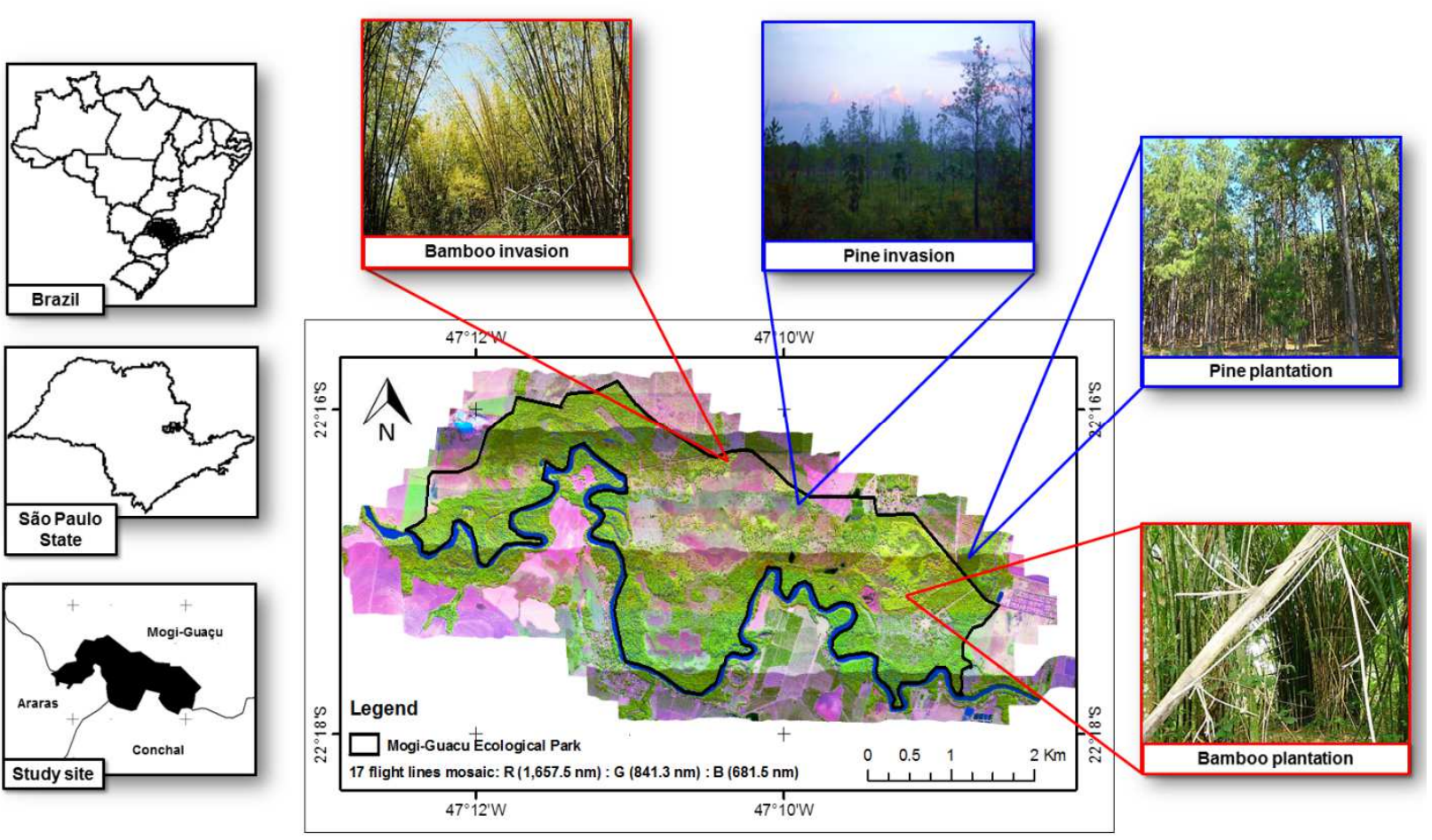

Fig. 1. Location of the study area (left) in Brazil, R:G:B (1,657.5: 841.3: $681.5 \mathrm{~nm}$ ) composition of ProSpecTIR-VS hyperspectral data coverage (center) and field appearance of the experimentally planted and invasive species: Dendrocalamus sp. (bamboo) and Pinus elliottii L. (slash pine).

\subsection{Hyperspectral data acquisition and preprocessing}

The ProSpecTIR-VS hyperspectral data (SpecTIR - Reno, NV, USA/ FotoTerra - São Paulo, SP, Brazil) were obtained using a combination of two airborne sensors on June $8^{\text {th }}, 2010$. The first sensor operates with a sampling interval of $~ 2.9 \mathrm{~nm}$ between 400 and $970 \mathrm{~nm}$ with 121 bands total. The second sensor operates with a sampling interval of $\sim 8.5 \mathrm{~nm}$ between 970 and 2,450 nm with 236 bands total. Seventeen flight lines (flown east-west) were acquired at a height of $\sim 1,350 \mathrm{~m}$, a width of $\sim 320 \mathrm{~m}$ and a ground-projected instantaneous field of view (GIFOV) of $1 \mathrm{~m}$.

Atmospheric compensation of radiance data was performed using ACORN 5 (Imspec LLC Palmdale, CA, USA) with water vapor and liquid estimated from the images. The water vapor was estimated using two moderate bands at 940 and $1140 \mathrm{~nm}$. No artifacts were suppressed, preserving the reflectance data.

Surface samples from unpaved roads were collected in all flight lines, and the sampling points were georeferenced by GPS in the field. The reflectance spectra of the samples were obtained in the laboratory using a FieldSpec 3 Hi-Res. (ASD Inc. - Boulder, CO, USA) spectrometer with a contact probe. The data were collected orthogonally using a contact probe in a dark room which minimized 
atmospheric effects on soil spectra. The ASD operates at sampling intervals of 1.4 and $2 \mathrm{~nm}$ between 350 and 2,500 $\mathrm{nm}$. The spectra had their absolute reflectance retrieved and the offsets between sensors corrected via PRISM software routines (Kokaly, 2011). The average spectrum for each sampling point was also calculated using PRISM. These laboratory spectral measurements were used to enhance the 17 atmospherically corrected image swaths by convoluting the laboratory data with the spectral response functions of the images using ACORN 5. Each of these images was georeferenced using flight data from a Geographic Lookup Table (GLT) and grouped into a mosaic.

The signal-to-noise ratios of the data were analyzed for each band. Two-hundred and sixteen bands from the visible (VIS) to short wave infrared (SWIR) spectra were preserved for processing due to their high signal-to-noise ratios. The bands located at the beginning of VIS and the end of SWIR in the offset region between the sensors, as well as the regions with strong water absorption, were excluded from the dataset.

\subsection{Preprocessing and Spectral Subsets}

A simple ratio $(S R=\rho 797.3 / \rho 681.5 \mathrm{~nm}$; Jordan, 1969) was applied to the ProSpecTIR-VS data to mask all unvegetated targets in the mosaic. Pixels with SR values below 0.5 were masked. Thus, only the data from the densest vegetation such as forest formations and individual trees in grasslands remained for SMA. The VSWIR (216 channels from $530 \mathrm{~nm}$ (Visible) to 2,352 nm (Shortwave Infrared)), VIS-NIR1 (82 channels from 530 to $919 \mathrm{~nm}$ ) and NIR2-SWIR (134 channels from 1,141 to $2,352 \mathrm{~nm}$ ) datasets had their continuum removed (CR) to test the efficiency of this procedure. Ultimately, six different input spectral subsets were considered for applying MESMA: VSWIR and VSWIR with CR; VIS-NIR1 and VIS-NIR1 with CR; NIR2-SWIR and NIR2-SWIR with CR.

\subsection{Acquisition of reference data and spectral libraries}

Several field campaigns were conducted from June 2010 to July 2012 to complete a woody stratum (trees and shrubs with diameter $\geq 5.0 \mathrm{~cm}$ at $1.30 \mathrm{~m}$ height) inventory, identify species and georeference the sampled species and physiognomies. Five classes of vegetation were selected for the study: the native woody formations (woodland savanna, alluvial and submontane seasonal semideciduous forests) and invasive species (Dendrocalamus sp. - bamboo and Pinus elliottii L. slash pine). The formations and physiognomies observed at the site were classified according to 
Veloso et al. (1991) and Ribeiro and Walter (2008). Based on these field data and the spectral analysis of the imagery, regions of interest (represented by polygons with areas of $4 \mathrm{~m}^{2}$ to $12 \mathrm{~m}^{2}$ ), were obtained for the crowns of the target classes. The average spectral data were extracted from each polygon for each of the six input data.

Spectral libraries were created for each class, and metadata were generated for each spectrum using ViperTools (Roberts et al., 2007). The metadata were composed of the following fields: spectrum name, class, habit, dominance of species in the formation, colonization environment, data scale, data source and brightness.

Those libraries were randomly divided into training and validation spectral libraries for each class (Table 1). An absolute limit of 10 spectra was defined for the training libraries used for the endmember selection to retain additional spectra for the validation process. This threshold value was empirically proposed and discussed by Roth et al. (2012) to provide a more balanced composition of training libraries while preserving an acceptable number of spectra for the validation process.

Table 1

Vegetation classes and the number of spectra used for the training and validation libraries. Seasonal semideciduous forest $=$ SSF .

\begin{tabular}{c|c|c}
\hline Vegetation type (Class) & $\begin{array}{c}\text { Training library } \\
\text { (\# spectra) }\end{array}$ & $\begin{array}{c}\text { Validation library } \\
\text { (\# spectra) }\end{array}$ \\
\hline Alluvial SSF (Alluv) & 10 & 57 \\
\hline Bamboo (Bamb) & 10 & 72 \\
\hline Slash pine (Pine) & 10 & 53 \\
\hline Submontane SSF (Submon) & 10 & 73 \\
\hline Woodland savanna (Wood) & 10 & 61 \\
\hline
\end{tabular}

Each training library contains information that is used in the different endmember selection procedures. This information was stored in a band sequential (BSQ) image as follows: RMSE (band 1), spectral angle (band 2), fractions for bright (band 3) and dark (band 4) endmembers, and type of data constraint (band 5) (Roberts et al., 2007). The threshold for the endmember fractions was defined between 0.5 and 1.05, and different RMSE restrictions were empirically tested to access results with better accuracy from the data with and without continuum removal $(\mathrm{CR})$. The initial tests were conducted with values used in previous studies, i.e., RMSE $=0.025$ for data without $\mathrm{CR}$ (Dennison and Roberts, 2003a; Youngentob et al., 2011; Roth et al., 2012) and 0.060 for data with CR (Youngentob et al., 2011). 
When applied to the six spectral data subsets (VSWIR, VIS-NIR1, NIR2-SWIR and CR equivalents), the best accuracies (overall accuracy and Kappa coefficient from the two-endmember modeling results) were reached when the RMSE $=0.050$ for data without $\mathrm{CR}$ and 0.070 for data with CR.

\subsection{Endmember selection}

Two different methods for endmember selection were tested with the global training libraries (spectra from the five vegetation classes) derived from the six input datasets. These were Endmember Average RMSE (EAR: Dennison and Roberts, 2003), Mean Average Spectral Angle (MASA: Dennison et al., 2004)_and Count-based Endmember Selection (COBI: Roberts et al., 2003), collectively known as EMC (Roberts et al., 2007) and Iterative Endmember Selection (IES:Schaaf et al., 2011). When using EMC in ViperTools (Roberts et al., 2007), endmembers were selected for each class by selecting spectra with the lowest EAR, the lowest MASA and the highest CoBI (see 3.2 for details). When the $\mathrm{CoBI}$ values were zero, the spectra were selected based on the positive CoBIn/CoBOut ratios. All of the spectra with positive CoBIn/CoBOut ratios were selected. The endmember selection using IES was conducted on the global training libraries with the aid of a tailored IDL code (Schaaf et al., 2011; Roth et al., 2012). The endmembers were automatically selected for every class.

\subsection{Spectral modeling with two endmembers}

The validation spectral libraries were modeled by the endmember libraries that were separately generated by the EMC and IES methods for each one of the six spectral datasets using the IDL code for two-endmember models (Roth et al., 2012). The accuracy of the modeling results was analyzed through the overall accuracy and Kappa coefficient metrics. One-way ANOVA tests were conducted using the $R$ statistical package ( $R$ Development Core Team, 2008) to test the null hypothesis, which was that the results are significantly different between the VIS-NIR1, NIR2-SWIR and VSWIR and equivalent CR datasets, as well as between the EMC and IES endmember selection methods.

The Producer (or omission error) and User (or commission error) accuracy were analyzed to understand the spectral mixture of the invasive species and the native woody formations present in the landscape of the study area. We also evaluated the implications for mapping the target invasive 
species in environments under the domain of specific neotropical formations. This analysis was based on the premise that a commission error is defined as the improper inclusion of a spectrum (pixel or area) in a category; while an omission error is the exclusion of a spectrum from a category to which it actually belongs. Therefore, each error represents an omission from the correct category or a commission in the wrong category (Congalton, 1991; Congalton and Green, 1999). The differences in misclassification between the invasive species classes and the woody formations classes were statistically tested through one-way ANOVA statistical models.

\subsection{Image unmixing with three endmembers}

The image unmixing procedure was based on the results of the two-endmember models that showed the best overall accuracies and the best User and Producer accuracies for the classes of invasive species simultaneously. Only the endmembers that modeled the validation spectra with a RMSE below 0.025 correctly in the two-endmember modeling were selected to compose the endmember libraries for image unmixing. MESMA was performed with three endmembers: targeted class of invasive species, other vegetation classes and photometric shade. The restrictions used for the two-endmember models were preserved: the fraction constraint was between 0.05 and 1.05, and the maximum RMSE was of 0.05 for the data without $C R$ and 0.07 for those with $C R$. At this stage, the endmembers were combined and spectral mixing models were generated for each image pixel. The models with the lowest RMSE were selected to generate the spectral fraction images (Roberts et al., 2012).

During post-processing, the images were normalized by removing the shade fraction from the products. This fraction also includes secondary illumination effects, which vary based on solar elevation and azimuth, slope and aspect and surface roughness (Adams et al., 1986; Smith et al., 1990a and 1990b). Shade normalization is a procedure that divides each non-shade fraction by the sum of all non-shade fractions in two-endmember models. This technique produces uniform normalized fractions of $100 \%$ pixel by pixel (Smith et al., 1990a; Dennison and Roberts, 2003a).

The pixel-based fraction images were assessed by analyzing the sub-pixel GV fractions (target invasive species and other vegetation types) abundances at the pixel and crown scales. Thus, the fraction images data were extracted from regions of interest representing crowns consisting of $100 \%$ invasive or native formations species as established in the field.. The sub-pixel abundance of 
each invasive species fraction was detected in all class validation pixels $(n=2,760)$ and crowns $(n=316)$. This procedure was conducted to verify whether the two-endmember classification results are realistically portrayed in the three-endmember unmixed images.

\section{Results}

\subsection{Endmember selection}

The EMC method for endmember selection yielded libraries with a higher number of endmembers relative to IES. From 50 training spectra, IES selected an average of 10.67 and 10.33 endmembers for the data with and without CR respectively. EMC selected an average of 14.33 and 23.67 for the equivalent data. The variance of the endmembers was higher for the $\mathrm{CR}$ data $(\mathrm{EMC}=$ 16.33 and IES $=9.33)$ versus the data with $\mathrm{CR}(\mathrm{EMC}=0.3$ and IES $=2.33)($ Fig. 2).

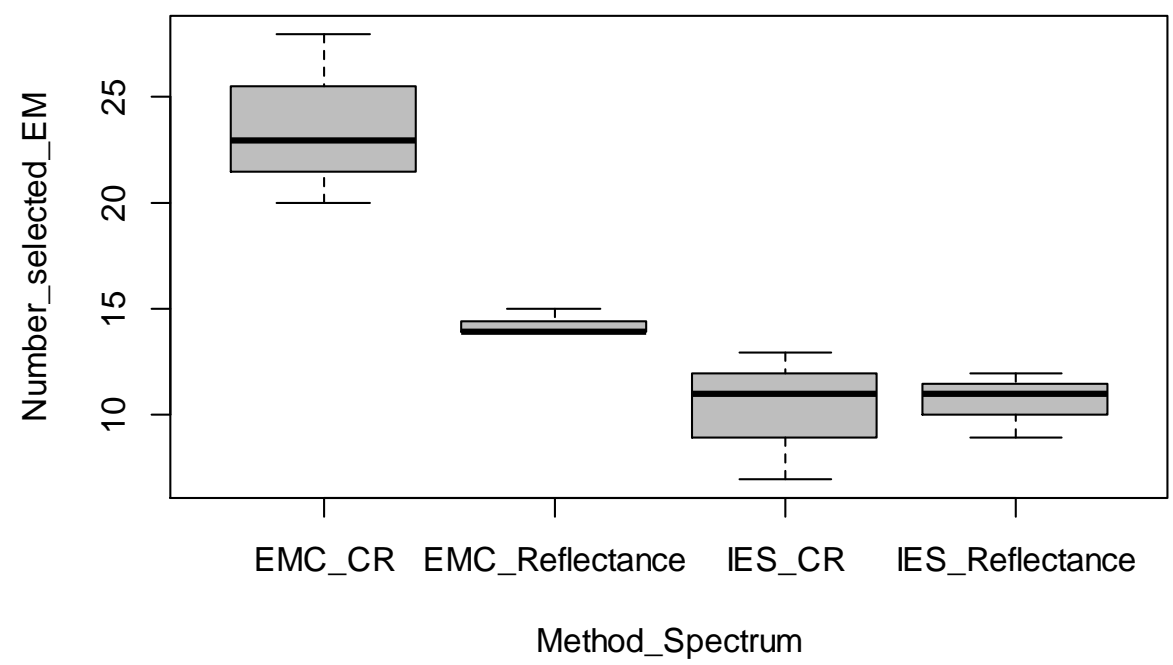

Fig. 2. Distribution of the number of endmembers selected from 50 training spectra by EMC and IES that were applied to the training spectral libraries with CR (CR) and without CR (Reflectance). The central horizontal lines denote the median of the dataset. The lower and upper edges of the boxes indicate the interval between 25 and $75 \%$ of the data distribution. The horizontal lines outside the boxes indicate the minimum and maximum values of the dataset that were not outliers.

The highest Kappa coefficients, which determine which endmembers are selected during IES, were achieved for the VSWIR data with CR (0.925), the NIR2-SWIR data with CR (0.850) and the NIR2-SWIR data without CR (0.803). The lowest Kappa values were obtained for the VIS-NIR1 data with CR (0.425), the VIS-NIR1 data without CR (0.621) and the VSWIR data without CR (0.709). The 
higher Kappa coefficient values obtained for the NIR2-SWIR data and the lowest values for the VISNIR1 data indicate the presence of additional discriminating spectral features from 1,141 to $2,352 \mathrm{~nm}$.

\subsection{Two-endmember spectral modeling}

\subsubsection{Overall accuracies}

The two-endmember spectral models yielded results that are considered satisfactory even though the overall accuracies were below $65 \%$, and the Kappa coefficients were below 0.56 (Table 2). In addition to the invasive species classes, woody formation classes with high species diversity, high levels of deciduousness and with shared generalist species (without habitat specialization) were also used for these classifications.

Table 2

Kappa coefficients and overall accuracies (\%) of the spectral classifications using MESMA with two endmembers on different datasets (preprocessed or not) and methods for endmember selection. The values are organized in decreasing order.

\begin{tabular}{c|c|c}
\hline Input data/Method & Kappa coefficient & Overall accuracy (\%) \\
\hline VSWIR(CR)/EMC & 0.558 & 64.56 \\
\hline NIR2-SWIR(CR)/IES & 0.549 & 63.92 \\
\hline VSWIR(CR)/IES & 0.522 & 61.71 \\
\hline NIR2-SWIR/IES & 0.484 & 58.54 \\
\hline VSWIR/EMC & 0.477 & 58.23 \\
\hline VSWIR/IES & 0.474 & 57.59 \\
\hline NIR2-SWIR(CR)/EMC & 0.444 & 55.06 \\
\hline VIS-NIR1(CR)/EMC & 0.438 & 55.06 \\
\hline VIS-NIR1/EMC & 0.426 & 54.75 \\
\hline NIR2-SWIR/EMC & 0.424 & 54.11 \\
\hline VIS-NIR1(CR)/IES & 0.330 & 45.89 \\
\hline VIS-NIR1/IES & 0.256 & 39.24
\end{tabular}

The null hypothesis, which was that the accuracies between the input data and methods are significantly different, was rejected $(\alpha=0.05)$ for the treatments with and without $C R$, as well as for the EMC and IES endmember selection methods $(\alpha=0.05)$. However, this hypothesis was accepted $(\alpha=$ 0.05) for the VIS-NIR1, NIR2-SWIR and VSWIR data, indicating that the accuracies obtained for the classifications based on these datasets are significantly different.

MESMA showed better performance for data with higher dimensionality, contrasting with the other classification techniques usually used for identifying remote species that require prior data dimensionality reduction. The VSWIR dataset achieved the highest accuracies (overall accuracy / 
Kappa coefficient: average $=60.5 \% / 0.51$, and variance $=10.5 / 0.002)$, followed by NIR2-SWIR $($ average $=57.9 \% / 0.48$ and variance $=19.7 / 0.003)$ and VIS-NIR1 $($ average $=48.7 \% / 0.36$ and variance $=58.15 / 0.007)($ Fig. 3). The higher accuracies (with lower variances) for the NIR2-SWIR dataset versus the VIS-NIR1 dataset reveal the importance of the infrared (IR) spectral range when discriminating between the studied classes. The variations between shade, green vegetation material (GV) and non-photosynthetic vegetation (NPV) fractions are also discriminatory in this spectral region and can be influenced by the species phenology.
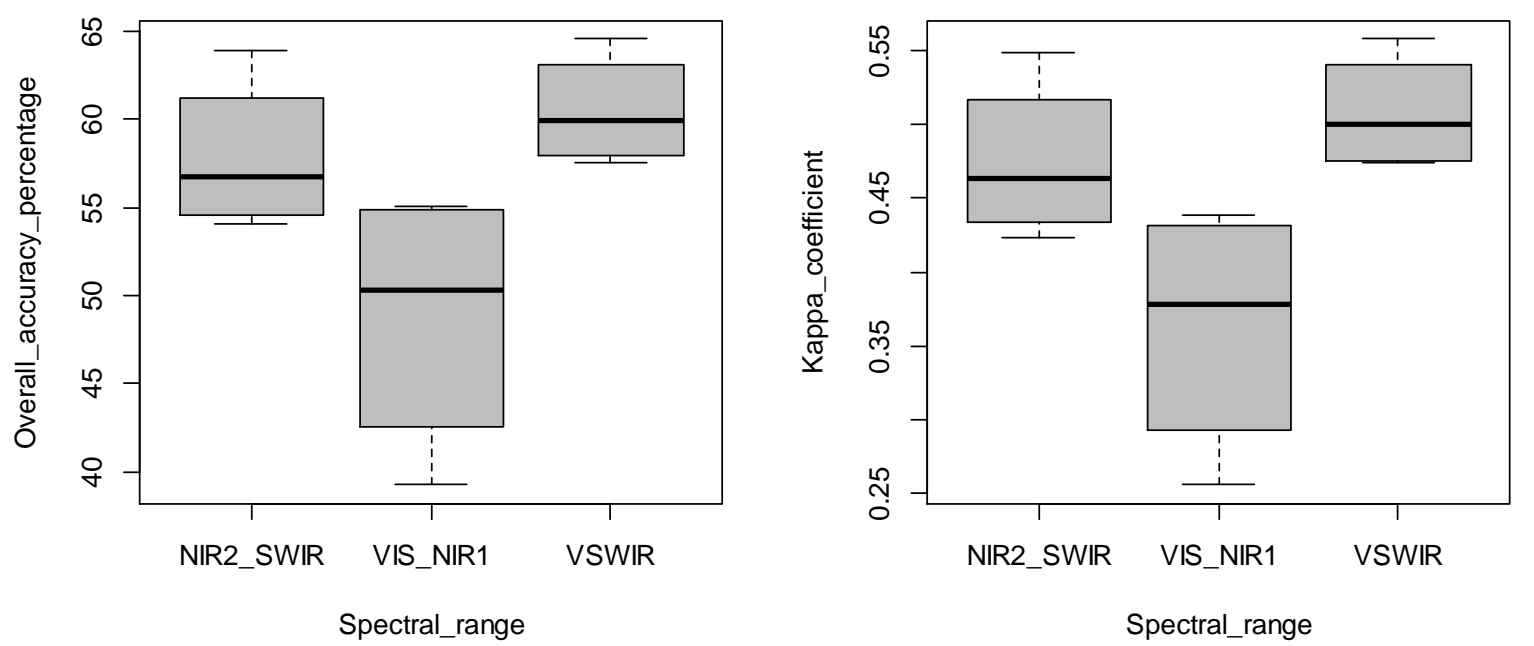

Fig. 3. Distribution of the overall accuracy (\%) and Kappa coefficient values based on the spectral range of input data. The central horizontal lines denote the median of the dataset. The lower and upper edges of the boxes indicate the interval between 25 and $75 \%$ of the data distribution. The horizontal lines outside of the boxes represent the minimum and maximum values of the dataset that were not outliers.

When considering all of the datasets that cover different spectral regions and endmember selection methods, $1.05 \%$ of the spectra with CR were classified as unmodeled (Table 3 ), and $5.06 \%$ of the spectra from the validation libraries without CR were not modeled by the selected endmembers. It is possible to verify that the data transformation (CR) increased the number of unmodeled spectra for the alluvial SSF $(+1.17 \%)$ and pine $(+0.63 \%)$ classes. The bamboo $(-11.57 \%)$, woodland savanna (- $1.64 \%)$ and submontane SSF (- 5.94\%) classes showed a decrease in the unmodeled spectra.

The VIS-NIR1 data (with and without CR) and the IES endmember selection generated the poorest results regarding the number of unmodeled spectra. Approximately $43 \%$ of the bamboo validation spectra remained unmodeled for the data without CR. MESMA showed the best 
performance when modeling the NIR2-SWIR(CR)/IES data. Only one spectrum from the alluvial SSF class was not modeled.

Table 3

Percentage of unmodeled spectra per class and input data/method separated by treatment with and without continuum removal $(\mathrm{CR})$. Alluv = Alluvial SSF, Bamb = Bamboo, Pine = Slash pine, Submon = Submontane SSF and, Woodl $=$ Woodland savanna.

\begin{tabular}{c|c|c|c|c|c|c}
\hline Input data/Method & Alluv & Bamb & Pine & Submon & Woodl & Overall \\
\hline VIS-NIR1/EMC & 0 & 2.78 & 0 & 0 & 0 & $\mathbf{0 . 6 3}$ \\
\hline VIS-NIR1/IES & 0 & 43.06 & 0 & 12.33 & 6.56 & $\mathbf{1 3 . 9 2}$ \\
\hline NIR2-SWIR/EMC & 0 & 6.94 & 0 & 1.37 & 0 & $\mathbf{1 . 9 0}$ \\
\hline NIR2-SWIR/IES & 0 & 11.11 & 0 & 4.11 & 0 & $\mathbf{3 . 4 8}$ \\
\hline VSWIR/EMC & 1.75 & 4.17 & 0 & 10.96 & 3.28 & $\mathbf{4 . 4 3}$ \\
\hline VSWIR/IES & 8.77 & 4.17 & 0 & 12.33 & 3.28 & $\mathbf{6 . 0 1}$ \\
\hline Overall & $\mathbf{1 . 7 5}$ & $\mathbf{1 2 . 0 4}$ & $\mathbf{0}$ & $\mathbf{6 . 8 5}$ & $\mathbf{2 . 1 9}$ & $\mathbf{5 . 0 6}$ \\
\hline Input data/Method & Alluv & Bamb & Pine & Submon & WoodI & Overall \\
\hline VIS-NIR1(CR)/EMC & 3.51 & 0 & 0 & 0 & 0 & $\mathbf{0 . 6 3}$ \\
\hline VIS-NIR1(CR)/IES & 1.75 & 2.78 & 3.77 & 4.11 & 3.28 & $\mathbf{3 . 1 6}$ \\
\hline NIR2-SWIR(CR)/EMC & 3.51 & 0 & 0 & 0 & 0 & $\mathbf{0 . 6 3}$ \\
\hline NIR2-SWIR(CR)/IES & 1.75 & 0 & 0 & 0 & 0 & $\mathbf{0 . 3 2}$ \\
\hline VSWIR(CR)/EMC & 3.51 & 0 & 0 & 1.37 & 0 & $\mathbf{0 . 9 5}$ \\
\hline VSWIR(CR)/IES & 3.51 & 0 & 0 & 0 & 0 & $\mathbf{0 . 6 3}$ \\
\hline Overall & $\mathbf{2 . 9 2}$ & $\mathbf{0 . 4 6}$ & $\mathbf{0 . 6 3}$ & $\mathbf{0 . 9 1}$ & $\mathbf{0 . 5 5}$ & $\mathbf{1 . 0 5}$ \\
\hline
\end{tabular}

4.2.2. Invasive species discriminant spectral features and their spectral relationships with the native woody formations

The VSWIR spectra of the individual endmembers (single species) selected using EMC are discriminated by their differences in reflectance (Fig. 4). As indicated by the previous sections, the spectral differences are more evident in the IR spectral region, where the bamboo had the highest reflectance, and the pine had the lowest reflectance. At the crown scale, the bamboo stands out due to its high GV presence, lower NPV presence and near-zero shade fractions. Pine shows larger NPV expression and higher shade. The diversity of the species and spectral behaviors in the canopy of the woodland and forest formations hinder conclusions based on spectral patterns within the classes that could distinguish them from the invasive species and each other. 


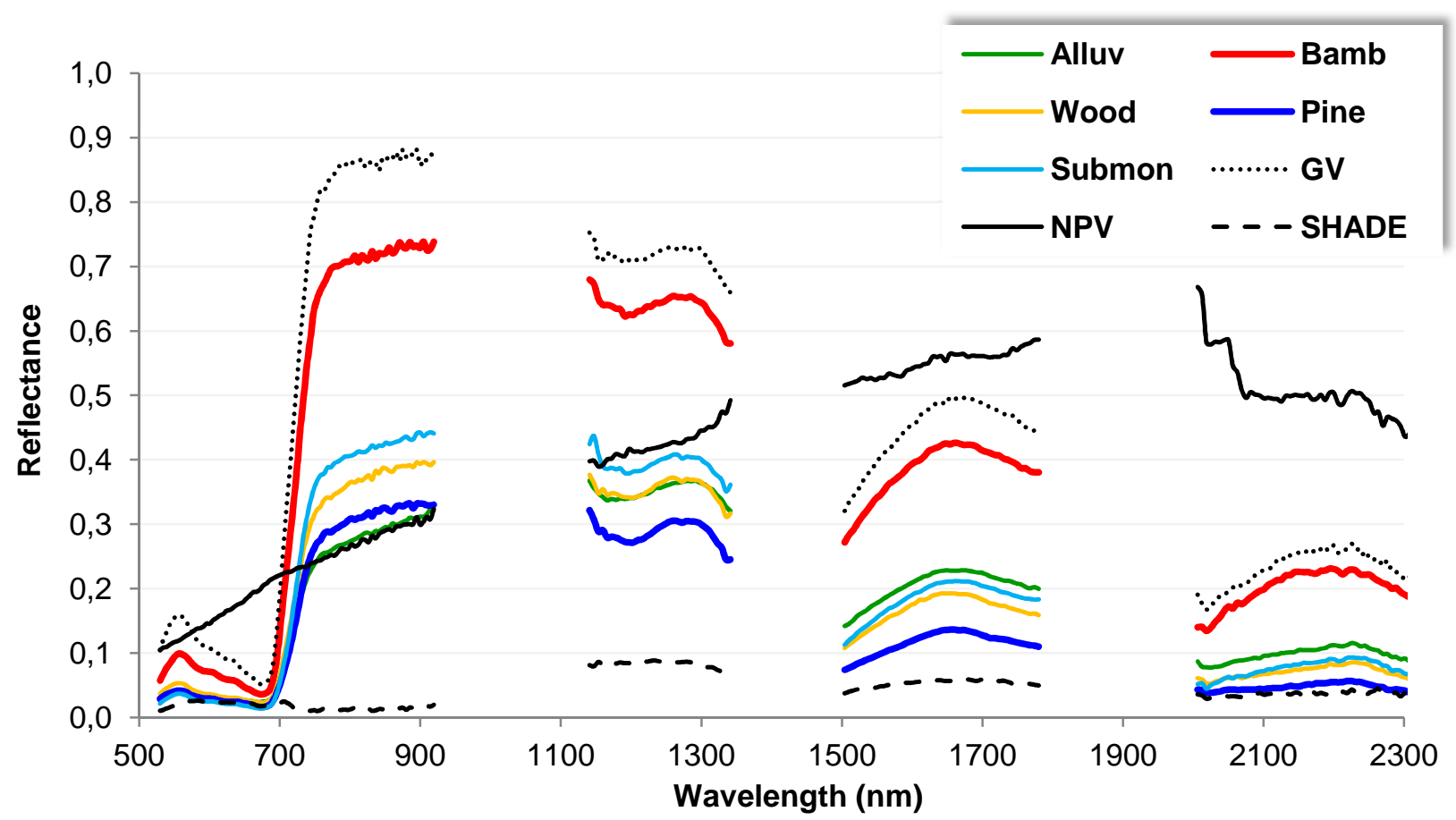

Fig. 4. Endmembers selected using EMC for alluvial SSF (Alluv), bamboo (Bamb), Woodland savanna (Woodl), pine (Pine) and submontane SSF (Submon) classes and endmembers of green vegetation (GV), nonphotosynthetic vegetation (NPV) and shade extracted from the hyperspectral image.

The invasive species were not confused with one another when the NIR2-SWIR dataset was used, regardless of the data normalization (with or without $C R$ ) or endmember selection method (EMC or IES). These classes were classified correctly when using the VSWIR dataset with CR. A maximum of three pine spectra (from its 53 validation spectra) were erroneously assigned to the bamboo class when using the original VSWIR reflectance data. When using the VIS-NIR1 dataset separately, a maximum of 16 pine spectra (from 53 validation spectra) were misclassified as members of the bamboo class (VIS-NIR1/EMC), and 10 spectra from the bamboo class validation spectral library (72 spectra) were grouped within the pine class (VIS-NIR1(CR)/IES).

After analyzing the best results obtained per spectral region while classifying the invasive species, specifically the results with the highest Producer (based on omission errors) and User accuracies (commission errors), a larger spectral omission for the classes of invasive species could be verified. A maximum of sixteen spectra (from 72 validation spectra) were omitted from the bamboo class and assigned to the woodland savanna class (VIS-NIR1(CR)/EMC), while a maximum of seven spectra (from 53 validation spectra) were omitted from the submontane SSF class and assigned to the pine class (VSWIR(CR)/IES).

The largest spectral confusion with the bamboo and pine classes occurred with the woodland savanna class, regardless of the spectral coverage of the dataset employed. The number of bamboo 
spectra erroneously assigned to the woodland savanna class was significantly higher than that assigned to the alluvial SSF $(\alpha=0.01)$ and submontane SSF $(\alpha=0.05)$. Additionally, more pine spectra were assigned to the woodland savanna class than to the SSF classes (statically significant differences at $\alpha=0.05)$. No statistical significance was observed between the number of pine spectra misclassified as alluvial and submontane SSF $(\alpha=0.05)$ (Fig. 5). The classification performed using the NIR2-SWIR data with the CR and EMC endmember selection method was the only process during which the bamboo class was not misclassified as the alluvial SSF class.
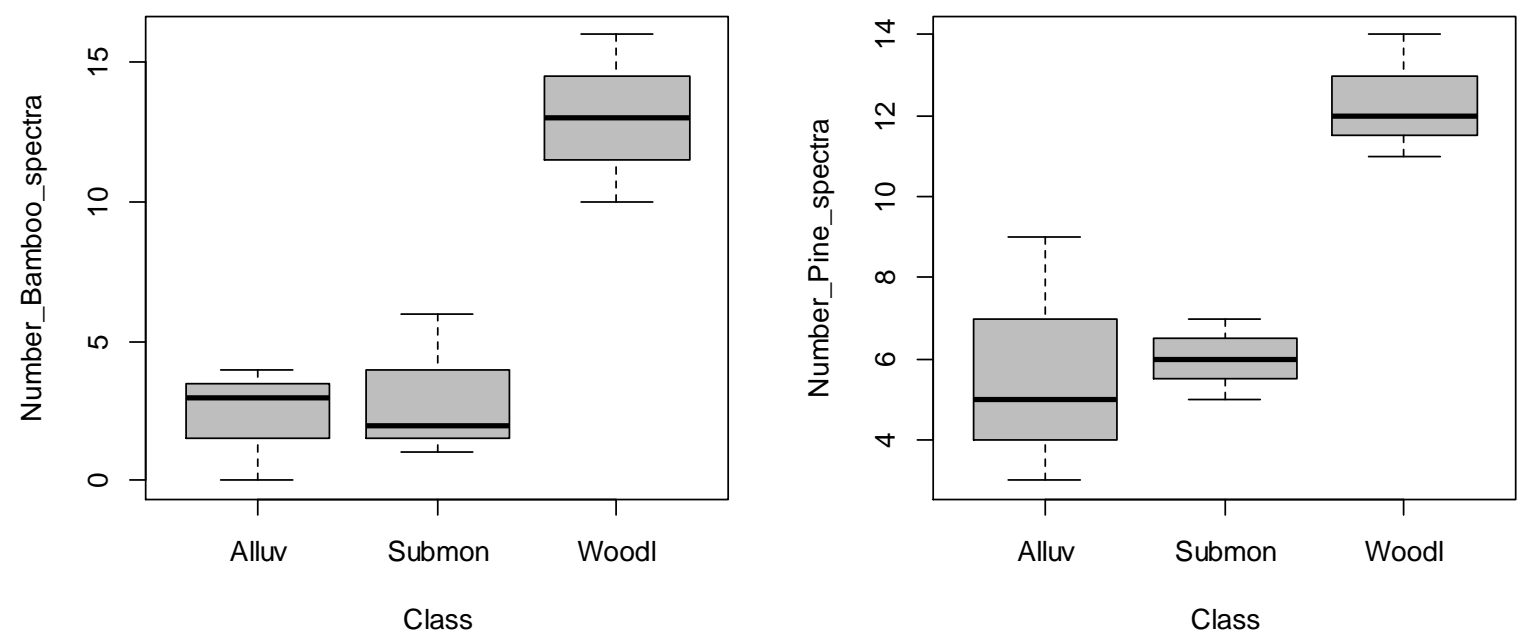

Fig. 5. Number of spectra omitted from the classes of invasive species (bamboo and pine) and assigned to the classes of woody formation (alluvial SSF (Alluv), submontane SSF (Submon) and woodland savanna (Woodl)). The central horizontal line denotes the median of the dataset. The lower and upper edges of the boxes indicate the interval between 25 and $75 \%$ of the data distribution. The horizontal lines outside the boxes indicate the minimum and maximum values of the dataset that were not outliers.

A maximum of four spectra from the alluvial SSF class were incorrectly assigned to the bamboo class, while three woodland savanna spectra and one submontane SSF spectrum were assigned to the bamboo class. A maximum of seven spectra from the submontane SSF class and two spectra from the woodland savanna class were misclassified within the pine class. No spectra from the alluvial SSF class were assigned to the pine class. However, the number of spectra from the native formations classes erroneously assigned either to bamboo or pine classes was not statistically significant. 


\subsubsection{Invasive species classes accuracy assessment}

The VSWIR and NIR2-SWIR datasets provided the highest accuracy for classifying bamboo. These datasets also showed the lowest spectral commission errors with CR while using the EMC method for endmember selection (User accuracy $=98.11 \%($ VSWIR) and $90.48 \%$ (NIR2-SWIR)), as well as the lowest spectral omission errors without CR while using the IES method (Producer accuracy $=94.44 \%(\mathrm{VSWIR})$ and $86.11 \%(\mathrm{NIR} 2-\mathrm{SWIR}))$. Using the VIS-NIR1 dataset with CR and IES the bamboo class displayed the worst spectral modeling; $95.83 \%$ of its validation spectra were omitted or unmodeled (Fig. 6).

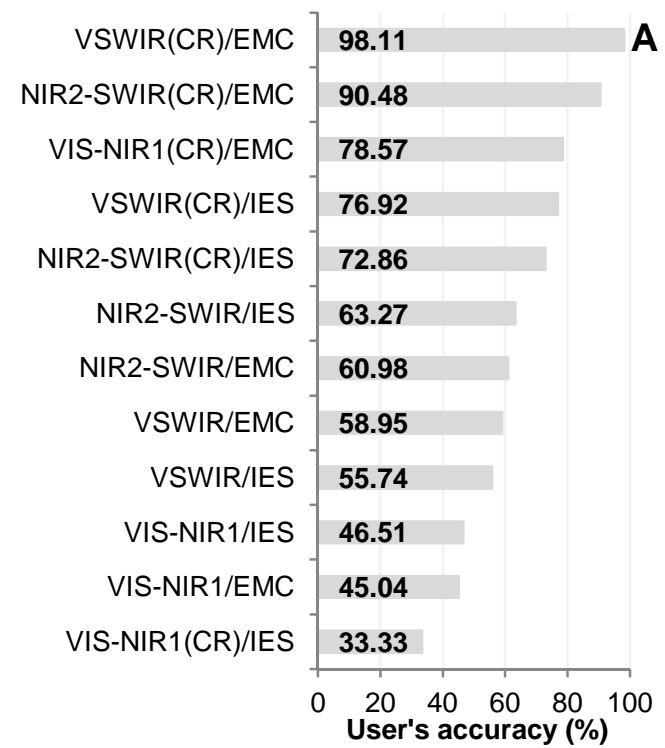

\begin{tabular}{|c|c|}
\hline VSWIR/IES & 94.44 \\
\hline NIR2-SWIR/IES & 86.11 \\
\hline VSWIR(CR)/IES & 83.33 \\
\hline VIS-NIR1/EMC & 81.94 \\
\hline NIR2-SWIR(CR)/EMC & 79.17 \\
\hline VSWIR/EMC & 77.78 \\
\hline VSWIR(CR)/EMC & 72.22 \\
\hline NIR2-SWIR(CR)/IES & 70.83 \\
\hline NIR2-SWIR/EMC & 69.44 \\
\hline VIS-NIR1(CR)/EMC & 61.11 \\
\hline VIS-NIR1/IES & 27.78 \\
\hline VIS-NIR1(CR)/IES & 4.17 \\
\hline
\end{tabular}

Fig. 6. User (A) and Producer accuracy (\%) (B) of the spectral classifications produced for the bamboo class based on the different input data (VIS-NIR1, NIR2SWIR or VSWIR, with or without CR)/endmember selection method (EMC or IES) ranked from highest to lowest.

The classification accuracies of the pine class strongly depended on the NIR2-SWIR region for spectral discrimination. The highest User and Producer accuracies were achieved while using the NIR2-SWIR dataset (i) with CR and IES (with no spectral commission errors, user accuracy $=100 \%$ ) and (ii) with CR and EMC (where a small number of spectra were confused by other classes or unmodeled; producer's accuracy $=71.70 \%$ ) (Fig. 7). Using VIS-NIR1 with CR and EMC generated the lowest classification accuracy for the pine class: $88.68 \%$ of its spectra were assigned to other classes or unmodeled; $76 \%$ of the spectra classified within the pine class were incorrectly modeled. 


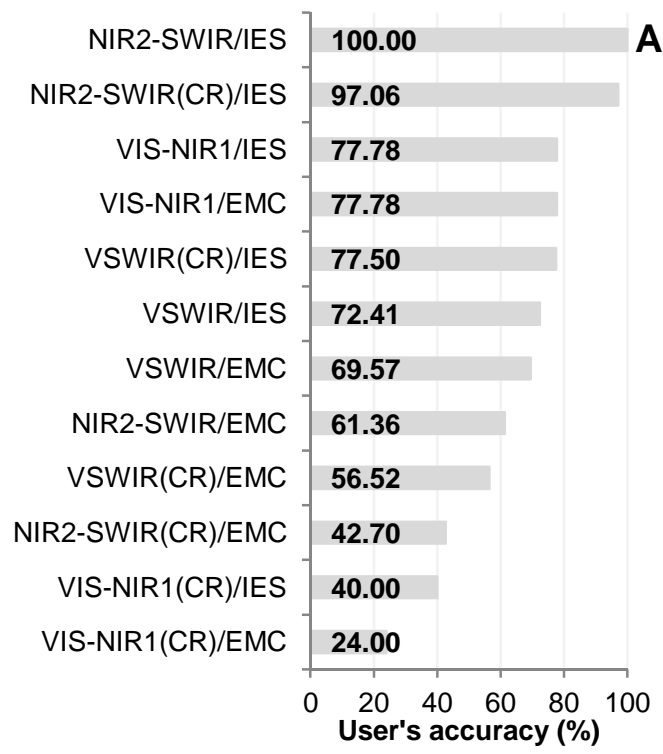

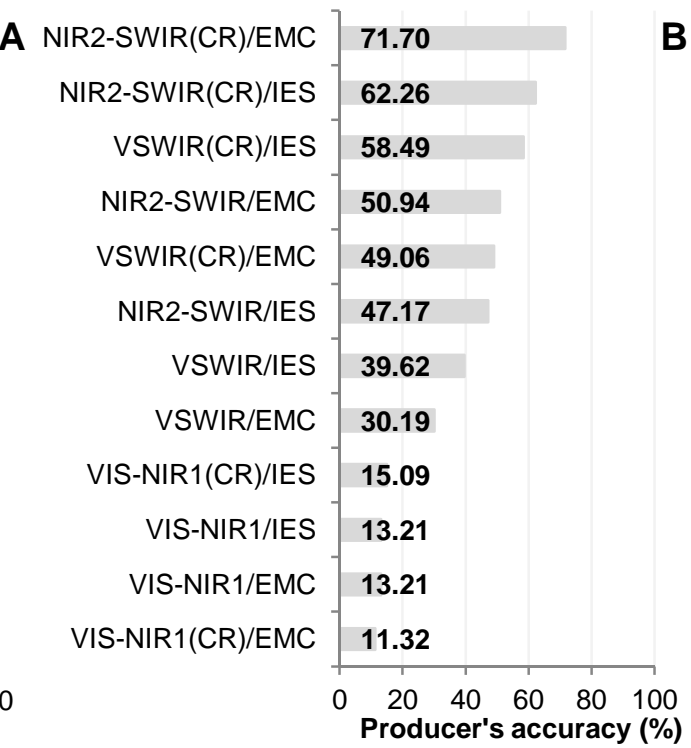

Fig. 7. User (A) and Producer accuracy (\%) (B) of the spectral classifications produced for the pine class based on the different input data (VIS-NIR1, NIR2SWIR or VSWIR, with or without CR)/endmember selection method (EMC or IES) ranked from highest to lowest.

The most accurate two-endmember classification for the bamboo class was based on the VSWIR (CR) data while using endmembers selected by EMC. The spectral classification for this dataset showed an overall accuracy of $64.56 \%$ (Kappa coefficient $=0.558$ ) and the bamboo class exhibited a User accuracy of $98.11 \%$ and Producer accuracy of $72.22 \%$. The pine spectra were best classified with the NIR2-SWIR (CR) data while using endmembers selected through the IES method. Based on these data, the overall accuracy was 63.92\% (Kappa coefficient $=0.549$ ) with a User accuracy of $97.06 \%$ and a Producer accuracy of $62.26 \%$ for the pine class.

The most accurate results revealed that a large number of invasive species spectra were omitted from their original classes and erroneously assigned to the native formations classes; 10 spectra (13.9\%) from the bamboo class and 12 spectra (22.6\%) from the pine class were erroneously classified within the woodland savanna class, followed by the misclassifications within the submontane SSF class (06 spectra (8.3\%) from the bamboo class and 05 spectra (9.4\%) from the pine class) and alluvial SSF class (04 spectra (5.6\%) from the bamboo class and 03 spectra $(5.7 \%)$ from the pine class). In contrast, only one alluvial SSF spectrum (1.8\% of its validation spectra) was erroneously assigned as bamboo, and one submontane SSF spectrum (1.4\%) assigned to the pine class.

\subsection{Image spectral unmixing via three-endmember models}

The bamboo and pine fractions were mapped based on the input data while using the best set of endmembers for classifying the target species during two-endmember modeling (see previous 
section). The image unmixing was performed with three endmembers: the targeted invasive species class, other vegetation classes and photometric shade. The endmembers modeled within class spectra with RMSE $\leq 0.025$ were used. The shade fraction was normalized to zero. Only the GV fractions, which were the target invasive species and other vegetation types, were preserved in the image. The final bamboo and pine fraction maps are illustrated in Figs. 8 and 9, respectively.

The critical areas of colonization by the target invasive species, in addition to their plantation areas, displayed pixels with high abundances of their spectral fractions. The invasive species have primarily colonized a large open and drained sector of the floodplain in the central sector of the study area (Figs. 8 and 9). Although the target species were well mapped, the other vegetation types showed high abundances of the invasive species fractions. Pixels representing "Bambuíra" species, which is in the same subfamily as Dendrocalamus sp., also displayed high abundances of the bamboo fraction. The pixels related to other Pinus spp. plantations (e.g., P. caribaea and P. hondurensis) and old Eucalyptus sp. plantations revealed a high abundance of pine fractions.

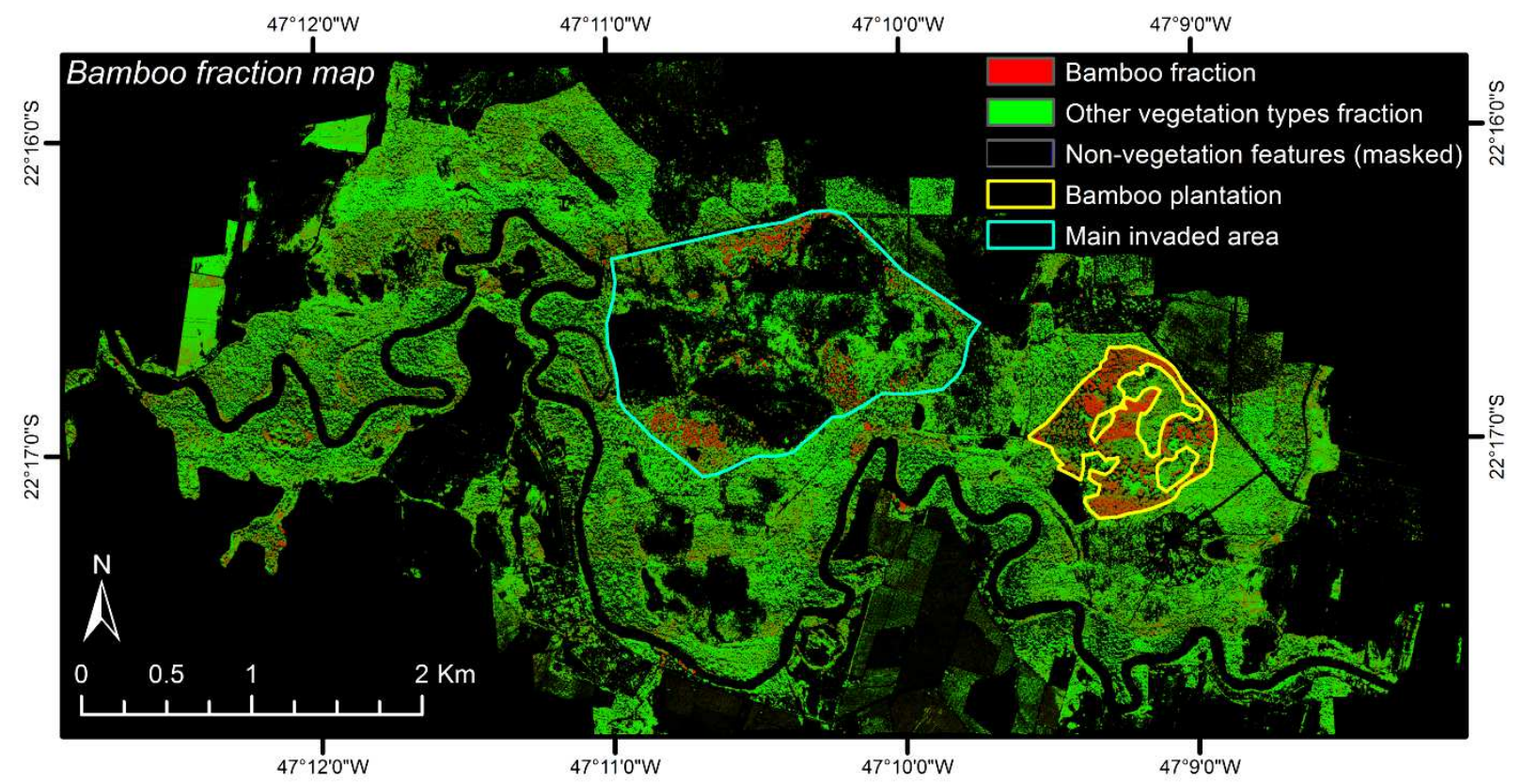

Fig. 8. Spectral fraction map (based on the VSWIR(CR)/EMC data) of the invasive species Dendrocalamus sp. bamboo (in red) and other types of vegetation (in green) in the Mogi-Guaçu Ecological Park, Brazil. Polygons: bamboo plantation (yellow) and the main area invaded by the target exotic species (cyan). 


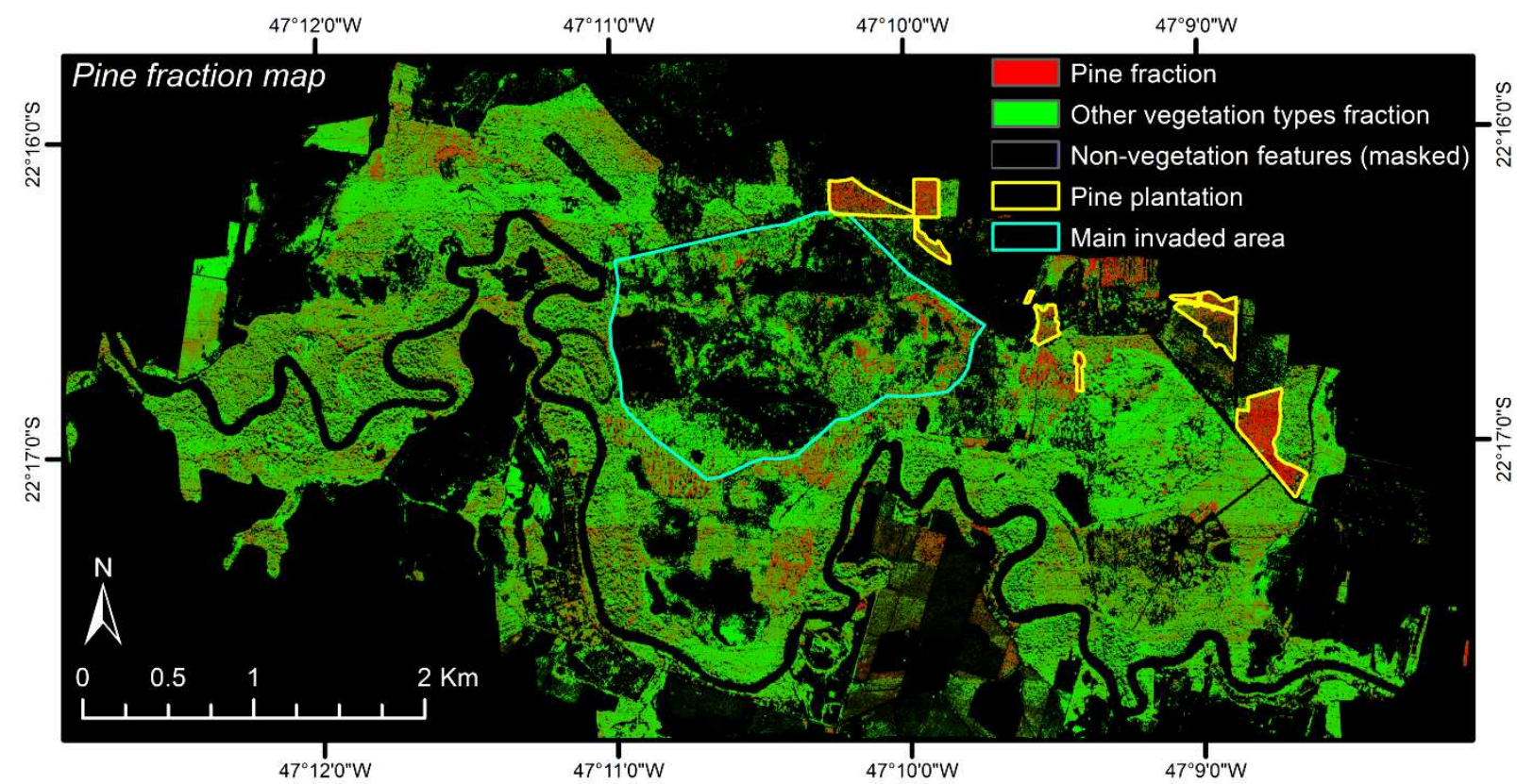

Fig. 9. Spectral fraction map (based on the NIR2-SWIR(CR)/IES data) of the invasive species Pinus elliottii L. slash pine (in red) and other types of vegetation (in green) in the Mogi-Guaçu Ecological Park, Brazil. Polygons: pine plantations (yellow) and the main area invaded by the target exotic species (cyan).

\subsubsection{Fraction images assessment at the pixel and crown scales}

The pixel-based fraction images were assessed by analyzing the sub-pixel GV fractions (target invasive species and other vegetation types) abundances at the pixel and crown scales.

Based on the bamboo fraction map (VSWIR(CR)/EMC), the bamboo validation pixels $(n=646)$ showed an average sub-pixel fraction of $66.2 \%$ (maximum value of $94.9 \%$ ). Some $81.0 \%$ of the bamboo validation pixels displayed bamboo sub-pixel fractions above $50 \%$ and $50.2 \%$ above $70 \%$. The validation pixels of the other vegetation classes in the same map showed bamboo sub-pixel fraction averages of $30.3 \%$ (woodland savanna, of 545 pixels), $27.3 \%$ (submontane SSF, $n=624$ ), $26.9 \%$ (alluvial SSF, $n=472$ ) and $22.0 \%$ (pine, $n=473$ ). The woodland savanna class had $10.8 \%$ of its validation pixels modeled by $50 \%$ or more of the bamboo fraction, while $9.8 \%$ of the submontane SSF pixels, $9.3 \%$ of the alluvial SSF pixels and $2.5 \%$ of the pine pixels showed the same bamboo abundance. Four pixels present in the alluvial SSF crowns were completely represented by the shade fraction; they did not show any GV fraction.

The bamboo validation crowns $(n=72)$ on the final bamboo fraction map had an average subpixel fraction of $66.0 \%$ and a maximum of $84.9 \%$. In addition, $86.1 \%$ of the bamboo validation crowns were modeled by more than $50 \%$ of the bamboo fraction; $48.8 \%$ of these crowns displayed bamboo fractions above $70 \%$. The crowns of the other vegetation classes showed bamboo sub-pixel fraction 
averages of $29.9 \%$ (woodland savanna, $n=61$ ), $27.3 \%$ (submontane SSF, $n=73$ ), $26.4 \%$ (alluvial SSF, $n=57$ ) and $22.1 \%$ (pine, $n=53$ ). Only $3.3 \%$ of the woodland savanna species crowns displayed bamboo sub-pixel fractions above $50 \%$, and $45.9 \%$ were above $30 \%$. Two alluvial crowns showed shade fractions as their pixel-based models (Fig. 10A).

On the pine fraction map (NIR2-SWIR(CR)/IES), the pine validation pixels exhibited an average sub-pixel fraction of $63.3 \%$ with a maximum of $94.8 \%$ for the modeled pixels. Approximately $4.7 \%$ of the pixels present in the crowns were not modeled; $76.4 \%$ of all of the pine validation pixels (including modeled and unmodeled pixels) were modeled by $50 \%$ (or more) of its fraction $(36.4 \%$ of them showed pine fractions above $70 \%$ ). The woodland savanna validation pixels had an average pine fraction of $35.8 \%$ (among its $96.0 \%$ of modeled pixels); the submontane SSF pixels averaged $30.5 \%(97.8 \%$ of modeled pixels), the alluvial SSF pixels averaged $22.3 \%(78.6 \%)$ and the bamboo pixels averaged $21.1 \%(95.4 \%)$. The woodland savanna class had $21.5 \%$ of its pixels (among modeled and unmodeled) with pine fractions above $50 \%$, followed by submontane SSF $(9.9 \%$ of its pixels), bamboo (3.3\%) and alluvial SSF (1.7\%).

The pine validation crowns had an average sub-pixel fraction of $64.0 \%$ (maximum value of $87.6 \%$ ) on their class final fraction map. Approximately $86.8 \%$ of the pine validation crowns displayed sub-pixel pine fractions above 50\% (39.6\% were above $70 \%)$. Only the alluvial class had unmodeled crowns $(8.8 \%$ of its validation crowns) on the pine final map. The woodland savanna validation crowns showed an average of pine sub-pixel fraction of $35.1 \%$, while the submontane SSF crowns averaged $30.3 \%$, the alluvial SSF crowns averaged $24.1 \%$ (among the modeled crowns) and the bamboo crowns averaged $20.9 \%$. The woodland savanna $(9.8 \%)$ and submontane SSF $(1.4 \%)$ species crowns also showed maxima of pine sub-pixel fraction above $50 \%$, which was not observed for the alluvial SSF species crowns or the bamboo crowns (Fig. 10B). 

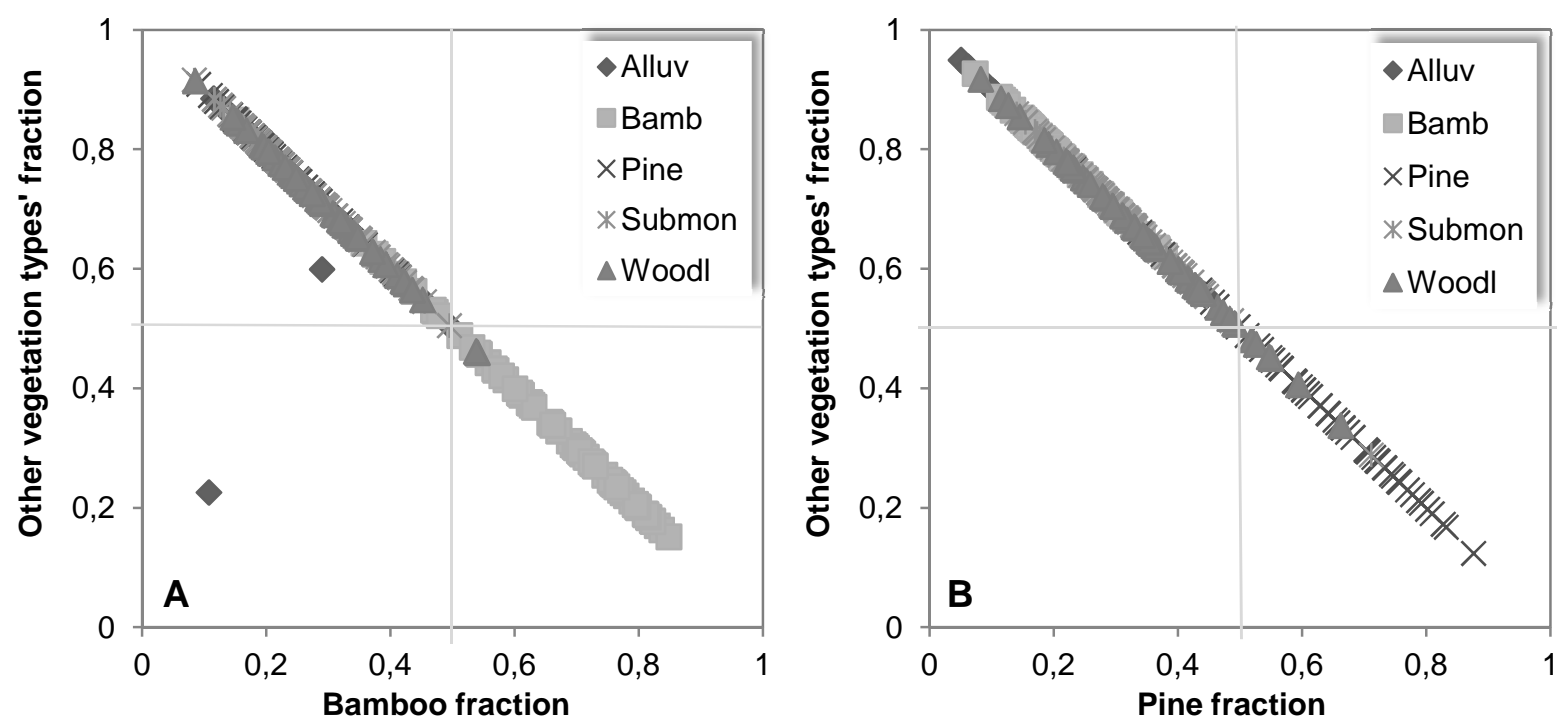

Fig. 10. Scatterplots showing the green vegetation two-endmember (target invasive species and other vegetation types) sub-pixel composition of the modeled validation crowns from the alluvial SSF (Alluv, $n=57$ for $A$ and $n=52$ for B), bamboo (Bamb, $n=72$ ), woodland savanna (Woodl, $n=61$ ), slash pine (Pine, $n=53$ ) and submontane SSF (Submon, $n=73$ ) classes. The data collected on the final map were the VSWIR(CR)/EMC for bamboo $(A)$ and NIR2-SWIR(CR)/IES for pine (B).

\section{Discussion}

The higher number of endmembers yielded by the EMC endmember libraries relative to IES libraries can be explained by the increased selection of spectra (more than one spectrum in some cases) with positive CoBIn/CoBOut ratios. According to Schaaf et al. (2011), EMC may fail due to the subjectivity of its manual selection process, whereas IES is a fully automated process, rendering it more accurate (Roth et al., 2012). The higher variance in the selected endmembers for the CR data relative to the reflectance (without $\mathrm{CR}$ ) data indicated that the variability of selected endmembers increases when enhancing spectral variations yielded by continuum removal, regardless of the spectral range.

Low overall accuracies and Kappa coefficients were expected in the two-endmember classifications because highly biodiverse vegetation classes (native woody formations) were used and the reference data at the crown scale that represent the maximum variability within class were selected. When a particular class is the focus of classification, the User and Producer accuracies become the most important metrics for determining the accuracy of a specific map (Congalton, 1991). Moreover, MESMA executes pixel-based classifications that have shown lower accuracies in certain studies when compared to object-based classifications that use most abundant class or a pixel majority within an object (e.g., Hamada et al., 2011). 
The higher two-endmember overall classification accuracies (with lower variances) observed for the NIR2-SWIR dataset relative to the VIS-NIR1 dataset revealed the importance of the infrared (IR) spectral range when discriminating between the studied classes. The VIS-NIR1 dataset includes spectral channels that encompass green, red and near infrared wavelengths. In this range, the spectral differences between classes occur due to the absorption of leaf pigments (especially chlorophylls at approximately $680 \mathrm{~nm}$ ) with variations in the red-edge region and albedo. The NIR2SWIR dataset in addition to the albedo variation can exhibit differences in the absorption features caused by water, nitrogen, proteins and lignocellulose compounds; these variants are closely related to the structural characteristics of the leaf and crown. The variation between the shade, green vegetation (GV) and non-photosynthetic vegetation (NPV) fractions is also discriminatory in this spectral region and can be influenced by the phenology of the species. Because three of the five studied vegetation classes represent semideciduous formations, the images were obtained in late autumn when the differences in the senescence and deciduousness between species are evident. Similar to the findings of Clark et al. (2005) and Clark and Roberts (2012), the NIR and the SWIR are essential regions during the spectral detection of species in tropical environments with high structural and phenological diversity in the canopy.

Regarding the number of unmodeled spectra, the bamboo class had the highest number of reflectance spectra unmodeled. After continuum removal, that class displayed the lowest number of unmodeled spectra among all studied classes. The Pine class had all of its reflectance spectra modeled and only VIS-NIR1 continuum-removed spectra unmodeled.

According to Ustin and Gamon (2010), the success when mapping invasive species is strongly related to the spectral variations caused by biochemical and/or structural differences between the invasive and native species. The bamboo endmember has the highest reflectance; it also stands out for its high GV, low NPV fractions and near-zero shade fractions. The pine has the lowest reflectance, showing a greater expression of NPV and higher shade fractions. As observed by several authors at different scales (e.g., Williams et al.,1991; Lawrence et al., 1993; and Roberts et al., 2004), the scattering of electromagnetic energy has a lower impact on conifers than on broadleaf plants due to the lower transmittance and greater absorptance caused by the structure of the needles and crowns of the conifers. In contrast, the native woody vegetation did not exhibit spectral patterns that could distinguish them from the invasive species classes or each other. The combined effect of the high 
biotic and abiotic diversity in tropical environments promotes the biogeochemical heterogeneity on several scales (Townsend et al., 2008). Therefore, the structural and chemical variations in the crown that affect the reflectance of the plant species and the communities in the landscape remain poorly understood in tropical formations with highly diverse canopies (Asner, 2008; Asner and Martin, 2008).

When using the best model for each spectral range, the invasive species were overestimated in the native formations. The commission errors in the spectra of both invasive species were statistically higher in the woodland savanna relative to the submontane and alluvial SSF classes. The large number of bamboo spectra erroneously assigned to the woodland savanna class was also statistically significant compared to those erroneously assigned to the submontane SSF $(\alpha=0.05)$ and alluvial SSF ( $\alpha=0.01)$ classes. Unlike the woodland savanna and submontane SSF, the alluvial SSF species occur at a high frequency in seasonally flooded environments, where the species commonly present strong expressions of the NPV and shade fractions. The proportions of these fractions in the bamboo crowns are not large. Based on the most accurate two-endmember MESMA classifications, the bamboo spectra were best classified when using the VSWIR data with CR and employing endmembers selected through the EMC method. The pine spectra were best classified using the NIR2-SWIR data with the CR and endmembers selected by the IES method.

The best spectral classifications of the invasive species were used for MESMA image unmixing with three-endmembers (target invasive species, other vegetation types and shade). The resulting fraction images showed pixels with higher abundances of the invasive species fractions where they are invading on a massive scale, as well as in their plantation areas. As predicted during two-endmember modeling, the invasive species were overestimated in the fraction maps, particularly in the woodland savanna pixels. Old plantations of Eucalyptus spp. also had their pixels modeled with a high abundance of the pine fraction. The Eucalyptus spp. are also exotic, but they did not exhibit invasive behavior in this area. The high pine fraction abundances indicate that those species are spectrally more similar to pine than the native species or bamboo. Adult Eucalyptus spp. individuals exhibit open crown structures with numerous shade and NPV fractions, matching what was observed for species in the Pinus genus. The fraction images generated by MESMA appeared to be well mapped across the flight lines, even when dealing with multiple flight lines with significant variations in brightness; these differences are due to the variable viewing geometry. These results demonstrate that the spectral mixture analysis, which allows multiple endmembers per target, performs well. 
Therefore, having well distributed training samples MESMA can overcome these differences in brightness across the flight lines.

Determining the impact of native woody formations on the spectral unmixing of invasive species was relevant. The number of invasive species spectra erroneously grouped with the native woody formations during the two-endmember classification was significantly different between formations and independent of the spectral range. This finding persisted for the most accurate results when analyzing the two-endmember spectral classifications and the three-endmember unmixed images at the pixel and crown scales (Fig. 11). The models generated for the woodland savanna species have higher sub-pixel abundance for both invasive species fractions compared to the models generated for the submontane and alluvial SSF species. Therefore, the relationships between the green vegetation (GV) spectral types present in the landscape must be analyzed a priori when mapping the invasive species in environments that have highly diverse native formations, such as the Cerrado biome. Ignoring these variations can strongly influence the analyses of the spatial distributions and ecological relationships for invasive species.
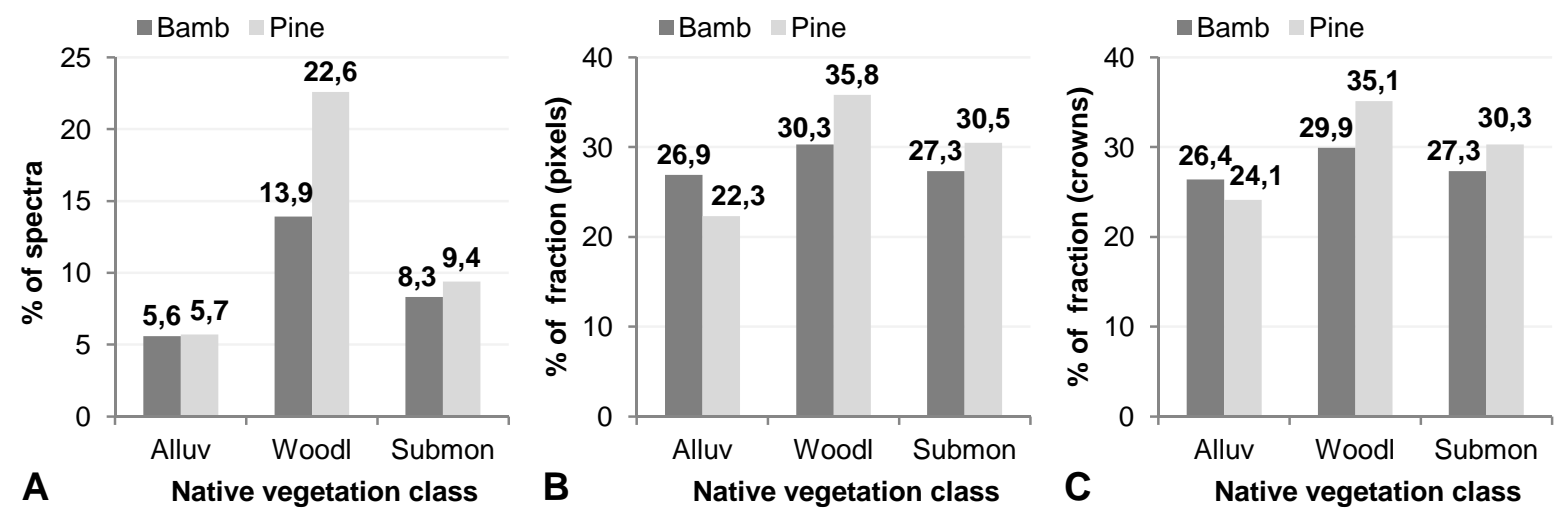

Fig. 11. Percentage of invasive species spectra erroneously assigned to the native vegetation classes in the twoendmember MESMA classification (A) and sub-pixel abundance averages of the invasive species fractions for the native vegetation classes observed in the three-endmember MESMA unmixed images at the pixel (B) and crown scales (C). Bamb = Bamboo, Alluv = Alluvial SSF, Woodl $=$ Woodland savanna and Submon $=$ Submontane SSF .

Despite the positive results achieved here, the technology and analytical methods to identify individual tree crown species is rapidly advancing (Baldeck et al., 2014). The use of temporal hyperspectral data has shown superior results against unitemporal data for invasive species discrimination in Hawaii, also using MESMA (Somer and Asner, 2013 and 2014). Baldeck et al. (2014) used a twofold Support Vector Machine model on VIS-NIR hyperspectral and Lidar data for African 
savanna crown-level classification; more than 500,000 tree and shrub crowns were mapped with $76 \%$ of accuracy.

\section{Conclusions}

This study demonstrates that Dendrocalamus sp. (bamboo) and Pinus elliottii L. (slash pine), which are invasive species in neotropical landscapes, can be mapped via pixel-based MESMA models with two or three endmembers. The spectral mixture relationships between the exotic species and the different native woody formations were also verified. The spectral unmixing performed between the investigated classes was more accurate when using the NIR2-SWIR data, which was the spectral region where the invasive species showed well-defined spectral patterns. At the crown scale, the bamboo stands out due to its high GV presence, lower NPV presence and near-zero shade fractions. Pine exhibits a higher expression of NPV and shade fractions in its spectrum. Based on the most accurate models for classifying invasive species in each spectral range, the invasive species spectra are erroneously assigned to the woodland savanna class more frequently relative to the alluvial and submontane SSF classes. Therefore, the spectral fractions of the invasive species are overestimated more on the woodland savanna formations during image unmixing.

The bamboo spectra were best classified by the VSWIR data with CR and endmembers selected through EMC, while pine was best classified by the NIR2-SWIR with CR and endmembers selected by IES. The most accurate results obtained during the two-endmember modeling were realistically translated into the pixel-based spectral unmixing of the images by using models with three endmembers (target invasive species, other vegetation types and photometric shade). Therefore, the models generated for the woodland savanna species (as at pixel scale as at crown scale) have higher sub-pixel abundances for both invasive species fractions relative to the models generated for the submontane and alluvial SSF species.

This research indicates that this method should be applied further in highly biodiverse landscapes, such as the Cerrado biome, that have been severely affected by the invasion of exotic species. However, the best maps for each target species can be generated using various spectral ranges and different endmember selection methods. Moreover, in highly biodiverse environments, the spectral mixture relationships between invasive species and main native formations must be assessed 
before modeling the image. Failing to account for these relationships can erroneously influence the spatial distribution and ecological interactions analyses of invasive species.

\section{Acknowledgments}

The authors thank the São Paulo Research Foundation (Fundação de Amparo à Pesquisa do Estado de São Paulo - FAPESP) for supporting the project (2010/51758-2) and to the FOTOTERRA/SpecTIR team, particularly Guilherme Pinho and Conrad Wright, for providing the images used during this study. We also acknowledge the Visualization \& Image Processing for Environmental Research Laboratory (VIPER Lab) of the University of California, Santa Barbara (UCSB), the Laboratory of Reflectance Spectroscopy (Laboratório de Espectroscopia de Reflectância - LER) of the State University of Campinas (Universidade Estadual de Campinas - UNICAMP), the Laboratory of Geological Computing (Laboratório de Informática Geológica - LIG) of the University of São Paulo (Universidade de São Paulo - USP) and the Forest Institute of the State of São Paulo (Instituto Florestal do Estado de São Paulo - IF-SP). The authors also thank their collaborators, including Dirceu de Souza for fieldwork and Kelly Roth and Seth Peterson for data processing. Cibele Hummel do Amaral thanks FAPESP for a doctoral scholarship (2010/51718-0). Carlos Roberto de Souza Filho and Teodoro Isnard Ribeiro de Almeida thank the Brazilian National Council for Scientific and Technological Development (Conselho Nacional de Desenvolvimento Científico e Tecnológico $\mathrm{CNPq}$ ) for their research grants.

\section{References}

Adams, J. B., Smith, M. O., \& Gillespie, A. R. (1993). Imaging spectroscopy: Interpretation based on spectral mixture analysis. In C. M. Pieters, \& P. A. J. Englert (Eds.), Remote geochemical analysis: Elemental and mineralogical composition. New York: Press Syndicate of the University of Cambridge.

Adams, J. B., Smith, M. O., \& Johnson, P. E. (1986). Spectral mixture modeling: A new analysis of rock and soil types at the Viking Lander 1 site.Journal of Geophysical Research: Solid Earth (1978-2012), 91(B8), 8098-8112.

Asner, G. P. (2008). Hyperspectral remote sensing of canopy chemistry, physiology, and biodiversity in tropical rainforests. In M. Kalacska, \& G. A. Sanchez-Azofeifa (Eds.), Hyperspectral remote sensing of tropical and subtropical forests (pp. 261-296). Boca Raton: CRC Press Taylor \& Francis Group.

Asner, G. P., \& Martin, R. E. (2008). Spectral and chemical analysis of tropical forests: scaling from leaf to canopy levels. Remote Sensing of Environment, 112, 3958-3970. 
Baldeck, C. A., Colgan, M. S., Féret, J. B., Levick, S. R., Martin, R. E., \& Asner, G. P. (2014). Landscape-scale variation in plant community composition of an African savanna from airborne species mapping. Ecological Applications, 24(1), 84-93.

Beck, K. G., Zimmerman, K., Schardt, J. D., Stone, J., Lukens, R. R., Reichard, S., Randall, J., Cangelosi, A. A., Cooper, D., \& Thompson, J. P. (2008). Invasive Species Defined in a Policy Context: Recommendations from the Federal Invasive Species Advisory Committee. Invasive Plant Science and Management, 1(4), 414-421.

Burkett, V. R., Wilcox, D. A., Stottlemyer, R., Barrowa, W., Fagre, D., Baron, J., Price, J., Nielsen, J. L., Allen, C. D., Peterson, D. L., Ruggerone, G. \& Doyle, T. (2005). Nonlinear dynamics in ecosystem response to climatic change: Case studies and policy implications. Ecological Complexity, 2, 357-394.

Clark, M. L, Roberts, D. A., \& Clark, D. B. (2005). Hyperspectral discrimination of tropical rain forest tree species at leaf to crown scales. Remote Sensing of Environment, 96, 375-398.

Clark, M. L. \& Roberts, D. A. (2012). Species-Level Differences in Hyperspectral Metrics among Tropical Rainforest Trees as Determined by a Tree-Based Classifier. Remote Sensing, 4, 1820-1855.

Clark, M. L. (2005). An assessment of Hyperspectral and Lidar Remote Sensing for the Monitoring of Tropical Rain Forest Trees (Doctoral dissertation).Retrieved from Dissertations and Theses database. (UMI No. 3186829).

Clark, R. N., \& Roush, T. L. (1984). Reflectance spectroscopy: Quantitative analysis techniques for remote sensing applications. Journal of Geophysical Research, 89, 6329-6340.

Congalton, R. G. (1991). A review of assessing the accuracy of classifications of remotely sensed data. Remote sensing of environment, 37(1), 35-46.

Congalton, R. G., \& Green, K. (1999). Assessing the accuracy of remotely sensed data: principles and practices. Boca Raton: CRC press.

Curran, P. J., Dungan, J. L., \& Peterson, D. L. (2001). Estimating the foliar biochemical concentration of leaves with reflectance spectrometry. Remote Sensing of Environment, 76, 349-359.

Dennison, P. E., \& Roberts, D. A. (2003a). Endmember selection for multiple endmember spectral mixture analysis using endmember average RMSE. Remote Sensing of Environment, 87, 123135.

Dennison, P. E., \& Roberts, D. A. (2003b). The effects of vegetation phenology on endmember selection and species mapping in southern California chaparral. Remote Sensing of Environment, 87, 295-309.

Dennison, P. E., Halligan, K. Q. \& Roberts, D. A. (2004). A comparison of error metrics and constraints for multiple endmember spectral mixture analysis and spectral angle mapper. Remote Sensing of Environment, 93, 359-367.

Eiten, G. (1963). Habitat flora of Fazenda Campininha. Proceedings of the 1st Symposium on Cerrado (pp. 189-23). São Paulo: USP.

Hamada, Y., Stow, D. A., \& Roberts, D. A. (2011). Estimating life-form cover fractions in California sage scrub communities using multispectral remote sensing. Remote Sensing of Environment, 115(12), 3056-3068.

Hestir, E. L., Khanna, S., Andrew, M. E., Santos, M. J., Viers, J. H., Greenberg, J. A., Rajapakse, S. S., \& Ustin, S.L. (2008). Identification of invasive vegetation using hyperspectral remote sensing in the California Delta ecosystem. Remote Sensing of Environment, 112, 4034-4047.

Huang, Z., Turner, B. J., Dury, S. J., Wallis, I. R., \& Foley, W. J. (2004). Estimating foliage nitrogen concentration from HYMAP data using continuum removal analysis. Remote Sensing of Environment, 93(1), 18-29.

Instituto Florestal do Estado de São Paulo. (2010). Áreas protegidas do Instituto Florestal: Estação Ecológica de Mogi-Guaçu [Protected areas of the Forest Institute: Mogi-Guaçu Ecological Station]. Retrieved from http://www.iflorestal.sp.gov.br/areas_protegidas/index.asp 
Joly, C.A., \& Bicudo, C.E. M. (1999). Biodiversidade do Estado de São Paulo, Brasil: síntese do conhecimento ao final do século XX -vol. 7: Infra-estrutura para conservação da biodiversidade [Biodiversity of the state of São Paulo, Brazil: summary of the knowledge at the end of the $20^{\text {th }}$ century - vol 7: Infrastructure for biodiversity conservation] (1st ed.).São Paulo: FAPESP.

Jordan, C.F. (1969). Derivation of Leaf-Area Index from quality of light on the forest floor. Ecology, 50, 663-666.

Klink, C. A., \& Machado, R. B. (2005). Conservation of the Brazilian Cerrado. Conservation Biology, 19(3), 707-713.

Kokaly, R. F. (2001). Investigating a physical basis for spectroscopic estimates of leaf nitrogen concentration. Remote Sensing of Environment, 75, 153-161.

Kokaly, R. F. (2011). PRISM: Processing routines in IDL for spectroscopic measurements. Retrieved from http://pubs.usgs.gov/of/2011/1155/

Kokaly, R. F., \& Clark, R. N. (1999). Spectroscopic determination of leaf biochemistry using banddepth analysis of absorption features and stepwise multiple linear regression. Remote Sensing of Environment, 67, 267-287.

Kokaly, R. F., Asner, G. P., Ollinger, S. V., Martin, M. E., \& Wessman, C. A. (2009). Characterizing canopy biochemistry from imaging spectroscopy and its application to ecosystem studies. Remote Sensing of Environment, 113, S78-S91.

Kruse, F. A., Lefkoff, A. B., Boardman, J. W., Heidebrecht, K. B., Shapiro, A. T., Barloon, P. J., \& Goetz, A. F. H. (1993). The spectral image processing system (SIPS)-interactive visualization and analysis of imaging spectrometer data. Remote Sensing of Environment, 44(2-3), 145-163.

Lass, L. W., \& Prather, T. S. (2004). Detecting the Locations of Brazilian Pepper Trees in the Everglades with a Hyperspectral Sensor 1. Weed technology, 18(2), 437-442.

Lawrence, W.T., Shimabukuro, Y.E., \& Gao, B. (1993). Analysis of hyperspectral AVIRIS image data over a mixed-conifer forest in Maine. Proceedings of the 7th Brazilian Remote Sensing Symposium (pp. 129-155). São José dos Campos: INPE.

Li, L., Ustin, S. L., \& Lay, M. (2005). Application of multiple endmember spectral mixture analysis (MESMA) to AVIRIS imagery for coastal salt marsh mapping: A case study in China Camp, CA, USA. International Journal of Remote Sensing, 26, 5193-5207.

Mooney, H.A., \& Hobbs, R.J. (2000). Invasive species in a changing world. Washington: Island Press.

Parry, M.L., Canziani, O.F., Palutikof, J.P., van der Linden, P.J., \& Hanson, C. E. (2007). Contribution of Working Group II to the Fourth Assessment Report of the Intergovernmental Panel on Climate Change. United Kingdom and New York: Cambridge University Press.

Pivello, V. R., Carvalho, V. M. C., Lopes, P. F., Peccinini, A. A., \& Rosso, S. (1999). Abundance and distribution of native and invasive alien grasses in a "cerrado' (Brazilian savanna) biological reserve. Biotropica, 31, 71-82.

Pivello, V.R. (2011). Invasões Biológicas no Cerrado Brasileiro: Efeitos da Introdução de Espécies Exóticas sobre a Biodiversidade [Biological invasions in the Brazilian Cerrado: Effects of the Introduction of Exotic Species on Biodiversity]. ECOLOGIA.INFO, 33. Retrieved from http://www.ecologia.info/cerrado.htm

Plourde, L. C., Ollinger, S. V., Smith, M. L., \& Martin, M. E. (2007). Estimating species abundance in a northern temperate forest using spectral mixture analysis. Photogrammetric Engineering and Remote Sensing, 73, 829-840.

$\mathrm{Pu}, \mathrm{R}$. (2011). Detecting and mapping invasive plant species by using hyperspectral data. In P.S. Thenkabail, J.G. Lyon, \& A. Huete (Orgs.), Hyperspectral Remote Sensing of Vegetation (pp. 447466). New York: CRC Press.

R Development Core Team (2008). R: A language and environment for statistical computing. $R$ Foundation for Statistical Computing, Vienna, Austria. Retrieved from http://www.R-project.org/ 
Ramsey III, E., Rangoonwala, A., Nelson, G., \& Ehrlich, R. (2005b). Mapping the invasive species, Chinese tallow, with EO1 satellite Hyperion hyperspectral image data and relating tallow occurrences to a classified Landsat Thematic Mapper land cover map. International Journal of Remote Sensing, 26(8), 1637-1657.

Ramsey III, E., Rangoonwala, A., Nelson, G., Ehrlich, R., \& Martella, K. (2005a). Generation and validation of characteristic spectra from EO1 Hyperion image data for detecting the occurrence of the invasive species, Chinese tallow. International Journal of Remote Sensing, 26(8), 1611-1636.

Ribeiro, J.F.,\& Walter, B.M.T. (2008). As principais fitofisionomias do Bioma Cerrado [The main plant physiognomies of the Cerrado Biome]. In S.M. Sano, S. P. Almeida, \& J. F. Ribeiro (Eds.). Cerrado: ecologia e flora [Cerrado: ecology and flora] (pp. 153-212). Planaltina: EMBRAPACPAC.

Roberts, D. A., Dennison, P. E., Gardner, M., Hetzel, Y. L., Ustin, S. L., \& Lee, C. (2003). Evaluation of the potential of Hyperion for fire danger assessment by comparison to the Airborne Visible Infrared Imaging Spectrometer. IEEE Transactions on Geoscience and Remote Sensing, 41, 1297-1310.

Roberts, D. A., Gamon, J., Keightley, K., Prentiss, D., Reith, E., \& Green, R. O. (1999). AVIRIS landsurface mapping in support of the BOReal Ecosystem-Atmosphere Study (BOREAS). Proceedings of the $8^{\text {th }}$ AVIRIS Earth Science Workshop (pp. 355-364). Pasadena: Jet Propulsion Laboratory.

Roberts, D. A., Gardner, M., Church, R., Ustin, S., Scheer, G., \& Green, R. O. (1998). Mapping Chaparral in the Santa Monica Mountains using multiple endmember spectral mixture models. Remote Sensing of Environment, 65, 267-279.

Roberts, D. A., Halligan, K. Q., \& Dennison, P. E. (2007). ViperTools. Retrieved from http://www.vipertools.org/

Roberts, D. A., Ustin, S. L., Ogunjemiyo, S., Greenberg, J., Dobrowski, S. Z., Chen, J., \& Hinckley, T. M. (2004). Spectral and structural measures of northwest forest vegetation at leaf to landscape scales. Ecosystems, 7(5), 545-8562.

Roberts, D. A., Quattrochi, D. A., Hulley, G. C., Hook, S. J. \& Green, R. O. (2012). Synergies between VSWIR and TIR data for the urban environment: An evaluation of the potential for the Hyperspectral Infrared Imager (HyspIRI) Decadal Survey mission, Remote Sensing of Environment, 117, 83-101.

Rosso, P. H., Ustin, S. L., \& Hastings, A. (2005). Mapping marshland vegetation of San Francisco Bay, California, using hyperspectral data. International Journal of Remote Sensing, 26, 51695191.

Roth, K. L., Dennison, P. E. \& Roberts, D. A. (2012). Comparing endmember selection techniques for accurate mapping of plant species and land cover using imaging spectrometer data. Remote Sensing of Environment, 127, 139-152.

Schaaf, A. N., Dennison, P. E., Fryer, G. K., Roth, K. L., \& Roberts, D. A. (2011). Mapping plant functional types at three spatial resolutions using multiple endmember spectral mixture analysis. GIScience and Remote Sensing, 48, 324-344.

Smith, M. O., Ustin, S. L., Adams, J. B., \& Gillespie, A. R. (1990a). Vegetation in deserts: I. A regional measure of abundance from multispectral images. Remote sensing of Environment, 31(1), 1-26.

Smith, M. O., Ustin, S. L., Adams, J. B., \& Gillespie, A. R. (1990b). Vegetation in deserts: II. Environmental influences on regional abundance. Remote sensing of Environment, 31(1), 27-52.

Somers, B., \& Asner, G. P. (2013). Multi-temporal hyperspectral mixture analysis and feature selection for invasive species mapping in rainforests. Remote Sensing of Environment, 136, 14-27.

Somers, B., \& Asner, G. P. (2014). Tree species mapping in tropical forests using multi-temporal imaging spectroscopy: Wavelength adaptive spectral mixture analysis. International Journal of Applied Earth Observation and Geoinformation, 31, 57-66.

Somers, B., Asner, G. P., Tits, L., \& Coppin, P. (2011). Endmember variability in spectral mixture analysis: A review. Remote Sensing of Environment, 115(7), 1603-1616.

Thenkabail, P.S., Lyon, J.G. \& Huete, A. (2011). Hyperspectral Remote Sensing of Vegetation. New York: CRC Press. 
Tits, L., De Keersmaecker, W., Somers, B., Asner, G. P., Farifteh, J., \& Coppin, P. (2012). Hyperspectral shape-based unmixing to improve intra-and interclass variability for forest and agroecosystem monitoring. ISPRS Journal of Photogrammetry and Remote Sensing, 74, 163-174.

Townsend A. R., Asner G. P., \& Cleveland, C. C. (2008). The biogeochemical heterogeneity of tropical forests. Trends in Ecology and the Environment, 23, 424-431.

Underwood, E. C., Mulitsch, M. J., Greenberg, J. A., Whiting, M. L., Ustin, S. L., \& Kefauver, S. C. (2006). Mapping invasive aquatic vegetation in the Sacramento-San Joaquin Delta using hyperspectral imagery. Environmental Monitoring and Assessment, 121, 47-64.

Underwood, E. C., Ustin, S. L., \& Di Pietro, D. (2003). Mapping nonnative plants using hyperspectral imagery, Remote Sensing of Environment, 86, 150-161.

Ustin, S. L., \& Gamon, J. A. (2010). Remote sensing of plant functional types. New Phytologist, 186(4), 795-816.

Veloso, H. P., Rangel Filho, A. L. R., \& Lima, J. C. A. (1991). Classificação da vegetação brasileira adaptada a um sistema universal [Classification of the Brazilian vegetation adapted to an universal system]. Rio de Janeiro: IBGE.

Vitousek, P. M., D’Antonio, C. M., Loope, L. L., \& Westbrooks, R. (1996). Biological invasions as global environmental change. American Scientist, 84, 468-478.

Williams, D. L. (1991). A comparison of spectral reflectance properties at the needle, branch and canopy level for selected conifer species. Remote Sensing of Environment, 35, 79-93.

Youngentob, K. N., Roberts, D. A., Held, A. A., Dennison, P. E., Jia, X., \& Lindenmayer, D. B. (2011). Mapping two Eucalyptus subgenera using multiple endmember spectral mixture analysis and continuum-removed imaging spectrometry data. Remote Sensing of Environment, 115(5), 11151128. 